

\title{
Thermochemical Ethanol via Direct Gasification and Mixed Alcohol Synthesis of Lignocellulosic Biomass
}

\author{
A. Dutta and S.D. Phillips
}

Prepared under Task No. BB07.3710

National Renewable Energy Laboratory 1617 Cole Boulevard, Golden, Colorado 80401-3393 303-275-3000 • www.nrel.gov

NREL is a national laboratory of the U.S. Department of Energy Office of Energy Efficiency and Renewable Energy

Operated by the Alliance for Sustainable Energy, LLC 


\section{NOTICE}

This report was prepared as an account of work sponsored by an agency of the United States government. Neither the United States government nor any agency thereof, nor any of their employees, makes any warranty, express or implied, or assumes any legal liability or responsibility for the accuracy, completeness, or usefulness of any information, apparatus, product, or process disclosed, or represents that its use would not infringe privately owned rights. Reference herein to any specific commercial product, process, or service by trade name, trademark, manufacturer, or otherwise does not necessarily constitute or imply its endorsement, recommendation, or favoring by the United States government or any agency thereof. The views and opinions of authors expressed herein do not necessarily state or reflect those of the United States government or any agency thereof.

Available electronically at http://www.osti.gov/bridge

Available for a processing fee to U.S. Department of Energy and its contractors, in paper, from:

U.S. Department of Energy

Office of Scientific and Technical Information

P.O. Box 62

Oak Ridge, TN 37831-0062

phone: 865.576 .8401

fax: 865.576 .5728

email: mailto:reports@adonis.osti.gov

Available for sale to the public, in paper, from:

U.S. Department of Commerce

National Technical Information Service

5285 Port Royal Road

Springfield, VA 22161

phone: 800.553.6847

fax: 703.605.6900

email: orders@ntis.fedworld.gov

online ordering: http://www.ntis.gov/ordering.htm 


\section{Acknowledgements}

We thank the Department of Energy for funding this work, Richard Bain and Andy Aden for reviewing the work and providing input, and Sara Havig for editing and formatting the document. 


\section{Executive Summary}

This work continues the study of thermochemical conversion processes for biomass to ethanol. An earlier study by Phillips et al. ${ }^{2}$ (NREL/TP-510-41168) looked into a process that used an indirect gasifier and showed that the process is capable of producing cost-competitive cellulosic ethanol below the $\$ 1.07$ per gallon minimum plant gate price targeted in 2012 using 2005 cost assumptions.

A high-pressure oxygen-blown direct gasifier is used in this study. The conversion costs for this process are higher than the 2012 cost target. This is primarily because of two reasons:

1. Extra capital cost of an air-separation unit

2. Lower conversion of methane to syngas after reformation at the higher pressures in this process.

The higher cost was expected and was the reason for the indirect gasifier process being studied first. Most of the assumptions in this study are similar to the indirect gasification process; this allows direct comparison between the processes. The process includes feed preparation, gasification, gas cleanup and conditioning, alcohol synthesis and purification, and the additional air separation unit. The minimum ethanol selling price (MESP) for the base case process was $\$ 1.57 /$ gallon using 2005 cost assumptions, compared with $\$ 1.01 /$ gallon in the indirect gasification process. The MESP was \$1.95/gallon using 2007 cost assumptions and 2012 performance targets (compared with $\$ 1.29 /$ gallon for the indirect process).

The technical barriers in tar reforming and alcohol synthesis are similar for the two processes, but the high pressure process is handicapped by lower equilibrium conversions during tar and methane reforming. A consequence of the lower methane conversion is the required addition of $\mathrm{CO}_{2}$ for the adjustment of the $\mathrm{H}_{2}$ : $\mathrm{CO}$ ratio in the syngas going to the synthesis reactor; this adds to the conversion cost.

There are challenges in the operability and on-time availability of biomass gasifiers, as with most other operations handling solids. This can be an added factor, beyond the cost, in the choice of gasifiers. The high-pressure direct gasification process may appear less prohibitive if there exists an air separation unit for other purposes and oxygen can be produced at a lower cost using economies of scale. The economics of the high pressure gasification process is expected to improve for synthesis fuels that operate at higher $\mathrm{H}_{2}$ : $\mathrm{CO}$ ratios such as methanol, methanol-togasoline, and Fischer-Tropsch liquids. 


\section{Table of Contents}

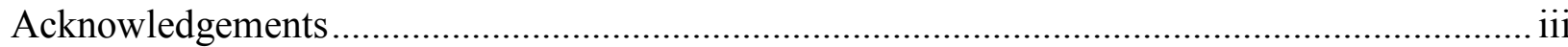

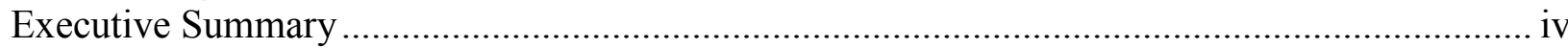

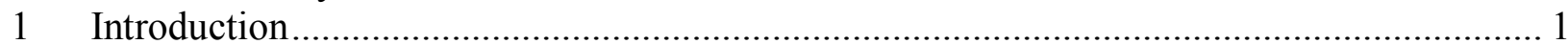

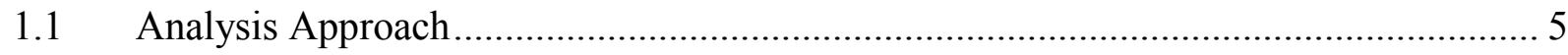

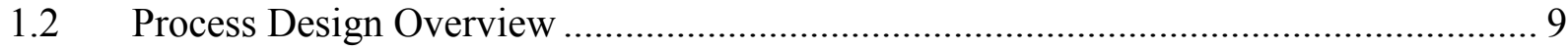

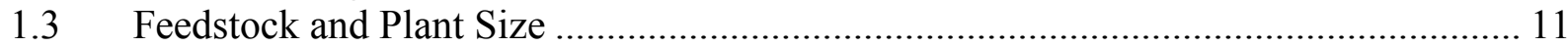

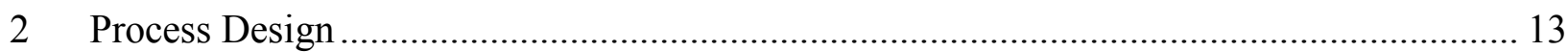

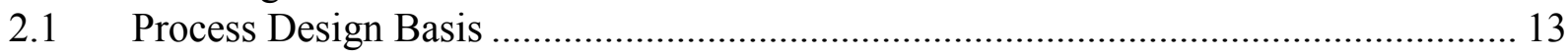

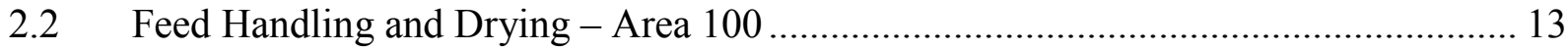

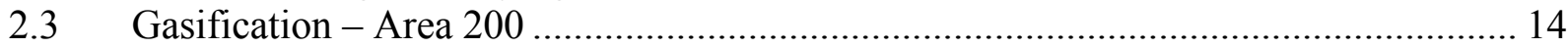

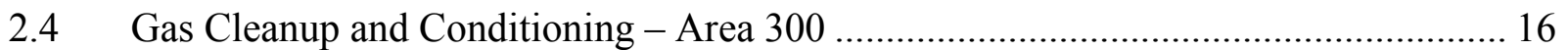

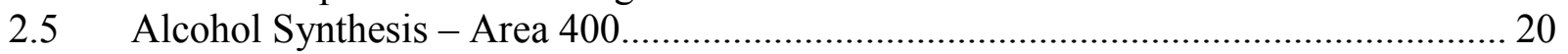

2.6 Alcohol Separation - Area 500 ........................................................................ 25

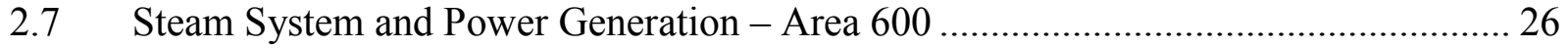

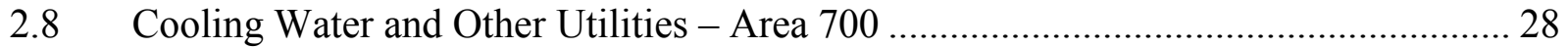

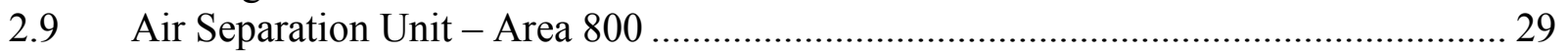

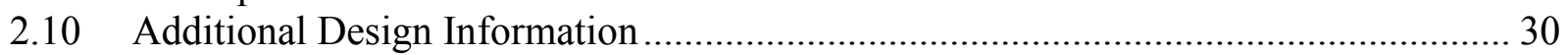

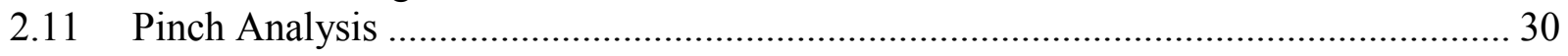

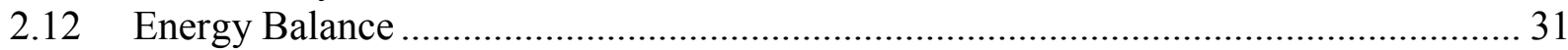

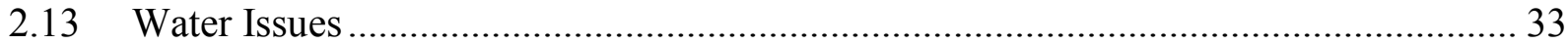

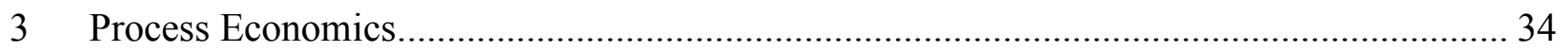

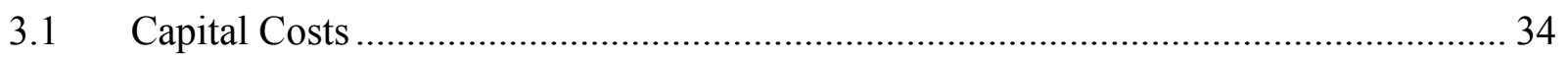

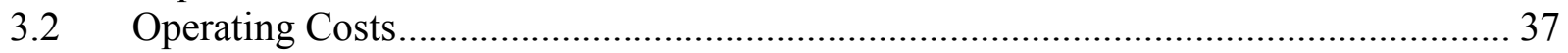

3.3 Value of Higher Alcohol Co-Products....................................................................... 41

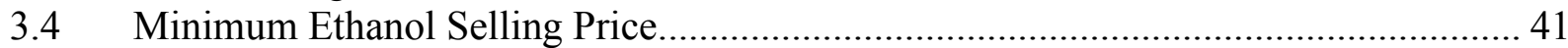

4 Process Economics, Sensitivity Analyses, and Alternate Scenarios...................................... 42

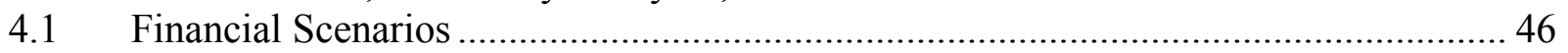

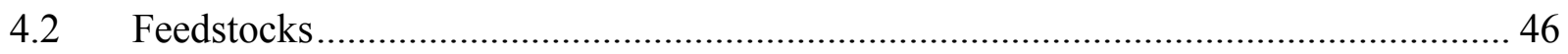

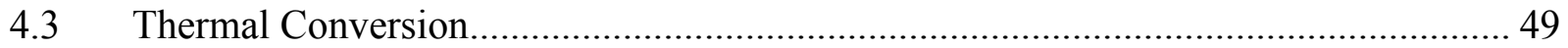

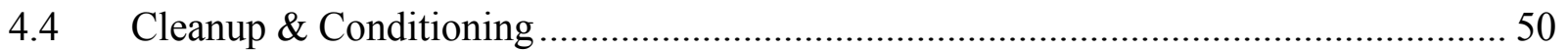

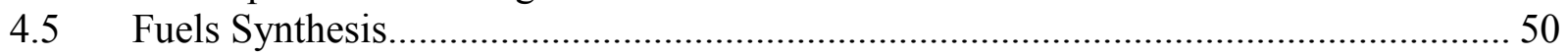

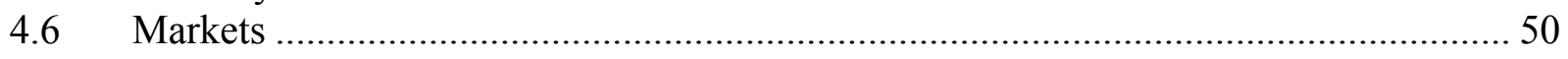

4.7 Operating the Gasifier at a Lower Pressure ………................................................... 51

4.8 Hypothetical Case to Delineate the Impact of Pressure on $\mathrm{CH}_{4}$ Conversion ................ 51

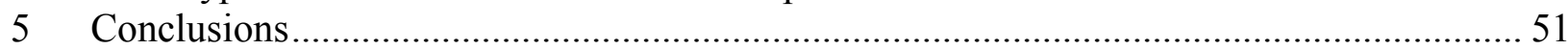

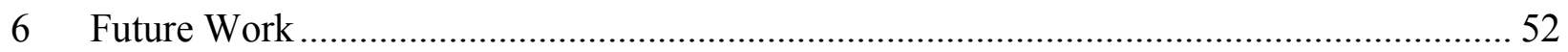

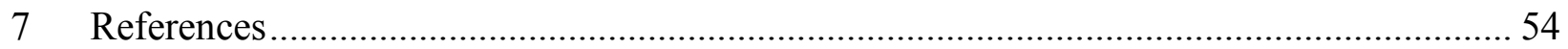




\section{List of Figures}

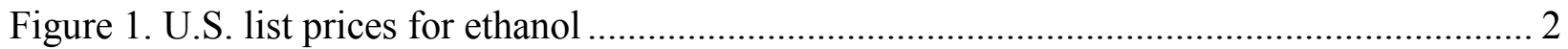

Figure 2. Estimated capital intensities for biomass-to-methanol processes ............................. 4

Figure 3. Approach to process analysis ........................................................................... 5

Figure 4. Chemical Engineering Magazine's Plant Cost Indices .......................................... 8

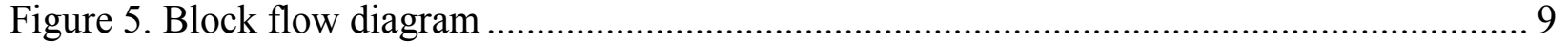

Figure 6. Expected availability of biomass ................................................................... 12

Figure 7. Cost contribution details from each process area ................................................ 43

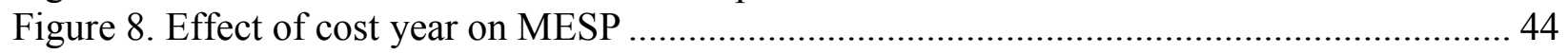

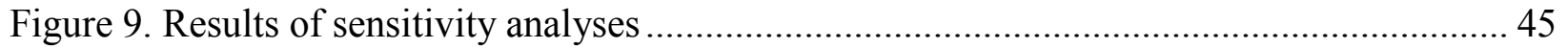

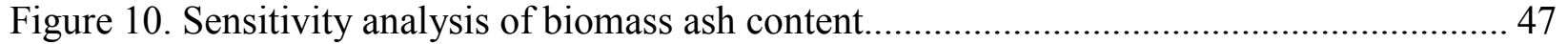

Figure 11. Sensitivity analysis of biomass moisture content ................................................ 48

Figure 12. Sensitivity analysis of raw syngas diverted for heat and power due to biomass

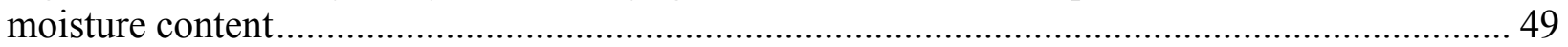

\section{List of Tables}

Table 1. Chemical Engineering Magazine's Plant Cost Indices.............................................. 8

Table 2. Ultimate Analysis of Hybrid Poplar Feed................................................................ 12

Table 3. Gasifier Operating Parameters, Gas Compositions, and Efficiencies ......................... 15

Table 4. Target Design Performance of Tar Reformer in the Phillips et al. Report ${ }^{2}$................. 16

Table 5. Conversions Used in the Tar Reformer ..................................................................... 17

Table 6. Target Design Tar Reformer Conditions and Outlet Gas Composition.......................... 18

Table 7. Acid Gas Removal Design Parameters ........................................................................ 19

Table 8. Process Conditions for Mixed Alcohols Synthesis.................................................. 21

Table 9. System of Reactions for Mixed Alcohol Synthesis .................................................. 23

Table 10. Mixed Alcohol Reaction Performance Results......................................................... 23

Table 11. Mixed Alcohol Synthesis Product Distributions ........................................................ 24

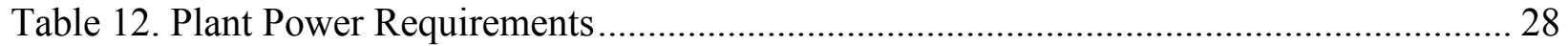

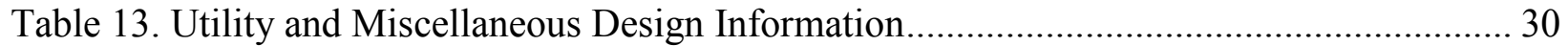

Table 14. Overall Energy Analysis (LHV basis) ................................................................. 32

Table 15. Process Water Demands for Thermochemical Ethanol via Direct Gasification........... 34

Table 16. General Cost Factors in Determining Total Installed Equipment Costs..................... 35

Table 17. Cost Factors for Indirect Costs ............................................................................ 35

Table 18. Feed Handling \& Drying and Gasifier \& Gas Cleanup Costs from the Literature Scaled

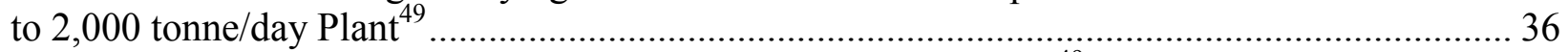

Table 19. System Design Information for Gasification References ${ }^{49}$.................................... 36

Table 20. Variable Operating Costs.................................................................................. 38

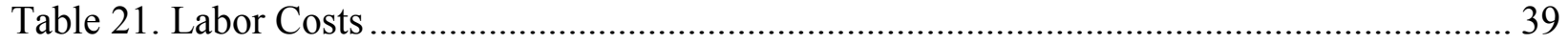

Table 22. Other Fixed Costs ............................................................................................. 40

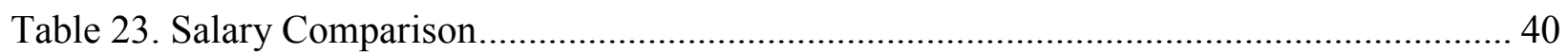

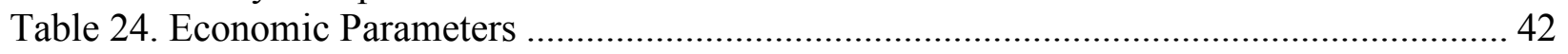




\section{Introduction}

This work addresses a policy initiative by the Federal Administration to apply United States Department of Energy (DOE) research to broadening the country's domestic production of economic, flexible, and secure sources of energy fuels. President Bush had proposed the Advanced Energy Initiative, ${ }^{1}$ which outlines significant new investments and policies to change the way we fuel our vehicles and the way we power our homes and businesses. The specific goal for biomass in the Advanced Energy Initiative is to foster the breakthrough technologies needed to make cellulosic ethanol cost-competitive with corn-based ethanol by 2012 .

A previous report ${ }^{2}$ studied the production of cellulosic ethanol with syngas from indirect gasification. This report extends the study of thermochemical conversion processes by looking into alcohol production using syngas from high-pressure oxygen blown direct gasifiers. The higher pressure in the gasification and tar reforming sections requires a supply of higher pressure steam. The biomass feed also needs to be pressurized before feeding. The oxygen blown gasifier also requires an Air Separation Unit (ASU) to provide oxygen. Since the syngas output is also at a higher pressure, one of the compressors used in the indirect gasification process to pressurize the syngas prior to acid gas removal is eliminated in this process. The remaining process is similar to the indirect steam gasification process. A conscious decision was made to keep overall process design similar to the previous study ${ }^{2}$ in order to focus on the effect of the type of gasifier on the overall process and economics. The heat exchanger network design after pinch analysis is different, which is expected because of a different thermal profile for this process. The numbers reported in the report use the same cost year and feedstock costs as the indirect gasification process. Results are also presented in 2007 dollars and with updated feedstock costs in Appendix I.

The intent of this report is to be a standalone reference without having to refer back to the indirect gasifier report. ${ }^{2}$ Hence some sections have been taken verbatim from that report. Some information in the appendices of the indirect gasifier study ${ }^{2}$ was not repeated.

The indirect steam gasification process ${ }^{2}$ was studied first because it was known that the cost of the high pressure oxygen blown direct gasification process would likely be higher, based on similar experience with methanol production. This is discussed in detail later in this introduction. As was expected, this study does predict a higher cost for the direct gasification process.

In previous biomass conversion design reports by the National Renewable Energy Laboratory (NREL), a benchmark for achieving production of ethanol from cellulosic feedstocks that would be "cost competitive with corn-ethanol" was quantified as $\$ 1.07$ per gallon ethanol production $\operatorname{cost}^{3}$ (where none of these values have been adjusted to a common cost year). The value can be put in context with the historic ethanol price data as shown in Figure $1 .^{4}$ The $\$ 1.07$ per gallon value represents the low side of the historical fuel ethanol prices. Given this historical price data, it is viewed that cellulosic ethanol would be commercially viable at this cost of production. 


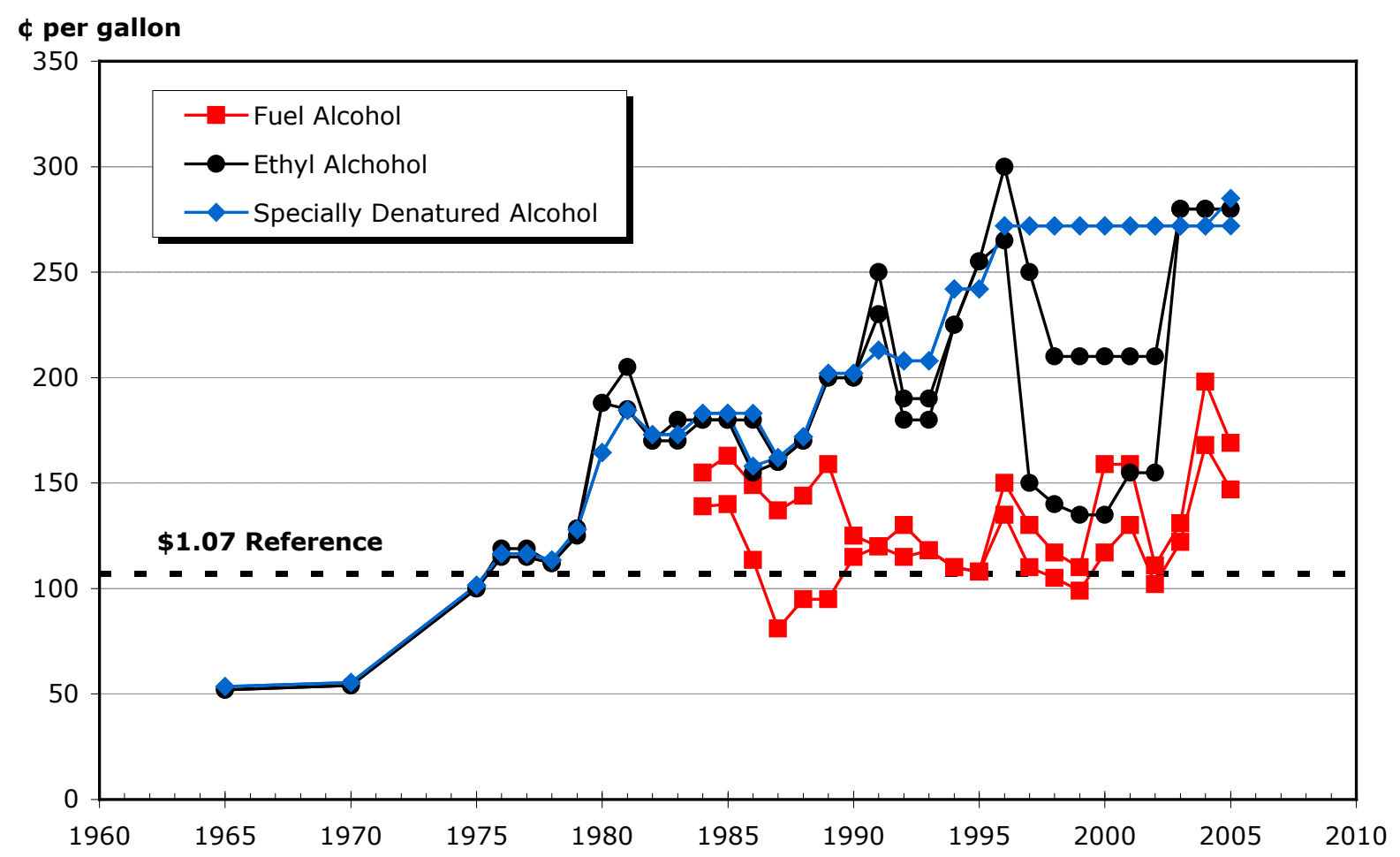

Figure 1. U.S. list prices for ethanol ${ }^{a}$

Conceptual process designs and associated design reports have previously been done by NREL for converting cellulosic biomass feedstock to ethanol via biochemical pathways. Two types of biomass that have been considered are yellow poplar ${ }^{5}$ and corn stover. ${ }^{3}$ These design reports have been useful to NREL and DOE program management for two main reasons. First of all, they enable comparison of research and development projects. A conceptual process design helps to direct research by establishing a benchmark to which other process configurations can be compared. Proposed research and the anticipated results can be translated into a new design; the economics incorporating these anticipated results can be determined and this new design can be compared to the benchmark case. Following this procedure for several proposed research projects allows DOE to make competitive funding decisions based on which projects have the greatest potential to lower the cost of ethanol production. Complete process design and economics are required for such comparisons because changes in performance in one research area may have significant impacts in other process areas not part of that research program (e.g., impacts in product recovery or waste treatment). The impacts on the other areas may have significant and unexpected impacts on the overall economics.

Secondly, they enable comparison of ethanol production to other fuels. A cost of production has also been useful to study the potential ethanol market penetration from technologies to convert lignocellulosic biomass to ethanol. The cost estimates developed must be consistent with

\footnotetext{
a The curve marked "Ethyl Alcohol" is for 190 proof, USP, tax-free, in tanks, delivered to the East Coast. That marked "Specially Denatured Alcohol" is for SDA 29, in tanks, delivered to the East Coast, and denatured with ethyl acetate. That marked "Fuel Alcohol" is for 200 proof, fob works, bulk, and denatured with gasoline.
} 
applicable engineering, construction, and operating practices for facilities of this type. The complete process (including not only industry-standard process components but also the newly researched areas) must be designed and their costs determined.

The process design in this report is part of an evaluation process of options to be considered to addresses the conversion of biomass to ethanol via thermochemical (TC) pathways that are expected to be demonstrated at the pilot-unit level by 2012. This assessment matches up:

- Currently established and published technology

- Technology currently under development or shortly to be under development from DOE Office of Biomass Program (OBP) funding (see Appendix B of the Phillips et al. report ${ }^{2}$ for these research targets and values)

- Biomass sources in the 2012 time frame consistent with the Billion Ton Vision study. ${ }^{6}$

This assessment directly builds upon the design report for the production of mixed alcohols using the indirect steam gasification process. ${ }^{2}$ The indirect gasification process was modified to include the high pressure oxygen blown direct gasifier and the air separation unit. Much of the modifications were based on an earlier report comparing the direct and indirect gasifiers. ${ }^{7}$

Indirect steam gasification was the first technology around which this process was developed based upon previous techno-economic studies for the production of methanol and hydrogen from biomass. ${ }^{8}$ The sub-process operations for ethanol production are very similar to those for methanol production (although the specific process configuration will be different). The general process areas include: feed preparation, gasification, gas cleanup and conditioning, and alcohol synthesis and purification.

Gasification involves the devolatilization and conversion of biomass in an atmosphere of steam and/or oxygen to produce a medium-calorific value gas. There are two general classes of gasifiers. Partial oxidation (POX) gasifiers (directly-heated gasifiers) use the exothermic reaction between oxygen and organics to provide the heat necessary to devolatilize biomass and to convert residual carbon-rich chars. In POX gasifiers, the heat to drive the process is generated internally within the gasifier. A disadvantage of POX gasifiers is that oxygen production is expensive and typically requires large plant sizes to improve economics. ${ }^{9}$

The second general class, steam gasifiers (indirectly-heated gasifiers), accomplish biomass heating and gasification through heat transfer from a hot solid or through a heat transfer surface. Either byproduct char and/or a portion of the product gas can be combusted with air (external to the gasifier itself) to provide the energy required for gasification. Steam gasifiers have the advantage of not requiring oxygen; but since most operate at low pressure, they require product gas compression for downstream purification and synthesis unit operations.

A number of POX and steam gasifiers are under development and have the potential to produce a synthesis gas suitable for liquid fuel synthesis. These gasifiers have been operated in the 4 to 350 ton per day scale. The decision as to which type of gasifier (POX or steam) will be the most economic depends upon the entire process, not just the cost for the gasifier itself. One indicator for comparing processes is "capital intensity," the capital cost required on a per unit product 
basis. Figure 2 shows the capital intensity of methanol processes ${ }^{10,11,12,13,14,15}$ based on indirect steam gasification and direct POX gasification. This figure shows that steam gasification capital intensity is comparable or lower than POX gasification. The estimates indicate that both steam gasification and POX gasification processes should be evaluated, although evaluation of steam gasification is a reasonable first choice. Hence this study follows the indirect gasification study. ${ }^{2}$

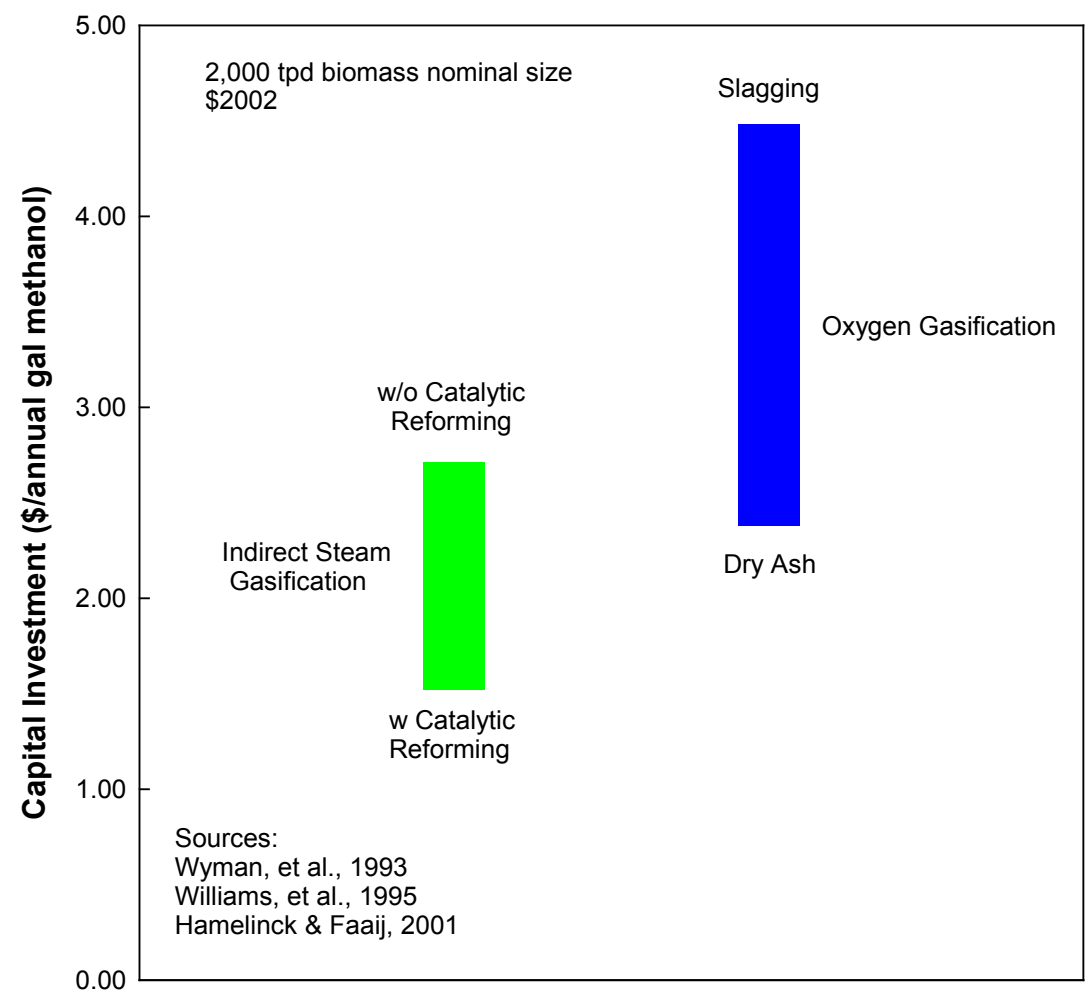

Figure 2. Estimated capital intensities for biomass-to-methanol processes

Another philosophy applied to the process development was to make the process "electrical energy neutral." The aim was to make all the electricity necessary for the process while trying to minimize excess electricity generation because it cuts down alcohol production. A "zeroelectricity" process was possible for the indirect gasification process. ${ }^{2}$ However, for the direct gasification process it was found that process steam requirements leave high temperature streams that are capable of generating electricity in excess of what is required by the plant.

Alternately, an external supply of fossil fuels such as coal or natural gas could be used to maintain process temperatures in the tar reformer or to generate steam while maximizing the amount of syngas that goes towards alcohol production. However, the decision was made to follow the directions specified in the indirect gasification process design ${ }^{2}$ and make the plant energy self-sufficient with no additional fuel supplied for heat and power. 


\subsection{Analysis Approach}

The general approach used in the development of the process design, process model, and economic analysis is depicted in Figure 3. The first step was to assemble a general process flow schematic or more detailed process flow diagrams (PFDs). (See Appendix F for the associated PFDs for this design). From this, detailed mass and energy balance calculations were performed around the process. For this design, Aspen Plus ${ }^{\circledR}$ software was used. Data from this model was then used to properly size all process equipment and fully develop an estimate of capital and operating costs. These costs could potentially have been used in several types of economic analysis. However, for this design, a discounted cash flow rate of return (DCFROR) analysis was used to determine the Minimum Ethanol Selling Price (MESP) necessary to meet a small hurdle rate (IRR) of $10 \%$.

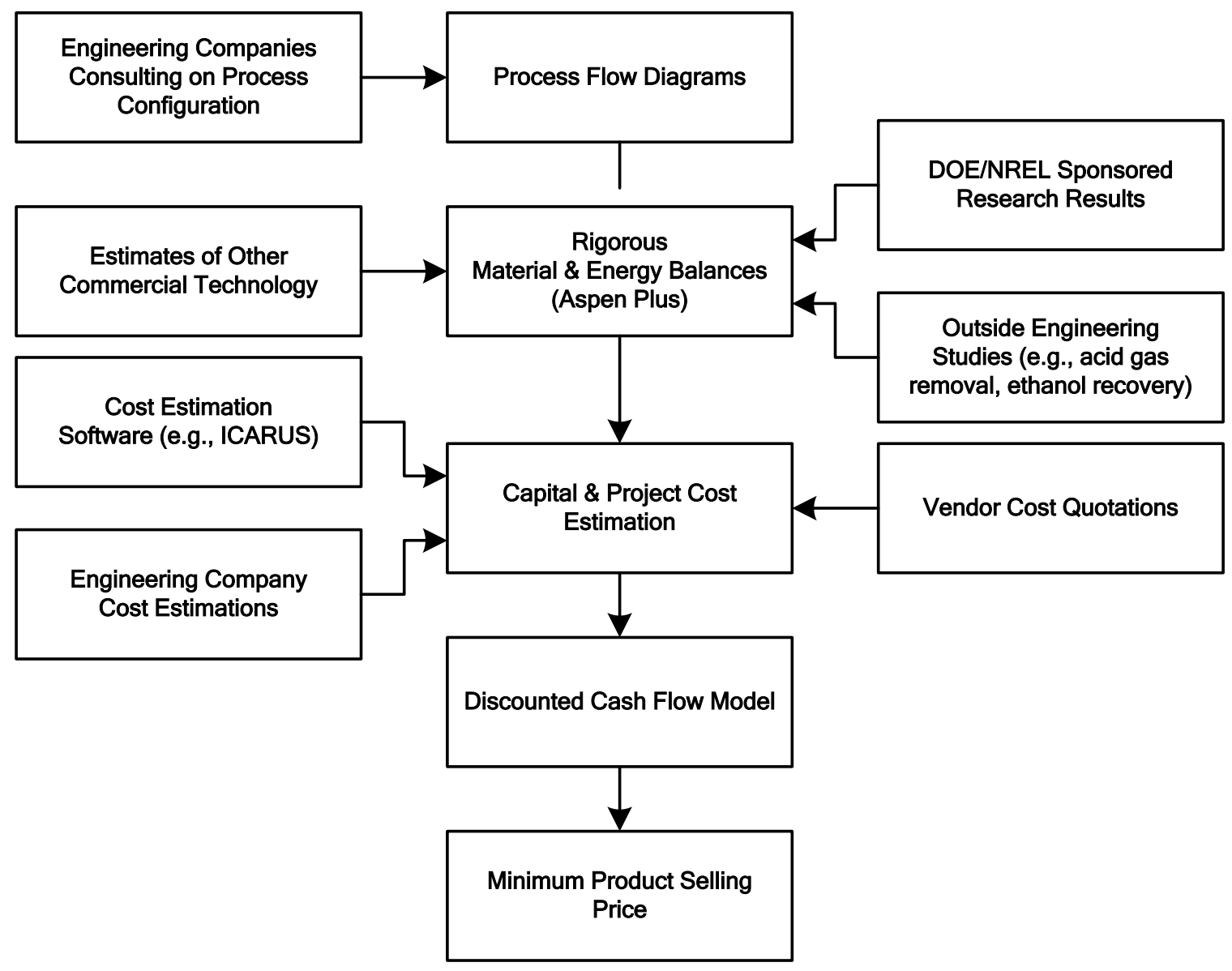

Figure 3. Approach to process analysis

This process was developed by modifying the indirect gasification process ${ }^{2}$ by inserting an Air Separation Unit and changing the indirect gasifier to a direct gasifier. These modifications were 
based on previous work done at NREL to compare the two gasification processes. ${ }^{7}$ Specific information about sub-processes was derived from these previous reports. ${ }^{2,7}$ Some of the information for the indirect gasification process design report, ${ }^{2}$ parts of which are also applicable to this process, was obtained as a result of a subcontract with Nexant Inc. ${ }^{16,17,18,19}$

Aspen Plus version 2004.1 was used to determine the mass and energy balances for the process. The operations were separated into eight major HIERARCHY areas:

- Feed Handling and Drying (Area 100)

- Gasification (Area 200)

- Cleanup and Conditioning (Area 300)

- Alcohol Synthesis (Area 400)

- Alcohol Separation (Area 500)

- Steam Cycle (Area 600)

- Cooling Water (Area 700)

- Air Separation Unit (Area 800)

Overall, the Aspen simulation consists of about 320 operation blocks (such as reactors, flash separators, etc.), 820 streams (mass, heat, and work), and 64 control blocks (design specs and calculator blocks). Many of the gaseous and liquid components were described as distinct molecular species using Aspen Plus's own component properties database. The raw biomass feedstock, ash, and char components were modeled as non-conventional components. There was more detail and rigor in some blocks (e.g., distillation columns) than in others (e.g., conversion extent in the alcohol synthesis reactor and the air separation unit). Because this design processes three different phases of matter (solid phase, gas phase, and liquid phase), no single thermodynamics package was sufficient. Instead, four thermodynamics packages were used within the Aspen simulation to give more appropriate behavior. The "PR-BM" and "RKS-BM" options were used throughout much of the process for high temperature, high pressure phase behavior. The non-random two-liquid "NRTL" option with ideal gas properties was used for alcohol separation calculations. The 1987 Steam Table properties were used for the steam cycle calculations. Finally, the ELECNRTL package was used to model the electrolyte species potentially present within the quench water system.

The process economics are based on the assumption that this is the "nth" plant, meaning that several plants using this same technology will have already been built and are operating. This means that additional costs for risk financing, longer start-ups, and other costs associated with first-of-a-kind plants are not included.

The capital costs were developed from a variety of sources. For some sub-processes that use well known technology and can be purchased as modular packages (i.e., amine treatment, acid gas removal, air separation unit), an overall cost for the package unit was used. Many of the common equipment items (tanks, pumps, simple heat exchangers) were costed using the Aspen Icarus ${ }^{\mathrm{TM}}$ Questimate $^{\circledR}$ and Aspen Icarus Process Evaluator ${ }^{\circledR}$ costing software. Other more specific unit 
operations (gasifier, molecular sieve, etc.) used cost estimates from other studies and/or from vendor quotes. As documented in the indirect gasifier design report, ${ }^{2}$ the installed capital costs were developed using general plant-wide factors. The installation costs incorporated cost contributions not only for the actual installation of the purchased equipment but also for instrumentation and controls, piping, electrical systems, buildings, yard improvements, etc. These are also described in more detail in Section 3.

The purchased component equipment costs reflect the base case for equipment size and cost year. The sizes needed in the process may actually be different than what was specifically designed. Instead of re-costing in detail, an exponential scaling expression was used to adjust the base equipment costs:

$$
\text { New Cost }=(\text { Base Cost })\left(\frac{\text { New Size }}{\text { Base Size }}\right)^{n}
$$

where $n$ is a characteristic scaling exponent (typically in the range of 0.6 to 0.7 ). The sizing parameters are based upon some characteristic of the equipment related to production capacity, such as inlet flow or heat duty in a heat exchanger (appropriate if the log-mean temperature difference is known not to change greatly). Generally these related characteristics are easier to calculate and give nearly the same result as resizing the equipment for each scenario. The scaling exponent $n$ can be inferred from vendor quotes (if multiple quotes are given for different sizes), from multiple Questimate estimates at different sizes, or from a standard reference (such as Garrett, ${ }^{20}$ Peters and Timmerhaus, ${ }^{21}$ or Perry et al. ${ }^{22}$ ).

Since a variety of sources were used, the bare equipment costs were derived based upon different cost years. Therefore, all capital costs were adjusted with the Chemical Engineering (CE) magazine's Plant Cost Index ${ }^{23}$ to a common basis year of 2005:

$$
\text { New Cost }=(\text { Base Cost })\left(\frac{\text { Cost Index in New Year }}{\text { Cost Index in Base Year }}\right) \text {. }
$$

The CE indices used in this study are listed in Table 1 and depicted in Figure 4. Notice that the indices were very nearly the same for 2000 to 2002 (essentially zero inflation) but take a very sharp increase after 2003 (primarily due to a run-up in worldwide steel prices). Appendix I shows the results using 2007 as the base year and a modified feedstock cost. 
Table 1. Chemical Engineering Magazine's Plant Cost Indices

\begin{tabular}{|c|c|c|c|}
\hline Year & Index & Year & Index \\
\hline 1990 & 357.6 & 1999 & 390.6 \\
\hline 1991 & 361.3 & 2000 & 394.1 \\
\hline 1992 & 358.2 & 2001 & 394.3 \\
\hline 1993 & 359.2 & 2002 & 395.6 \\
\hline 1994 & 368.1 & 2003 & 402.0 \\
\hline 1995 & 381.1 & 2004 & 444.2 \\
\hline 1996 & 381.7 & 2005 & 468.2 \\
\hline 1997 & 386.5 & 2006 & 507.2 \\
\hline 1998 & 389.5 & 2007 & 525.4 \\
\hline
\end{tabular}

Chemical Engine ering Plant Cost Index

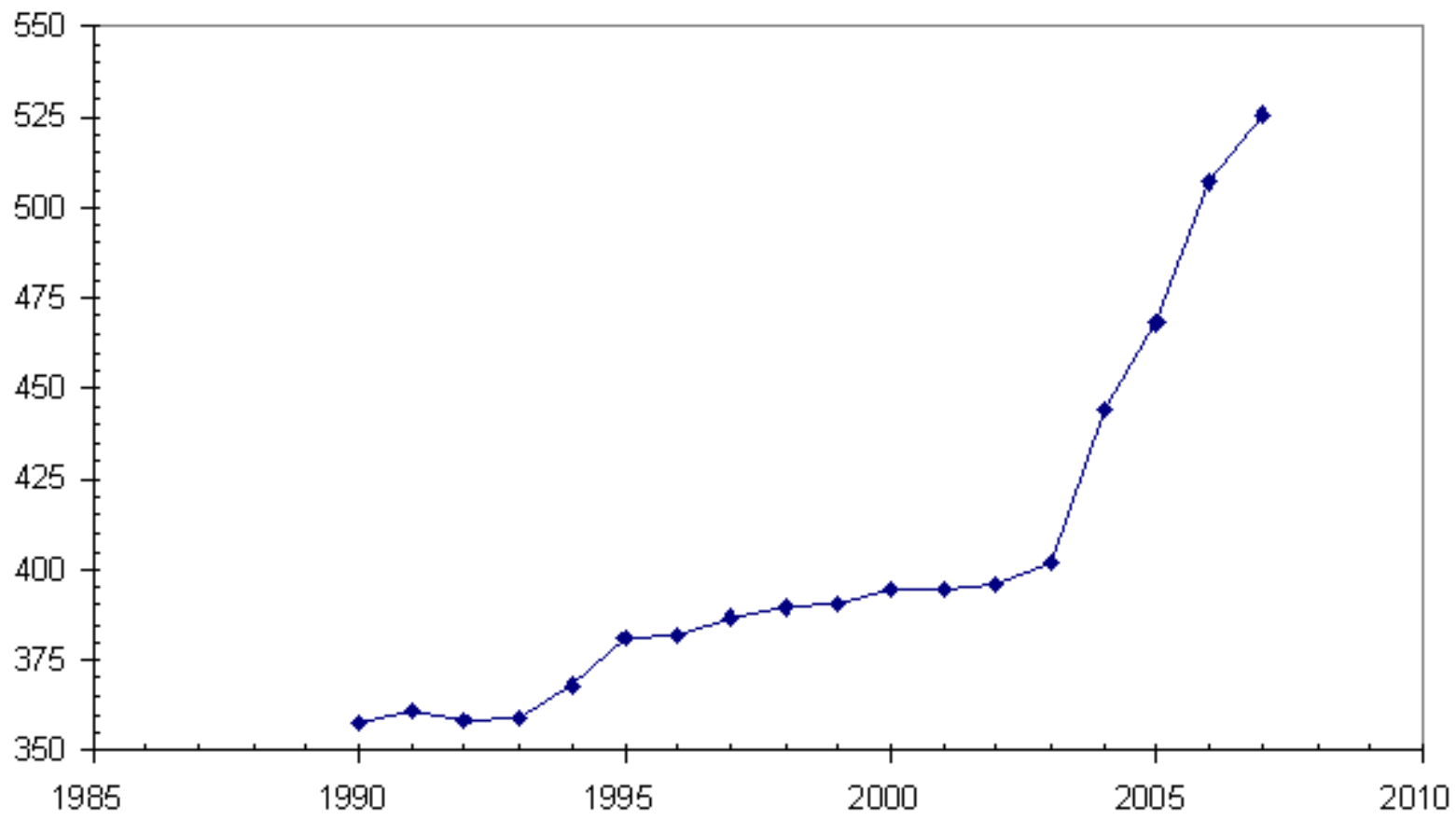

Figure 4. Chemical Engineering Magazine's Plant Cost Indices

Once the scaled, installed equipment costs were determined, overhead and contingency factors were applied to determine a total plant investment cost. That cost, along with the plant operating expenses (generally developed from the Aspen Plus model's mass and energy balance results), was used in a discounted cash flow analysis to determine the cost of ethanol production (referred to as the Minimum Ethanol Selling Price, or MESP) using a specific discount rate. For the analysis done here, the MESP is the primary value used to compare alternate designs. 


\subsection{Process Design Overview}

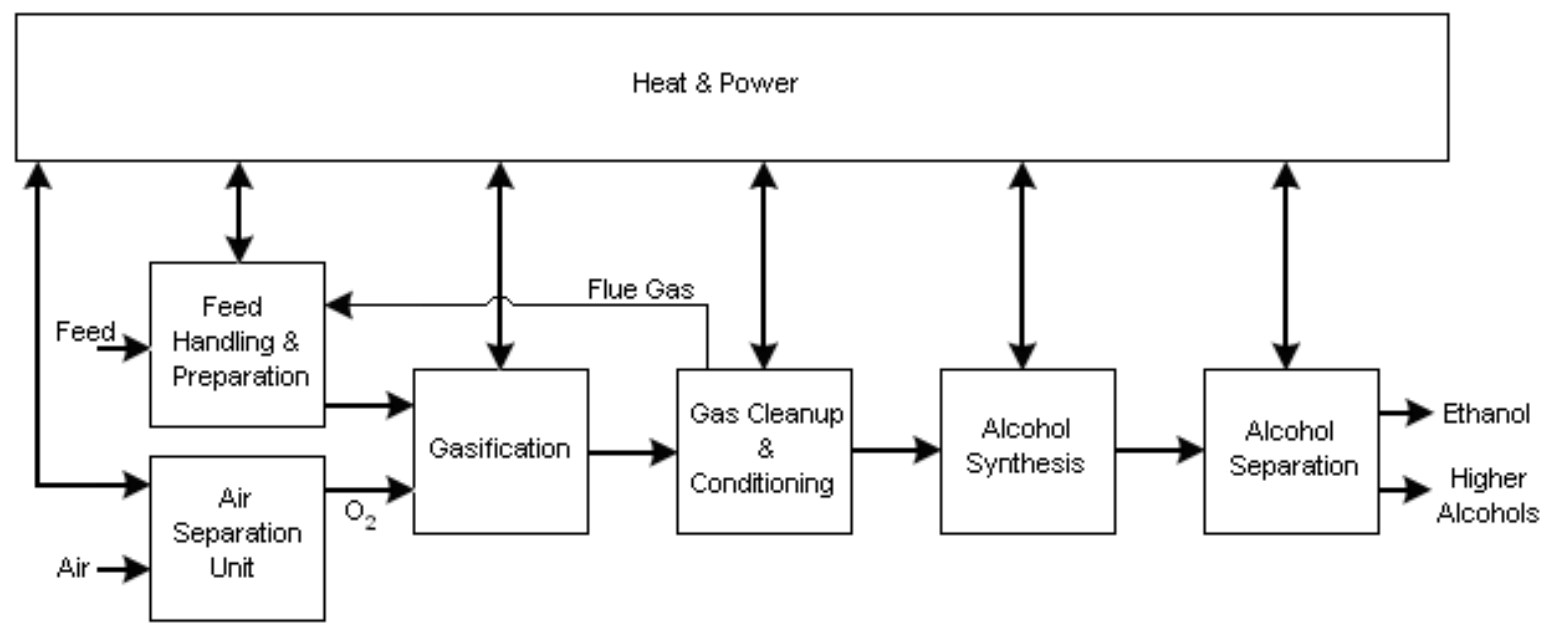

Figure 5. Block flow diagram

A simple block flow diagram of the current design is depicted in Figure 5. The detailed process flow diagrams (PFDs) are in Appendix F. The process has the following steps:

- Feed Handling \& Preparation. The biomass feedstock is dried from the as-received moisture content to that required for proper feeding into the gasifier. Flue gases from the fuel combustor of the tar reformer are used for this purpose.

- Air Separation Unit. High pressure oxygen required by the gasifier is produced by the air separation unit. Air is liquefied by pressurizing and cooling it. Oxygen is separated as the liquid product of cryogenic distillation. The nitrogen produced is used for pressurizing lock hoppers in the biomass feed system. (Alternately, $\mathrm{CO}_{2}$ from the amine system can be used for pressurizing the lock hoppers. Since both $\mathrm{N}_{2}$ and $\mathrm{CO}_{2}$ are available in the process the economics will not be altered. $\mathrm{CO}_{2}$ is the preferable option if the feeding system allows excessive $\mathrm{N}_{2}$ to leak into the gasifier).

- Gasification. An oxygen-blown direct gasifier developed by GTI (Gas Technology Institute, formerly IGT or Institute of Gas Technology) is used in this study. ${ }^{24}$ Heat for the endothermic gasification reactions is supplied by combusting part of the biomass within the gasifier. Pressurized lock hoppers with screw conveyors are used to push the feed into the high pressure gasifier. The lock hoppers are pressurized using nitrogen from the air separation unit. Alternately, carbon dioxide from the acid gas removal system can be used to pressurize the hopper. Steam is injected at the bottom of the gasifier in order to fluidize the bed. Oxygen is introduced higher up in the bed, close to the biomass feed point. The three basic steps during direct gasification ${ }^{24}$ are (a) Devolatilization - the instantaneous thermal decomposition of biomass to primarily produce $\mathrm{H}_{2}, \mathrm{CO}_{2}$, light hydrocarbons, and water; (b) Char Gasification - the gasification of biomass char with 
steam in the presence of $\mathrm{H}_{2}$ to produce $\mathrm{CH}_{4}, \mathrm{CO}, \mathrm{H}_{2}$, and $\mathrm{CO}_{2}$; and (c) Char Combustion - the combustion of residual biomass char, which supplies the energy required for endothermic char gasification. Two cyclones at the exit of the gasifier separate the char, olivine, and ash from the syngas. These solids are then depressurized and cooled; water is added to avoid dust before being sent for solid waste disposal. Syngas from the gasifier is sent for cleanup and conditioning.

- Gas Cleanup \& Conditioning. This consists of multiple operations: reforming of tars and other hydrocarbons to $\mathrm{CO}$ and $\mathrm{H}_{2}$; syngas cooling/quench; and acid gas $\left(\mathrm{CO}_{2}\right.$ and $\left.\mathrm{H}_{2} \mathrm{~S}\right)$ removal with subsequent reduction of $\mathrm{H}_{2} \mathrm{~S}$ to sulfur. Tar reforming is envisioned to occur in an isothermal fluidized bed reactor; de-activated reforming catalyst is separated from the effluent syngas and regenerated on-line. The hot syngas is cooled through heat exchange with the steam cycle and with additional cooling via water scrubbing. The scrubber also removes impurities such as particulates and ammonia along with any residual tars. The excess scrubber water is sent off-site to a wastewater treatment facility. The cooled syngas enters an amine unit to remove the $\mathrm{CO}_{2}$ and $\mathrm{H}_{2} \mathrm{~S}$. The $\mathrm{H}_{2} \mathrm{~S}$ is reduced to elemental sulfur and stockpiled for disposal. The $\mathrm{CO}_{2}$ is vented to the atmosphere in this design but can easily be sequestered when tested methods are available.

- Alcohol Synthesis. The cleaned and conditioned syngas is converted to alcohols in a fixed bed reactor. The mixture of alcohol and unconverted syngas is cooled through heat exchange with the steam cycle. The liquid alcohols are separated away by condensing them from the unconverted syngas. Though the unconverted syngas has the potential to be recycled back to the entrance of the alcohol synthesis reactor, no significant recycle is done in this process design. Instead it is recycled to the Gas Cleanup \& Conditioning section, mostly as feed to the tar reformer.

- Alcohol Separation. The alcohol stream from the Alcohol Synthesis section is depressurized in preparation for dehydration and separation. Another rough separation is performed in a flash separator; the evolved syngas is recycled to the Gas Cleanup \& Conditioning section, mostly as feed to the tar reformer. The depressurized alcohol stream is dehydrated using vapor-phase molecular sieves. The dehydrated alcohol stream is introduced to the main alcohol separation column that splits methanol and ethanol from the higher molecular weight alcohols. The overheads are topped in a second column to remove the methanol to ASTM sales specifications. The methanol leaving in the overheads is used to flush the adsorbed water from the molecular sieves. This methanol/water mixture is recycled back to the entrance of the alcohol synthesis reactor.

- Heat \& Power. A conventional steam cycle produces heat (as steam) for the gasifier and reformer operations and electricity for internal power requirements (with the possibility of exporting excess electricity as a co-product). The steam cycle is integrated with the biomass conversion process. Pre-heaters, steam generators, and super-heaters are integrated within the process design to create the steam. The steam runs through turbines to drive compressors, to generate electricity, or to be withdrawn at various pressure levels for injection into the process. The condensate is sent back to the steam cycle, de-gassed, and combined with makeup water. 
A cooling water system is also included in the Aspen Plus model to determine the requirements of the cooling water heat exchangers within the biomass conversion process as well as the requirements of the cooling tower.

Previous analyses of gasification processes have shown the importance of properly utilizing the heat from the high temperature streams. A pinch analysis was performed to design a heat exchanger network for this ethanol production process. The pinch concept offers a systematic approach to optimize the energy integration of the process. Details of the pinch analysis will be discussed in Section 2.11.

\subsection{Feedstock and Plant Size}

Based upon expected availability per the Billion Ton Vision ${ }^{6}$ study, forest resources were chosen as the primary feedstock. The Billion Ton Vision study addressed short and long term availability issues for biomass feedstocks without giving specific time frames. The amounts are depicted in Figure 6. The upper sets of numbers (labeled "High Yield Growth with Energy Crops" and "High Yield Growth without Energy Crops") are projections of availability that will depend upon changes to agricultural practices and the creation of a new energy crop industry. In the target year of 2012 it is most probable that the amounts labeled "Existing \& Unexploited Resources" will be the only ones that can be counted on to supply a thermochemical processing facility. Notice that the expected availability of forest resources is nearly the same as that of agricultural resources. Prior studies for biochemical processing have largely focused on using agricultural resources. It makes sense to base thermochemical processing on the forest resources. TC processing could fill an important need to provide a cost-effective technology to process this major portion of the expected biomass feedstock. 


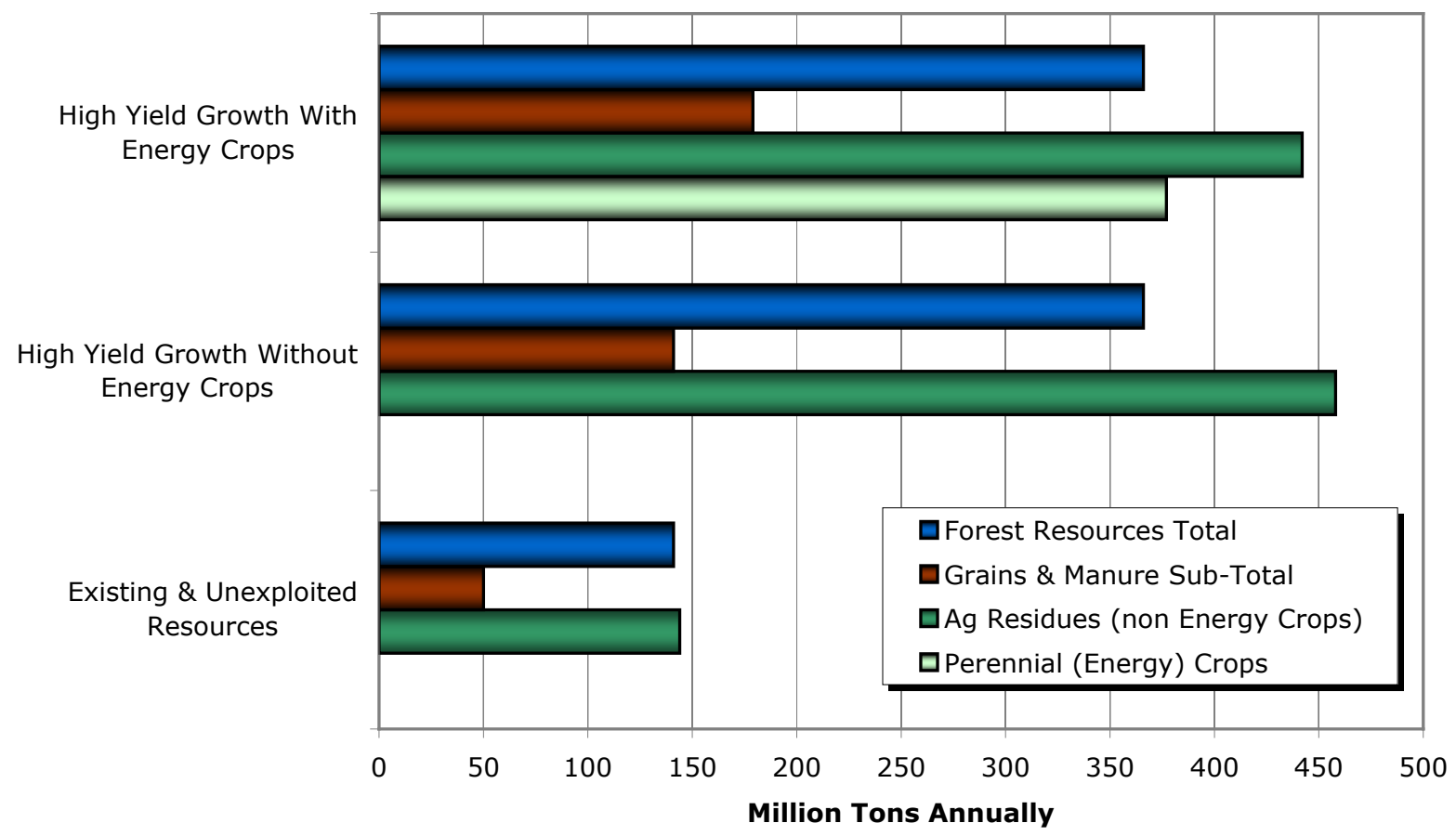

Figure 6. Expected availability of biomass

The indirect gasification design report ${ }^{2}$ used hybrid poplar wood chips delivered at $50 \mathrm{wt} \%$ moisture to model forest resources; the same will be done here. The ultimate analysis for the feed used in this study is given in Table 2. Performance and cost effects due to composition and moisture content were examined as part of the sensitivity analysis and alternate scenarios.

Table 2. Ultimate Analysis of Hybrid Poplar Feed

\begin{tabular}{|l|c|}
\hline Component (wt\%, dry basis $^{\mathbf{2 5}}$ ) & \\
\hline Carbon & 50.88 \\
\hline Hydrogen & 6.04 \\
\hline Nitrogen & 0.17 \\
\hline Sulfur & 0.09 \\
\hline Oxygen & 41.90 \\
\hline Ash & 0.92 \\
\hline Heating value $^{\mathrm{a}}(\mathrm{Btu} / \mathrm{lb})$ & $8,671 \mathrm{HHV}^{\mathrm{b}}$ \\
& $8,060 \mathrm{LHV}^{\mathrm{c}}$ \\
\hline
\end{tabular}

${ }^{\text {a }}$ Calculated using the Aspen Plus Boie correlation.

${ }^{\mathrm{b}}$ Higher Heating Value

${ }^{\mathrm{c}}$ Lower Heating Value 
The design plant size of 2,000 dry metric tonnes per day was chosen to match that of the Aden et al. biochemical process ${ }^{3}$ and the Phillips et al. indirect gasification process. ${ }^{2}$ With an expected 8,406 operating hours per year $(96 \%$ operating factor) the annual feedstock requirement is 700,000 dry metric tonnes per year. As can be seen in Figure 6, this is a small portion of the 140 million dry tons per year of forest resources potentially available. Cost effects due to plant size were examined as part of the sensitivity analysis.

The delivered feedstock cost was chosen to match the number used in the indirect gasifier report, which was $\$ 35 /$ dry ton. The $\$ 35 /$ dry ton in 2005 dollars was the 2012 target feedstock cost based on previous analyses done at the Idaho National Laboratory (INL) ${ }^{26}$ The feedstock cost target for 2012 has since been revised (and will be published in an updated version of the Biomass Program's Multi-Year Program Plan ${ }^{27}$ ) to $\$ 50.70 /$ dry ton (in 2007 dollars) and has been used to generate the updated results in Appendix I. Cost effects due to feedstock costs were also examined as part of the sensitivity analysis.

\section{Process Design}

\subsection{Process Design Basis}

The process design developed for this study is based upon the current operation and R\&D performance goals for the catalytic tar destruction and heteroatom removal work at NREL and alcohol synthesis work at NREL and PNNL. This target design shows the effect of meeting these specific research and development $(\mathrm{R} \& \mathrm{D})$ goals.

The process consists of the following major sections:

- Feed handling and drying

- Gasification

- Gas cleanup and conditioning

- Alcohol synthesis

- Alcohol separation

- Integrated steam system and power generation cycle

- Cooling water and other utilities

- Air separation unit.

\subsection{Feed Handling and Drying - Area 100}

This section of the process accommodates the delivery of biomass feedstock, short term on-site storage, and the preparation of the feedstock for processing in the gasifier. The design is based upon a woody feedstock. It is expected that a feed handling area for agricultural residues or energy crops would be very similar.

The feed handling and drying section is shown in PFD-P810-A101 and PFD-P810-A102. Wood chips are delivered to the plant primarily via trucks. However, it is envisioned that there could be some train transport. Assuming that each truck capacity is about 25 tons, ${ }^{28}$ this means that if the 
wood, at a moisture content of 50\%, was delivered to the plant via truck transport only, then 176 truck deliveries per day would be required. As the trucks enter the plant they are weighed (M-101) and the wood chips are dumped into a storage pile. From the storage pile, the wood chips are conveyed (C-102) through a magnetic separator (S-101) and screened (S-102). Particles larger than 2 inches are sent through a hammer mill (T-102/M-102) for further size reduction. Front end loaders transfer the wood chips to the dryer feed bins (T-103).

Drying is accomplished by direct contact of the biomass feed with hot flue gas. Because of the large plant size there are two identical, parallel feed handling and drying trains. The wet wood chips enter each rotary biomass dryer (M-104) through a dryer feed screw conveyor (C-104). The wood is dried to a moisture content of $5 \mathrm{wt} \%$ with flue gas from the tar reformer's fuel combustor (R-303A). The exhaust gas exiting the dryer is sent through a cyclone (S-103) and baghouse filter (S-104) to remove particulates prior to being emitted to the atmosphere. The stack temperature of the flue gas is set at $62^{\circ}$ above the dew point of the gas, $237^{\circ} \mathrm{F}\left(114^{\circ} \mathrm{C}\right)$. The stack temperature is controlled by cooling the hot flue gas from the tar reformer $(\mathrm{H}-311$ in simulation, which physically translates to H-AP-1, H-AP-2, H-AP-3 and H-AP-4 after pinch analysis) prior to entering the dryer. This heat is used to preheat a tar reformer inlet stream (HAP-1), superheat steam (H-AP-2), generate steam (H-AP-3), and heat boiler feed water (H-AP4). The dried biomass is then pressurized with nitrogen available from the Air Separation Unit in a lock hopper (T-105) and conveyed to the gasifier train via a feed hopper (T-104) and a screw conveyor (C-105).

The cost of the feed handling system was averaged from various sources shown in Table 18.

\subsection{Gasification - Area 200}

This section of the process converts a mixture of dry feedstock, oxygen, and steam to syngas, char, and ash. Heat is provided by partial combustion of the biomass. The amount of oxygen supplied dictates the amount of biomass combusted. This is used to control the temperature of the gasifier.

From the feed handling and drying section, the dried wood enters the gasifier section as shown in PFD-P810-A201. Because of the plant size, it is assumed that there are two parallel gasifier trains. The gasifier (R-201) used in this analysis is a high-pressure oxygen blown bubbling fluidized bed gasifier. The gasifier was modeled using correlations based on data from the Gas Technology Institute (GTI) 12 tonne/day test facility ${ }^{24}$ (see Appendix G).

The inert solid in the gasifier is synthetic olivine, a calcined magnesium silicate, primarily Enstatite $\left(\mathrm{MgSiO}_{3}\right)$, Forsterite $\left(\mathrm{Mg}_{2} \mathrm{SiO}_{3}\right)$, and Hematite $\left(\mathrm{Fe}_{2} \mathrm{O}_{3}\right)$, used as a heat transfer solid for various applications. A small amount of $\mathrm{MgO}$ must be added to the fresh olivine to avoid the formation of glass-like bed agglomerations that would result from the biomass potassium interacting with the silicate compounds. The $\mathrm{MgO}$ titrates the potassium in the feed ash. Without $\mathrm{MgO}$ addition, the potassium will form glass, $\mathrm{K}_{2} \mathrm{SiO}_{4}$, with the silica in the system. $\mathrm{K}_{2} \mathrm{SiO}_{4}$ has a low melting point $\left(\sim 930^{\circ} \mathrm{F}, 500^{\circ} \mathrm{C}\right)$, and its formation will cause the bed media to become sticky, agglomerate, and eventually defluidize. Adding $\mathrm{MgO}$ makes the potassium form a high melting point $\left(\sim 2,370^{\circ} \mathrm{F}, 1,300^{\circ} \mathrm{C}\right)$ ternary eutectic with the silica, thus sequestering it. Potassium carry-over in the gasifier/combustor cyclones is also significantly reduced. The ash content of the 
feed is assumed to contain $0.2 \mathrm{wt} \%$ potassium. The $\mathrm{MgO}$ flow rate is set at two times the molar flow rate of potassium.

The gasifier fluidization medium is steam that is supplied from the steam cycle (Steam System and Power Generation - Area 600). The steam-to-feed ratio is $0.2 \mathrm{lb}$ of steam per $\mathrm{lb}$ of dried biomass (the dried biomass has $5 \mathrm{wt} \%$ moisture). The gasifier pressure is $438 \mathrm{psia}$. Olivine is added at a rate of $1 \mathrm{wt} \%$ of the dry ash free biomass flow rate to make up for attrited and entrained olivine leaving the gasifier. The heat loss from the gasifier is set at $1 \%$ of the heating value of the feedstock.

The target temperature of the gasifier is set at $1600^{\circ} \mathrm{F}$. Oxygen input is controlled to maintain this temperature. Oxygen feed was about $0.23 \mathrm{lb}$ per lb of bone dry feed for a gasifier temperature of $1600^{\circ} \mathrm{F}$. Adding more steam or increasing the target temperature increases the amount of combustion, which depletes the amount of syngas that can be used for alcohol synthesis. The composition of the outlet gas from the gasifier is shown in Table 3.

Particulate removal from the raw syngas exiting the gasifier is performed using two-stage cyclone separators. Nearly all of the olivine $(99.9 \%)$ and char $(99 \%)$ is separated in the primary gasifier cyclone (S-201). A secondary cyclone (S-202) removes $99 \%$ of any residual fines. The solids are depressurized and cooled. The olivine and char mixture from the two cyclones is landfilled, but prior to this the solids are cooled and water is added to the sand/ash stream for conditioning to prevent the mixture from being too dusty to handle. First the ash and sand mixture is cooled to $300^{\circ} \mathrm{F}\left(149^{\circ} \mathrm{C}\right)$ using the water cooled screw conveyor $(\mathrm{M}-201)$, then water is added directly to the mixture until the mixture water content is $10 \mathrm{wt} \%$.

Table 3. Gasifier Operating Parameters, Gas Compositions, and Efficiencies

\begin{tabular}{|c|c|c|}
\hline Gasifier Variable & \multicolumn{2}{|c|}{ Value } \\
\hline Temperature & \multicolumn{2}{|c|}{$1,600^{\circ} \mathrm{F}\left(871^{\circ} \mathrm{C}\right)$} \\
\hline Pressure & \multicolumn{2}{|c|}{$438 \mathrm{psia}(30.2 \mathrm{bar})$} \\
\hline Gasifier outlet gas composition & mol\% (wet) & mol\% (dry) \\
\hline $\mathrm{H}_{2}$ & 17.82 & 22.85 \\
\hline $\mathrm{CO}_{2}$ & 29.02 & 37.21 \\
\hline $\mathrm{CO}$ & 14.50 & 18.60 \\
\hline $\mathrm{H}_{2} \mathrm{O}$ & 22.01 & -- \\
\hline $\mathrm{CH}_{4}$ & 13.88 & 17.79 \\
\hline $\mathrm{C}_{2} \mathrm{H}_{6}$ & 0.66 & 0.84 \\
\hline $\mathrm{C}_{6} \mathrm{H}_{6}$ & 0.99 & 1.26 \\
\hline $\operatorname{tar}\left(\mathrm{C}_{10} \mathrm{H}_{8}\right)$ & 0.32 & 0.41 \\
\hline $\mathrm{NH}_{3}$ & 0.20 & 0.26 \\
\hline $\mathrm{H}_{2} \mathrm{~S}$ & 0.04 & 0.06 \\
\hline $\mathrm{N}_{2}$ & 0.03 & 0.03 \\
\hline $\mathrm{Ar}$ & 0.53 & 0.68 \\
\hline $\mathrm{H}_{2}$ :CO molar ratio & \multicolumn{2}{|c|}{1.23} \\
\hline Gasifier Efficiency & \multicolumn{2}{|c|}{$79.7 \%$ HHV basis } \\
\hline
\end{tabular}

Capital costs for the equipment in this section along with sources are shown in Table 18. Note that the cost shown in Table 18 included the cost of the gasifier and the tar reformer for a 2,000 
ton/day plant. The tar reformer is included in Area 300. In order to split the cost between the gasification section (A200) and the gas cleanup section (A300), the capital costs were split equally between two gasifier trains and a reformer. The capital cost estimate is approximate and was compiled for a previous study by Spath et al. ${ }^{49}$ The operating costs for this section are listed in Appendix D and consist of makeup $\mathrm{MgO}$ and olivine and sand/ash/char removal.

\subsection{Gas Cleanup and Conditioning - Area 300}

This section of the process cleans up and conditions the syngas so that the gas can be synthesized into alcohol. The type and the extent of cleanup are dictated by the requirements of the synthesis catalyst:

- The tars in the syngas are reformed to additional $\mathrm{CO}$ and $\mathrm{H}_{2}$

- Particulates are removed by quenching

- Acid gases $\left(\mathrm{CO}_{2}\right.$ and $\left.\mathrm{H}_{2} \mathrm{~S}\right)$ are removed.

The gas from the secondary gasifier cyclone is sent to the catalytic tar reformer (R-303). In this bubbling fluidized bed reactor the hydrocarbons are converted to $\mathrm{CO}$ and $\mathrm{H}_{2}$ while $\mathrm{NH}_{3}$ is converted to $\mathrm{N}_{2}$ and $\mathrm{H}_{2}$. In the Aspen simulation, the conversion of each compound is set to match targets that are believed to be attainable through near-term research efforts. Table 4 gives the conversion targets for 2012 used in the 2007 indirect gasifier design report, ${ }^{2}$ which assumes a pressure of 16 psi in the tar reformer.

Table 4. Target Design Performance of Tar Reformer in the Phillips et al. Report ${ }^{2}$

\begin{tabular}{|c|c|}
\hline Compound & $\begin{array}{c}\text { Target Conversion } \\
\text { to } \mathbf{C O} \text { \& } \mathbf{H}_{\mathbf{2}} \\
\mathbf{( 2 0 1 2})\end{array}$ \\
\hline Methane $\left(\mathrm{CH}_{4}\right)$ & $80 \%$ \\
\hline Ethane $\left(\mathrm{C}_{2} \mathrm{H}_{6}\right)$ & $99 \%$ \\
\hline Ethylene $\left(\mathrm{C}_{2} \mathrm{H}_{4}\right)$ & $90 \%$ \\
\hline Tars $\left(\mathrm{C}_{10+}\right)$ & $99.9 \%$ \\
\hline Benzene $\left(\mathrm{C}_{6} \mathrm{H}_{6}\right)$ & $99 \%$ \\
\hline Ammonia $\left(\mathrm{NH}_{3}\right)^{\mathrm{a}}$ & $90 \%$ \\
\hline
\end{tabular}

However, the targets shown in Table 4 are not valid at the higher pressure of 431 psi used in this design because they exceed equilibrium conversions at that condition. The pressure of $431 \mathrm{psi}$ was chosen because it was slightly lower than the gasifier exit pressure of 438 psi. Operating at these conditions saves on downstream compression costs. The conversions were modified to approach $80 \%$ of equilibrium for methane and $90 \%$ of equilibrium for ammonia (consistent with Table 4) at the reaction conditions shown in Table 6. The equilibrium compositions were calculated by Gibbs free energy minimization (RGIBBS) in Aspen Plus. The equilibrium for the other species in Table 4 was either not affected significantly by pressure or these species were not present in any significant quantities in the simulation to warrant changing their conversions.

\footnotetext{
${ }^{\text {a }}$ Converts to $\mathrm{N}_{2}$ and $\mathrm{H}_{2}$
} 
The conversions used in this model are shown in Table 5.

Table 5. Conversions Used in the Tar Reformer

\begin{tabular}{|c|c|}
\hline Compound & $\begin{array}{c}\text { Target Conversion } \\
\text { to CO \& } \mathbf{H}_{\mathbf{2}}\end{array}$ \\
\hline Methane $\left(\mathrm{CH}_{4}\right)$ & $46.2 \%$ \\
\hline Ethane $\left(\mathrm{C}_{2} \mathrm{H}_{6}\right)$ & $99 \%$ \\
\hline Ethylene $\left(\mathrm{C}_{2} \mathrm{H}_{4}\right)$ & $90 \%$ \\
\hline Tars $\left(\mathrm{C}_{10+}\right)$ & $99.9 \%$ \\
\hline Benzene $\left(\mathrm{C}_{6} \mathrm{H}_{6}\right)$ & $99 \%$ \\
\hline Ammonia $\left(\mathrm{NH}_{3}\right)^{\mathrm{a}}$ & $78 \%$ \\
\hline
\end{tabular}

The impact of the lower methane conversion has far-reaching effects on the economics of the process. The higher methane at the inlet of the synthesis reactor results in a lower fraction of the throughput being converted to mixed alcohols. This increases the recycle of unconverted gases and the throughput through the tar reformer, increasing capital costs. Also, the $\mathrm{H}_{2}$ : $\mathrm{CO}$ ratio, which is required to be between 1 and 1.2 at the alcohols synthesis reactor inlet (in this design), is significantly higher and closer to 2 without any mitigation. This is because the steam input is based on the total carbon going into the tar reformer and not on the actual conversion, which means there is a higher amount of steam available for water gas shift; this shifts the equilibrium toward $\mathrm{H}_{2}$ production. To mitigate the $\mathrm{H}_{2}$ : $\mathrm{CO}$ ratio, $\mathrm{CO}_{2}$ is added to the tar reformer, which in turn further increases the volume of the reactor. A significant portion of the added $\mathrm{CO}_{2}$ comes out unreacted from the tar reformer. To meet the $\mathrm{CO}_{2}$ specification of $5 \%$ in the alcohol synthesis reactor, the amine system needs to expend greater energy and requires higher capital costs to remove the higher amounts of $\mathrm{CO}_{2}$. While dry reforming with $\mathrm{CO}_{2}$ is known to be used for lowering $\mathrm{H}_{2}$ : $\mathrm{CO}$ ratios, ${ }^{29}$ it is not economical in this case. The economics of running the direct gasifier at a lower pressure of 100 psi are worse than for the base case of this report and are discussed in Appendix K.

In the Aspen simulation the tar reformer operates isothermally at $1,600^{\circ} \mathrm{F}$. An implicit assumption in this mode of operation is that the energy needed for the endothermic reforming reactions can be transferred into the catalyst bed. Although conceptual reactor designs are readily created for providing the heat of reaction from the fuel combustion area directly into the reformer catalyst bed, in practice this may be a difficult and prohibitively expensive design option requiring internal heat transfer tubes operating at high temperatures. An alternate approach, not used in this study, would be to preheat the process gas upstream of the reformer above the current reformer exit temperature and to operate the reformer adiabatically with a resulting temperature drop across the bed and a lower exit gas temperature. In this configuration, the required inlet and exit gas temperatures would be set by the extent of conversion, the kinetics of the reforming reactions, and the amount of catalyst in the reactor. The composition of the gas from the tar reformer can be seen in Table 6 .

\footnotetext{
${ }^{\text {a }}$ Converts to $\mathrm{N}_{2}$ and $\mathrm{H}_{2}$
} 
Table 6. Target Design Tar Reformer Conditions and Outlet Gas Composition

\begin{tabular}{|c|c|c|}
\hline Tar Reformer Variable & \multicolumn{2}{|c|}{ Value } \\
\hline Tar reformer inlet temperature & \multicolumn{2}{|c|}{$1,600^{\circ} \mathrm{F}\left(871^{\circ} \mathrm{C}\right)$} \\
\hline Tar reformer outlet temperature & \multicolumn{2}{|c|}{$1,600^{\circ} \mathrm{F}\left(871^{\circ} \mathrm{C}\right)$} \\
\hline Tar reformer pressure & \multicolumn{2}{|c|}{$431 \mathrm{psi}$} \\
\hline Tar reformer outlet gas composition & mol\% (wet) & mol\% (dry) \\
\hline $\mathrm{H}_{2}$ & 31.16 & 39.72 \\
\hline $\mathrm{CO}_{2}$ & 14.47 & 18.45 \\
\hline $\mathrm{CO}$ & 25.99 & 33.14 \\
\hline $\mathrm{H}_{2} \mathrm{O}$ & 21.56 & --- \\
\hline $\mathrm{CH}_{4}$ & 4.66 & 5.94 \\
\hline $\mathrm{C}_{2} \mathrm{H}_{6}$ & 20.45 ppmv & $26.07 \mathrm{ppmv}$ \\
\hline $\mathrm{C}_{3} \mathrm{H}_{8}$ & 0.06 & 0.08 \\
\hline $\mathrm{N}-\mathrm{C} 4 \mathrm{H} 10$ & $69.75 \mathrm{ppmv}$ & $88.92 \mathrm{ppmv}$ \\
\hline $\mathrm{C} 5 \mathrm{H} 12$ & $8.47 \mathrm{ppmv}$ & $10.80 \mathrm{ppmv}$ \\
\hline $\mathrm{C}_{6} \mathrm{H}_{6}$ & $25.24 \mathrm{ppmv}$ & $32.17 \mathrm{ppmv}$ \\
\hline $\operatorname{tar}\left(\mathrm{C}_{10} \mathrm{H}_{8}\right)$ & $0.82 \mathrm{ppmv}$ & $1.05 \mathrm{ppmv}$ \\
\hline $\mathrm{NH}_{3}$ & $122.96 \mathrm{ppmv}$ & $156.76 \mathrm{ppmv}$ \\
\hline $\mathrm{H}_{2} \mathrm{~S}$ & $142.59 \mathrm{ppmv}$ & $181.78 \mathrm{ppmv}$ \\
\hline $\mathrm{Ar}$ & 1.70 & 2.17 \\
\hline $\mathrm{N}_{2}$ & 0.35 & 0.45 \\
\hline lar ratio & & \\
\hline
\end{tabular}

Prior to the quench step, the hot syngas is cooled to $320^{\circ} \mathrm{F}\left(160^{\circ} \mathrm{C}\right)$ with heat exchangers $(\mathrm{H}-$ 301A in the simulation, which translates to physical exchangers H-AP-6, H-AP-8, H-AP-9, HAP-10 after pinch analysis) that are integrated with various cold streams in the process that need to be heated. Details of the pinch analysis are shown in Appendix H, and the exchangers are also shown in the process flow diagrams in Appendix F. Additional cooling is carried out via water scrubbing, shown in PFD-P810-A305. The scrubber also removes impurities such as particulates, residual ammonia, and any residual tars. The scrubbing system consists of a venturi scrubber (M302) and quench chamber (M-301). The scrubbing system quench water is a closed recirculation loop with heat rejected to the cooling tower and a blow down rate of approximately $5.9 \mathrm{gpm}$ $(2,963 \mathrm{lb} / \mathrm{hr})$ that is sent to a wastewater treatment facility.

The quench water flow rate is determined by adjusting its circulation rate until the L/G (liquid by gas volumetric flows) ratio is 1 liter $/ \mathrm{m}^{3}$. This was based on a study of venturi scrubbers indicating that this results in near-optimal performance. ${ }^{30}$ After further heat exchange with process streams (H-301D in the simulation, which translates to physical exchangers H-BP-1 through $\mathrm{H}-\mathrm{BP}-16$ after pinch analysis) and cooling water exchangers (H-301C and $\mathrm{H}-303)$, the syngas is cooled to $110^{\circ} \mathrm{F}\left(43^{\circ} \mathrm{C}\right)$. Any solids that settle out in T-301 are sent off-site for treatment as well. For modeling purposes, the water content of the sludge stream was set at 50 $\mathrm{wt} \%$. A significant amount of water is condensed in the knock-out drum S-301. This water is free of any significant particulates and heavy hydrocarbons because of prior scrubbing and is sent for reuse in the steam system after going through a water softener (M-601) and deaerator (T-603).

Depending on the specific catalysts being used downstream of the tar reformer, varying concentrations of acid gas compounds can be tolerated in the syngas. For example, sulfur concentrations (as $\mathrm{H}_{2} \mathrm{~S}$ ) must be below $0.1 \mathrm{ppm}$ for copper based synthesis catalysts. This design is based upon sulfided molybdenum catalysts, which actually require up to $100 \mathrm{ppm}$ of $\mathrm{H}_{2} \mathrm{~S}$ in 
the syngas to maintain catalyst activity. Because the syngas exiting the gasifier can be as high as 400 ppmv of $\mathrm{H}_{2} \mathrm{~S}$ (higher for agricultural residues like corn stover than for woody biomass), some level of sulfur removal will be required by any of the synthesis catalysts currently of interest.

Carbon dioxide is the other acid gas that needs to be removed in the syngas conditioning process. Similar to the sulfur compounds, the acceptable level of $\mathrm{CO}_{2}$ depends on the specific catalyst being used in the synthesis reactor to make alcohols. Some synthesis catalysts require low levels of $\mathrm{CO}_{2}$ while others, such as the sulfided molybdenum catalysts, can tolerate relatively high $\mathrm{CO}_{2}$ levels. $\mathrm{CO}_{2}$ is a major component of the gasification product, so significant amounts of $\mathrm{CO}_{2}$ may need to be removed upstream of the synthesis reactor.

Since the catalyst selected for this study is a sulfided catalyst that is tolerant of sulfur up to 100 ppmv and $\mathrm{CO}_{2}$ up to $7 \mathrm{~mol} \%$ (see Appendix $\mathrm{J}$ of the Phillips et al. report ${ }^{2}$ for more detail), a design that can provide for the removal of both sulfur and carbon dioxide was chosen. An amine system capable of selectively removing $\mathrm{CO}_{2}$ and $\mathrm{H}_{2} \mathrm{~S}$ from the main process syngas stream is used. The amine assumed for this study is monoethanolamine (MEA), based on the recommendation by Nexant. ${ }^{31}$

The acid gas scrubber was simulated using a simplified model of SEP blocks and by specifying the amount of $\mathrm{CO}_{2}$ and $\mathrm{H}_{2} \mathrm{~S}$ that needs to be removed to meet design specifications of $50 \mathrm{ppmv}$ $\mathrm{H}_{2} \mathrm{~S}$ and $5 \mathrm{~mol} \% \mathrm{CO}_{2}$ at the synthesis reactor inlet, including any recycle streams to that unit operation. The amine system heating and cooling duties were calculated using information taken from section 21 of the GPSA Data Handbook ${ }^{32}$. This method gave a heat duty of 2,364 Btu per pound of $\mathrm{CO}_{2}$ removed, with a similar magnitude cooling duty provided by forced-air cooling fans. Power requirements for pumping and fans were also calculated using GPSA recommended values. The acid gas scrubber operating values for the base case are given in Table 7.

Table 7. Acid Gas Removal Design Parameters

\begin{tabular}{|c|c|}
\hline Acid Gas Removal Parameter & Value \\
\hline Amine Used & Monoethanolamine (MEA) \\
Amine Concentration & $35 \mathrm{wt} \%$ \\
Amine Circ. Rate & $3,910 \mathrm{gpm}$ \\
Amine Temp. @ Absorber & $110^{\circ} \mathrm{F}$ \\
Absorber Pressure & $414 \mathrm{psia}$ \\
Stripper Condenser Temperature & $212^{\circ} \mathrm{F}$ \\
Stripper Reboiler Temperature & $237^{\circ} \mathrm{F}$ \\
Stripper Pressure & $65 \mathrm{psia}$ \\
Stripper Reboiler Duty & $281.5 \mathrm{MMBtu} / \mathrm{hr}$ \\
Stripper Condenser Duty & $187.7 \mathrm{MMBtu} / \mathrm{hr}$ \\
Amine Cooler Duty & $93.8 \mathrm{MMBtu} / \mathrm{hr}$ \\
Heat Duty per Pound $\mathrm{CO}_{2}$ removed & $2,364 \mathrm{Btu} / \mathrm{bb}$ \\
\hline
\end{tabular}

If a highly $\mathrm{CO}_{2}$-tolerant alcohol synthesis catalyst is used, it may become possible to use other syngas conditioning processes or methods to selectively remove $\mathrm{H}_{2} \mathrm{~S}$, with less energy and possibly at a significantly lower capital cost. 
The acid gases removed in the amine scrubber are then stripped to regenerate the sorbent and sent through a sulfur removal operation using a liquid phase oxidation process as shown in PFDP810-A308. The combined Amine/ LO-CAT ${ }^{\circledR}$ process will remove the sulfur and $\mathrm{CO}_{2}$ to the levels desired for the selected moly-sulfide catalyst. Although there are several liquid-phase oxidation processes for $\mathrm{H}_{2} \mathrm{~S}$ removal and conversion available today, the LO-CAT process was selected because of its progress in minimizing catalyst degradation and its environmentallybenign catalyst. LO-CAT is an iron chelate-based process that consists of a venturi precontactor (M-303), liquid-filled absorber (M-304), air-blown oxidizer (R-304), air blower (K-302), solution circulation pump (P-303), and solution cooler (H-305). Elemental sulfur is produced in the oxidizer and since only a small amount (1.6 ton/day) is produced, it is stockpiled either for eventual disposal or sold as an unconditioned product. The LO-CAT process was modeled to remove the $\mathrm{H}_{2} \mathrm{~S}$ to a concentration of $10 \mathrm{ppmv}$ in the $\mathrm{CO}_{2}$ vent effluent from the amine scrubber. The air flow rate for re-oxidizing the LO-CAT solution was included in the simulation and calculated based on the requirement of 2 moles of $\mathrm{O}_{2}$ per mole of $\mathrm{H}_{2} \mathrm{~S}$. Prior to entering the LOCAT system the gas stream is superheated by $10^{\circ} \mathrm{F}\left(5.6^{\circ} \mathrm{C}\right)$ in a preheater $(\mathrm{H}-304)$. The dewpoint of this stream is about $120^{\circ} \mathrm{F}$, and this degree of superheating is required for the LOCAT system. The $\mathrm{CO}_{2}$ from the LO-CAT unit is vented to the atmosphere.

The capital costs for the equipment in this section are described in further detail in Appendix C. The operating costs consist of makeup reforming catalyst, LO-CAT and amine chemical makeup, as well as reforming catalyst disposal cost and wastewater treatment. These are described in further detail in Section 3.

\subsection{Alcohol Synthesis - Area $\mathbf{4 0 0}$}

The alcohol synthesis reactor system is the heart of the entire process. Entering this process area, the syngas has been reformed, quenched, compressed, and treated to have reduced acid gas concentrations $\left(\mathrm{H}_{2} \mathrm{~S}, \mathrm{CO}_{2}\right)$. After that, it is further compressed and heated to the synthesis reaction conditions of about 1,000 psia and $570^{\circ} \mathrm{F}\left(300^{\circ} \mathrm{C}\right)$. The syngas reacts to form an alcohol mixture across a fixed bed catalyst. The product gas is subsequently cooled, allowing the alcohols to condense and separate from the unconverted syngas. The liquid alcohols are then sent to alcohol separation and purification (Area 500). The residual gas stream is recycled back to the tar reformer with a small purge to fuel combustion (8\%).

Research on alcohol synthesis catalysts has waxed and waned over many decades for a variety of reasons. In order to review the status of mixed alcohol technology and how it has developed over the past 20 years, two activities were initiated. First, a literature search was conducted. This search and its findings are described in more detail in Appendix J of the Phillips et al. report, ${ }^{2}$ along with a discussion on specific terminology such as "yield," "selectivity," and "conversion." These terms will be used throughout the remainder of this document. Second, an engineering consulting company (Nexant) was hired to document the current state of technology with regard to mixed alcohols production and higher alcohol synthesis. Their results are published in an NREL subcontract report. ${ }^{33}$

Based on the results of this background technology evaluation, a modified Fischer-Tropsch catalyst was used for this process design; specifically, a molybdenum-disulfide-based $\left(\mathrm{MoS}_{2}\right)$ catalyst. The former Dow/UCC catalyst was chosen because of its relatively high ethanol selectivity and because its product slate is a mixture of linear alcohols (as opposed to the 
branched alcohols that result from modified methanol catalysts). This particular catalyst uses high surface area $\mathrm{MoS}_{2}$ promoted with alkali metal salts (e.g., potassium carbonate) and cobalt $(\mathrm{CoS})$. These promoters shift the product slate from hydrocarbons to alcohols, and they can either be supported on alumina or activated carbon or be used unsupported.

Table 8 lists several process and syngas conditioning requirements for this synthesis reaction. These include experimentally verified conditions typical of those found in literature as well as targeted conditions from the OBP-funded research plan used in the model.

Table 8. Process Conditions for Mixed Alcohols Synthesis

\begin{tabular}{|l|c|c|}
\hline Parameter & $\begin{array}{c}\text { "State of Technology" } \\
\text { Conditions }\end{array}$ & $\begin{array}{c}\text { Target Conditions } \\
\text { Used in Process Design \& } \\
\text { Aspen Model }\end{array}$ \\
\hline Temperature $\left({ }^{\circ} \mathrm{C}\right)$ & $\sim 300$ & 300 \\
\hline Pressure $(p s i a)$ & $1,500-2,000$ & 1,000 \\
\hline $\mathrm{H}_{2} / \mathrm{CO}$ ratio & $1.0-1.2$ & 1.2 \\
\hline $\mathrm{CO}_{2}$ concentration $(\mathrm{mol} \%)$ & $0 \%-7 \%$ & $5.0 \%$ \\
\hline Sulfur concentration $(\mathrm{ppmv})$ & $50-100$ & 50 \\
\hline
\end{tabular}

Though the synthesis reactor is modeled as operating isothermally, it is recognized that maintaining a constant temperature in a fixed bed reactor system would be difficult, especially since these reactions are highly exothermic. Temperature has a significant impact on the alcohol selectivity and product distribution. High pressures are typically required to ensure the production of alcohols. $\mathrm{MoS}_{2}$ catalysts are efficient Fischer-Tropsch (FT) catalysts at ambient or low pressures. However, significantly raising the pressure (in addition to promoting with alkali) helps to shift the kinetic pathways from hydrocarbon production toward alcohol production. However, compression requirements for achieving these pressures can be quite substantial. Thus, targeting a catalyst that achieves optimal performance at lower pressures can potentially provide significant cost savings.

The $\mathrm{CO}_{2}$ concentration requirements for the syngas are less well-known. Herman ${ }^{34}$ states that in the first Dow patent application, the presence of larger amounts of $\mathrm{CO}_{2}$ in the synthesis gas retarded the catalyst activity. Further study showed that increasing the $\mathrm{CO}_{2}$ concentration to 30 vol $\%$ decreased the $\mathrm{CO}$ conversion but did not significantly alter the alcohol:hydrocarbon ratio of the product. With $\mathrm{CO}_{2}$ concentrations up to $6.7 \mathrm{vol} \%$, the extent of $\mathrm{CO}$ conversion is not affected; however, higher chain alcohol yield relative to methanol does tend to decrease. This is why $\mathrm{CO}_{2}$ concentrations were reduced to $5 \mathrm{~mol} \%$ in the model using the amine system as part of syngas conditioning. The effect of $\mathrm{CO}_{2}$ concentration on alcohol production will be studied in future laboratory experiments.

One of the benefits of this catalyst is its sulfur tolerance. It must be continuously sulfided to

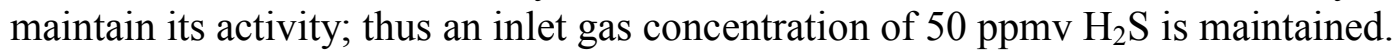

Concentrations above 100 ppmv inhibit both the reaction rate and higher alcohol selectivity.

The overall stoichiometric reaction for alcohol synthesis can be summarized as:

$$
n \mathrm{CO}+2 n \mathrm{H}_{2} \rightarrow \mathrm{C}_{n} \mathrm{H}_{2 n+1} \mathrm{OH}+(n-1) \mathrm{H}_{2} \mathrm{O}
$$


Stoichiometry suggests an optimum $\mathrm{H}_{2}$ :CO ratio of 2.0. However, this catalyst maintains significant water-gas shift activity and will generate its own $\mathrm{H}_{2}$ from $\mathrm{CO}$ and $\mathrm{H}_{2} \mathrm{O}$ :

$$
\mathrm{CO}+\mathrm{H}_{2} \mathrm{O} \rightarrow \mathrm{H}_{2}+\mathrm{CO}_{2}
$$

This shifts the optimal ratio closer to 1.0 and also shifts the primary byproduct from water to $\mathrm{CO}_{2}$. Experiments have been typically conducted using ratios in the range of 1.0 to 1.2.

The compressor (K-410) in this area is a 3-stage steam-driven compressor that takes the syngas from 414 psia to 1,000 psia, requiring 9,167 HP (assuming a polytropic efficiency of 78\%). The outlet syngas from the compressor is then mixed with recycled methanol from Alcohol Purification (Area 500), heated to $570^{\circ} \mathrm{F}\left(300^{\circ} \mathrm{C}\right)$, and sent to the reactor. The capital cost for the compressor was developed using Questimate.

The mixed alcohol synthesis reactor is a fixed-bed reactor system that contains the $\mathrm{MoS}_{2}$ catalyst. Because this is a net exothermic reaction system, water is cross exchanged with the reactor to produce steam for the process while helping to maintain a constant reactor temperature. Questimate was used to develop the reactor capital cost.

The purchase price of the catalyst itself was estimated at $\$ 5.25 / \mathrm{lb}$ based on conversations NREL researchers had with CRITERION, a petroleum/hydrocarbon catalyst provider. This represents a generalized cost of molybdenum-based catalyst at around $\$ 5 / \mathrm{lb}$ being sulfided for an additional $\$ 0.25 / 1$ b. In addition, NREL was able to speak with Dow catalyst experts ${ }^{35}$ who said that in today's market, the raw material costs for producing such a catalyst system would run about $\$ 20 / \mathrm{lb}$. Adding more cost for the catalyst preparation would bring that cost to $\$ 22-\$ 40 / 1 \mathrm{~b}$. However, these costs could go down as demand goes up, and could decrease quite substantially at a large enough scale.

In reality, each company developing a process like this will have its own proprietary catalyst and associated formulation. The costs for these catalysts are difficult to predict at the present time since so few providers of mixed alcohols catalyst currently exist (and costs will likely be negotiated with individual providers). Nexant also provided information on general catalyst price ranges in their report. They reported molybdenum ranging from $\$ 2-\$ 40 / 1 b$.

The lifetime of the catalyst was assumed to be 5 years. While existing mixed alcohols catalysts have not been tested for this long, they have operated for more than 8,000 hours (roughly 1 year of continuous operating time) with little or no loss in performance.

The reactor was modeled as a simple conversion-specified reactor using a series of alcohol and hydrocarbon production reactions as shown in Table 9. The propane, butane, and pentane+ reactions are set to zero because the catalyst will likely not favor these reactions. The specific conversions of each of the other reactions were set in order to reach catalyst performance targets. Those targets are shown in Table 10 along with values for those parameters typically found in literature. 
Table 9. System of Reactions for Mixed Alcohol Synthesis

\begin{tabular}{|cc|}
\hline Water-Gas Shift & $\mathrm{CO}+\mathrm{H}_{2} \mathrm{O} \leftrightarrow \mathrm{H}_{2}+\mathrm{CO}_{2}$ \\
Methanol & $\mathrm{CO}+2 \mathrm{H}_{2} \rightarrow \mathrm{CH}_{3} \mathrm{OH}$ \\
Methane & $\mathrm{CH}_{3} \mathrm{OH}+\mathrm{H}_{2} \rightarrow \mathrm{CH}_{4}+\mathrm{H}_{2} \mathrm{O}$ \\
Ethanol & $\mathrm{CO}+2 \mathrm{H}_{2}+\mathrm{CH}_{3} \mathrm{OH} \rightarrow \mathrm{C}_{2} \mathrm{H}_{5} \mathrm{OH}+\mathrm{H}_{2} \mathrm{O}$ \\
Ethane & $\mathrm{C}_{2} \mathrm{H}_{5} \mathrm{OH}+\mathrm{H}_{2} \rightarrow \mathrm{C}_{2} \mathrm{H}_{6}+\mathrm{H}_{2} \mathrm{O}$ \\
Propanol & $\mathrm{CO}+2 \mathrm{H}_{2}+\mathrm{C}_{2} \mathrm{H}_{5} \mathrm{OH} \rightarrow \mathrm{C}_{3} \mathrm{H}_{7} \mathrm{OH}+\mathrm{H}_{2} \mathrm{O}$ \\
Propane & $\mathrm{C}_{3} \mathrm{H}_{7} \mathrm{OH}+\mathrm{H}_{2} \rightarrow \mathrm{C}_{3} \mathrm{H}_{8}+\mathrm{H}_{2} \mathrm{O}$ \\
n-Butanol & $\mathrm{CO}+2 \mathrm{H}_{2}+\mathrm{C}_{3} \mathrm{H}_{7} \mathrm{OH} \rightarrow \mathrm{C}_{4} \mathrm{H}_{9} \mathrm{OH}+\mathrm{H}_{2} \mathrm{O}$ \\
Butane & $\mathrm{C}_{4} \mathrm{H}_{9} \mathrm{OH}+\mathrm{H}_{2} \rightarrow \mathrm{C}_{4} \mathrm{H}_{10}+\mathrm{H}_{2} \mathrm{O}$ \\
Pentanol+ & $\mathrm{CO}+2 \mathrm{H}_{2}+\mathrm{C}_{4} \mathrm{H}_{9} \mathrm{OH} \rightarrow \mathrm{C}_{5} \mathrm{H}_{11} \mathrm{OH}+\mathrm{H}_{2} \mathrm{O}$ \\
Pentane+ & $\mathrm{C}_{5} \mathrm{H}_{11} \mathrm{OH}+\mathrm{H}_{2} \rightarrow \mathrm{C}_{5} \mathrm{H}_{12}+\mathrm{H}_{2} \mathrm{O}$ \\
\hline
\end{tabular}

Table 10. Mixed Alcohol Reaction Performance Results

\begin{tabular}{|l|c|c|}
\hline \multicolumn{1}{|c|}{ Result } & $\begin{array}{c}\text { "State of Technology" } \\
\text { Value Ranges }\end{array}$ & $\begin{array}{c}\text { Target Results } \\
\text { Used in Process Design \& } \\
\text { Aspen Model }\end{array}$ \\
\hline Total CO Conversion (per-pass) & $10 \%-40 \%$ & $60 \%$ \\
\hline $\begin{array}{l}\text { Total Alcohol Selectivity } \\
\left(\mathrm{CO}_{2} \text {-free basis) }\right.\end{array}$ & $70 \%-80 \%$ & $90 \%$ \\
\hline Gas Hourly Space Velocity $\left(\mathrm{hr}^{-1}\right)$ & $1,600-12,000$ & 4,000 \\
\hline $\begin{array}{l}\text { Catalyst Alcohol Productivity }(\mathrm{g} / \mathrm{kg}- \\
\text { catalyst/hr })^{\mathrm{a}}\end{array}$ & $150-350$ & 600 \\
\hline
\end{tabular}

The individual target values are less important than the net result of the entire collection. For example, a catalyst system can have a high CO conversion well above $40 \%$, but if most of that $\mathrm{CO}$ is converted to methane or $\mathrm{CO}_{2}$, then the alcohol selectivities would be very low and the entire process economics would suffer. Likewise, if the catalyst had a high CO conversion and selectivity but had very low productivity, a much larger reactor would have to be built to accommodate the volume of catalyst required. The set of targets shown above are improvements over current literature values, but they were chosen as targets believed to be achievable through catalyst research and development. There is precedent for these results from other catalyst systems. For example, FT catalysts are currently capable of CO conversions above $70 \% .{ }^{37}$ Also, commercial methanol catalysts have productivities over $1000 \mathrm{~g} / \mathrm{kg}$-catalyst $/ \mathrm{hr}^{34}$

The reaction conversions were also set to achieve a certain product distribution of alcohols. The mixed alcohol products described in literature are often high in methanol, but contain a wide distribution of several different alcohols. The product distributions described by Dow and SRI are shown in Table 11 along with the relative product concentrations calculated by the model.

\footnotetext{
${ }^{\mathrm{a}}$ Based on assumed catalyst density of $64 \mathrm{lb} / \mathrm{ft}^{3}, 600 \mathrm{~g} / \mathrm{kg}$-catalyst $/ \mathrm{hr}=615 \mathrm{~g} / \mathrm{L}$-catalyst $/ \mathrm{hr}$.
} 
Table 11. Mixed Alcohol Synthesis Product Distributions

\begin{tabular}{|c|c|c|c|}
\hline Alcohol & $\begin{array}{l}\text { Dow }^{38} \\
\text { (wt \%) }\end{array}$ & $\begin{array}{l}\text { SRI }^{39} \\
\text { (wt\%) }\end{array}$ & $\begin{array}{c}\text { NREL Model } \\
(w t \%)^{\mathrm{a}}\end{array}$ \\
\hline Methanol & $30-70 \%$ & $30.77 \%$ & $4.83 \%$ \\
\hline Ethanol & $34.5 \%$ & $46.12 \%$ & $67.13 \%$ \\
\hline Propanol & $7.7 \%$ & $13.3 \%$ & $9.48 \%$ \\
\hline Butanol & $1.4 \%$ & $4.14 \%$ & $1.17 \%$ \\
\hline Pentanol + & $1.5 \%$ & $2.04 \%$ & $0.15 \%$ \\
\hline Acetates (C1 \& C2) & $2.5 \%$ & $3.63 \%$ & \\
\hline $\begin{array}{l}\text { Others }(\mathrm{CH} 4, \mathrm{C} 2 \mathrm{H} 6, \\
\mathrm{C} 3 \mathrm{H} 8, \mathrm{C} 4 \mathrm{H} 10, \mathrm{C} 5+)\end{array}$ & & & $14.58 \%$ \\
\hline Water & $2.4 \%$ & & $2.66 \%$ \\
\hline Total & $100 \%$ & $100 \%$ & $100 \%$ \\
\hline
\end{tabular}

The most significant differences between the NREL model product distribution and those shown in literature are with regard to the methanol and ethanol distributions. This is primarily due to the almost complete recycle of methanol within this process. In the alcohol purification section downstream, virtually all methanol is recovered via distillation and recycled back to mix with the compressed syngas. This is done in order to increase the production of ethanol and higher alcohols. While this concept has been proposed in literature, it has never been tested or quantified in an integrated setting. In literature, experiments are often conducted on closed or batch systems and do not examine the potential impacts of recycled compounds or other integration issues. Therefore it becomes difficult to predict what impact this might have on catalyst performance.

A kinetic model was used to guide these conversion assumptions to help predict how the catalyst may perform as a result of significant methanol recycle. Very few kinetic models have been developed for this catalyst system. ${ }^{40,41,42}$ Of these, only Gunturu examined the possibility of methanol recycle. Therefore NREL reproduced this kinetic model using Polymath software. This kinetic model predicted that methanol entering the reactor would largely be converted to ethanol and methane. This model also predicted that maintaining high partial pressures of methanol in the reactor would further reduce the production of alcohols higher than ethanol. More detailed discussion on the kinetic model can be found in Appendix K of the Phillips et al. report. ${ }^{2}$

After the reactor, the effluent is cooled to $110^{\circ} \mathrm{F}\left(43^{\circ} \mathrm{C}\right)$ through a series of heat exchangers while maintaining high pressure. First, the reacted syngas is cross exchanged with cooler process streams, lowering the temperature to $275^{\circ} \mathrm{F}\left(135^{\circ} \mathrm{C}\right)$. Air-cooled exchangers then bring the temperature down to $140^{\circ} \mathrm{F}\left(60^{\circ} \mathrm{C}\right)$. The temperature at the inlet of the air-cooled exchanger was determined by the heat rejection requirements of the process based on pinch analysis. The final $30^{\circ} \mathrm{F}\left(17^{\circ} \mathrm{C}\right)$ drop is provided by heat exchange with cooling water. A knock-out drum (S-501) is then used to separate the liquids (primarily alcohols) from the remaining gas, which is composed of unconverted syngas, $\mathrm{CO}_{2}$, and methane. Aspen Plus contains other physical property packages that model non-ideal liquid systems much better than the Redlich-Kwong-Soave (RKS) equation of state used throughout the model. Therefore, the Non-Random Two-Liquid (NRTL) package was used to model the alcohol condensation.

\footnotetext{
${ }^{\text {a }}$ Prior to alcohol purification and methanol recycle
} 
From here, the liquid crude alcohols are sent to product purification while the residual syngas is superheated to $1,500^{\circ} \mathrm{F}\left(816^{\circ} \mathrm{C}\right)$ and sent through an expander to generate additional power for the process. The pressure is dropped from 967 to 465 psia prior to being recycled to the tar reformer. An $8 \%$ purge stream is sent to fuel combustion.

Alternate configurations will be discussed later in this report, as will the economic sensitivity of certain synthesis parameters. One particular variation would be to recycle the unconverted syngas to the throat of the synthesis reactor instead of to the tar reformer. This would save money on upstream equipment costs because of lower process throughput, but it would also lower yields because the $\mathrm{CO}_{2}$ would build up in the recycle loop. In the base case of this design report there is very little scope for extra recycle because the $\mathrm{H}_{2}: \mathrm{CO}$ ratio is already close to 1.2.

Future experiments and analysis will examine the impacts of methanol recycle and of variations in concentration of $\mathrm{CO}_{2}, \mathrm{CH}_{4}$, and other compounds. Alternate reactor designs will also be examined. For example, FT technology has largely switched to slurry reactors instead of fixedbed reactors because the slurry fluidization achieves better heat and mass transfer properties that allow, in turn, for higher conversions. Such improvements could help to achieve the conversion targets outlined above and reduce the costs of major equipment items.

\subsection{Alcohol Separation - Area $\mathbf{5 0 0}$}

The mixed alcohol stream from Area 400 is sent to Area 500 where it is de-gassed, dried, and separated into three streams: methanol, ethanol, and mixed higher-molecular weight alcohols. The methanol stream is used to back-flush the molecular sieve drying column and then recycled, along with the water removed during back flushing, to the inlet of the alcohol synthesis reactor in Area 400. The ethanol and mixed alcohol streams are cooled and sent to product storage tanks.

Carbon dioxide is readily absorbed in alcohol. Although the majority of the non-condensable gases leaving the synthesis reactor are removed in the separator vessel, S-501, a significant quantity of these gases remains in the alcohol stream, especially at the high system pressure. These gases are removed by depressurizing from 970 to 60 psia. Most of the dissolved gases separate from the alcohols in the knock-out vessel S-502. This gas stream is made up primarily of carbon dioxide with some small amounts of hydrocarbons and alcohols; it is recycled to the tar reformer in Area 300. After being vaporized (H-BP-16, H-BP-2) and superheated (H-BP-3) by $20^{\circ} \mathrm{F}\left(11^{\circ} \mathrm{C}\right)$ by cross exchanging with tar reformer exhaust streams, the alcohol stream goes to the molecular sieve dehydrator unit operation.

The molecular sieve dehydrator design was based upon previous biochemical ethanol studies ${ }^{5,3}$ and assumed to have similar performance with mixed alcohols. In the biochemical ethanol cases, the molecular sieve is used to dry ethanol after it is distilled to the azeotropic concentration of ethanol and water $(92.5 \mathrm{wt} \%$ ethanol). The adsorbed water is flushed from the molecular sieves with a portion of the dried ethanol and recycled to the rectification column. The water ultimately leaves out the bottom of the distillation column. In this thermochemical process, however, it was determined that drying the entire mixed alcohol stream before any other separation would be preferable. The adsorbed water is desorbed from the molecular sieves by a combination of depressurization and flushing with methanol. This methanol/water mixture is then recycled back to the Alcohol Synthesis section (A400). 
The molecular sieve units require a superheated vapor. The liquid mixed alcohol stream is vaporized, superheated, and then fed to one of two parallel adsorption columns. The adsorption column preferentially removes water and a small amount of the alcohols. While one adsorption bed is adsorbing water, the other is regenerating. The water is desorbed from the bed during regeneration by applying a vacuum and flushing with dry methanol from D-505. This methanol/water mixture is recycled back to the Alcohol Synthesis section (A400). This methanol/water mixture is cooled to $140^{\circ} \mathrm{F}\left(60^{\circ} \mathrm{C}\right)$ using a forced air heat exchanger and separated from any uncondensed vapor. The gaseous stream is recycled to the tar reformer, and the condensate is pumped to 1,000 psia in P-514 and mixed with high-pressure syngas from compressor K-410 in Area 400 upstream of the synthesis reactor pre-heater.

The dry mixed alcohol stream leaving the molecular sieve dehydrator enters into the first of two distillation columns, D-504. D-504 is a typical distillation column using trays, an overhead condenser, and a reboiler. The methanol and ethanol are separated from the incoming stream with $99 \%$ of the incoming ethanol being recovered in the overhead stream along with essentially all incoming methanol. The D-504 bottom stream consists of $99 \%$ of the incoming propanol, $1 \%$ of the incoming ethanol, and all of the butanol and pentanol. The mixed alcohol bottom stream is considered a co-product of the plant and is cooled and sent to storage. The methanol/ethanol overhead stream from D-504 goes to a second distillation column, D-505, for further processing.

D-505 separates the methanol from the binary methyl/ethyl alcohol mixture. The ethanol recovery in D-505 is $99 \%$ of the incoming ethanol and has a maximum methanol concentration of 0.5 mole percent to meet product specifications for fuel ethanol. The ethanol, which exits from the bottom of D-505, is cooled before being sent to product storage. The methanol and a small quantity of ethanol exiting the overhead of column D-505 are used to flush the molecular sieve column during its regeneration step as explained above. The entire amount of methanol from D505 is recycled through the molecular sieve dehydrator and then to the synthesis reactor in Area 400.

\subsection{Steam System and Power Generation - Area 600}

This process design includes a steam cycle that produces steam by recovering heat from the hot process streams throughout the plant. Steam demands for the process include the gasifier, reformer, amine system reboiler, alcohol purification reboilers, and LO-CAT preheater. Of these, only the steam to the gasifier and reformer is directly injected into the process; the rest of the plant heat demands are provided by indirect heat exchange of process streams with the steam and have condensate return loops. Power for internal plant loads is produced from the steam cycle using an extraction steam turbine/generator (M-602). Power is also produced from the process expander (K-412), which takes the unconverted syngas from 967 psia to 465 psia before it is recycled to the tar reformer.

The pressure for the high pressure steam is about 865 psia and is determined by the temperature requirement of the alcohol synthesis reactor. The synthesis reactor needs to be maintained at $570^{\circ} \mathrm{F}$ by generating steam. At 865 psia, water boils at roughly $527^{\circ} \mathrm{F}$, and the generated steam should be appropriate for maintaining the reactor at $570^{\circ} \mathrm{F}$. Steam is supplied to the gasifier and the reformer from the medium pressure (490 psia) turbine exhaust stage. The steam extraction pressure is determined by the process conditions of the gasifier and reformer. Low pressure steam (65 psia) is used for indirect heat exchange, and the choice is determined by the 
requirement to maintain a reasonable temperature differential for heat exchange. The plant energy balance is managed to generate a minimum amount of excess electricity beyond the requirements of the plant. However, in order to meet the steam requirements of the process, some excess electricity is generated in the extraction steam turbine system. The excess electricity comes at the cost of lower production of mixed alcohols. The steam system and power generation area is shown in PFD-P810-A601, PFD-P810-A602, and PFD-P810-A603 in Appendix F.

A condensate collection tank (T-601) gathers condensate from the syngas cooling and from the process reboilers along with the steam turbine condensate and makeup water. The total condensate stream is heated to the saturation temperature and sent to the deaerator (T-603) to remove dissolved gases from the water. The water from the deaerator is first pumped to a pressure of 930 psia and then pre-heated to its saturation (bubble point) temperature using a series of exchangers. Steam is generated by exchanging heat with the alcohol synthesis reactor (R-410), by cooling the fuel combustor flue gases (H-AP-3), and by cooling part of the reformer exhaust (H-AP-6). The saturated steam is collected in the steam drum (T-604). To prevent solids build up, water must be periodically discharged from the steam drum. The blowdown rate is equal to $2 \%$ of the water circulation rate. The saturated steam from the steam drum is superheated with another series of exchangers. Superheated steam enters the turbine at $900^{\circ} \mathrm{F}$ and $850 \mathrm{psia}$ and is expanded to a pressure of $490 \mathrm{psia}$. The remaining steam then enters the low pressure turbine and is expanded to a pressure of 65 psia. Finally, the steam enters a condensing turbine and is expanded to a pressure of 1.5 psia. The steam is condensed in the steam turbine condenser $(\mathrm{H}-601)$ and the condensate is re-circulated back to the condensate collection tank.

The integration of the heat exchangers can be seen in the PFDs and in a discussion of the pinch analysis included in Appendices $\mathrm{F}$ and $\mathrm{H}$, respectively. To close the heat balance of the system, the Aspen Plus model increases or decreases the water flow rate through the steam cycle until the heat balance of the system is met.

This process design assumes that the five compressors in this process (K-384, K410, K-801, K$802, \mathrm{~K}-802 \mathrm{~N}$ ) are steam-driven. All other drives for pumps, fans, etc. are electric motors. Additionally, an allowance of $10 \%$ of excess power is made to the total power requirement to account for miscellaneous usage and general electric needs (lights, computers, etc). Table 12 contains the power requirement of the plant broken out into the different plant sections. Because some compressors, including the one for the air separation unit, are steam driven and do not require electricity, the total power requirement is much less than it would be if all compression demands were included. 
Table 12. Plant Power Requirements

\begin{tabular}{|c|c|}
\hline Plant Section & Power Requirement (kW) \\
\hline Feed Handling \& Drying & 742 \\
\hline Gasification & 123 \\
\hline Tar Reforming, Cleanup, \& Conditioning & 3,862 \\
\hline Mixed Alcohol Synthesis & 147 \\
\hline Alcohol Separation and Purification & 203 \\
\hline Steam System \& Power Generation & 521 required \\
& 10,994 generated \\
\hline Cooling Water \& Other Utilities & 199 \\
\hline Air Separation Unit & 690 \\
\hline Miscellaneous & 649 \\
\hline Total plant power requirement & 7,136 \\
\hline
\end{tabular}

\subsection{Cooling Water and Other Utilities - Area $\mathbf{7 0 0}$}

The cooling water system is shown on PFD-P810-A701. A mechanical draft cooling tower (M701) provides cooling water to several heat exchangers in the plant. The tower utilizes large fans to force air through circulated water. Heat is transferred from the water to the surrounding air by the transfer of sensible and latent heat. Cooling water is used in the following pieces of equipment:

- The sand/ash cooler (M-201), which cools the char/sand/ash mixture from the gasifier

- The quench water recirculation cooler (H-301), which cools the water used in the syngas quench step

- Water-cooled aftercoolers (H-301C-1, H-303) for cooling the syngas prior to acid gas removal

- The LO-CAT ${ }^{\circledR}$ absorbent solution cooler (H-305), which cools the regenerated solution that circulates between the oxidizer and absorber vessels

- Wastewater cooler (H-306) for cooling water prior to discharge to the wastewater system

- The post alcohol synthesis cooler (H-414-1), which cools the gas in order to condense out the liquid alcohols

- The end product finishing coolers (H-591-1, H-593-1) for both the higher alcohols coproduct and the primary ethanol product

- The steam turbine condenser (H-601), which condenses the steam exiting the steam turbine

- The blowdown water-cooled cooler (H-603), which cools the blowdown from the steam drum. 
Makeup water for the cooling tower is supplied at 14.7 psia and $60^{\circ} \mathrm{F}\left(16^{\circ} \mathrm{C}\right)$. Water losses include evaporation, drift (water entrained in the cooling tower exhaust air), and tower basin blowdown. Drift losses were estimated to be $0.2 \%$ of the water going into the cooling tower. Evaporation losses and blowdown were calculated based on information and equations in Perry et al. ${ }^{22}$ The cooling water returns to the process at a supply pressure of 65 psia and temperature is $90^{\circ} \mathrm{F}\left(32^{\circ} \mathrm{C}\right)$. The cooling water return temperature after process heat exchange is $110^{\circ} \mathrm{F}\left(43^{\circ} \mathrm{C}\right)$.

An instrument air system is included to provide compressed air for both service and instruments. The instrument air system is shown on PFD-P810-A701. The system consists of an air compressor (K-701), dryer (S-701), and receiver (T-701). The instrument air is delivered at a pressure of 115 psia, a moisture dew point of $-40^{\circ} \mathrm{F}\left(-40^{\circ} \mathrm{C}\right)$, and is oil free.

Other miscellaneous items that are taken into account in the design include:

- A firewater storage tank (T-702) and pump (P-702)

- A diesel tank (T-703) and pump (P-703) to fuel the front loaders

- An ammonia storage tank (T-704) and pump (P-704)

- An olivine truck scale with dump (M-702) and an olivine lock hopper (T-705) as well as an $\mathrm{MgO}$ lock hopper (T-706)

- A hydrazine storage tank (T-707) and pump (P-705) for oxygen scavenging in the cooling water.

These equipment items are shown on PFD-P810-A702.

\subsection{Air Separation Unit - Area 800}

The air separation unit consists of a compressor and distillation columns for the cryogenic distillation of air to produce oxygen and nitrogen. This technology is mature and commercially available and was not modeled in detail in Aspen Plus. Capital costs for such units are available in literature. ${ }^{43}$ It is also known that the inlet air compressor is the main energy user in the unit. It uses up to $95 \%$ of the utility costs, according to one source. ${ }^{44}$ It has been reported ${ }^{45}$ that a cryogenic air separation system consumes about 260 to $340 \mathrm{kWh}$ of energy per long ton $(1,016$ $\mathrm{kg}$ ) of $\mathrm{O}_{2}$ produced, with about $90 \%$ of the energy used by the main compressor. In this study it is assumed that the air compressor uses $90 \%$ of the energy of the air separation unit. The base case uses about $6,900 \mathrm{kWh}(10 \%$ of it as electricity and $90 \%$ for steam driven compressor) to produce $42,281 \mathrm{lb}$ of $\mathrm{O}_{2}$, which is roughly $365 \mathrm{kWh}$ per long ton $(1,016 \mathrm{~kg})$, slightly more than the 260 to $340 \mathrm{kWh}$ mentioned above.

Air is compressed to 132 psia. The compressor is modeled using an MCOMPR block in Aspen Plus with a polytropic efficiency of $78 \%$. Steam generated in other parts of the process is used to drive the compressor. The total operating costs are inferred based on the assumption that the compressor uses $90 \%$ of the utility costs for the unit. A possible configuration of an air separation unit using a Linde Double-Column is shown in PFD-P810-A801. These units are typically installed and operated by companies specializing in air separation. 
Although the most common process for oxygen production is used in this design, other options can be explored in the future. ${ }^{46}$

\subsection{Additional Design Information}

Table 13 contains some additional information used in the Aspen Plus model and production design.

Table 13. Utility and Miscellaneous Design Information

\begin{tabular}{|c|c|}
\hline Item & Design Information \\
\hline Ambient air conditions $^{\mathrm{a}, \mathrm{b}, \mathrm{c}}$ & $\begin{array}{l}\text { Pressure: } 14.7 \text { psia } \\
\mathrm{T}_{\text {Dry Bulb: }} 90^{\circ} \mathrm{F} \\
\mathrm{T}_{\text {Wet Bulb: }} 80^{\circ} \mathrm{F} \\
\text { Composition }(\mathrm{mol} \%): \\
\mathrm{N}_{2}: 75.7 \% \quad \mathrm{O}_{2}: 20.3 \% \text { Ar: } 0.9 \% \quad \mathrm{CO}_{2}: 0.03 \% \quad \mathrm{H}_{2} \mathrm{O}: 3.1 \%\end{array}$ \\
\hline Pressure drop allowance & $\begin{array}{l}\text { Syngas compressor intercoolers }=2 \mathrm{psi} \\
\text { Heat exchangers and packed beds }=5 \mathrm{psi}\end{array}$ \\
\hline
\end{tabular}

\subsection{Pinch Analysis}

A pinch analysis was performed for the base case process. Details of the results from the analysis are shown in Appendix H. Pinch analysis allows the selection of a network of exchangers so that heat can be exchanged optimally within the process. Process streams that need to be heated and streams that need to be cooled are matched to minimize external utility requirements. The minimum approach temperature was set at $16.8^{\circ} \mathrm{F}$. The upper and lower pinch temperatures were $314.8^{\circ} \mathrm{F}$ and $298^{\circ} \mathrm{F}$, respectively.

There can be various designs for the heat exchanger network based on design objectives. One particular design was used for this study. The network designs above and below the pinch for the base case process are shown in Appendix H. All the exchangers above the pinch are named as $\mathrm{H}$ AP- $n$, and those below the pinch are named H-BP- $n, n$ being numbers assigned to exchangers according to their positions in the sequence. The capital costs for the heat exchangers were estimated using Aspen Icarus Process Evaluator.

It must be noted that the additional cases run for sensitivity analysis were not analyzed separately. The overall hot and cold duties were balanced. However, capital costs and the heat exchanger network were assumed to remain the same. It is to be noted that the costs of the heat exchangers were estimated individually using actual LMTDs and assumed heat transfer coefficients. The equipment cost after pinch analysis was about \$5.2MM compared with $\$ 1.25 \mathrm{MM}$ in the indirect gasification process (both in 2005 dollars). Some of this may be

\footnotetext{
${ }^{a}$ In the GPSA Engineering Data Book ${ }^{47}$, see Table 11.4 for typical design values for dry bulb and wet bulb temperature by geography. Selected values would cover summertime conditions for most of the lower 48 states.

${ }^{\mathrm{b}}$ In Weast ${ }^{48}$, see F-172 for composition of dry air. Nitrogen value adjusted slightly to force mole fraction closure using only $\mathrm{N}_{2}, \mathrm{O}_{2}$, Ar, and $\mathrm{CO}_{2}$ as air components.

${ }^{\mathrm{c}}$ In Perry et al., ${ }^{22}$ see psychrometric chart, Figure 12-2, for moisture content of air.
} 
attributed to higher pressures and lower LMTDs in some parts of the oxygen blown direct gasification process, although some of the additional cost may be a result of the more detailed approach to the costing for this report. These capital equipment cost variations lead to variations up to about 2 cents/gallon in the calculated MESP, which is not very significant.

\subsection{Energy Balance}

Energy integration is extremely important to the overall economics and efficiency of this process. Therefore a detailed understanding of how and where the energy is utilized and recovered is required. Detailed energy balances around the major process areas were derived using data from the Aspen Plus simulation. Comparing the process energy inputs and outputs enables the energy efficiency of the process to be quantified. Also, tracing energy transfer between process areas makes it possible to identify areas of potential improvement to the energy efficiency.

The philosophy of defining the "energy potential" of a stream is the same as described in the indirect gasifier report and is based on the lower heating value of each component. ${ }^{2}$

The total energy potential for a stream has other contributions beyond that of the heating value. Other energy contributions are:

- Sensible heat effect - the stream is at a temperature (and pressure) different from that of the standard conditions at which the heating values are defined

- Latent heat effect - one or more components in the stream are in a different phase from that at which their heating values are defined

- Non-ideal mixing effect - any heating or cooling due to blending dissimilar components in a mixture.

The procedure for calculating the energy potential of a stream is the same as used in the indirect gasifier report. ${ }^{2}$ The enthalpy values reported by Aspen Plus can be adjusted in a fairly simple manner to reflect either an HHV or LHV basis for the energy potential. The enthalpies calculated and reported by Aspen Plus are actually based upon a heat of formation for the energy potential of a stream. So, the reported enthalpies already include the sensible, latent, and non-ideal mixing effects. The reported enthalpy values were adjusted as part of a spreadsheet calculation. The factors used to adjust the reported enthalpies were calculated from the difference between each component's heat of combustion (LHV) and the reported pure component enthalpy at combustion conditions.

This process for thermochemical conversion of cellulosic biomass was designed with the goal of being energy self-sufficient. Natural gas inputs that could be used to fire the fuel combustor have been eliminated. Instead, a slipstream of "dirty" unreformed syngas and a slipstream of unreacted syngas from alcohol synthesis are used to meet the fuel demand. The downside to this is a decrease in ethanol yield. In addition, the process was designed to require no electricity purchase from the grid. An integrated combined heat and power system supplies all steam and electricity needed by the plant. While it is desired to produce no extra electricity, the steam demands of the process result in excess electricity being generated in the extraction steam turbine system. 
The major process energy inputs and outputs are listed in Table 14 along with their energy flow rates. The ratio of each input and output to the biomass energy entering the system is also calculated. The biomass is of course the primary energy input; however, other energy inputs are required. Air is required for both the fuel combustor and the air separation unit, but it remains a minor energy input. Some water is used to wet the ash leaving the gasification system, however, the majority of process water is used for boiler feed water makeup and cooling water makeup. A large negative energy flow value is associated with this because it enters the process as a liquid.

Table 14. Overall Energy Analysis (LHV basis)

\begin{tabular}{|c|c|c|}
\hline & $\begin{array}{c}\text { Energy Flow } \\
\text { (MMBTU/hr, LHV basis) }\end{array}$ & $\begin{array}{c}\text { Ratio to Feedstock } \\
\text { Energy Flow }\end{array}$ \\
\hline \multicolumn{3}{|l|}{ Energy Inlets } \\
\hline Wood Chip Feedstock (wet) & 1275.6 & 1.000 \\
\hline Natural Gas & 0.0 & 0.000 \\
\hline Air & 2.4 & 0.002 \\
\hline Olivine & 0.0 & 0.000 \\
\hline $\mathrm{MgO}$ & 0.0 & 0.000 \\
\hline Water & -67.3 & -0.053 \\
\hline Tar Reforming Catalyst & 0.0 & 0.000 \\
\hline Other & 0.0 & 0.000 \\
\hline Total & 1210.7 & 0.949 \\
\hline \multicolumn{3}{|l|}{ Energy Outlets } \\
\hline Ethanol & 504.9 & 0.396 \\
\hline Higher Alcohols Co-product & 100.2 & 0.079 \\
\hline Cooling Tower Evaporation & 5.4 & 0.004 \\
\hline Flue Gas & 42.1 & 0.033 \\
\hline Sulfur & 0.3 & 0.000 \\
\hline Compressor Heat & 49.5 & 0.039 \\
\hline Heat from Air-cooled Exchangers & 374.3 & 0.293 \\
\hline $\begin{array}{l}\text { Vents to Atmosphere } \\
\text { (including excess } \mathrm{CO}_{2} \text { ) }\end{array}$ & 1.1 & 0.001 \\
\hline Char, Sand and Ash & 136.3 & 0.107 \\
\hline Catalyst Purge & 0.0 & 0.000 \\
\hline Wastewater & -2.9 & -0.002 \\
\hline Byproduct Electricity & 13.2 & 0.010 \\
\hline Ambient Heat and Work Losses & 19.0 & 0.015 \\
\hline Other & -32.7 & -0.026 \\
\hline Total & 1210.7 & 0.949 \\
\hline
\end{tabular}

Besides the saleable alcohol products, other important process energy outlets also exist. The flue gases from the reformer fuel combustor account for about 3\% of the energy in the raw biomass. Cooling tower evaporative losses, excess $\mathrm{CO}_{2}$ vent to the atmosphere, and wastewater streams are also minor process energy outlets. A significant $11 \%$ goes out with the char, sand, and ash, with most of the heating value coming from the char. With efficient gasifiers the char content can be much lower. Some cases with lower char content are reported as part of sensitivity studies later in this report. The char content and composition out of the gasifier were based on the correlation shown in Appendix G. Two other large energy outlets come from air-cooled 
interstage cooling of the compressors (3.9\%) and from several other air-cooled heat exchangers (29.3\%). The "other" category consists primarily of other losses from the cooling tower system (drift and blowdown), but also accounts for energy losses from condensate streams of compressors and any other outlet streams not accounted for in the other categories.

Some of this lost heat could potentially be recovered by further process heat integration. In this case there were no more cold process streams that could use the heat in the temperature ranges of the air and water cooled exchangers. Integration with external users capable of using this heat could be an option.

Overall, the process is approximately $38 \%$ efficient on an LHV basis for moisture-free biomass, as shown in Appendices D and E. Table 14 shows that approximately $47.5 \%$ of the energy in the wet raw biomass is recovered in the two alcohol products. Improvements in these energy efficiencies could result in additional cost savings to the process.

\subsection{Water Issues}

Water is required as a reactant, a fluidizing agent, and a cooling medium in this process. As a reactant, it participates in reforming and in water gas shift reactions. In the high pressure direct oxygen blown gasifier, it also acts as the fluidizing agent in the form of steam. Its cooling uses are outlined in Section 2.8 .

Water usage is becoming an increasingly important aspect of plant design, specifically with regard to today's ethanol plants. Most ethanol plants reside in the Midwest where many places are experiencing significant water supply concerns. ${ }^{47}$ For several years, significant areas of water stress have been reported during the growing season, while livestock and irrigation operations also compete for the available resources.

Today's dry mill ethanol plants have a high degree of water recycle. In fact, many plants use what is known as a "zero discharge" design where no process water is discharged to wastewater treatment. The use of centrifuges and evaporators enables this recycle of process water. Therefore, much of the consumptive water demand of an ethanol plant comes from the evaporative losses from the cooling tower and utility systems. Oftentimes well water, which draws from the local aquifers that are not readily recharged, is used to supply the water demands of the ethanol plants. This is driven by the need for high quality water in the boiler system. Studies have shown that water usage by today's corn ethanol plants ranges from 3-7 gallons per gallon of ethanol produced. This means that a $50 \mathrm{MM}$ gal/yr dry mill will use between 150-350 MM gallons/yr of water that is essentially a non-renewable resource. This ratio, however, has decreased over time from an average of $5.8 \mathrm{gal} / \mathrm{gal}$ in 1998 to $4.2 \mathrm{gal} / \mathrm{gal}$ in $2005 .{ }^{48}$

Therefore, a primary design consideration for this process was the minimization of fresh water requirements, which therefore meant minimizing the cooling water demands and recycling process water as much as possible. Air-cooling was used in several areas of the process in place of cooling water (e.g., distillation condensers, compressor interstage cooling). However, there are some instances where cooling water is required to reach a sufficiently low temperature that air-cooling cannot reach. 
Table 15 quantifies the particular water demands of this design. Roughly $46 \%$ of the fresh water demand is from cooling tower makeup, with most of the remainder needed as makeup boiler feed water. Some of this water is directly injected into the gasifier, but other system losses (blowdown) also exist. The overall water demand is considerably less than today's ethanol plants. This design requires 1.24 gallons of fresh water for each gallon of ethanol produced.

Table 15. Process Water Demands for Thermochemical Ethanol via Direct Gasification

\begin{tabular}{|l|c|}
\hline \multicolumn{1}{|c|}{ Fresh Water Demands } & lb per hour \\
\hline Cooling Tower Makeup & 28,503 \\
\hline Boiler Feed Makeup & 32,032 \\
\hline Char/sand/ash Wetting & 1,351 \\
\hline Total & $\mathbf{6 1 , 8 8 6}$ \\
\hline & $62,335,351$ \\
\hline Water Used (gal/year) & $50,409,555$ \\
\hline Ethanol Produced (gal/yr) & $\mathbf{1 . 2 4}$ \\
\hline $\begin{array}{l}\text { Overall Water Demand (gal } \\
\text { water / gal ethanol) }\end{array}$ & \\
\hline
\end{tabular}

The water usage in this process is lower than the indirect gasification process, which reports 1.94 gallons of water per gallon of ethanol. ${ }^{2}$

\section{Process Economics}

The total project investment (based on total equipment cost), as well as variable and fixed operating costs, were developed first. With these costs, a discounted cash flow analysis was used to determine the production cost of ethanol when the net present value of the project is zero. This section describes the cost areas and the assumptions made to complete the discounted cash flow analysis.

\subsection{Capital Costs}

The following sections discuss the methods and sources for determining the capital cost of each piece of equipment within the plant. A summary of the individual equipment costs can be found in Appendix C.

The capital cost estimates are based on previous reports by Phillips et al, ${ }^{2}$ Aden et al, ${ }^{3}$ and Spath and Eggeman. ${ }^{7}$ Much of the costs for Phillips et $\mathrm{al}^{2}$ came from the biomass to hydrogen report by Spath et al. ${ }^{49}$ The original cost data was primarily from literature and Questimate (an equipment capital cost estimating software tool by Aspen Tech), not from vendor quotes. The capital costs of heat exchangers from pinch analysis (in this report) were obtained from Aspen Icarus Process Evaluator. Since most of the equipment for this report and the indirect gasifier report ${ }^{2}$ is from similar sources, it puts both reports on a similar cost basis for comparison purposes. Using the estimated equipment costs, the purchased cost of the equipment for the specific size of the plant and the cost year was calculated. Cost factors were then used to determine the installed equipment cost. This method of cost estimation has an expected accuracy of roughly $+30 \%$ to $10 \%$. The factors used in determining the total installed cost (TIC) of each piece of equipment are shown in Table $16 .^{50}$ 
Table 16. General Cost Factors in Determining Total Installed Equipment Costs

\begin{tabular}{|l|c|}
\hline & \% of TPEC \\
\hline Total Purchased Equipment Cost (TPEC) & 100 \\
\hline Purchased equipment installation & 39 \\
\hline Instrumentation and controls & 26 \\
\hline Piping & 31 \\
\hline Electrical systems & 10 \\
\hline Buildings (including services) & 29 \\
\hline Yard improvements & 12 \\
\hline Total Installed Cost (TIC) & 247 \\
\hline
\end{tabular}

The indirect costs (non-manufacturing fixed-capital investment costs) were estimated using the same cost factors as in the indirect gasifier report. The factors are shown in Table $17^{50}$ and have been put as percentages in terms of total purchased equipment cost (TPEC), total installed cost (TIC), and total project investment (TPI, the sum of the TIC and the total indirect costs).

Table 17. Cost Factors for Indirect Costs

\begin{tabular}{|l|c|c|c|}
\hline Indirect Costs & \% of TPEC & \% of TIC & \% of TPI \\
\hline Engineering & 32 & 13 & 9 \\
\hline Construction & 34 & 14 & 10 \\
\hline Legal and contractors fees & 23 & 9 & 7 \\
\hline Project contingency & 7.4 & 3 & 2 \\
\hline Total Indirect Costs & 96.4 & 39 & 28 \\
\hline
\end{tabular}

The biomass handling and drying costs as well as the gasification and gas cleanup costs were estimated by Spath et al. ${ }^{49}$ using several reports by others that documented detailed design and cost estimates. Some of the reports gave costs for individual pieces of equipment while others grouped the equipment costs into areas. The costs from the reports were amalgamated into:

- Feedstock handling and drying

- Gasification and cleanup.

Costs from those reports scaled to a 2,000 bone dry tonne/day plant are given in Table 18 .

Table 19 gives the basic dryer and gasifier design basis for the references. Spath et al. ${ }^{49}$ used an average feed handling and drying cost from all of the literature sources. An average gasifier and gas cleanup cost was used by Spath and Eggeman ${ }^{7}$ for the GTI gasifier.

It has to be noted that the cost estimate for the gasifier in Table 16 includes the cost of the tar reformer. Also, the gasifier section is split into two trains because of the high throughput. It was assumed that the total cost of gasification and cleanup is shared almost equally between the two gasifiers and the reformer. The Utrecht report ${ }^{14}$ split the cost 50/50 between the two areas. The sum of the reformer and gasifier costs is close to the average cost shown in Table 16. 
Table 18. Feed Handling \& Drying and Gasifier \& Gas Cleanup Costs from the Literature Scaled to 2,000 tonne/day Plant ${ }^{49}$

\begin{tabular}{|c|c|c|}
\hline Reference & $\begin{array}{c}\text { Scaled Feed } \\
\text { Handling and } \\
\text { Drying Cost \$K } \\
\text { (2002) }\end{array}$ & $\begin{array}{c}\text { GTI - Scaled } \\
\text { Gasifier and Gas } \\
\text { Cleanup Cost \$K } \\
(2002)\end{array}$ \\
\hline Breault and Morgan $^{51(a)}$ & $\$ 15,048$ & -- \\
\hline $\begin{array}{l}\text { Dravo Engineering Companies } \\
\text { (a) }\end{array}$ & $\$ 14,848$ & --- \\
\hline Weyerhaeuser et al. ${ }^{53(a)}$ & $\$ 21,241$ & --- \\
\hline Stone \& Webster et al. ${ }^{54(a)}$ & $\$ 25,067$ & $\$ 36,232$ \\
\hline Wan and Malcolm ${ }^{55(a)}$ & $\begin{array}{l}\$ 18,947^{(b)} \\
\$ 14,098^{(c)}\end{array}$ & --- \\
\hline Weyerhaeuser $^{56}$ (a) & $\$ 13,468$ & --- \\
\hline Wright and Feinberg $^{5 /(a)}$ & $\begin{array}{c}\$ 26,048-\mathrm{BCL} \\
\text { design } \\
\$ 21,942-\mathrm{GTI} \text { design }\end{array}$ & $\$ 38,605$ \\
\hline Craig $^{58}$ & $\$ 13,680$ & $\$ 48,229$ \\
\hline AVERAGE & $\$ 18,840$ & $\$ 41,071$ \\
\hline
\end{tabular}

Table 19. System Design Information for Gasification References ${ }^{49}$

\begin{tabular}{|c|c|c|}
\hline Reference & $\begin{array}{c}\text { Feed Handling and } \\
\text { Drying }\end{array}$ & $\begin{array}{l}\text { GTI Gasifier and } \\
\text { Gas Cleanup }\end{array}$ \\
\hline Breault and Morgan $^{51}$ & Rotary dryer & --- \\
\hline $\begin{array}{l}\text { Dravo Engineering } \\
\text { Companies }\end{array}$ & Rotary drum dryer & --- \\
\hline Weyerhaeuser, et al. ${ }^{53}$ & Steam dryer & --- \\
\hline Stone \& Webster, et al. ${ }^{54}$ & Flue gas dryer & $\begin{array}{l}\text { Cyclones, heat } \\
\text { exchange, \& tar } \\
\text { reformer }\end{array}$ \\
\hline Wan and Malcolm ${ }^{55}$ & Flue gas dryer & --- \\
\hline Weyerhaeuser ${ }^{56}$ & Flue gas dryer & --- \\
\hline Wright and Feinberg $^{5 /}$ & Unclear & $\begin{array}{l}\text { Heat exchange \& } \\
\text { solids - removal - } \\
\text { details are not clear }\end{array}$ \\
\hline Craig $^{58}$ & Rotary drum dryer & $\begin{array}{l}\text { Cyclones, heat } \\
\text { exchange, \& tar } \\
\text { reformer }\end{array}$ \\
\hline
\end{tabular}

The costs of reactors, heat exchangers, compressors, blowers, and pumps were estimated for a "base" size using Questimate or Aspen Icarus Process Evaluator (IPE) and then scaled using material and energy balance results from the Aspen Plus simulation. The reactors were sized based on a gas hourly space velocity (GHSV), where GHSV is measured at standard temperature and pressure, $60^{\circ} \mathrm{F}$ and $1 \mathrm{~atm},{ }^{59}$ and a height to diameter ratio of 2 . The GHSV values for the mixed alcohol reactor and tar reformer were set at $6,000 / \mathrm{hr}$ and $2,475 / \mathrm{hr}$, respectively, as in the indirect gasification process. ${ }^{2}$ These were used to determine the cost of catalysts loaded in the

${ }^{\text {a }}$ From detailed design and cost estimates

${ }^{\mathrm{b}}$ Estimated from a 200 dry ton/day plant design

${ }^{\mathrm{c}}$ Estimated from a 1,000 dry ton/day plant design 
reactors. The heat exchanger costs were mostly developed based on the required surface area as calculated from the heat transfer equation appropriate for a 1-1 shell and tube heat exchanger:

$$
Q=U A(\Delta T)_{l m} \Rightarrow A=\frac{Q}{U(\Delta T)_{l m}}
$$

where $Q$ is the heat duty, $U$ is the heat transfer coefficient, $A$ is the exchanger surface area, and $(\Delta T)_{l m}$ is the log mean temperature difference. The heat transfer coefficients were estimated from literature sources, primarily Perry et al. ${ }^{22}$ The costs of exchangers from the pinch analysis were evaluated for their specific sizes in the base case. At present, these duties will not change as the process changes, unless the pinch calculations are specifically updated. This is acceptable as long as the total cost of the heat exchange network remains a small fraction of the overall MESP and as long as plant scale does not change significantly.

For the various pieces of equipment, the design temperature is determined to be the operating temperature plus $50^{\circ} \mathrm{F}\left(28^{\circ} \mathrm{C}\right) .{ }^{60}$ The design pressure is the higher of the operating pressure plus 25 psi or the operating pressure times $1.1 .^{60}$ These allowances were sometimes higher for the heat exchangers from pinch analysis.

The following costs were estimated based on the Aden et al. design report ${ }^{3}$ :

- Cooling tower

- Plant and instrument air

- Steam turbine/generator/condenser package

- Deaerator

- Alcohol separation equipment (e.g., the distillation columns and molecular sieve unit).

Appendix B contains the design parameters and cost references for the various pieces of equipment in the plant.

The capital cost for the Air Separation Unit was obtained from literature. ${ }^{43}$ Installed cost provided was converted to equipment cost using a factor of 2.47 , which is the average installation factor for this study.

\subsection{Operating Costs}

There are two kinds of operating costs: variable and fixed costs. The following sections discuss the operating costs, including the assumptions and values for these costs.

There are many variable operating costs accounted for in this analysis. The variables, information about them, and costs associated with each variable are shown in Table 20. 
Table 20. Variable Operating Costs

\begin{tabular}{|c|c|}
\hline Variable & Information and Operating Cost \\
\hline Tar reformer catalyst & $\begin{array}{l}\text { To determine the amount of catalyst inventory, the tar reformer was } \\
\text { sized for a gas hourly space velocity (GHSV) of } 2,476 / h r \text { based on } \\
\text { the operation of the tar reformer at NREL's TCPDU where GHSV is } \\
\text { measured at standard temperature and pressure. } \text {. Initial fill then a } \\
\text { replacement of } 0.01 \% \text { per day of the total catalyst volume. } \\
\text { Price: } \$ 4.67 / \mathrm{lb}^{61}\end{array}$ \\
\hline $\begin{array}{l}\text { Alcohol Synthesis } \\
\text { Catalyst }\end{array}$ & $\begin{array}{l}\text { Initial fill then replacement every } 5 \text { years based on typical catalyst } \\
\text { lifetime. } \\
\text { Catalyst inventory based on GHSV of } 6,000 / \mathrm{hr} \text {. } \\
\text { Price: } \$ 5.25 / \mathrm{lb}^{62}\end{array}$ \\
\hline Gasifier bed material & $\begin{array}{l}\text { Synthetic olivine and MgO. Delivered to site by truck equipped with } \\
\text { self-contained pneumatic unloading equipment. Disposal by landfill. } \\
\text { Olivine price: } \$ 172.90 / \text { ton }^{63} \\
\text { MgO price: } \$ 365 / \text { ton }^{64}\end{array}$ \\
\hline Solids disposal cost & Price: $\$ 18 /$ ton $^{65}$ \\
\hline Diesel fuel & $\begin{array}{l}\text { Usage: } 10 \text { gallon } / \mathrm{hr} \text { plant wide use } \\
\text { Price: } \$ 1.00 / \text { gallon }{ }^{66} \text { (see note below) }\end{array}$ \\
\hline Chemicals & $\begin{array}{l}\text { Boiler chemicals - Price: } \$ 1.40 / \mathrm{lb}^{3} \\
\text { Cooling tower chemicals - Price: } \$ 1.00 / \mathrm{lb}^{3} \\
\text { LO-CAT }^{\circledR} \text { chemicals - Price: } \$ 150 / \text { tonne of sulfur produced }\end{array}$ \\
\hline Wastewater & $\begin{array}{l}\text { The wastewater is sent off-site for treatment. } \\
\text { Price: } \$ 2.07 / 100 \mathrm{ft}^{3} 68\end{array}$ \\
\hline
\end{tabular}

Note that diesel fuel costs have gone up significantly. The MESP will go up by approximately 0.19 cents per gallon for every dollar per gallon increase in diesel prices, which is not a significant part of the overall cost. The price of diesel was left at $\$ 1.00$ per gallon in order to maintain parity with the indirect gasifier report. ${ }^{2}$ A summary of the operating costs is shown in Appendix D.

The fixed operating costs (i.e., salaries, overhead, maintenance, etc.) used here are identical to those in the study by Phillips et al. ${ }^{2}$ Fixed operating costs for a biochemical ethanol facility given in Aden et al. $(2002)^{3}$ were used as a starting point by Phillips et al.

The fixed operating costs used in this analysis are shown in Table 21 (labor costs) and Table 22 (other fixed costs). They are shown in 2002 U.S. dollars. The following changes in base salaries and number of employees were made compared with those used in the ethanol plant design in Aden et al. (2002). ${ }^{3}$

- Plant manager salary raised from $\$ 80,000$ to $\$ 110,000$

- Shift supervisor salary raised from $\$ 37,000$ to $\$ 45,000$

- Lab technician salary raised from $\$ 25,000$ to $\$ 35,000$

- Maintenance technician salary raised from $\$ 28,000$ to $\$ 40,000$ 
- Shift operators salaries raised from $\$ 25,000$ to $\$ 40,000$

- Yard employees salaries raised from $\$ 20,000$ to $\$ 25,000$ and number reduced from 32 to 12

- General manager position eliminated

- Clerks and secretaries salaries raised from $\$ 20,000$ to $\$ 25,000$ and number reduced from 5 to 3 .

The number of yard employees was changed to reflect a different feedstock and feed handling system compared with Aden et al. (2002). ${ }^{3}$ Handling baled stover requires more hands-on processing compared with handling a wood chip feedstock. Based on a 4-shift system, three yard employees were estimated to be needed, mostly to run the front end loaders. The general manager position was eliminated because a plant manager would likely be sufficient for this type of facility. Biomass gasification plants are more likely to be operated by larger companies instead of operating like the dry mill ethanol model of farmer co-ops. Finally, the number of clerks and secretaries was reduced from 5 to 3 . The estimate of three comes from needing one person to handle the trucks and scales entering and leaving the facility, one to handle accounting matters, and another to answer phones and do administrative work.

Table 21. Labor Costs

\begin{tabular}{|l|c|c|c|}
\hline \multicolumn{1}{|c|}{ Position } & Salary & Number & Total Cost \\
\hline Plant manager & $\$ 110,000$ & 1 & $\$ 110,000$ \\
\hline Plant engineer & $\$ 65,000$ & 1 & $\$ 65,000$ \\
\hline Maintenance supervisor & $\$ 60,000$ & 1 & $\$ 60,000$ \\
\hline Lab manager & $\$ 50,000$ & 1 & $\$ 50,000$ \\
\hline Shift supervisor & $\$ 45,000$ & 5 & $\$ 225,000$ \\
\hline Lab technician & $\$ 35,000$ & 2 & $\$ 70,000$ \\
\hline Maintenance technician & $\$ 40,000$ & 8 & $\$ 320,000$ \\
\hline Shift operators & $\$ 40,000$ & 20 & $\$ 800,000$ \\
\hline Yard employees & $\$ 25,000$ & 12 & $\$ 300,000$ \\
\hline Clerks \& secretaries & $\$ 25,000$ & 3 & $\$ 75,000$ \\
\hline Total salaries (2002 \$) & & & $\$ 2,080,000$ \\
\hline \multicolumn{2}{|r|}{$(2005 \$)$} & & $\$ 2,270,000$ \\
\hline
\end{tabular}

Since the salaries listed above are not fully loaded (i.e., do not include benefits), a general overhead factor was used. This also covers general plant maintenance, plant security, janitorial services, communications, etc. The 2003 PEP yearbook ${ }^{69}$ lists the national average loaded labor rate at $\$ 37.66$ per hr. Using the salaries in Table 21 above along with the $60 \%$ general overhead factor from Aden et al. ${ }^{3}$ gave an average loaded labor rate of $\$ 30$ per hr. To more closely match the PEP yearbook average, the overhead factor was raised to $95 \%$. The resulting average loaded labor rate was $\$ 36$ per $\mathrm{hr}$. 
Table 22. Other Fixed Costs

\begin{tabular}{|c|c|c|}
\hline Cost Item & Factor & Cost \\
\hline General overhead & $95 \%$ of total salaries & $\$ 2,155,000$ \\
\hline Maintenance $^{50}$ & $2 \%$ of total project investment & $\$ 5,082,000$ \\
\hline Insurance $\&$ taxes $^{50}$ & $2 \%$ of total project investment & $\$ 5,082,000$ \\
\hline
\end{tabular}

The updated salaries in Table 21 above were examined against salaries from a free salary estimation tool ${ }^{70}$ that uses Bureau of Labor Statistics data and several other sources. Because the biomass analysis does not reflect a specific site in the U.S., National Average Salaries for 2003 were used. With such an extensive listing of job titles in the salary estimation tool, a general position such as "clerks and secretaries" could be reflected by multiple job titles. In these instances, care was taken to examine several of the possible job titles that were applicable. A list of the job positions at the production plant and the corresponding job titles in the salary estimation tool $^{70}$ is shown in Table 23. Overall, the salaries used in the biomass-to-hydrogen production plant design are close to the U.S. national average values given in column 4 .

Table 23. Salary Comparison

\begin{tabular}{|c|c|c|c|c|}
\hline $\begin{array}{c}\text { Job Title in } \\
\text { Biomass Plant }\end{array}$ & $\begin{array}{c}\text { Corresponding Job } \\
\text { Title in Salary } \\
\text { Estimating Tool }^{70}\end{array}$ & $\begin{array}{c}\text { Salary Range } \\
\left(17^{\text {th }} \text { to } 67^{\mathrm{th}}\right. \\
\text { percentile })\end{array}$ & $\begin{array}{c}\text { Average } \\
\text { Salary (U.S. } \\
\text { national } \\
\text { average) }\end{array}$ & $\begin{array}{c}\text { Salary used } \\
\text { in Biomass } \\
\text { Plant Design } \\
\text { (see Table 21) }\end{array}$ \\
\hline Plant manager & $\begin{array}{l}\text { Plant manager } \\
\text { (experience) }\end{array}$ & $\begin{array}{l}\$ 81,042- \\
\$ 220,409\end{array}$ & $\$ 106,900$ & $\$ 110,000$ \\
\hline Plant engineer & Plant engineer & $\$ 36,213-\$ 66,542$ & $\$ 58,324$ & $\$ 65,000$ \\
\hline \multirow[t]{3}{*}{$\begin{array}{l}\text { Maintenance } \\
\text { supervisor }\end{array}$} & $\begin{array}{l}\text { Maintenance crew } \\
\text { supervisor }\end{array}$ & $\$ 35,036-\$ 53,099$ & $\$ 45,191$ & \multirow[t]{3}{*}{$\$ 60,000$} \\
\hline & $\begin{array}{l}\text { Supervisor } \\
\text { maintenance }\end{array}$ & $\$ 34,701-\$ 56,097$ & $\$ 47,046$ & \\
\hline & $\begin{array}{l}\text { Supervisor } \\
\text { maintenance \& } \\
\text { custodians }\end{array}$ & $\$ 23,087-\$ 45,374$ & $\$ 39,924$ & \\
\hline Lab manager & Laboratory manager & $\$ 38,697-\$ 70,985$ & $\$ 51,487$ & $\$ 50,000$ \\
\hline Shift supervisor & Supervisor production & $\$ 32,008-\$ 51,745$ & $\$ 43,395$ & $\$ 45,000$ \\
\hline Lab technician & Laboratory technician & $\$ 25,543-\$ 41,005$ & $\$ 34,644$ & $\$ 35,000$ \\
\hline $\begin{array}{l}\text { Maintenance } \\
\text { technician }\end{array}$ & Maintenance worker & $\$ 27,967-\$ 46,754$ & $\$ 39,595$ & $\$ 40,000$ \\
\hline Shift operators & Operator control room & $\$ 33,983-\$ 61,362$ & $\$ 49,243$ & $\$ 40,000$ \\
\hline Yard employees & $\begin{array}{l}\text { Operator front end } \\
\text { loader }\end{array}$ & $\$ 24,805-\$ 39,368$ & $\$ 31,123$ & $\$ 25,000$ \\
\hline \multirow{3}{*}{$\begin{array}{l}\text { Clerks \& } \\
\text { secretaries }\end{array}$} & Administrative clerk & $\$ 19,876-\$ 25,610$ & $\$ 26,157$ & \multirow[t]{3}{*}{$\$ 25,000$} \\
\hline & Secretary & $\$ 20,643-\$ 31,454$ & $\$ 26,534$ & \\
\hline & Clerk general & $\$ 15,984-\$ 25,610$ & $\$ 22,768$ & \\
\hline
\end{tabular}

Overall, Aden et al. ${ }^{3}$ lists fixed operating costs totaling $\$ 7.54 \mathrm{MM}$ in $\$ 2000$. Using the labor indices, this equates to $\$ 7.85 \mathrm{MM}$ in $\$ 2002$. The mixed alcohols design report using indirect gasification $^{2}$ had fixed operating costs of $\$ 12.06 \mathrm{MM}$ in $\$ 2005$. The fixed operating costs calculated by this study were $\$ 14.59 \mathrm{MM}$ in $\$ 2005$ because of higher maintenance, insurance, and taxes on the higher capital costs. 


\subsection{Value of Higher Alcohol Co-Products}

The alcohol synthesis process will create higher molecular weight alcohols. The value of this coproduct will depend on the market where it is sold. Two extreme cases were envisioned. At the high end, these co-products might be sold into the chemical market. This could command a high value, upward of $\$ 3.70$ to $\$ 4.20$ per gallon. ${ }^{62}$ However, it is unlikely that the market would support more than one or two biomass plants at these prices. Because of this, the biomass process did not include any detailed separation or cleanup of the separate alcohols. It is envisioned that if this co-product was sold for this purpose, it would be transferred "over the fence" as is, and the buyer would take on the costs of separation and cleanup. So, even at the high end, the highest value would be some fraction of the chemical market value.

At the low end, the co-product could command a value for a fuel with minimal ASTM standards on its specifications. This would be priced similar to a residual fuel oil. Historically, this is about $80 \%$ of gasoline price. ${ }^{71}$ Using the $\$ 1.07$ per gallon MESP as a scaled reference gasoline price (adjusted for ethanol's lower heating value), this translates to $\$ 0.85$ per gallon.

For the baseline case, a middle ground was chosen. It is anticipated that the higher alcohols coproduct would make an excellent gasoline additive or gasoline replacement in its own right, though engine testing and certification would be required. If this is done, then it should command a price similar to that of gasoline. Again using the $\$ 1.07$ per gallon MESP as a scaled reference gasoline price, and adjusting to n-propanol's heating value (the major constituent of the higher alcohol stream), then its value should be $\$ 1.25$ per gallon. However, since no special efforts were taken in the process design to clean up this stream to meet anticipated specifications, its value is discounted to $\$ 1.15$ per gallon.

\subsection{Minimum Ethanol Selling Price}

Once the capital and operating costs were determined, a minimum ethanol selling price (MESP) was determined using a discounted cash flow rate of return analysis. The methodology used is identical to that used in Phillips et al. ${ }^{2}$ and Aden et al. ${ }^{3}$ The MESP is the selling price of ethanol that makes the net present value of the process equal to zero with a $10 \%$ discounted cash flow rate of return over a 20 year plant life. The base case economic parameters used in this analysis are given in Table 24. A sensitivity analysis was performed to examine the MESP for different financial scenarios. These are discussed in Section 4. 
Table 24. Economic Parameters

\begin{tabular}{|l|c|}
\hline \multicolumn{1}{|c|}{ Assumption } & Value \\
\hline Internal rate of return (after-tax) & $10 \%$ \\
\hline Debt/equity & $0 \% / 100 \%$ \\
\hline Plant life & 20 years \\
\hline General plant depreciation ${ }^{\text {a }}$ & $200 \%$ DDB \\
\hline General plant recovery period $^{\text {a }}$ & 7 years \\
\hline Steam plant depreciation $^{\text {a }}$ & $150 \%$ DDB \\
\hline Steam plant recovery period & 20 years \\
\hline Construction period $^{\text {st } 6 \text { months expenditures }}$ & 2.5 years \\
Next 12 months expenditures & $8 \%$ \\
Last 12 months expenditures $^{\text {Start-up time }}$ & $60 \%$ \\
Revenues & $32 \%$ \\
Variable costs & 6 months \\
Fixed costs & $50 \%$ \\
\hline Working capital & $75 \%$ \\
\hline Land & $100 \%$ \\
& 5\% of Total Capital Investment \\
\hline
\end{tabular}

\section{Process Economics, Sensitivity Analyses, and Alternate Scenarios}

The cost of ethanol as determined in the previous section was derived using technology that has been developed and demonstrated or is currently being developed as part of the OBP research program. Unlike the indirect gasification process, the cost target of \$1.07 in 2005 dollars appears to be unachievable using the direct gasification process when using a process design similar to the indirect gasification process. It is unlikely that design modifications will be able to drop the cost of ethanol below $\$ 1.07$ per gallon. A summary of the breakdown of costs is depicted in Figure 7 and costs are further tabulated in Appendix D. Costs in 2007 dollars are shown in Appendix I. Cost comparisons with the indirect gasification process ${ }^{2}$ are shown Appendix J.

\footnotetext{
${ }^{a}$ The depreciation amount was determined using the same method as that documented in Aden et al. ${ }^{3}$ using the IRS Modified Accelerated Cost Recovery System (MACRS).
} 


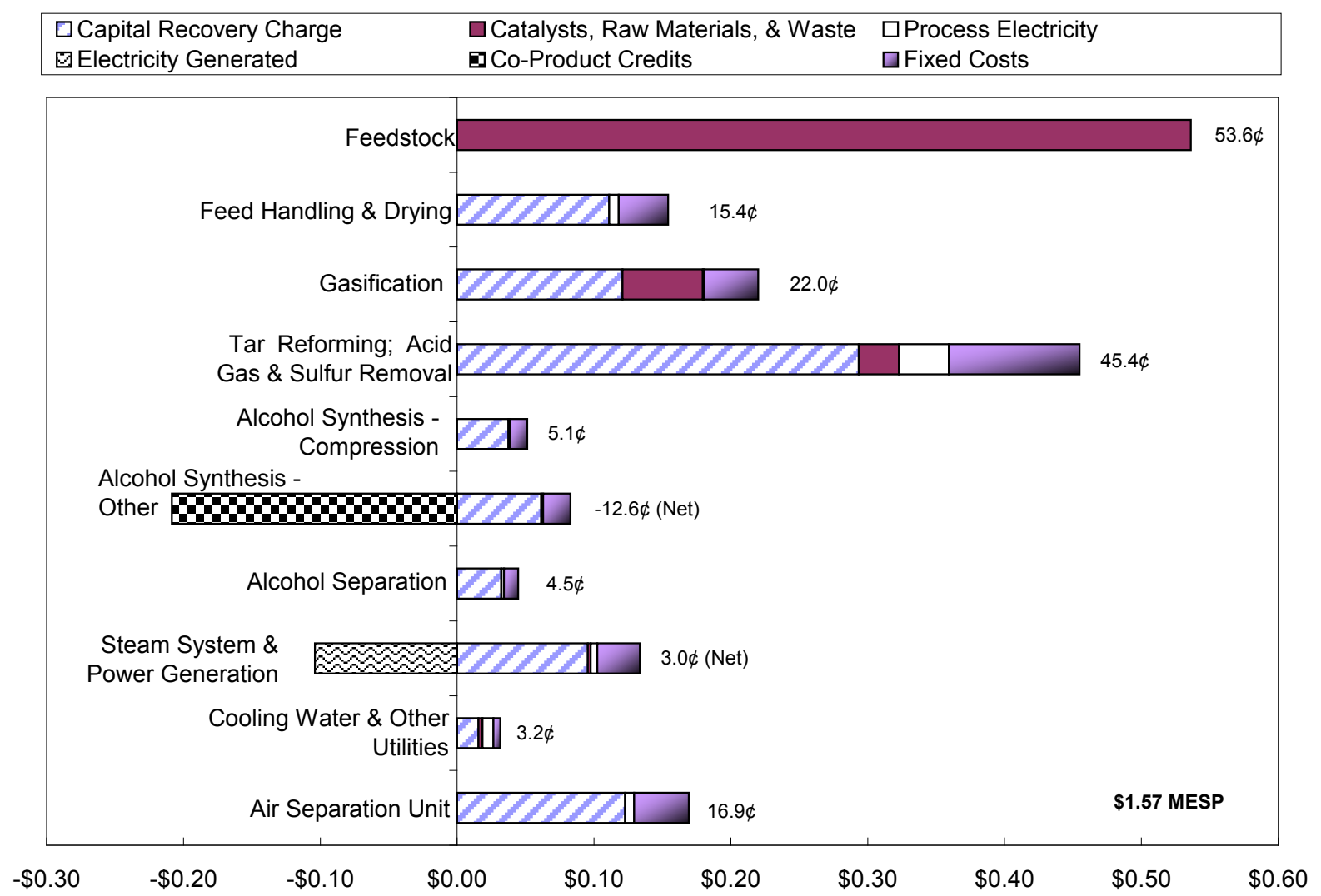

Figure 7. Cost contribution details from each process area

This cost contribution chart shows two different co-product credits: alcohols from the Alcohol Synthesis area and electricity from the Steam System \& Power Generation area. As mentioned earlier, it was not possible to achieve a net zero electricity production with the process design derived from the indirect gasification study. ${ }^{2}$ It will be beneficial to the overall economics if this is done by modifying the process design.

The cost year chosen for the analysis had a significant effect on the results. As discussed in Section 1.1, capital costs increased significantly after 2003 primarily because of the large increase in steel costs worldwide. Figure 8 depicts how the MESP for this process would change depending on the cost year chosen for the analysis. Notice that for the years 2000 to 2003 the MESP is much lower, at \$1.37 to \$1.40 per gallon ethanol, than the \$1.57 determined for 2005 . Appendix I shows values that were calculated after adjusting for the projected feedstock costs based on the Biomass Multi-Year Program Plan ${ }^{27}$ and in 2007 dollars. 


\section{Cost Year}

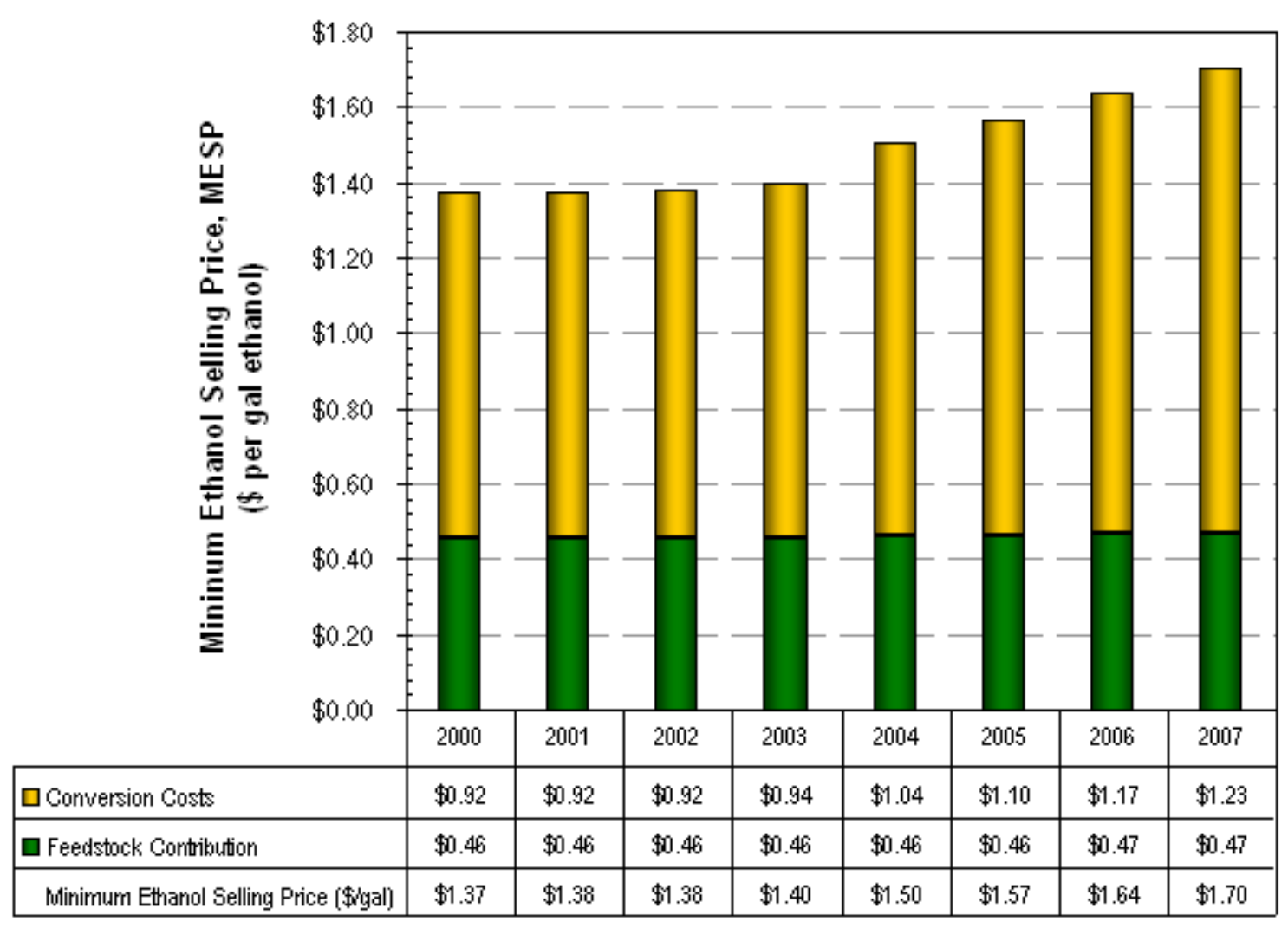

Figure 8. Effect of cost year on MESP ${ }^{a}$

The process costs (as indicated by the MESP) are determined from various assumptions about technology (based upon 2012 research targets), markets (such as the value of the higher alcohol co-products), and various financial assumptions (such as required Return on Investment, or ROI). There are varying degrees of uncertainty when any research target cannot be met or a market or financial assumption does not hold. In addition, uncertainty about equipment design and installation and construction costs will impact the economics. The key is to understand the impact of those types of parameters that are likely to vary and how they might be controlled to a definable range. Discussed here are process targets that had been identified a priori as key ones to understand and achieve. (As can be seen from the sensitivity results, many items examined had much less effect on the MESP than had been thought.) In most cases, values used for the sensitivities are picked from current experimental data to demonstrate the effect of technology advancement (or lack of) on the economic viability of the process.

\footnotetext{
${ }^{a}$ Note that the relative splits between feedstock and conversion costs have been scaled to attribute proportions of the costs to the mixed alcohol and electricity co-products. So, the feedstock contribution appears to be different than what is depicted in the cost contribution chart for the different areas. This accounting practice was kept the same as in the 2007 Phillips et al. design report.
} 
The results for the sensitivity analyses discussed in the following sections are depicted in Figure 9; those sensitivities directly impacted by research programs are shown first. Nearly all of these ranges represent variations of a single variable at a time (e.g., varying ash content while holding the ratio of the non-ash elements constant). There are a few exceptions to this:

- The feedstock comparison of corn stover to lignin necessitated varying the ultimate elemental analysis, ash content, and moisture content simultaneously.

- The Combined Tar Reformer Conversions incorporated all of the ranges listed for the methane, benzene, and tar simultaneously.

- In some cases, especially in the high moisture and ash content feeds, the tar reformer temperature had to be raised in order to supply enough heat to be able to dry the feedstock to the specified 5\% moisture content level. In these cases the excess electricity generated is minimized because much of the heat is used up in drying the feed.

Note that all items in the chart have values associated with them. If a bar is not readily seen, then the MESP effect over the range listed is insignificant.

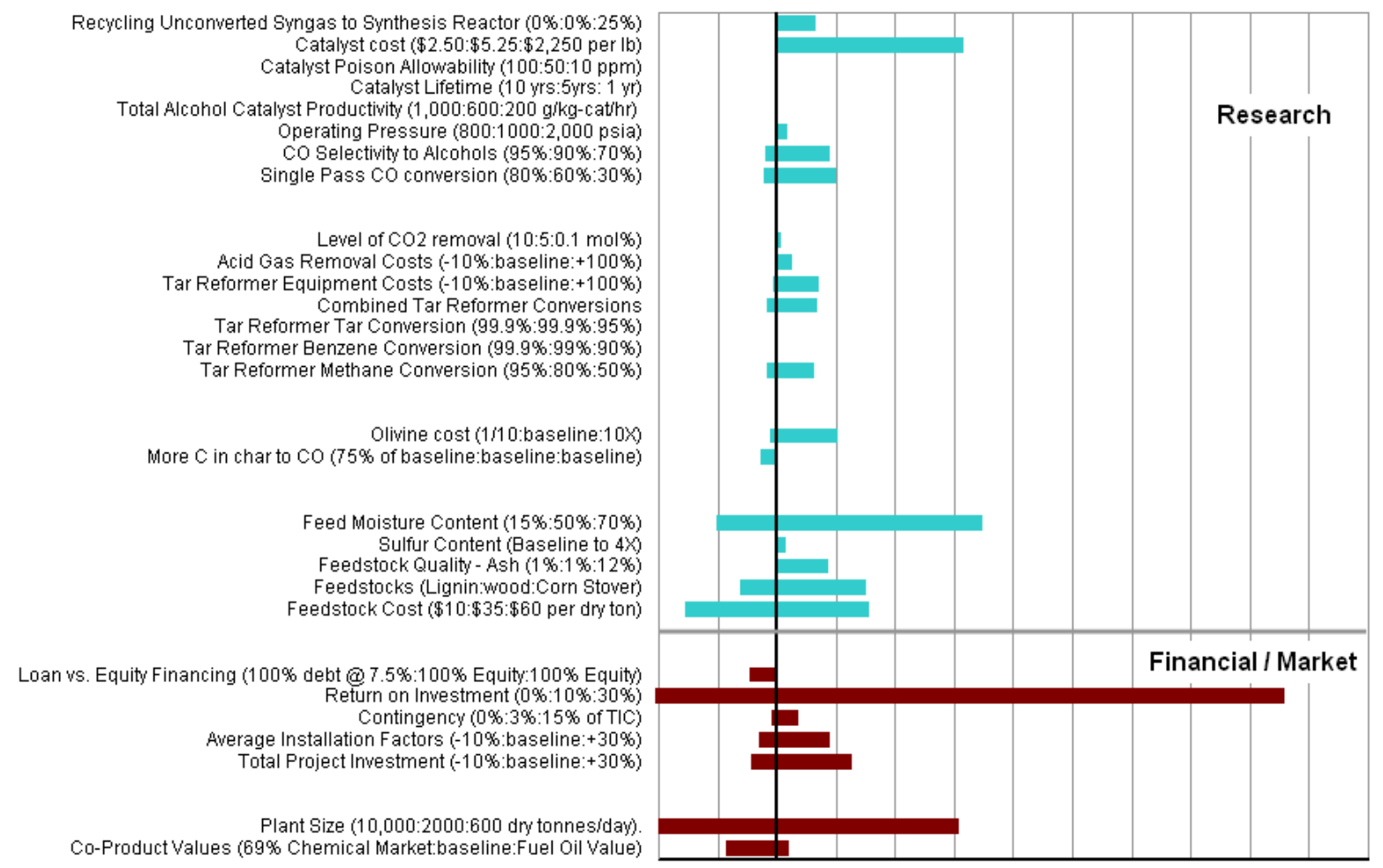

$(\$ 0.50)(\$ 0.25) \$ 0.00 \$ 0.25 \$ 0.50 \$ 0.75 \$ 1.00 \$ 1.25 \$ 1.50 \$ 1.75 \$ 2.00 \$ 2.25 \$ 2.50$ Change to MESP (\$ per gallon Ethanol)

Figure 9. Results of sensitivity analyses 
All the scenarios are discussed further in the following sections.

\subsection{Financial Scenarios}

These parameters have the greatest effect on the MESP, but R\&D has the smallest direct effect on them. In particular, the required ROI for the project could more than double the calculated MESP. Successful R\&D and demonstration projects would, at best, ease the ROI requirements of corporations and/or lending institutions and reduce the required MESP toward the baseline case in this report.

A conceptual design like this is normally thought to give accuracy in the capital requirements of $-10 \%$ to $+30 \%$. Using this range for the TPI (Total Project Investment) gives an MESP range of $7 \%$ to $+20 \%$.

\subsection{Feedstocks}

Because this process has been designed for utilization of forest resources, there may be little control over the feedstock quality coming to the plant. ${ }^{\text {a }}$ The two most important feedstock quality parameters that can impact the process economics are moisture and ash content.

The high range of the ash content examined here is more indicative of agricultural residues (from fertilizer) or lignin-rich biochemical process residues; forest resources should have ash contents near that of this baseline case (about 1\%). It was originally thought that the cost effects of high ash content could be damped by basing feedstock payments on a dry and ash-free basis, not just a dry basis. However, Figure 10 shows that this is not the case. Keeping the feedstock cost constant on a moisture and ash free ("maf") basis will reduce the MESP somewhat, but there is an inherent loss of alcohol yield that is more important in the increased MESP. Some of this yield loss is due to the necessity to divert more raw syngas to the fuel system for heat and power requirements.

\footnotetext{
${ }^{a}$ At least less so than using agricultural residues or energy crops that can be bred for specific properties in these lignocellulosic materials.
} 


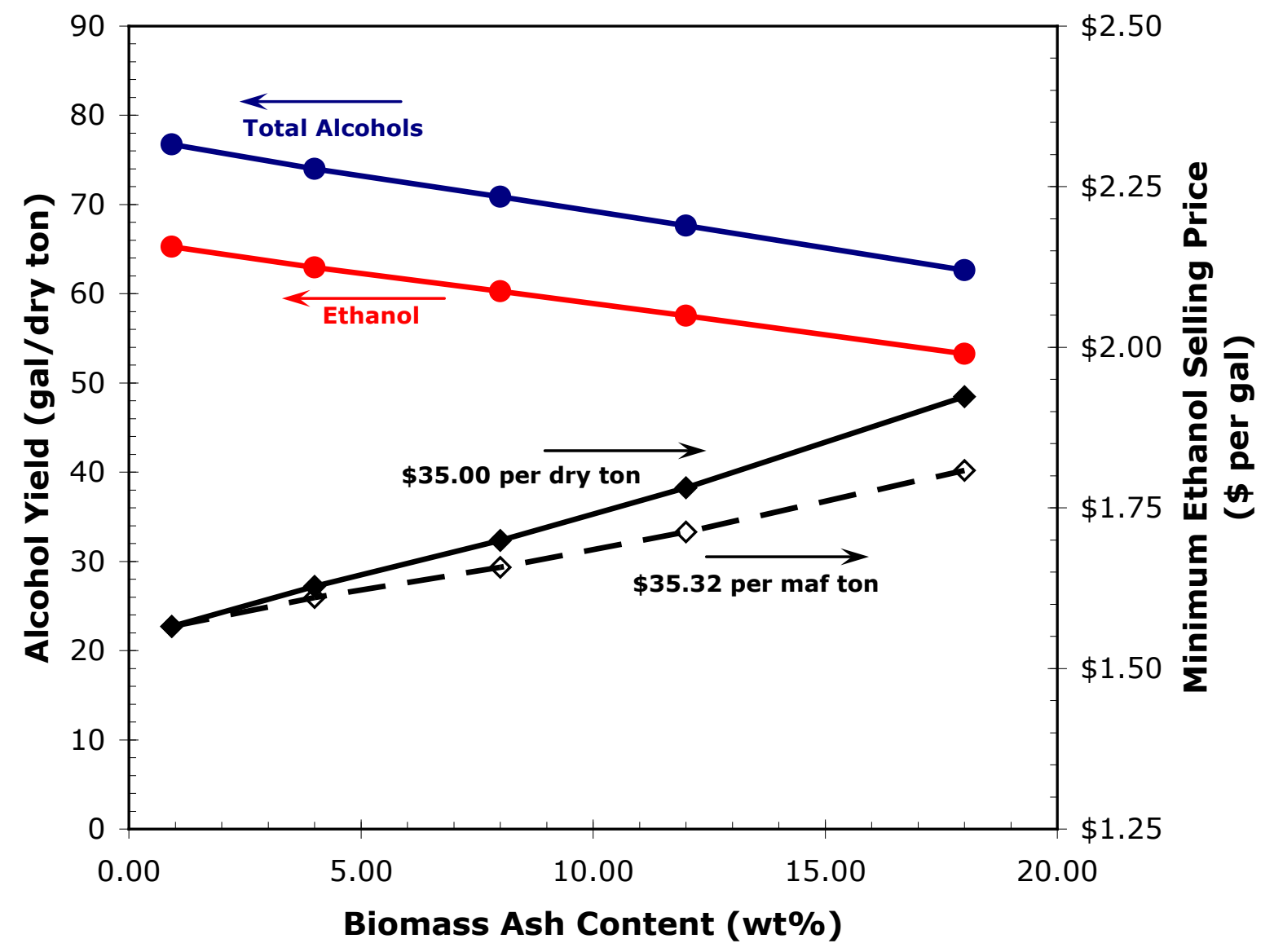

Figure 10. Sensitivity analysis of biomass ash content

The biomass feedstock's moisture content is a problem if it is higher than the baseline $50 \%$. This is not envisioned as being very likely except in the case of processing wet ensiled agricultural residues or energy crops; however, these feedstocks are envisioned to be processed more by biochemical means, not thermochemical means. Drier feedstocks will have lower MESPs because of decreased heat requirements to dry the incoming feedstock; this directly relates to lower raw syngas diversion to heat and power and higher alcohol yields. This is depicted in Figure 11 and Figure 12. As the moisture content increases, the alcohol yield will decrease because more raw syngas must be diverted for heat. Note that very low moisture contents do not continue to give increased alcohol yields; this is because a certain amount of raw syngas needs to be diverted to meet process temperature conditions. Heat that is not wasted in drying the biomass is diverted for generating power, which drops the MESP but does not increase alcohol yields. 


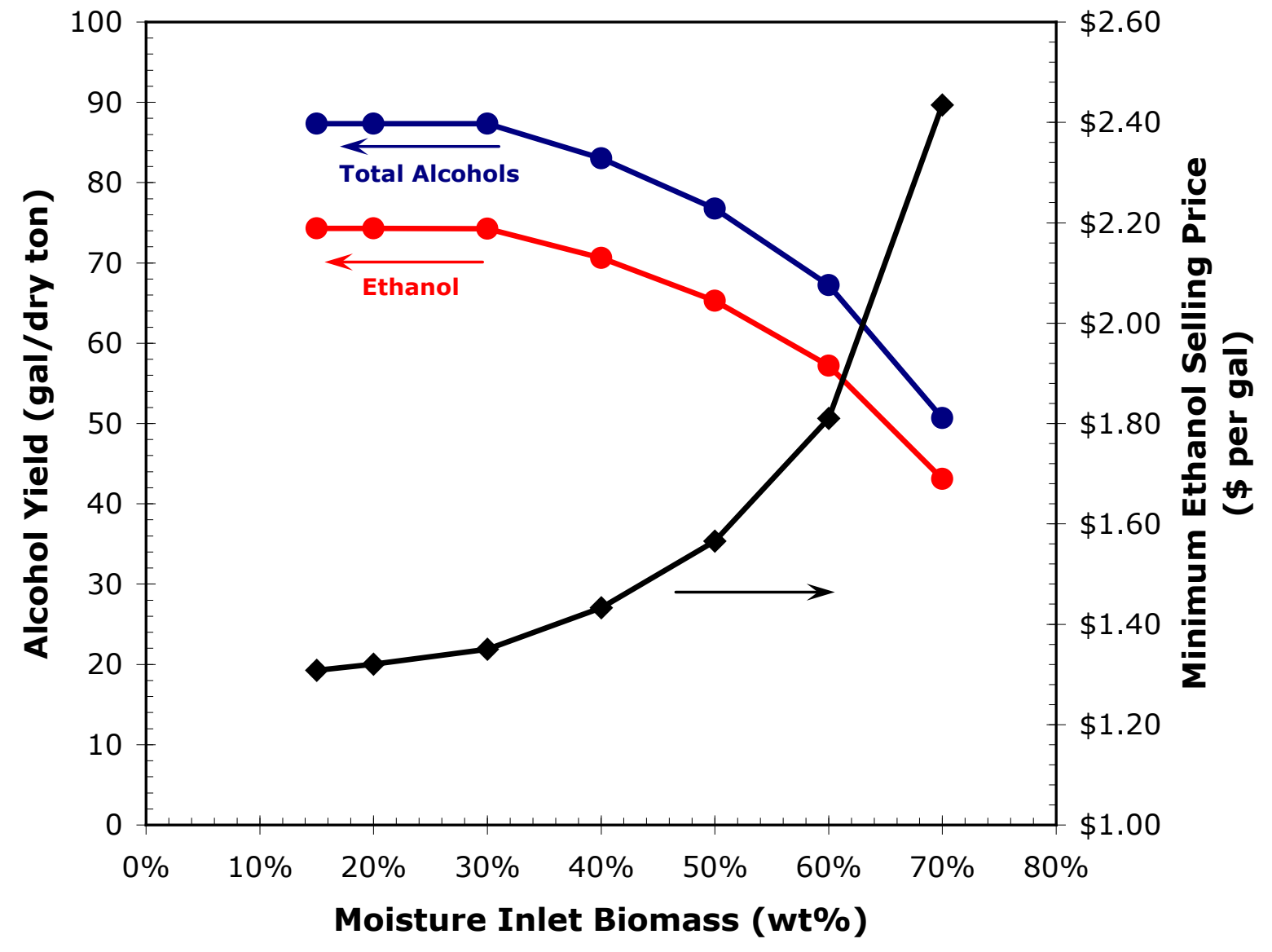

Figure 11. Sensitivity analysis of biomass moisture content 


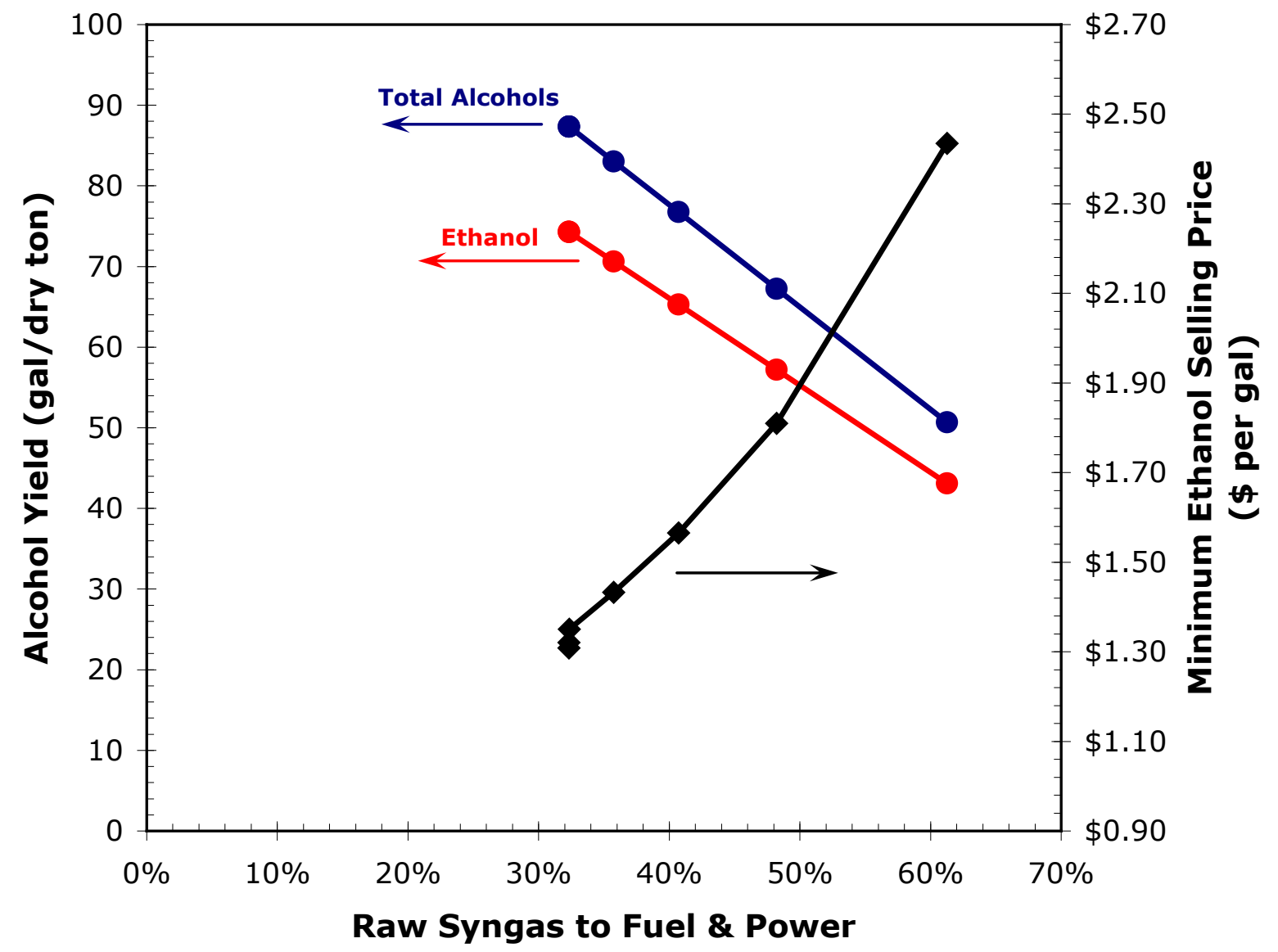

Figure 12. Sensitivity analysis of raw syngas diverted for heat and power due to biomass moisture content

Two combined scenarios were analyzed for two different kinds of feedstocks: corn stover and lignin-rich residues from a biochemical process. The compositions of both are consistent with the Phillips et al. ${ }^{2}$ and Aden et al. design reports. ${ }^{3}$ Corn stover gives rise to a higher MESP even though its elemental analysis is very similar to wood and its moisture content is very low. The overwhelming effect is due to its higher ash content. Lignin-rich residues have a much lower MESP. Lignin-rich residues also have the virtue of making much more electricity than the process needs. The excess electricity available is a very positive sign because incorporating a thermochemical conversion unit with a biochemical conversion unit and make the heat and power for the entire complex will be cost effective. The feed handling system may have to be different, however, since lignin tends to get very powdery when dried; direct contact with the flue gas for drying would very likely lead to high losses of the feedstock. Drying with indirect contact of the heating medium must be investigated.

\subsection{Thermal Conversion}

The effect of increasing the olivine cost by an order of magnitude (due to increased olivine makeup and/or increased cost because of catalytic modification) could increase the MESP by 
$17 \%$. This can be significant. However, if this is because of catalyst modification, it is expected that it will lead to savings in downstream processing units.

The amount of char coming out of the direct gasifier is higher than in the indirect gasification case $^{2}$ because the indirect gasification process involves near complete combustion of the char in the char combustor, as opposed to partial oxidation in the direct gasifier. The base case process used in this study produces char at the rate of $10,330 \mathrm{lb} / \mathrm{hr}$ from a moisture free basis feed of $183,720 \mathrm{lb} / \mathrm{hr}$, which is roughly $5.6 \%$.

Figure 9 shows a scenario where $5,570 \mathrm{lb} / \mathrm{hr}$ or $3 \%$ char is produced. The MESP drops by about $4 \%$ (from $\$ 1.57$ to $\$ 1.50$ ) for this extra conversion of char. It can be expected that improvements in gasifier designs will improve char utilization and lower the cost of ethanol from this process.

\subsection{Cleanup \& Conditioning}

These scenarios appeared to have a small effect on the MESP. However, the impact is greater than in the indirect gasification study. ${ }^{2}$ This is because of the higher cost of the higher pressure tar reforming equipment compared with the indirect gasifier study. Although the numbers show a small impact, there can be greater economic repercussions than the numbers show. The scenarios primarily show cost effects due to the material and energy balances. Since the amount of tar is small compared with the amount of $\mathrm{CO}$ and $\mathrm{H}_{2}$, these effects are small. In reality, cleanup and conditioning is absolutely required for acceptable performance of gas compressors, wastewater treatment, and alcohol synthesis catalysts. Excessive tars in the syngas would significantly impact compressors and wastewater treatment, with severe consequences to equipment and increased operating costs that are not rigorously modeled here. So, not meeting these targets would give poor performance, leading to greater cost effects than reflected by the sensitivity analysis for this area.

\subsection{Fuels Synthesis}

These scenarios show the importance of the R\&D for the synthesis catalysts. Poor performance (conversion and selectivity) could increase MESP by $15 \%$ or more for the ranges shown in Figure 9. This could be because of actual non-target catalyst formulations or poor performance in Cleanup and Conditioning that leads to poor alcohol synthesis catalyst performance. The catalyst cost sensitivity range was extremely large, from $\$ 2.50 / 1 \mathrm{~b}$ to more than $\$ 2,250 / 1 \mathrm{~b}$. This was done to bracket a variety of potential catalyst systems, not just cobalt moly-sulfide. Exotic metals such as rhodium $(\mathrm{Rh})$ or ruthenium $(\mathrm{Ru})$ can add considerable cost to a catalyst system even at relatively low concentrations. At low catalyst costs, total $\mathrm{CO}$ conversion and alcohol selectivity $\left(\mathrm{CO}_{2}\right.$-free basis) have the largest impact on the overall MESP. The catalyst productivity $(\mathrm{g} / \mathrm{kg} / \mathrm{hr})$ did not show much impact over the sensitivity range chosen. In reality, all of these catalyst performance indicators are tightly linked. It is unlikely that research could change one without affecting the others.

\subsection{Markets}

Crediting the co-product higher alcohols with the lower fuel oil value increases the MESP by about 3\%. But, of even more significance is that selling these higher alcohols for even $69 \%$ of their chemical market value will lead to a significant reduction of MESP (about 13\%). This shows that the first couple of thermochemical conversion plants could get a significant economic advantage in their early life by being able to do this. 


\subsection{Operating the Gasifier at a Lower Pressure}

The lower conversions in the tar reformer (when operating at higher pressures than in the Phillips et al. report ${ }^{2}$ ) have a significant impact on the economics as quantified in Appendix L (about $\$ 0.27$ /gallon ethanol). Hence the economics of the gasifier operating at a lower pressure of 100 psi were also studied. The low limit of the data available for the gasifier was around $100 \mathrm{psi}^{24}$ It is shown in Appendix $\mathrm{K}$ that the economics are worse than the base case of this study (440 psi), primarily because of higher compression costs.

\subsection{Hypothetical Case to Delineate the Impact of Pressure on $\mathrm{CH}_{4}$ Conversion} Appendix L shows a hypothetical case in which the tar reformer conversion target for methane was not discounted for the lower equilibrium conversion at the higher pressures (compared with the indirect gasifier design ${ }^{2}$ ). The analysis shows that the MESP would be higher than in the indirect gasification process (at $\$ 1.30 /$ gallon). The MESP is higher primarily because of the capital cost of the air separation unit and the loss of carbon via unconverted char. The base case shows that the lower conversion of methane, when superimposed on these effects, contributes another 27 $\phi /$ gallon to the MESP. The direct gasification process for the production of ethanol would not meet the cost target of $\$ 1.07 /$ gallon even in this hypothetical case.

\section{Conclusions}

It was shown earlier that it is possible to produce ethanol from biomass at or below the cost competitive target of $\$ 1.07$ per gallon using syngas from an indirect steam gasifier. ${ }^{2}$ The purpose of this study was to compare the effect on ethanol MESP if an oxygen-blown direct gasifier was used instead. The overall process was not modified beyond the necessary changes such as the addition of an air separation unit and the replacement of the indirect gasifier with a direct one. There were also changes to the heat exchanger network because of the different thermal profile of the process. Unlike the indirect gasification case, there was an excess of about $4 \mathrm{MW}$ of electricity sold to the grid in the base case. This is because the steam demand in the process is met by the use of an extractive steam turbine, which generates electricity. The MESP for ethanol from this process was $\$ 1.57$ using 2012 targets and 2005 cost basis. This price is higher than the $\$ 1.07$ target (using 2005 dollars and feedstock costs). The higher predicted price confirms an earlier notion that indirect gasification is the more economical route for the production of mixed alcohols when using the assumptions for tar reforming and synthesis catalysts outlined in this report. A cost comparison chart is shown in Appendix J.

Some of the major differences between the two processes are:

- There is lower production of mixed alcohols from the same amount of feed because a greater amount of the syngas from the gasifier is diverted to meet the energy demands of the process.

- A considerably larger amount of carbon is lost via char.

- The lower possible equilibrium conversion of hydrocarbons (primarily of methane) in the reformer at higher pressures has a significant negative impact on the economics.

- The high pressure direct gasification process required the addition of carbon dioxide to mitigate the high $\mathrm{H}_{2}: \mathrm{CO}$ ratios after tar reforming. This adds to the conversion cost by 
adding to the capital and energy costs during acid gas removal. The impact of the higher $\mathrm{CO}_{2}$ produced by the direct gasifier is inconsequential because the process requires the recycle of more $\mathrm{CO}_{2}$ on top of what is produced in the gasifier.

- The capital costs of the high pressure gasifier and tar reformer are more than the lower pressure gasifier and tar reformer used in the indirect gasification process.

- The air separation unit is an added cost in the direct gasification process.

- Total energy used by the compressors was lower in the high pressure case. This is because more energy is expended to compress the gasified products in the low-pressure case than to compress the reactants, much of which are solid in the high-pressure case.

- Water usage was 1.24 gallon/gallon of ethanol produced in this process compared with 1.94 gallon/gallon in the indirect process. Water was recycled after the quench scrubber in both processes. Similar water treatment was used for recycled water in both cases.

While the direct gasification process shows higher costs for the specific products and process configurations used in this study, there may be advantages to using this process for other synthesis products that require higher $\mathrm{H}_{2}$ : $\mathrm{CO}$ ratios for fuel synthesis, e.g., methanol and FischerTropsch liquids. Also, if an air separation unit is co-located with this unit, the cost of oxygen can go down dramatically. Improved efficiencies of char conversion in the direct gasifier can also improve the economics. Practical realities like technology maturity and reliability can also impact the selection of gasifiers for the conversion of biomass to liquid fuels.

\section{Future Work}

Many of the goals for future work listed in the indirect gasification study ${ }^{2}$ are true for this direct gasification process as well.

Future R\&D work to develop and demonstrate reforming and synthesis catalysts is inherent in this study. Many other areas of demonstration and process development are also required:

- Demonstrate gasifier performance on other feedstocks (agricultural residues such as corn stover, energy crops such as switchgrass, and lignin-rich residues that would be available from a co-located biochemical conversion process). Of particular importance for the lignin-rich residues is the impact on process performance of trace amounts of chemicals used in the biochemical processing that might negatively impact the thermochemical conversion process.

- Examine the trade-offs of the greater use of water cooling (greater water losses in the cooling tower) vs. air cooling (greater power usage) vs. organic Rankine cycle for cooling and power production.

- Better understand the trade-offs between operating parameters in the alcohol synthesis reactor (pressure, temperature, extent of reaction, extent of methanol recycle). A "tuned" kinetics-based model would be required for this. 
- Explore alternate synthesis reactor configurations (slurry phase vs. fixed bed).

- Understand trade-offs between a close to energy neutral alcohol production facility and one that could also supply heat and electricity to a co-located biochemical conversion facility.

- Further explore the potential benefits of integrating biochemical and thermochemical technologies.

- Examine the potential for decreased heat integration complexity and increased overall energy efficiency.

- Better understand the kinetics of catalytic tar reforming and deactivation and the necessary regeneration kinetics to achieve a sustainable tar reforming process.

- Examine the emissions profile from the plant and explore alternate emissions control equipment.

- Experimentally examine the effect of pressure on the performance of the tar reformer and tar reformer catalysts to better quantify economic tradeoffs and optimal operating pressures for the production of mixed alcohols using direct gasification.

- Examine ways to improve char utilization in a direct gasifier.

- Study the use of a high temperature slagging gasifier with the same downstream process configuration.

- Study the use of direct gasifiers for the production of other synthesis fuels.

- Obtain more recent quotes of gasifier costs for use in the economic analysis.

- Investigate and incorporate more economical ways for acid gas cleanup. 


\section{References}

${ }^{1}$ Office of the Press Secretary. "State of the Union: The Advanced Energy Initiative." The White House Web site, http://georgewbush-whitehouse.archives.gov/news/releases/2006/01/200601316.html. Accessed June 1, 2009.

${ }^{2}$ Phillips, S.; Aden, A.; Jechura, J.; Dayton, D.; Eggeman, T. Thermochemical Ethanol via Indirect Gasification and Mixed Alcohol Synthesis of Lignocellulosic Biomass. NREL/TP-51041168. Golden, CO: National Renewable Energy Laboratory, April 2007. http://www.nrel.gov/docs/fy07osti/41168.pdf.

${ }^{3}$ Aden, A.; Ruth, M.; Ibsen, K.; Jechura, J.; Neeves, K.; Sheehan, J.; Wallace, B.; Montague, L.; Slayton, A.; Lukas, J. Lignocellulosic Biomass to Ethanol Process Design and Economics Utilizing Co-Current Dilute Acid Prehydrolysis and Enzymatic Hydrolysis for Corn Stover. NREL/TP-510-32438. Golden, CO: National Renewable Energy Laboratory, June 2002. http://www.nrel.gov/docs/fy02osti/32438.pdf.

4 “CEH Marketing Research Report - Ethyl Alcohol." Chemical Economics Handbook - SRI International. SRI Consulting, Menlo Park, CA. 2002; pp. 50-51.

${ }^{5}$ Wooley, R.; Ruth, M.; Sheehan, J.; Ibsen, K. Lignocellulosic Biomass to Ethanol Process Design and Economics Utilizing Co-Current Dilute Acid Prehydrolysis and Enzymatic Hydrolysis Current and Futuristic Scenarios. NREL/TP-580-26157. Golden, CO: National Renewable Energy Laboratory, July 1999. http://devafdc.nrel.gov/pdfs/3957.pdf.

${ }^{6}$ Perlack, R.D.; Wright, L.L.; Turhollow, A.F.; Graham, R.L.; Stokes, B.J.; Erbach, D.C. Biomass as Feedstock for a Bioenergy and Bioproducts Industry: The Technical Feasibility of a BillionTon Annual Supply. A joint U.S. Department of Energy and U.S. Department of Agriculture report. DOE/GO-102995-2135, ORNL/TM-2005/66. Oak Ridge, TN: Oak Ridge National Laboratory, April 2005.

http://www1.eere.energy.gov/biomass/pdfs/final_billionton_vision_report2.pdf.

${ }^{7}$ Spath, P.; Eggeman, T. Effect of Oxygen Purity on Direct-Fired Gasifier \& Comparison to Indirect Gasification. NREL Milestone Report. Golden, CO: National Renewable Energy Laboratory, September 30, 2005.

${ }^{8}$ Bain, R. L.; Craig, K. R.; Overend, R. P. "Gasification for Heat and Power, Methanol, and Hydrogen," Chapter 9.2. Rosillo-Calle, F. et al., ed. Industrial Uses of Biomass Energy. London, UK: Taylor and Francis, 2000. ISBN-0-7484-0884-3.

${ }^{9}$ Wyman, C.E.; Bain, R. L.; Hinman, N.D.; Stevens, D.J. "Ethanol and Methanol from Cellulosic Materials," Chapter 21. Johansson, T.B. et al., ed. Renewable Energy: Sources for Fuels and Electricity. Washington, DC: Island Press, 1993. 
${ }^{10}$ Chem Systems. Assessment of Costs and Benefits of Flexible and Alternative Fuel Use in the U.S. Transportation Sector. DOE/PE-0093. Work performed by Chem Systems, Tarrytown, NY. Washington, DC: U.S. Department of Energy, November 1989; 46 pp.

${ }^{11}$ Feldmann, H.F.; Paisley, M.A.; Appelbaum, H.R.; Taylor, D.R. Conversion of Forest Residues to a Methane-Rich Gas in a High-Throughput Gasifier. PNL-6570. Work performed by Battelle Columbus Division, Columbus, OH. Richland, WA: Pacific Northwest Laboratory, May 1988.

${ }^{12}$ Wan, E. I.; Fraser, M. D. "Economic Assessment of Advanced Biomass Gasification Systems." Proceedings of the IGT Biomass Conference; February 1989, New Orleans, LA. McLean, VA: Science Applications International Corporation, 1989.

${ }^{13}$ Wyman, C.E.; Bain, R. L.; Hinman, N.D.; Stevens, D.J. "Ethanol and Methanol from Cellulosic Materials," Chapter 21. Johansson, T.B. et al., ed. Renewable Energy: Sources for Fuels and Electricity. Washington, DC: Island Press, 1993.

${ }^{14}$ Hamelinck, C. N.; Faaij, A. P. C. Future Prospects for Production of Methanol and Hydrogen from Biomass. Report No. NWS-E-2001-49. Utrecht, the Netherlands: Utrecht University, 2001. ISBN-90-73958-84-9.

${ }^{15}$ Williams, R. H.; Larson, E. D.; Katofsky, R.E.; Chen, J. Methanol and Hydrogen from Biomass for Transportation, with Comparisons to Methanol and Hydrogen from Natural Gas and Coal. PU/CEES Report No. 292. Princeton, NJ: Princeton University, July 1995.

${ }^{16}$ Nexant Inc. Equipment Design and Cost Estimation for Small Modular Biomass Systems, Synthesis Gas Cleanup, and Oxygen Separation Equipment, Task 1: Cost Estimates of Small Modular Systems. NREL/SR-510-39943. Work performed by Nexant Inc., San Francisco, CA. Golden, CO: National Renewable Energy Laboratory, May 2006.

http://www.nrel.gov/docs/fy06osti/39943.pdf.

${ }^{17}$ Nexant Inc. Equipment Design and Cost Estimation for Small Modular Biomass Systems, Synthesis Gas Cleanup, and Oxygen Separation Equipment, Task 2: Gas Cleanup Design and Cost Estimates - Wood Feedstock. NREL/SR-510-39945. Work performed by Nexant Inc., San Francisco, CA. Golden, CO: National Renewable Energy Laboratory, May 2006. http://www.nrel.gov/docs/fy06osti/39945.pdf.

${ }^{18}$ Nexant Inc. Equipment Design and Cost Estimation for Small Modular Biomass Systems, Synthesis Gas Cleanup, and Oxygen Separation Equipment, Task 2.3: Sulfur Primer. NREL/SR510-39946. Work performed by Nexant Inc., San Francisco, CA. Golden, CO: National Renewable Energy Laboratory, May 2006. http://www.nrel.gov/docs/fy06osti/39946.pdf.

${ }^{19}$ Nexant Inc. Equipment Design and Cost Estimation for Small Modular Biomass Systems, Synthesis Gas Cleanup, and Oxygen Separation Equipment, Task 9: Mixed Alcohols From Syngas - State of Technology. NREL/SR-510-39947. Work performed by Nexant Inc., San Francisco, CA. Golden, CO: National Renewable Energy Laboratory, May 2006. http://www.nrel.gov/docs/fy06osti/39947.pdf. 
${ }^{20}$ Garrett, D.E. Chemical Engineering Economics. New York: Van Nostrand Reinhold, 1989.

${ }^{21}$ Peters, M.S.; Timmerhaus, K.D. Plant Design and Economics for Chemical Engineers. $5^{\text {th }}$ edition. New York: McGraw-Hill, Inc., 2003.

${ }^{22}$ Perry, R.H.; Green, D.W.; Maloney, J.O. Perry's Chemical Engineers' Handbook. $7^{\text {th }}$ edition. New York: McGraw-Hill, Inc., 1997.

${ }^{23}$ Chemical Engineering Plant Cost Index. Chemical Engineering. May 2008.

${ }^{24}$ Evans, R.J.; Knight, R.A.; Onischak, N.; Babu, S.P. Development of Biomass Gasification to Produce Substitute Fuels. PNL-6518. Richland, WA: Pacific Northwest Laboratory, March 1988.

${ }^{25}$ Craig, K.R.; Mann, M.K. Cost and Performance Analysis of Biomass-Based Integrated Gasification Combined-Cycle (BIGCC) Power Systems. NREL/TP-430-21657. Golden, CO: National Renewable Energy Laboratory, October 1996. http://www.nrel.gov/docs/legosti/fy97/21657.pdf.

${ }^{26}$ Foust, T.D; Wooley, R; Sheehan, J.; Wallace, R.; Ibsen, K.; Dayton, D.; Himmel, M.; Ashworth, J.; McCormick, R.; Melendez, M.; Hess, J.R.; Kenney, K.; Wright, C.; Radtke, C.; Perlack, R.; Mielenz, J.; Wang, M.; Synder, S.; Werpy, T. A National Laboratory Market and Technology Assessment of the 30x30 Scenario. NREL/TP-510-40942. Golden, CO: National Renewable Energy Laboratory, March 2007. http://www.nrel.gov/docs/fy07osti/40942.pdf.

${ }^{27}$ Office of the Biomass Program. Biomass Multi-Year Program Plan March 2008. Washington, DC: Office of the Biomass Program, Energy Efficiency and Renewable Energy, U.S. Department of Energy, March 2008. New revision forthcoming in 2009. http://www1.eere.energy.gov/biomass/pdfs/biomass program mypp.pdf

${ }^{28}$ Mann, M.K.; Spath, P.L. Life Cycle Assessment of a Biomass Gasification Combined-Cycle Power System. TP-430-23076. Golden, CO: National Renewable Energy Laboratory, 1997. http://www.nrel.gov/docs/legosti/fy98/23076.pdf.

${ }^{29}$ Kumar, S.; Agrawal, M.; Kumar, S.; Jilani, S. "The Production of Syngas by Dry Reforming in Membrane Reactor Using Alumina-Supported Rh Catalyst: A Simulation Study." International Journal of Chemical Reactor Engineering; Vol. 6: A109, 2008.

http://www.bepress.com/ijcre/vol6/A109.

${ }^{30}$ Ravi, G.; Gupta, S.K.; Viswanathan, S.; Ray, M.B. "Optimization of Venturi Scrubbers Using Genetic Algorithm.” Ind. Eng. Chem. Res.; Vol. 41, No.12, 2002; pp. 2988-3002.

${ }^{31}$ Nexant Inc. Equipment Design and Cost Estimation for Small Modular Biomass Systems, Synthesis Gas Cleanup, and Oxygen Separation Equipment, Task 2: Gas Cleanup Design and Cost Estimates - Wood Feedstock. NREL/SR-510-39945. Work performed by Nexant Inc., San Francisco, CA. Golden, CO: National Renewable Energy Laboratory, May 2006. http://www.nrel.gov/docs/fy06osti/39945.pdf. 
${ }^{32}$ Gas Processors Suppliers Association. Engineering Data Book. FPS Version, $12^{\text {th }}$ edition. Tulsa, OK: Gas Processors Suppliers Association, 2004.

${ }^{33}$ Nexant Inc. Equipment Design and Cost Estimation for Small Modular Biomass Systems, Synthesis Gas Cleanup, and Oxygen Separation Equipment, Task 9: Mixed Alcohols From Syngas - State of Technology. NREL/SR-510-39947. Work performed by Nexant Inc., San Francisco, CA. Golden, CO: National Renewable Energy Laboratory, May 2006.

http://www.nrel.gov/docs/fy06osti/39947.pdf.

${ }^{34}$ Herman, R.G. "Classical and Non-classical Routes for Alcohol Synthesis.” Chapter 7. Guczi, L., ed. New Trends in CO Activation. New York: Elsevier, 1991; pp. 265-349.

${ }^{35}$ Dayton, D. Email correspondence between David Dayton, NREL, and Mark Jones, Dow Chemical. National Renewable Energy Laboratory, Golden, CO, January 19, 2007.

${ }^{36}$ Forzatti, P.; Tronconi, E.; Pasquon, I. "Higher Alcohol Synthesis." Catalysis Reviews Science and Engineering; Vol. 33(1-2), 1991; pp. 109-168.

${ }^{37}$ Hamelinck, C.; Faaij, A.P.C.; den Uil, H.; Boerrigter, H. Production of FT Transportation Fuels from Biomass; Technical Options, Process Analysis and Optimisation, and Development Potential. Utrecht, the Netherlands: Utrecht University, Copernicus Institute, March 2003. ISBN 90-393-3342-4.

${ }^{38}$ Quarderer, G.J. "Mixed Alcohols from Synthesis Gas." Proceedings from the $78^{\text {th }}$ Spring National AIChE Meeting, April 6-10, 1986, New Orleans, LA.

${ }^{39}$ Nirula, S. Dow/Union Carbide Process for Mixed Alcohols from Syngas. PEP Review No. 851-4. Menlo Park, CA: SRI International, March 1986.

${ }^{40}$ Park, T.; Nam, I; Kim, Y. "Kinetic Analysis of Mixed Alcohol Synthesis from Syngas over $\mathrm{K} / \mathrm{MoS}_{2}$ Catalyst.” Ind. Eng. Chem. Res.; Vol 36, 1997; pp. 5246-5257.

${ }^{41}$ Gunturu, A.K.; Kugler, E.L.; Cropley, J.B.; Dadyburjor, D.B. "A Kinetic Model for the Synthesis of High-Molecular-Weight Alcohols over a Sulfided Co-K-Mo/C Catalyst." Ind. Eng. Chem. Res.; Vol. 37, 1998; pp. 2107-2115.

${ }^{42}$ Smith, K.J.; Herman, R.G.; Klier, K. "Kinetic Modeling of Higher Alcohol Synthesis over Alkali-Promoted $\mathrm{Cu} / \mathrm{ZnO}$ and $\mathrm{MoS}_{2}$ Catalysts." Chemical Engineering Science; Vol. 45 (8), 1990; pp. 2639-2646.

${ }^{43}$ Tijmensen, M.; Faaij, A.; Hamelinck, C; Hardeveld, M. "Exploration of the Possibilities for Production of Fischer Tropsch Liquids and Power via Biomass Gasification." Biomass and Bioenergy; Vol. 23, 2002; pp. 129-152.

${ }^{44}$ West Virginia University Chemical Engineering Department. "Large-scale Process Design Projects: Air Separation into Oxygen, Nitrogen and Argon."

http://www.che.cemr.wvu.edu/publications/projects/large_proj/air.PDF. Accessed June 1, 2009. 
${ }^{45}$ American Water Works Association, American Society of Civil Engineers. Water Treatment Plant Design. $3^{\text {rd }}$ edition. New York: McGraw Hill, 1997.

${ }^{46}$ Smith, A.R.; Klosek, J. "A Review of Air Separation Technologies and their Integration with Energy Conversion Processes.” Fuel Processing Technology; Vol 79, 2001; pp. 115-134.

${ }^{47}$ Keeney, D.; Muller, M. Water Use by Ethanol Plants: Potential Challenges. Minneapolis, MN: The Institute for Agriculture and Trade Policy, October 2006.

http://www.iatp.org/iatp/publications.cfm?accountID=258\&refID=89449.

${ }^{48}$ Aden, A. "Water Usage for Current and Future Ethanol Production." Southwest Hydrology; September/October 2007; pp. 22-23.

${ }^{49}$ Spath, P.; Aden, A.; Eggeman, T.; Ringer, M.; Wallace, B.; Jechura, J. Biomass to Hydrogen Production Detailed Design and Economics Utilizing the Battelle Columbus Laboratory Indirectly-Heated Gasifier. NREL/TP-510-37408. Golden, CO: National Renewable Energy Laboratory, May 30, 2005. http://www.nrel.gov/docs/fy05osti/37408.pdf.

${ }^{50}$ Peters, M.S.; Timmerhaus, K.D. Plant Design and Economics for Chemical Engineers. $5^{\text {th }}$ edition. New York: McGraw-Hill, Inc., 2003.

${ }^{51}$ Breault, R.; Morgan, D. Design and Economics of Electricity Production From An IndirectlyHeated Biomass Gasifier. Report TR4533-049-92. Columbus, OH: Battelle Columbus Laboratory, 1992.

${ }^{52}$ Paisley, M. Dravo Engineering Companies, Gasification Capital Cost Estimation, 1987. Obtained from Mark Paisley, Battelle Columbus Laboratory, August 1994.

${ }^{53}$ Weyerhaeuser; Nexant; Stone \& Webster. Biomass Gasification Combined Cycle. DOE/DEFC36-96GO10173. Work performed by Weyerhaeuser Company, Tacoma, WA. Washington, DC: U.S. Department of Energy, 2000.

${ }^{54}$ Stone \& Webster; Weyerhaeuser; Amoco; Carolina Power \& Light. New Bern Biomass to Energy Project - Phase 1: Feasibility Study. NREL/TP-421-7942. Work performd by Stone \& Webster, Weyerhauser, Amoco, and Carolina Power \& Light in response to NREL Contract No. LOI No. RCA-3-13326. Golden, CO: National Renewable Energy Laboratory, June 1995.

${ }^{55}$ Wan, E. I.; Malcolm D. F. "Economic Assessment of Advanced Biomass Gasification Systems," in Klass, D.L., ed. Energy from Biomass and Wastes XIII. Chicago: Institute of Gas Technology, 1990; pp.791-827.

${ }^{56}$ Paisley, M. Weyerhaeuser, Gasification Capital Cost Estimation, 1992. Obtained from Mark Paisley, Battelle Columbus Laboratory, August 1994. 
${ }^{57}$ Wright, J.; Feinberg, D. A Comparison of the Production of Methanol and Ethanol from Biomass. Report prepared for Contract No. 23218-1-9201/01-SQ. Paris, France: International Energy Agency, 1993.

${ }^{58}$ Craig, K. Electric Power Generation Cost - Version 1.11. Spreadsheet obtained from Kevin Craig, July 6, 1994.

${ }^{59}$ Fogler, H.S. Elements of Chemical Reaction Engineering. 2nd edition. Englewood Cliffs, NJ: Prentice Hall, 1992.

${ }^{60}$ Walas, S.M. Chemical Process Equipment Selection and Design. Newton, MA: ButterworthHeinemann, 1988.

${ }^{61}$ Leiby, S.M. Operations for Refinery Hydrogen. SRI Report No. 212. Menlo Park, CA: SRI International, 1994.

${ }^{62}$ Aden, A.; Spath, P.; Atherton, B. The Potential of Thermochemical Ethanol via Mixed Alcohols Production. NREL Milestone Report. Golden, CO: National Renewable Energy Laboratory, September 30, 2005. http://devafdc.nrel.gov/bcfcdoc/9432.pdf.

${ }^{63}$ Jeakel, D. Price quote from AGSCO for super sacks or bulk, obtained 2004.

${ }^{64}$ Chemical Marketing Reporter. (2004). August 23-30 issues.

${ }^{65}$ Chem Systems. Biomass to Ethanol Process Evaluation. Report prepared for NREL by Chem Systems, Tarrytown, NY, 1994.

${ }^{66}$ Energy Information Administration (EIA). "Petroleum Marketing Monthly, 2003.” Official Energy Statistics from the U.S. Government. http://www.eia.doe.gov/pub/oil_gas/petroleum/data_publications/petroleum_marketing_monthly /current/pdf/pmmtab16.pdf.

${ }^{67}$ Graubard, D. Personal correspondence. Gas Technology Products LLC, Schaumburg, IL, 2004.

${ }^{68}$ East Bay Municipal Utility District. Wastewater Rates, Charges and Fees, 2004. East Bay Municipal Utility District Web site, http://www.ebmud.com/wastewater/industrial \& commercial permits \& fees/wastewater rates default.htm\#non-residential\%20rates.

${ }^{69}$ SRI International. PEP Yearbook International. Volume 1E. Menlo Park, CA: SRI International, 2003.

${ }^{70}$ Baker, Thomsen Associates Insurance Services Inc. (BTA), Salary Expert ePro $\bigcirc$, www.salaryexpert.com, 2004. 
${ }^{71}$ Energy Information Administration (EIA). "Petroleum" Based on historical wholesale prices found on the Energy Information Administration Web site, Official Energy Statistics from the U.S. Government, http://www.eia.doe.gov/oil_gas/petroleum/info_glance/petroleum.html. 
Appendix A

List of Acronyms 


\begin{tabular}{|c|c|c|c|}
\hline ASME & $\begin{array}{l}\text { American Society of Mechanical } \\
\text { Engineers }\end{array}$ & MESP & Minimum ethanol selling price \\
\hline BCL & Battelle Columbus Laboratory & $\mathrm{MoS}_{2}$ & Molybdenum disulfide \\
\hline BFW & Boiler Feed Water & MTBE & Methyl Tertiary-Butyl Ether \\
\hline bpd & Barrels per day & MW & Megawatt \\
\hline BTU & British Thermal Unit & MYPP & Multi-Year Program Plan \\
\hline CFM & Cubic Feet per Minute & NREL & National Renewable Energy Laboratory \\
\hline $\mathrm{CH}_{4}$ & Methane & NRTL & $\begin{array}{l}\text { Non-Random Two-Liquid activity } \\
\text { coefficient method }\end{array}$ \\
\hline CIP & Clean-in-place & OBP & Office of the Biomass Program \\
\hline CO & Carbon Monoxide & PFD & Process flow diagram \\
\hline Co & Cobalt & PEFI & Power Energy Fuels, Inc. \\
\hline $\mathrm{CO}_{2}$ & Carbon Dioxide & PNNL & Pacific Northwest National Laboratory \\
\hline DCFROR & $\begin{array}{l}\text { Discounted Cash Flow Rate of } \\
\text { Return }\end{array}$ & PPMV & Parts per million by volume \\
\hline DOE & U.S. Department of Energy & psia & Pounds per square inch (absolute) \\
\hline EIA & $\begin{array}{l}\text { Energy Information } \\
\text { Administration }\end{array}$ & RKS-BM & $\begin{array}{l}\text { Redlich-Kwong-Soave equation of state } \\
\text { with Boston-Mathius modifications }\end{array}$ \\
\hline EtOH & Ethanol & SEHT & $\begin{array}{l}\text { Snamprogetti, Enichem and Haldor } \\
\text { Topsoe }\end{array}$ \\
\hline FT & Fischer-Tropsch & SMR & Steam Methane Reformer \\
\hline FY & Fiscal Year & TC EtOH & Thermochemical Ethanol \\
\hline GHSV & Gas Hourly Space Velocity & tpd & Short tons per day \\
\hline GJ & GigaJoule & TPI & Total Project Investment \\
\hline gpm & Gallons per minute & UCC & Union Carbide Corporation \\
\hline GTI & Gas Technology Institute & WGS & Water Gas Shift \\
\hline $\mathbf{H}_{2}$ & Hydrogen & WRI & Western Research Institute \\
\hline HAS & Higher Alcohol Synthesis & WWT & Wastewater Treatment \\
\hline HHV & Higher Heating Value & & \\
\hline IFP & Institut Francais du Petrole & & \\
\hline IGT & $\begin{array}{l}\text { Institute of Gas Technology (now } \\
\text { GTI) }\end{array}$ & & \\
\hline IRR & Internal Rate of Return & & \\
\hline kWh & Kilowatt-hour & & \\
\hline LHV & Lower Heating Value & & \\
\hline MA & Mixed Alcohols & & \\
\hline MASP & Minimum alcohols selling price & & \\
\hline МeOH & Methanol & & \\
\hline
\end{tabular}


Appendix B

NREL Biorefinery Design Database Description and Summary 
NREL's Process Engineering Team has developed a database of primary inf ormation on all of the equipment in the benchmatk model. This database contains information about the cost, reference year, scaling factor, scaling characteristic, design information and back-up cost referencing. The inform ation is stored in a secure database and can be directly linked to the economic portion of the model. In addition to having all of the cost inf ormation used by the model, it has the ability to store documents pertairing to the piece of equipment. These include sizing and costing calculations and vendor information when available.

The following summarizes the important fields of inf ormation contained in the database. A partial listing of the inf ormation is attached for each piece of equipment. Additional information from the database is contained in the equipment cost listing in Appendix C.

Equipment Number: ${ }^{A B}$

Equipment Name: ${ }^{\mathrm{AB}}$ Associated PFD:

Equipment Category. ${ }^{A}$ Equipment Type:

Equipment Description: ${ }^{A}$

Number Recuired: ${ }^{B}$

Number Spares: ${ }^{B}$

Scaling Stream: ${ }^{B}$

Base Cost: ${ }^{\text {B }}$

Cost Basis: ${ }^{A}$

Cost Year: ${ }^{\mathrm{B}}$

Base for Scaling: ${ }^{\text {B }}$

Base Type:

Base Urits:

Installation Factor: ${ }^{\mathrm{B}}$

Install ation Factor B asis:

Scale Factor Exponent: ${ }^{B}$

Scale Factor Basis:

Material of Construction ${ }^{A}$

Notes:

Document:

Design Date:

Modified Date:
Unique identifier, the first letter indicates the equipment type and the fir st number represents the process area, e.g, P-301 is a pump in Area 300 Descriptive name of the piece of equipment

PFD num ber on which the piece of equipment appears, e.g, PFD-P800-A101

Code indicating the general type of equipment, e.g, PUMP

Code indicating the specific type of equipment, e.g., CENTRIFUGAL for a pump

Short description of the size or characteristics of the piece of equipment, e.g, $20 \mathrm{gpm}, 82 \mathrm{ft}$ head for a pump

Number of duplicate pieces of equipment needed

Number of on-line spares

Stream number or other characteristic variable from the ASPEN model by which the equiptme nit cost will be scaled

Equipment cost

Source of the equipment cost, e.g., ICARUS or VENDOR

$Y$ ear for which the cost estimate is based

$V$ alue of the scaling stream or variable used to obtain the base cost of the equipment

Type of variable used for scaling, e.g, FLOW, DUTY, etc.

Urits of the scaling stream or variable, e.g., $\mathrm{KG} / \mathrm{HR}, \mathrm{CAL} / \mathrm{S}$

$V$ alue of the installation factor. Installed Cost $=B$ ase Cost $x$ Installation

Factor

Source of the installation factor value, e.g., ICARUS, VENDOR

$\mathrm{V}$ alue of the ex ponential scaling equation

Source of the scaling exponent value, e.g., GARRETT, VENDOR

Material of Construction

Any other important information about the design or cost

Complete, multi-page document contairing design calculations, vendor literature and quotations and any other im portant information This is stored as an electroric document and can be pages from a spreadsheet other electroric sources or scarned inform ation from vendors.

Original date for the design of this piece of equipm ent

The system automatically m atks the date in this field whenever any field is changed

\footnotetext{
${ }^{A}$ These fields are listed for all pieces of equipment in this Appendix.
}

${ }^{\mathrm{B}}$ These fields are part of the equipment cost listing in Appendix C. 


\begin{tabular}{|c|c|c|c|c|c|c|}
\hline \multicolumn{2}{|c|}{ EQUIPMENT_NUIEQUIPMENT_NAME } & \multicolumn{2}{|c|}{ EQUIPMENT_CATEGOIEQUIPMENT_TYPE } & \multirow[t]{2}{*}{ EQUIPMENT_DESCRIPTION } & \multicolumn{2}{|c|}{ MATERIAL_CONS COST_BASIS } \\
\hline \multicolumn{2}{|c|}{ PFD-P810-A101-2 } & & & & & \\
\hline C-101 & Hopper Feeder & CONVEYOR & VIBRATING-FEEDER & Included in overall cost for feed handling \& drying taken from several literature sources & cs & LITERATURE \\
\hline C-102 & Screener Feeder Conveyor & CONVEYOR & BELT & Included in overall cost for feed handling \& drying taken from several literature sources & CS & LITERATURE \\
\hline C-103 & Radial Stacker Conveyor & CONVEYOR & BELT & Included in overall cost for feed handling \& drying taken from several literature sources & CS & LITERATURE \\
\hline C-104 & Dryer Feed Screw Conveyor & CONVEYOR & SCREW & Included in overall cost for feed handling \& drying taken from several literature sources & CS & LITERATURE \\
\hline C-105 & Gasifier Feed Screw Conveyor & CONVEYOR & SCREW & Included in overall cost for feed handling \& drying taken from several literature sources & $316 \mathrm{ss}$ & LITERATURE \\
\hline H-AP-1 & Hot Flue gas /Cold AlcSepLtToRef Exchanger & HEATX & SHELL-TUBE & $\begin{array}{l}\text { Fixed TS; area=12 f^^2; tube pres=550 psig; tube temp=1400F; shell pres=30 psig; shell } \\
\text { temp }=1000 \mathrm{~F}\end{array}$ & $316 \mathrm{~S} / \mathrm{CS}$ & Aspen IPE \\
\hline H-AP-2 & Hot Flue gas /Cold SteamSuperHt Exchanger & HEATX & SHELL-TUBE & $\begin{array}{l}\text { Fixed TS; area }=1050 \mathrm{ft} \wedge 2 \text {; tube pres=1000 psig; tube temp=1050F; shell pres=55 psig; } \\
\text { shell temp }=1000 \mathrm{~F}\end{array}$ & $316 \mathrm{~S} / \mathrm{CS}$ & Aspen IPE \\
\hline H-AP-3 & Hot Flue gas /Cold SteamGen Exchanger & HEATX & SHELL-TUBE & $\begin{array}{l}\text { Fixed TS; area }=35 \mathrm{ft} 22 \text {; tube pres=1000 psig; tube temp=650F; shell pres }=55 \mathrm{psig} \text {; shell } \\
\text { temp }=1000 \mathrm{~F}\end{array}$ & $316 \mathrm{~S} / \mathrm{CS}$ & Aspen IPE \\
\hline H-AP-4 & Hot Flue gas /Cold WaterPreHt Exchanger & HEATX & SHELL-TUBE & $\begin{array}{l}\begin{array}{l}\text { Fixed TS; area }=650 \mathrm{ft} \wedge \\
\text { temp } \text {; tube pres }=1000 \mathrm{~F}\end{array}\end{array}$ & $316 \mathrm{~S} / \mathrm{CS}$ & Aspen IPE \\
\hline K-101 & Flue Gas Blower & FAN & CENTRIFUGAL & Included in overall cost for feed handling \& drying taken from several literature sources & SS304 & LITERATURE \\
\hline M-101 & Hydraulic Truck Dump with Scale & SCALE & TRUCK-SCALE & Included in overall cost for feed handling \& drying taken from several literature sources & & LITERATURE \\
\hline M-102 & Hammermill & SIZE-REDUCTION & & Included in overall cost for feed handling \& drying taken from several literature sources & CS & LITERATURE \\
\hline M-103 & Front End Loaders & VEHICLE & LOADER & Included in overall cost for feed handling \& drying taken from several literature sources & CS & LITERATURE \\
\hline M-104 & Rotary Biomass Dryer & DRYER & ROTARY-DRUM & Included in overall cost for feed handling \& drying taken from several literature sources & CS & LITERATURE \\
\hline S-101 & Magnetic Head Pulley & SEPARATOR & MAGNET & Included in overall cost for feed handling \& drying taken from several literature sources & CS & LITERATURE \\
\hline S-102 & Screener & SEPARATOR & SCREEN & Included in overall cost for feed handling \& drying taken from several literature sources & CS & LITERATURE \\
\hline S-103 & Dryer Air Cyclone & SEPARATOR & GAS CYCLONE & Included in overall cost for feed handling \& drying taken from several literature sources & cs & LITERATURE \\
\hline S-104 & Dryer Air Baghouse Filter & SEPARATOR & FABRIC-FILTER & Included in overall cost for feed handling \& drying taken from several literature sources & & LITERATURE \\
\hline $\mathrm{T}-101$ & Dump Hopper & TANK & LIVE-BTM-BIN & Included in overall cost for feed handling \& drying taken from several literature sources & CS & LITERATURE \\
\hline T-102 & Hammermill Surge Bin & TANK & LIVE-BTM-BIN & Included in overall cost for feed handling \& drying taken from several literature sources & cs & LITERATURE \\
\hline $\mathrm{T}-103$ & Dryer Feed Bin & TANK & LIVE-BTM-BIN & Included in overall cost for feed handling $\&$ drying taken from several literature sources & CS & LITERATURE \\
\hline $\mathrm{T}-104$ & Dried Biomass Hopper & TANK & VERTICAL-VESSEL & Included in overall cost for feed handling \& drying taken from several literature sources & CS & LITERATURE \\
\hline $\mathrm{T}-105$ & Lock Hopper & TANK & VERTICAL-VESSEL & Included in overall cost for feed handling \& drying taken from several literature sources & CS & LITERATURE \\
\hline $\mathrm{T}-106$ & Feed Hopper & TANK & LIVE-BTM-BIN & Included in overall cost for feed handling \& drying taken from several literature sources & cs & LITERATURE \\
\hline \multicolumn{2}{|c|}{ PFD-P810-A201 } & & & & & \\
\hline C-201 & Sand/ash Conditioner/Conveyor & CONVEYOR & SCREW & $\begin{array}{l}\text { Included in overall cost for gasification \& gas clean up taken from several literature } \\
\text { sources }\end{array}$ & CS & LITERATURE \\
\hline C-202 & MgO Screw Conveyor & CONVEYOR & SCREW & $\begin{array}{l}\text { Included in overall cost for gasification \& gas clean up taken from several literature } \\
\text { sources }\end{array}$ & CS & LITERATURE \\
\hline C-203 & Olivine Screw Conveyor & CONVEYOR & SCREW & $\begin{array}{l}\text { Included in overall cost for gasification \& gas clean up taken from several literature } \\
\text { sources }\end{array}$ & CS & LITERATURE \\
\hline M-201 & Sand/ash Cooler & MISCELLANEOUS & MISCELLANEOUS & $\begin{array}{l}\text { Included in overall cost for gasification \& gas clean up taken from several literature } \\
\text { sources }\end{array}$ & & LITERATURE \\
\hline $\mathrm{R}-201$ & Directly Heated Gasifier & REACTOR & VERTICAL-VESSEL & $\begin{array}{l}\text { Included in overall cost for gasification \& gas clean up taken from several literature } \\
\text { sources }\end{array}$ & CS w/refractory & LITERATURE \\
\hline S-201 & Primary Gasifier Cyclone & SEPARATOR & GAS CYCLONE & $\begin{array}{l}\text { Included in overall cost for gasification \& gas clean up taken from several literature } \\
\text { sources }\end{array}$ & CS w/refractory & LITERATURE \\
\hline S-202 & Secondary Gasifier Cyclone & SEPARATOR & LONE & $\begin{array}{l}\text { Included in overall cost for gasification \& gas clean up taken from several literature } \\
\text { sources }\end{array}$ & CS w/refractory & LITERATURE \\
\hline $\mathrm{T}-201$ & Sand/ash Bin & TANK & $\begin{array}{l}\text { FLAT-BTM- } \\
\text { STORAGE }\end{array}$ & $\begin{array}{l}\text { Included in overall cost for gasification \& gas clean up taken from several literature } \\
\text { sources }\end{array}$ & CS & LITERATURE \\
\hline \multicolumn{2}{|c|}{ PFD-P810 } & & & & & \\
\hline S-306 & Tar Reformer Cyclone & SEPARATOR & GAS CYCLONE & Included in the cost of the tar reformer catalyst renegerator, R-204 & CS & LITERATURE \\
\hline
\end{tabular}




\begin{tabular}{|c|c|c|c|c|c|c|}
\hline \multicolumn{2}{|c|}{ EQUIPMENT_NUIEQUIPMENT_NAME } & \multicolumn{2}{|c|}{ EQUIPMENT_CATEGOIEQUIPMENT_TYPE } & \multirow{2}{*}{$\begin{array}{l}\text { EQUIPMENT_DESCRIPTION } \\
\text { Fixed TS; area=36 ft²; tube pres=1000 psig; tube temp=700F; shell pres=55 psig; shell } \\
\text { temp=550F }\end{array}$} & \multicolumn{2}{|c|}{ MATERIAL_CONS COST_BASIS } \\
\hline H-AP-5 & Cold FCAirPreHt /Hot WaterBlwdn Exchanger & HEATX & SHELL-TUBE & & $316 \mathrm{~S} / \mathrm{CS}$ & Aspen IPE \\
\hline H-AP-6 & Hot RefExhQuench /Cold SteamGen Exchanger & HEATX & SHELL-TUBE & $\begin{array}{l}\text { Fixed TS; area }=2350 \mathrm{ft}^{\wedge} 2 \text {; tube pres }=1000 \mathrm{psig} \text {; tube temp }=700 \mathrm{~F} \text {; shell pres }=550 \mathrm{psig} \text {; } \\
\text { shell temp }=900 \mathrm{~F}\end{array}$ & $\mathrm{cs} / \mathrm{cs}$ & Aspen IPE \\
\hline H-AP-8 & Hot RefExhQuench /Cold AlcSynPreHt Exchanger & HEATX & SHELL-TUBE & $\begin{array}{l}\text { Fixed TS; area=10950 ft^2; tube pres=1100 psig; tube temp=700F; shell pres=550 psig; } \\
\text { shell temp }=800 \mathrm{~F}\end{array}$ & $304 \mathrm{~S} / \mathrm{CS}$ & Aspen IPE \\
\hline H-AP-10 & Hot RefExhQuench /Cold RefBleedPreHt Exchanger & HEATX & SHELL-TUBE & $\begin{array}{l}\text { Fixed TS; area= }=550 \mathrm{ft} \wedge 2 \text {; tube pres }=550 \mathrm{psig} ; \text { tube temp }=1300 \mathrm{~F} \text {; shell pres }=550 \mathrm{psig} \text {; } \\
\text { shell temp=900F }\end{array}$ & $316 \mathrm{~S} / \mathrm{A} 285 \mathrm{C}$ & Aspen IPE \\
\hline H-BP-4 & Cold FCAirPreHt/Hot Reformate Exchanger & HEATX & SHELL-TUBE & $\begin{array}{l}\text { Fixed TS; area }=5500 \mathrm{ft} \wedge 2 \text {; tube pres }=550 \mathrm{psig} \text {; tube temp=550F; shell pres }=25 \mathrm{psig} \text {; shell } \\
\text { temp=450F }\end{array}$ & CS/A214 & Aspen IPE \\
\hline H-BP-7 & Cold RefBleedPreHt/Hot Reformate Exchanger & HEATX & SHELL-TUBE & $\begin{array}{l}\text { Fixed TS; area }=450 \mathrm{ft} \wedge 2 \text {; tube pres }=550 \mathrm{psig} \text {; tube temp }=550 \mathrm{~F} \text {; shell pres }=550 \mathrm{psig} \text {; shell } \\
\text { temp }=550 \mathrm{~F}\end{array}$ & CS/A214 & Aspen IPE \\
\hline H-BP-12 & Cold Water /Hot Reformate Exchanger & HEATX & SHELL-TUBE & $\begin{array}{l}\text { Fixed TS; area }=800 \mathrm{ft} 22 \text {; tube pres }=550 \text { psig; tube temp=450F; shell pres=50 psig; shell } \\
\text { temp }=450 \mathrm{~F}\end{array}$ & CS/A214 & Aspen IPE \\
\hline $\mathrm{H}-\mathrm{BP}-13$ & Cold RefBleedPreHt /Hot Reformate Exchanger & HEATX & SHELL-TUBE & $\begin{array}{l}\text { Fixed TS; area }=550 \mathrm{ft} \wedge 2 \text {; tube pres }=550 \mathrm{psig} \text {; tube temp=450F; shell pres }=550 \mathrm{psig} \text {; shell } \\
\text { temp }=450 \mathrm{~F}\end{array}$ & CS/A214 & Aspen IPE \\
\hline H-BP-15 & Cold FCAirPreHt /Hot Reformate Exchanger & HEATX & SHELL-TUBE & $\begin{array}{l}\begin{array}{l}\text { Fixed TS; area }=6000 \mathrm{ft} 2 \\
\text { temp } ; \text { tube pres }=550 \mathrm{~F}\end{array} \\
\text { te psig; tube temp=450F; shell pres }=50 \mathrm{psig} \text {; shell }\end{array}$ & CS/A214 & Aspen IPE \\
\hline K-305 & Regenerator Combustion Air Blower & FAN & CENTRIFUGAL & gas flow rate $($ actual $)=70133 \mathrm{CFM}$; & SS304 & QUESTIMATE \\
\hline K-313 & Blower for Dryer Exhaust to Fuel Combustor & FAN & ROTARY BLOWER & gas flow rate $($ actual $)=100 \mathrm{CFM}$; gauge pressure $=4 \mathrm{psig}$ & CS & Aspen IPE \\
\hline$R-303$ & Tar Reformer & REACTOR & VERTICAL-VESSEL & $\begin{array}{l}\text { Included in overall cost for gasification \& gas clean up taken from several literature } \\
\text { sources }\end{array}$ & CS w/refractory & LITERATURE \\
\hline R-301A & Tar Reformer Catalyst Regenerator & REACTOR & VERTICAL-VESSEL & Taken from literature source & CS w/refractory & LITERATURE \\
\hline $\mathrm{H}-301$ & Quench Water Recirculation Cooler & HEATX & SHELL-TUBE & $\begin{array}{l}\text { Included in overall cost for gasification \& gas clean up taken from several literature } \\
\text { sources }\end{array}$ & cs & LITERATURE \\
\hline $\mathrm{H}-303$ & Water-cooled Aftercooler & HEATX & SHELL-TUBE & $\begin{array}{l}\text { duty = } 2.9 \mathrm{MMBtu} / \mathrm{hr} ; \text { LMTD = 25F; U = } 150 \mathrm{Btu} / \mathrm{hr}-\mathrm{ft}^{\wedge} 2-\mathrm{F} ; \text { surface area }=794 \mathrm{ft} 2 \text {; fixed } \\
\text { TS }\end{array}$ & SS304CS/A214 & QUESTIMATE \\
\hline H-301C-1 & Pre-syngas water knockout, water-cooled exchanger & HEATX & SHELL-TUBE & $\begin{array}{l}\text { Fixed TS; area=2800 ft^2; tube pres=550 psig; tube temp=250F; shell pres=100 psig; } \\
\text { shell temp }=150 \mathrm{~F}\end{array}$ & A214 & Aspen IPE \\
\hline $\mathrm{H}-306$ & Waste Water Cooler / Cooling Water & HEATX & SHELL-TUBE & $\begin{array}{l}\text { Pre-engineered U-tube; area }=50 \mathrm{ff}{ }^{\wedge} 2 \text {; tube pres }=550 \text { psig; tube temp }=400 \mathrm{~F} ; \text { shell } \\
\text { pres }=100 \text { psig; shell temp }=150 \mathrm{~F}\end{array}$ & CS & Aspen IPE \\
\hline M-300 & Fuel Mixer for Combustor & MISCELLANEOUS & MISCELLANEOUS & Plumbing - included in installation factor & & \\
\hline M-300H & Mixer Prior to Tar Reformer & MISCELLANEOUS & MISCELLANEOUS & Plumbing - included in installation factor & & \\
\hline M-330 & Mixer Prior to Reformate Quench & MISCELLANEOUS & MISCELLANEOUS & Plumbing - included in installation factor & & \\
\hline M-301 & Syngas Quench Chamber & MISCELLANEOUS & & $\begin{array}{l}\text { Included in overall cost for gasification \& gas clean up taken from several literature } \\
\text { sources }\end{array}$ & Cs & LITERATURE \\
\hline M-302 & Syngas Venturi Scrubber & MISCELLANEOUS & & $\begin{array}{l}\text { Included in overall cost for gasification \& gas clean up taken from several literature } \\
\text { sources }\end{array}$ & CS & LITERATURE \\
\hline $\mathrm{P}-301$ & Sludge Pump & PUMP & CENTRIFUGAL & 1.4 GPM; 0.053 brake HP; design pressure $=60$ psia & $\mathrm{CS}$ & QUESTIMATE \\
\hline P-302 & Quench Water Recirculation Pump & PUMP & CENTRIFUGAL & Included in the cost of the gasification \& gas clean up system & CS & LITERATURE \\
\hline P-303 & LO-CAT Absorbent Solution Circulating Pump & PUMP & CENTRIFUGAL & Included in LO-CAT system cost & $304 S S$ & VENDOR \\
\hline S-301 & Syngas Recycle Water Knockout Vessel & SEPARATOR & KNOCK-OUT DRUM & $18 \mathrm{ft}$ diameter; $36 \mathrm{ft}$ height; design pres $=40$ psia; design temp $=197 \mathrm{~F}$ & Cs & QUESTIMATE \\
\hline S-303 & Pre-Amine System Knock-out & SEPARATOR & KNOCK-OUT DRUM & $7 \mathrm{ft}$ diameter; $14 \mathrm{ft}$ height; design pres $=506 \mathrm{psia}$; design temp $=160 \mathrm{~F}$ & cs & QUESTIMATE \\
\hline T-301 & Sludge Settling Tank & SEPARATOR & CLARIFIER & $3 \mathrm{ft}$ diameter; $7 \mathrm{ft}$ height; 431 gal volume; & SS304 & QUESTIMATE \\
\hline $\mathrm{T}-302$ & Quench Water Recirculation Tank & TANK & $\begin{array}{l}\text { HORIZONTAL- } \\
\text { VESSEL }\end{array}$ & $\begin{array}{l}\text { Included in overall cost for gasification \& gas clean up taken from several literature } \\
\text { sources }\end{array}$ & CS & LITERATURE \\
\hline H-304-1 & LO-CAT Preheater/Steam & HEATX & SHELL-TUBE & $\begin{array}{l}\text { Pre-engineered U-tube; area }=18 \mathrm{ft}^{\wedge} 2 \text {; tube pres }=120 \mathrm{psig} ; \text { tube temp }=500 \mathrm{~F} \text {; shell } \\
\text { pres }=100 \text { psig; shell temp }=250 \mathrm{~F}\end{array}$ & Cs & Aspen IPE \\
\hline $\mathrm{H}-305$ & LO-CAT Absorbent Solution Cooler & HEATX & SHELL-TUBE & Included in LO-CAT system cost & $304 S S$ & VENDOR \\
\hline K-302 & LO-CAT Feed Air Blower & FAN & CENTRIFUGAL & Included in LO-CAT system cost & Cs & VENDOR \\
\hline K-373 & Light-Ends for Alcohol Sep to Reformer Compressor & COMPRESSOR & CENTRIFUGAL & COPIED FROM K-414 & A285C & QUESTIMATE \\
\hline K-384 & CO2 Recycle into Tar Reformer & COMPRESSOR & RECIPROCATING & gas flow rate (actual) $=130 \mathrm{CFM}$; inlet $11 \mathrm{psig}$, discharge $446 \mathrm{psig}$; inlet temp $149 \mathrm{~F}$ & & Aspen IPE \\
\hline
\end{tabular}




\begin{tabular}{|c|c|c|c|c|c|c|}
\hline \multicolumn{2}{|c|}{ EQUIPMENT_NUIEQUIPMENT_NAME } & \multicolumn{2}{|c|}{ EQUIPMENT_CATEGOIEQUIPMENT_TYPE } & \multirow{2}{*}{\begin{tabular}{|l|} 
EQUIPMENT_DESCRIPTION \\
Included in LO-CAT system cost \\
\end{tabular}} & \multicolumn{2}{|c|}{ MATERIAL_CONS COST_BASIS } \\
\hline M-303 & LO-CAT Venturi Precontactor & MISCELLANEOUS & & & $304 \mathrm{SS}$ & VENDOR \\
\hline M-304 & LO-CAT Liquid-filled Absorber & COLUMN & ABSORBER & Included in LO-CAT system cost & $304 \mathrm{SS}$ & VENDOR \\
\hline R-304 & LO-CAT Oxidizer Vessel & REACTOR & VERTICAL-VESSEL & Included in LO-CAT system cost & $304 \mathrm{SS}$ & VENDOR \\
\hline S-310 & L.P. Amine System & COLUMN & ABSORBER & & & OTHER \\
\hline M-312A & Mixer In Syngas Quench Exchangers Train & MISCELLANEOUS & MISCELLANEOUS & Plumbing - included in installation factor & & \\
\hline SP-312B & Flow Split In Syngas Quench Exchangers Train & MISCELLANEOUS & MISCELLANEOUS & Plumbing - included in installation factor & & \\
\hline SP-330 & Exchangers & MISCELLANEOUS & MISCELLANEOUS & Plumbing - included in installation factor & & \\
\hline \multicolumn{7}{|c|}{ PFD-P810-A401-2 } \\
\hline $\mathrm{K}-410$ & Mixed Alcohol Gas Compressor & COMPRESSOR & CENTRIFUGAL & $\begin{array}{l}\begin{array}{l}\text { gas flow rate }=2,481 \text { CFM; } 4 \text { impellers; design outlet pressure }=700 \text { psi; 10,617 HP; } \\
\text { intercoolers, aftercooler, \& K.O.s included }\end{array} \\
\end{array}$ & A285C & QUESTIMATE \\
\hline H-AP-9 & $\begin{array}{l}\text { Hot RefExhQuench /Cold AlcSynUnRxToRef } \\
\text { Exchanger }\end{array}$ & HEATX & SHELL-TUBE & $\begin{array}{l}\begin{array}{l}\text { Fixed TS; area }=25600 \mathrm{ft} 2 \\
\text { sell tube pres }=1000 \mathrm{psig} ; \text { tube temp }=1250 \mathrm{~F} \text {; shell pres }=550 \mathrm{psig} ; \\
\text { shell temp=900F }\end{array}\end{array}$ & $316 \mathrm{~S} / \mathrm{CS}$ & Aspen IPE \\
\hline H-AP-11 & Hot Alc.Rx.Exh. /Cold WaterPreHt Exchanger & HEATX & SHELL-TUBE & $\begin{array}{l}\begin{array}{l}\text { Fixed TS; area }=3500 \mathrm{ft} \mathrm{ft}^{\wedge} \text {; tube pres }=1000 \mathrm{psig} ; \text { tube temp=550F; shell pres=1100 psig; } \\
\text { shell temp }=800 \mathrm{~F}\end{array}\end{array}$ & $\mathrm{cs} / \mathrm{cs}$ & Aspen IPE \\
\hline H-AP-12 & Hot WaterBIwdn /Cold WaterPreHt Exchanger & HEATX & SHELL-TUBE & $\begin{array}{l}\text { Fixed TS; area=150 f^^2; tube pres=1000 psig; tube temp=550F; shell pres=1000 psig; } \\
\text { shell temp=800F }\end{array}$ & $\mathrm{cs} / \mathrm{cs}$ & Aspen IPE \\
\hline $\mathrm{H}-\mathrm{BP}-1$ & Hot Reformate /Cold AlcSynPreHt Exchanger & HEATX & SHELL-TUBE & $\begin{array}{l}\text { Fixed TS; area=4400 f^^2; tube pres=1100 psig; tube temp=450F; shell pres=550 psig; } \\
\text { shell temp }=450 \mathrm{~F}\end{array}$ & CS/A214 & Aspen IPE \\
\hline H-BP-5 & Hot Reformate /Cold AlcSynUnRx Exchanger & HEATX & SHELL-TUBE & $\begin{array}{l}\text { Fixed TS; area=3000 f^^2; tube pres=1100 psig; tube temp=550F; shell pres=550 psig; } \\
\text { shell temp }=550 \mathrm{~F}\end{array}$ & CS/A214 & Aspen IPE \\
\hline H-BP-10 & Hot Reformate /Cold AlcSynPreHt Exchanger & HEATX & SHELL-TUBE & $\begin{array}{l}\text { Fixed TS; area=2100 ft^2; tube pres=1100 psig; tube temp=450F; shell pres=550 psig; } \\
\text { shell temp }=450 \mathrm{~F}\end{array}$ & CS/A214 & Aspen IPE \\
\hline H-BP-14 & Hot Reformate /Cold AlcSynUnRx Exchanger & HEATX & SHELL-TUBE & $\begin{array}{l}\text { Fixed TS; area=3300 ft^2; tube pres=1100 psig; tube temp=450F; shell pres=550 psig; } \\
\text { shell temp }=450 \mathrm{~F}\end{array}$ & CS/A214 & Aspen IPE \\
\hline H-BP-17 & Hot Alc.Rx.Exh. /Cold Water Exchanger & HEATX & SHELL-TUBE & $\begin{array}{l}\text { Fixed TS; area=2100 ft^2; tube pres=1000 psig; tube temp=450F; shell pres=1100 psig; } \\
\text { shell temp }=550 \mathrm{~F}\end{array}$ & CS/A214 & Aspen IPE \\
\hline K-412 & Purge Gas Expander & COMPRESSOR & CENTRIFUGAL & gas flow rate = 144 CFM; design outlet pressure $=25$ psi; $2740 \mathrm{HP}$ & A285C & QUESTIMATE \\
\hline K-414A & Mixed Alcohol Recycle Gas Compressor & COMPRESSOR & RECIPROCATING & gas flow rate $=0.05 \mathrm{CFM}$; inlet pres $958 \mathrm{psig}$; outlet pres $979 \mathrm{psig}$; temp $110 \mathrm{~F}$ & A285C & Aspen IPE \\
\hline $\mathrm{H}-414-1$ & Mixed Alcohol Condenser & HEATX & SHELL-TUBE & $\begin{array}{l}\begin{array}{l}\text { Fixed TS; area }=1200 \mathrm{ft} 2 \\
\text { sel tube pres }=1100 \mathrm{psig} ; \text { tube temp }=250 \mathrm{~F} ; \text { shell pres }=100 \mathrm{psig} ; \\
\text { shell temp }=150 \mathrm{~F}\end{array}\end{array}$ & A214 & Aspen IPE \\
\hline $\mathrm{H}-413$ & Mixed Alcohol first Condenser (air cooled) & HEATX & $\begin{array}{l}\text { AIR-COOLED } \\
\text { EXCHANGER }\end{array}$ & & & \\
\hline S-501 & Mixed Alcohols Condensation Knock-out & SEPARATOR & KNOCK-OUT DRUM & $\begin{array}{l}\mathrm{H} / \mathrm{D}=2 ; 5 \mathrm{ft} \text { diam; } 9 \mathrm{ft} \text { height; operating pressure }=1993 \text { psia; operating temperature = } \\
110 \mathrm{~F}\end{array}$ & A-515 & QUESTIMATE \\
\hline$R-410$ & Mixed Alcohol Reactor & REACTOR & VERTICAL-VESSEL & $\begin{array}{l}\text { Fixed Bed Synthesis Reactor with MoS2-based catalyst. Sized from hourly space velocity } \\
\text { of } 3000 \text { (hr-1) }\end{array}$ & CS w/refractory & QUESTIMATE \\
\hline SP-470 & Flow Split Before Alc.Syn. Below Pinch Exchangers & MISCELLANEOUS & MISCELLANEOUS & Plumbing - included in installation factor & & \\
\hline M-470A & Mixer After Alc.Syn. Below Pinch Exchangers & MISCELLANEOUS & MISCELLANEOUS & Plumbing - included in installation factor & & \\
\hline \multicolumn{7}{|c|}{ PFD-P810-A501-2 } \\
\hline $\mathrm{H}-513$ & Mol Sieve Flush Condenser (air cooled) & HEATX & $\begin{array}{l}\text { AIR-COOLED } \\
\text { EXCHANGER }\end{array}$ & & & \\
\hline $\mathrm{H}-504 \mathrm{C}$ & D-504 condenser (air cooled) & HEATX & $\begin{array}{l}\text { AIR-COOLED } \\
\text { EXCHANGER }\end{array}$ & & & \\
\hline $\mathrm{H}-505 \mathrm{C}$ & D-505 condenser (air cooled) & HEATX & \begin{tabular}{|l|} 
AIR-COOLED \\
EXCHANGER \\
\end{tabular} & & & \\
\hline M-500B & Mol-Sieve Off Gas Mixer & MISCELLANEOUS & MISCELLANEOUS & Plumbing - included in installation factor & & \\
\hline S-503 & Molecular Sieve (9 pieces) & MISCELLANEOUS & PACKAGE & $\begin{array}{l}\text { Superheater, twin mole sieve columns, product cooler, condenser, pumps, vacuum } \\
\text { source. }\end{array}$ & Ss & VENDOR \\
\hline S-502 & LP Syngas Separator & SEPARATOR & KNOCK-OUT DRUM & & & \\
\hline D-504 & Ethanol/Propanol Splitter & COLUMN & DISTILLATION & & & \\
\hline D-505 & Methanol/Ethanol Splitter & COLUMN & DISTILLATION & & & \\
\hline
\end{tabular}




\begin{tabular}{|c|c|c|c|c|c|c|}
\hline \multicolumn{2}{|c|}{ EQUIPMENT_NUIEQUIPMENT_NAME } & \multicolumn{2}{|c|}{ EQUIPMENT_CATEGOIEQUIPMENT_TYPE } & \multirow[t]{2}{*}{ EQUIPMENT_DESCRIPTION } & \multicolumn{2}{|c|}{\begin{tabular}{|l|l|} 
MATERIAL_CONS & COST_BASIS \\
\end{tabular}} \\
\hline $\mathrm{H}-504 \mathrm{R}$ & Ethanol/Propanol Splitter Reboiler & HEATX & SHELL-TUBE & & & \\
\hline $\mathrm{H}-505 \mathrm{R}$ & Methanol/Ethanol Splitter Reboiler & HEATX & SHELL-TUBE & & & \\
\hline P-504B & Ethanol/Propanol Splitter Bottoms Pump & PUMP & CENTRIFUGAL & & & \\
\hline P-505B & Methanol/Ethanol Splitter Bottoms Pump & PUMP & CENTRIFUGAL & & & \\
\hline P-504R & Ethanol/Propanol Splitter Reflux Pump & PUMP & CENTRIFUGAL & & & \\
\hline P-505R & Methanol/Ethanol Splitter Reflux Pump & PUMP & CENTRIFUGAL & & & \\
\hline T-504 & Ethanol/Propanol Splitter Reflux Drum & TANK & KNOCK-OUT DRUM & & & \\
\hline T-505 & Methanol/Ethanol Splitter Reflux Drum & TANK & KNOCK-OUT DRUM & & & \\
\hline P-590 & Mixed Alcohol Product Pump & PUMP & CENTRIFUGAL & & & \\
\hline P-592 & Ethanol Product Pump & PUMP & CENTRIFUGAL & & & \\
\hline P-591 & Mixed Alcohol Product Pump & PUMP & CENTRIFUGAL & & & \\
\hline P-593 & Ethanol Product Pump & PUMP & CENTRIFUGAL & & & \\
\hline $\mathrm{H}-592-1$ & Ethanol Product Cooler (air cooled) & HEATX & $\begin{array}{l}\text { AIR-COOLED } \\
\text { EXCHANGER }\end{array}$ & & & \\
\hline $\mathrm{H}-590-1$ & Mixed Alcohol Product Cooler (air cooled) & HEATX & $\begin{array}{l}\text { AIR-COOLED } \\
\text { EXCHANGER }\end{array}$ & & & \\
\hline $\mathrm{H}-591-1$ & Higher Alcohol Product Finishing cooler & HEATX & SHELL-TUBE & $\begin{array}{l}\begin{array}{l}\text { Pre-engineered U-tube; area }=40 \mathrm{ft}^{\wedge} 2 \text {; tube pres }=100 \mathrm{psig} ; \text { tube temp }=300 \mathrm{~F} ; \text { shell } \\
\text { pres }=100 \text { psig; shell temp }=150 \mathrm{~F}\end{array}\end{array}$ & CS & Aspen IPE \\
\hline H-593-1 & ETHANOL Product Finishing cooler & HEATX & SHELL-TUBE & $\begin{array}{l}\text { Fixed TS; area }=240 \mathrm{ft} \wedge 2 \text {; tube pres=100 psig; tube temp=300F; shell pres=100 psig; shell } \\
\text { temp=150F }\end{array}$ & cs & Aspen IPE \\
\hline $\mathrm{H}-\mathrm{BP}-2$ & Cold MolSievPreHt /Hot Reformate Exchanger & HEATX & SHELL-TUBE & $\begin{array}{l}\begin{array}{l}\text { Fixed TS; area }=900 \mathrm{ft} \wedge 2 \text {; tube pres }=550 \mathrm{psig} \text {; tube temp }=550 \mathrm{~F} \text {; shell pres }=80 \mathrm{psig} \text {; shell } \\
\text { temp }=450 \mathrm{~F}\end{array}\end{array}$ & CS/A214 & Aspen IPE \\
\hline H-BP-3 & Cold MolSievPreHt/Hot Reformate Exchanger & HEATX & SHELL-TUBE & 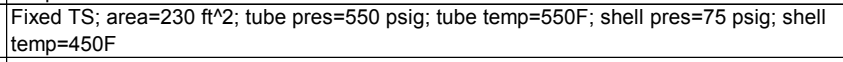 & CS/A214 & Aspen IPE \\
\hline H-BP-16 & Cold MolSievPreHt/Hot Reformate Exchanger & HEATX & SHELL-TUBE & $\begin{array}{l}\text { Fixed TS; area }=5000 \text { ft^2; tube pres }=550 \text { psig; tube temp=450F; shell pres }=80 \text { psig; shell } \\
\text { temp }=450 \mathrm{~F}\end{array}$ & CS/A214 & Aspen IPE \\
\hline T-592 & Ethanol Product Storage Tank & TANK & $\begin{array}{l}\text { FLAT-BTM- } \\
\text { STORAGE }\end{array}$ & & & \\
\hline $\mathrm{T}-590$ & Mixed Alcohol Product Storage Tank & TANK & $\begin{array}{l}\text { FLAT-BTM- } \\
\text { STORAGE }\end{array}$ & & & \\
\hline \multicolumn{7}{|c|}{ PFD-P810-A601-3 } \\
\hline $\mathrm{H}-601$ & Steam Turbine Condenser & HEATX & SHELL-TUBE & $\begin{array}{l}\text { Included in the cost of the steam trubine/generator (M-602); condenser steam flow rate = } \\
342,283 \mathrm{lb} / \mathrm{hr}\end{array}$ & & $\begin{array}{l}\text { ADEN, ET. AL. } \\
2002\end{array}$ \\
\hline $\mathrm{H}-603$ & Blowdown Water-cooled Cooler & HEATX & SHELL-TUBE & duty $=0.6 \mathrm{MMBtu} / \mathrm{hr} ; \mathrm{LMTD}=47 \mathrm{~F} ; \mathrm{U}=225 \mathrm{Btu} / \mathrm{hr}-\mathrm{ft}^{\wedge} 2-\mathrm{F} ;$ area $=60 \mathrm{ft} \mathrm{ft}^{\wedge} ;$ fixed TS & A214 & QUESTIMATE \\
\hline H-BP-6 & Hot Reformate /Cold Water Exchanger & HEATX & SHELL-TUBE & $\begin{array}{l}\text { Fixed TS; area }=7500 \mathrm{ft} 22 \text {; tube pres }=1000 \text { psig; tube temp=550F; shell pres=550 psig; } \\
\text { shell temp }=550 \mathrm{~F}\end{array}$ & CS/A214 & Aspen IPE \\
\hline H-BP-8 & Cold Water /Hot Reformate Exchanger & HEATX & SHELL-TUBE & $\begin{array}{l}\begin{array}{l}\text { Fixed TS; area }=80 \mathrm{ft} 2 \text {; tube pres }=550 \mathrm{psig} \text {; tube temp }=450 \mathrm{~F} \text {; shell pres }=50 \mathrm{psig} \text {; shell } \\
\text { temp }=450 \mathrm{~F}\end{array} \\
\text { te }\end{array}$ & CS/A214 & Aspen IPE \\
\hline H-BP-9 & Cold Water /Hot Reformate Exchanger & HEATX & SHELL-TUBE & $\begin{array}{l}\begin{array}{l}\text { Fixed TS; area }=350 \mathrm{ft} \wedge 2 \text {; tube pres }=550 \mathrm{psig} \text {; tube temp }=450 \mathrm{~F} \text {; shell pres }=50 \mathrm{psig} \text {; shell } \\
\text { temp }=450 \mathrm{~F}\end{array}\end{array}$ & CS/A214 & Aspen IPE \\
\hline H-BP-11 & Hot Reformate /Cold WaterRecy Exchanger & HEATX & SHELL-TUBE & $\begin{array}{l}\text { Fixed TS; area }=2000 \mathrm{ft}^{\wedge} 2 \text {; tube pres }=550 \mathrm{psig} \text {; tube temp=450F; shell pres }=550 \mathrm{psig} \text {; } \\
\text { shell temp }=450 \mathrm{FF}\end{array}$ & CS/A214 & Aspen IPE \\
\hline M-601 & Hot Process Water Softener System & MISCELLANEOUS & PACKAGE & $\begin{array}{l}\text { scaled cost to } 700 \mathrm{gpm} \text { flow, 24" dia softener. Includes filters, chemical feeders, piping, } \\
\text { valves }\end{array}$ & & RICHARDSON \\
\hline M-602 & Extraction Steam Turbine/Generator & GENERATOR & STEAM-TURBINE & 25.6 MW generated; $34,308 \mathrm{HP}$ & & VENDOR \\
\hline P-601 & Collection Pump & PUMP & CENTRIFUGAL & 513 GPM; 4 brake HP; outlet pressure $=25$ psia & $\mathrm{cs}$ & QUESTIMATE \\
\hline P-602 & Condensate Pump & PUMP & CENTRIFUGAL & 190 GPM; 4 brake HP; outlet pressure $=25$ psia & SS304 & QUESTIMATE \\
\hline P-603 & Deaerator Feed Pump & PUMP & CENTRIFUGAL & 702 GPM; 14 brake HP; outlet pressure $=40$ psia & $\mathrm{cs}$ & QUESTIMATE \\
\hline P-604 & Boiler Feed Water Pump & PUMP & CENTRIFUGAL & 730 GPM; 759 brake HP; outlet pressure $=1,345$ psia & cs & QUESTIMATE \\
\hline T-601 & Condensate Collection Tank & TANK & $\begin{array}{l}\text { HORIZONTAL- } \\
\text { VESSEL }\end{array}$ & residence time $=10$ minutes; $H / D=2 ; 8 \mathrm{ft}$ diameter $; 17 \mathrm{ft}$ height & cs & QUESTIMATE \\
\hline
\end{tabular}




\begin{tabular}{|c|c|c|c|c|c|c|}
\hline \multicolumn{2}{|c|}{ EQUIPMENT_NUIEQUIPMENT_NAME } & \multicolumn{2}{|c|}{ EQUIPMENT_CATEGOIEQUIPMENT_TYPE } & \multirow{2}{*}{\begin{tabular}{|l} 
EQUIPMENT_DESCRIPTION \\
residence time $=10$ minutes; $\mathrm{H} / \mathrm{D}=2 ; 9 \mathrm{ft}$ diameter; $17 \mathrm{ft}$ height
\end{tabular}} & \multicolumn{2}{|c|}{\begin{tabular}{|l|l|} 
MATERIAL_CONS & COST_BASIS \\
\end{tabular}} \\
\hline $\mathrm{T}-602$ & Condensate Surge Drum & TANK & $\begin{array}{l}\text { HORIZONTAL- } \\
\text { VESSEL }\end{array}$ & & CS & QUESTIMATE \\
\hline T-603 & Deaerator & TANK & $\begin{array}{l}\text { HORIZONTAL- } \\
\text { VESSEL }\end{array}$ & liquid flow rate $=348,266 \mathrm{lb} / \mathrm{hr} ; 150 \mathrm{psig}$ design pressure; 10 min residence time & Cs;SS316 & VENDOR \\
\hline $\mathrm{T}-604$ & Steam Drum & TANK & $\begin{array}{l}\text { HORIZONTAL- } \\
\text { VESSEL }\end{array}$ & 424 gal, 4.5' x 4'dia, 15 psig & Cs & ICARUS \\
\hline S-601 & Blowdown Flash Drum & TANK & $\begin{array}{l}\text { HORIZONTAL- } \\
\text { VESSEL }\end{array}$ & $\begin{array}{l}\mathrm{H} / \mathrm{D}=2 \text {; residence time }=5 \mathrm{~min} ; 2 \mathrm{ft} \text { diameter } ; 4 \mathrm{ft} \text { height; op press }=1,280 \mathrm{psi} ; \text { op temp }= \\
575 \mathrm{~F}\end{array}$ & CS & QUESTIMATE \\
\hline \multicolumn{7}{|c|}{ PFD-P810-A701-2 } \\
\hline K-701 & Plant Air Compressor & COMPRESSOR & RECIPROCATING & $450 \mathrm{cfm}, 125 \mathrm{psig}$ outlet & $\mathrm{Cs}$ & ICARUS \\
\hline M-701 & Cooling Tower System & COOLING-TOWER & INDUCED-DRAFT & approx $16,500 \mathrm{gpm}, 140 \mathrm{MMBtu} / \mathrm{hr}$ & FIBERGLASS & DELTA-T98 \\
\hline M-702 & Hydraulic Truck Dump with Scale & SCALE & TRUCK-SCALE & Hydraulic Truck Dumper with Scale & cs & VENDOR \\
\hline M-703 & Flue Gas Stack & MISCELLANEOUS & MISCELLANEOUS & 42 inch diameter; $250 \mathrm{deg} \mathrm{F}$ & A515 & QUESTIMATE \\
\hline P-701 & Cooling Water Pump & PUMP & CENTRIFUGAL & 16,188 GPM; 659 brake HP; outlet pressure 75 psi & cs & QUESTIMATE \\
\hline P-702 & Firewater Pump & PUMP & CENTRIFUGAL & $2,500 \mathrm{gpm}, 50 \mathrm{ft}$ head & CS & ICARUS \\
\hline P-703 & Diesel Pump & PUMP & CENTRIFUGAL & $30 \mathrm{gpm}, 150 \mathrm{ft}$ head & Cs & ICARUS \\
\hline P-704 & Ammonia Pump & PUMP & CENTRIFUGAL & $8.5 \mathrm{gpm}, 22 \mathrm{ft}$ head & cs & ICARUS \\
\hline P-705 & Hydrazine Pump & PUMP & CENTRIFUGAL & $5 \mathrm{gpm}, 75 \mathrm{ft}$ head & CS & DELTA-T98 \\
\hline S-701 & Instrument Air Dryer & DRYER & PACKAGE & 400 SCFM Air Dryer, -40 F Dewpoint & cs & RICHARDSON \\
\hline $\mathrm{T}-701$ & Plant Air Receiver & TANK & $\begin{array}{l}\text { HORIZONTAL- } \\
\text { VESSEL }\end{array}$ & 900 gal., 200 psig & Cs & ICARUS \\
\hline $\mathrm{T}-702$ & Firewater Storage Tank & TANK & $\begin{array}{l}\text { FLAT-BTM- } \\
\text { STORAGE }\end{array}$ & 600,000 gal, $4 \mathrm{hr}$ res time, $51^{\prime}$ dia $\times 40^{\prime}$ high, atmospheric & A285C & ICARUS \\
\hline T-703 & Diesel Storage Tank & TANK & $\begin{array}{l}\text { FLAT-BTM- } \\
\text { STORAGE }\end{array}$ & $10,667 \mathrm{gal}, 120 \mathrm{hr}$ res time, $90 \% \mathrm{wv}, 10^{\prime}$ dia $\times 18.2^{\prime}$ high, atmospheric & A285C & ICARUS \\
\hline $\mathrm{T}-704$ & Ammonia Storage Tank & TANK & $\begin{array}{l}\text { HORIZONTAL- } \\
\text { STORAGE }\end{array}$ & Included in the cost of the feed handling step. & A515 & ICARUS \\
\hline $\mathrm{T}-705$ & Olivine Lock Hopper & TANK & VERTICAL-VESSEL & Included in the cost of the feed handling step. & CS & DELTA-T98 \\
\hline T-706 & MgO Lock Hopper & TANK & VERTICAL-VESSEL & $20^{\prime} \times 20^{\prime}$ Bin, Tapering to $3^{\prime} \times 3^{\prime}$ at Bottom. Capacity $6,345 \mathrm{cf}$, two truck loads. & cs & DELTA-T98 \\
\hline $\mathrm{T}-707$ & Hydrazine Storage Tank & TANK & VERTICAL-VESSEL & 260 gal, 4.9' x 3'dia., 10psig & SS316 & ICARUS \\
\hline \multicolumn{7}{|c|}{ PFD-P810-A801 } \\
\hline $\mathrm{H}-802 \mathrm{~N}$ & N2-compressor water cooled aftercooler & HEATX & SHELL-TUBE & duty $=0.3 \mathrm{MMBtu} / \mathrm{hr} ; \mathrm{LMTD}=25 \mathrm{~F} ; \mathrm{U}=150 \mathrm{Btu} / \mathrm{hr}-\mathrm{ft}^{\wedge} 2-\mathrm{F} ;$ area $=74 \mathrm{ft} \mathrm{t}^{\wedge} 2$;ixed TS & A214 & QUESTIMATE \\
\hline K-802N & post ASU N2 compressor & COMPRESSOR & CENTRIFUGAL & $\begin{array}{l}\text { Centrifugal compr - horiz.l; gas flow rate (actual) }=2042 \text { CFM, design inlet pres }=46 \text { psig; } \\
\text { design outlet pres }=440 \text { psig }\end{array}$ & CS & Aspen IPM \\
\hline M-802 & Air Separation Unit (ASU) including air compressor & MISCELLANEOUS & MISCELLANEOUS & Biomass and Bioenergy 23 (2002) 129-152, Tijmensen & & LITERATURE \\
\hline S-801N & Pre N2-compressor KO & SEPARATOR & KNOCK-OUT DRUM & $3 \mathrm{ft}$ diameter; $35 \mathrm{ft}$ height; design pres $=91 \mathrm{psia} ;$ design temp $=123 \mathrm{~F}$ & cs & QUESTIMATE \\
\hline S-802N & Post N2-compressor KO & SEPARATOR & KNOCK-OUT DRUM & $3 \mathrm{ft}$ diameter; $6 \mathrm{ft}$ height; design pres $=468 \mathrm{psia} ;$ design temp $=160 \mathrm{~F}$ & CS & QUESTIMATE \\
\hline K-802 & post ASU O2 compressor & COMPRESSOR & CENTRIFUGAL & $\begin{array}{l}\text { Centrifugal compr }- \text { horiz.; gas flow rate (actual) }=1530 \mathrm{CFM} \text {, design inlet pres=57 psig; } \\
\text { design outlet pres }=430 \text { psig; max interstage temp }=400 \mathrm{~F}\end{array}$ & Cs & Aspen IPM \\
\hline $\mathrm{S}-803$ & Pre O2-compressor KO & SEPARATOR & KNOCK-OUT DRUM & $3 \mathrm{ft}$ diameter; $35 \mathrm{ft}$ height; design pres $=91 \mathrm{psia} ;$ design temp $=123 \mathrm{~F}$ & $\mathrm{cs}$ & QUESTIMATE \\
\hline
\end{tabular}


Appendix C

Individual Equipment Cost Summary 


\begin{tabular}{|c|c|c|c|c|c|c|c|c|c|c|c|c|c|c|c|c|c|c|}
\hline $\begin{array}{c}\text { Equipment } \\
\text { Number }\end{array}$ & $\begin{array}{l}\text { Number } \\
\text { Required }\end{array}$ & $\begin{array}{l}\text { Number } \\
\text { Spares }\end{array}$ & Equipment Name & Scaling Stream & $\begin{array}{l}\text { Scaling Stream Flow } \\
\text { (Ib/hr or btullhr) }\end{array}$ & New Stream Flow & Size Ratio & $\begin{array}{l}\text { Original Equip } \\
\text { Cost (per unit) }\end{array}$ & Base Year & $\begin{array}{c}\text { Total Original Equip Cost } \\
\text { Req'd \& Spare) in Base } \\
\text { Year }\end{array}$ & Scaling Exp. & $\begin{array}{r}\text { Scaled Cost in Base } \\
\text { Year }\end{array}$ & $\begin{array}{l}\text { Instal } \\
\text { Factor }\end{array}$ & $\begin{array}{l}\text { Installed Cost in Base } \\
\text { Year }\end{array}$ & $\begin{array}{c}\text { Installed Cost in } \\
2005 s\end{array}$ & $\begin{array}{l}\begin{array}{l}\text { Saled Uninstalled Cost } \\
\text { in 2005s }\end{array} \\
\text { | }\end{array}$ & $\begin{array}{l}\text { Installed Cost in } \\
20075\end{array}$ & $\begin{array}{c}\text { Scaled Uninstalled } \\
\text { Cost in 20075 }\end{array}$ \\
\hline$c-101$ & 4 & & Hopper Fedder & STRM.A100.101 & 367,437 & 367,437 & 1.00 & so & 2002 & \$o & 0.75 & so & 2.47 & $\$ 0$ & so & so & so & so \\
\hline$c-102$ & 2 & & Screener Feeder Conveyor & STRM.A100.101 & 36,437 & 367,437 & 1.00 & sol & 2002 & so & 0.75 & so & 2.47 & so & so & so & so & so \\
\hline C-103 & 2 & & Radial Stacker Conveyor & STRM.A100.101 & 367,437 & 367,437 & 1.00 & so & 2002 & so & 0.75 & so & 2.47 & \$0 & so & so & so & so \\
\hline c-104 & 2 & & Dryer Feed Screw Conveyor & STRM.A100.101 & 367,437 & 367,437 & 1.00 & so & 2002 & so & 0.75 & so & 2.47 & \$0 & so & so & so & so \\
\hline C-105 & 2 & & Gasifier Feed Screw Conveyor & STRM.A100.104 & 208,771 & 193,388 & 0.93 & so & 2002 & \$0 & 0.75 & $\$ 0$ & 2.47 & $\$ 0$ & so & \$0 & \$o & \$0 \\
\hline H-AP-1 & 1 & & Hot Flue gas ICold AlCSepltToRef Exchanger & PINCH & $1,100,472$ & $1,100,472$ & 1.00 & $\$ 23,723$ & 2006 & $\$ 23,723$ & 0.65 & $\$ 23,723$ & 2.47 & $\$ 5,5966$ & $\$ 54,913$ & $\$ 22,232$ & $\$ 61,622$ & $\$ 24,948$ \\
\hline H-AP-2 & 1 & & Hot Flue gas I Cold SiteamSuperitt Exchanger & PINCH & $109,947,990$ & $109,947,990$ & 1.00 & $\$ 103,115$ & 2006 & $\$ 103,115$ & 0.65 & $\$ 103,115$ & 2.47 & $\$ 254,694$ & $\$ 238,686$ & $\$ 96,634$ & $\$ 267,847$ & $\$ 108,400$ \\
\hline H-AP-3 & 1 & & Hot Flue gas /Cold SteamGen Exchanger & PINCH & $4,689,295$ & $4,689,295$ & 1.00 & $\$ 24,123$ & 2006 & $\$ 24,123$ & 0.65 & $\$ 24,123$ & 2.47 & $\$ 59,584$ & $\$ 55,839$ & $\$ 22,607$ & $\$ 62,661$ & $\$ 25,369$ \\
\hline H-AP-4 & 1 & & Hot Flue gas / Cold WaterPreett Exchanger & PINCH & $80,143,108$ & $80,143,108$ & 1.00 & $\$ 72,115$ & 2006 & $\$ 72,115$ & 0.65 & $\$ 72,115$ & 2.47 & $\$ 178,124$ & $\$ 166,929$ & $\$ 67,583$ & $\$ 187,323$ & $\$ 75,839$ \\
\hline K-101 & 2 & & Flue Gas Blower & STRM.114 & 639,530 & 881,793 & 1.38 & so & 2002 & \$0 & 0.75 & so & 2.47 & \$0 & so & so & sol & so \\
\hline M-101 & 4 & & Hydraulic Truck Dump with Scale & STRM.A100.101 & 367,437 & 367,437 & 1.00 & so & 2002 & so & 0.75 & \$o & 2.47 & so & so & so & so & so \\
\hline M-102 & 2 & & Hammemill & STRM.A100.101 & 367,437 & 367,437 & 1.00 & so & 2002 & so & 0.75 & so & 2.47 & so & so & so & so & so \\
\hline$M-103$ & 3 & & Front End Loaders & STRM.A100.101 & 367,437 & 367,437 & 1.00 & so & 2002 & so & 0.75 & so & 2.47 & $\$ 0$ & so & so & so & so \\
\hline M-104 & 2 & & Rotary Biomass Dryer & STRM.A100.101 & 367,437 & 367,437 & 1.00 & $\$ 3,813,728$ & 2002 & $\$ 7,627,455$ & 0.75 & $\$ 7,627,450$ & 2.47 & $\$ 18,839,801$ & $\$ 22,297,257$ & $\$ 9,027,230$ & $\$ 25,021,313$ & $\$ 10,130,086$ \\
\hline s-101 & 2 & & Magnetic Head Pulley & STRM.A100.101 & 367,437 & 367,437 & 1.00 & so & 2002 & so & 0.75 & so & 2.47 & so & so & so & so & so \\
\hline s-102 & 2 & & Screener & STRM.A100.101 & 367,437 & 367,437 & 1.00 & so & 2002 & so & 0.75 & so & 2.47 & so & so & so & so & so \\
\hline s-103 & 2 & & Dyer Air Cyclone & STRM.A100.110 & 639,530 & 890,700 & 1.39 & so & 2002 & so & 0.75 & so & 2.47 & \$0 & so & so & so & so \\
\hline s-104 & 2 & & Dryer Air Baghouse Filter & $\begin{array}{l}\text { STRM.A100.103 } \\
\end{array}$ & 208,771 & 193,388 & 0.93 & so & 2002 & so & 0.75 & so & 2.47 & so & so & so & so & so \\
\hline$T-101$ & 4 & & Dump Hopper & STRM.A100.101 & 367,437 & 367,437 & 1.00 & so & 2002 & so & 0.75 & so & 2.47 & so & so & so & sol & so \\
\hline$T-102$ & 1 & & Hammemmil Surge Bin & STRM.A100.101 & 367,437 & 367,437 & 1.00 & so & 2002 & so & 0.75 & so & 2.47 & \$0 & so & so & so & so \\
\hline$T-103$ & 2 & & Dryer Feed Bin & STRM.A100.101 & 367,437 & 367,437 & 1.00 & so & 2002 & so & 0.75 & so & 2.47 & so & so & so & so & 50 \\
\hline T-104 & 2 & & Dried Biomass Hopper & STRM.A100.104 & 208,771 & 193,388 & 0.93 & so & 2002 & so & 0.75 & so & 2.47 & so & so & so & so & so \\
\hline$T-105$ & 2 & & Lock Hopper & STRM.A100.104 & 367,437 & 193,388 & 0.53 & so & 2002 & so & 0.75 & so & 2.47 & \$0 & so & so & so & so \\
\hline$T-106$ & 2 & & Feed Hopper & STRM.A100.104 & 208,771 & 193,388 & 0.93 & so & 2002 & so & 0.75 & \$o & 2.47 & so & so & so & so & so \\
\hline & & & & & & & & & & & & & & & & & & \\
\hline A100 & & & & & & & & & Subtotal & $\begin{array}{ll}7,850,531 \\
\end{array}$ & & \begin{tabular}{|l|l}
$57,850,526$ \\
\end{tabular} & 2.47 & $\$ 19,390,799$ & 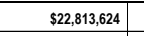 & \begin{tabular}{|l|l|l|l}
$99,23,285$ \\
\end{tabular} & \begin{tabular}{|l|l|}
$\$ 25,600,765$ \\
\end{tabular} & $\$ 10,364,682$ \\
\hline & & & & & & & & & & & & & & & & & & \\
\hline C-201 & 1 & & Sandlash ConditioneriConveyor & STRM.A200.219 & 7,380 & 13,509 & 1.83 & so & 2002 & so & 0.65 & so & 2.47 & so & so & so & so & so \\
\hline c-202 & 1 & & MgO Screw Conveyor & STRM.A200.219 & 7,380 & 13,509 & 1.83 & so & 2002 & so & 0.65 & so & 2.47 & 50 & so & so & $\$ 0$ & so \\
\hline c-203 & 1 & & Olivine Screw Conveyor & STRM.A200.219 & 7,380 & 13,509 & 1.83 & so & 2002 & 50 & 0.65 & so & 2.47 & 50 & so & so & s0 & so \\
\hline M-201 & 2 & & $\begin{array}{l}\text { Sandlash Cooler } \\
\end{array}$ & STRM.A200.217 & 6,642 & 12,158 & 1.83 & so & 2002 & so & 0.65 & so & 2.47 & 50 & so & so & $\$ 0$ & so \\
\hline R-201 & 2 & & Directly Heated Gasfifer & STRM.A200.201 & 208,770 & 138,087 & 0.66 & $\$ 5,542,673$ & 2002 & $\$ 11,085,347$ & 0.65 & $\$ 8,473,522$ & 2.47 & $\$ 20,929,599$ & $\$ 24,770,572$ & $\$ 10,028,572$ & $\$ 227,796,794$ & $\$ 11,253,763$ \\
\hline$s-201$ & 2 & & Primary Gasfifie Cydone & STRM._200.202 & $5,228,880$ & 276,174 & 0.05 & so & 2002 & so & 0.65 & so & 2.47 & so & so & so & so & so \\
\hline s-202 & 2 & & Secondary Gasifier Cyclone & STRM.A200.222 & 246,484 & 264,120 & 1.07 & so & 2002 & $\$ 0$ & 0.65 & so & 2.47 & so & so & so & so & so \\
\hline T-201 & 1 & & Sand/ash Bin & STRM.А200.222 & 6.642 & 264,20 & 39.77 & so & 2002 & so & 0.65 & so & 2.47 & so & \$0 & so & so & so \\
\hline & & & & & & & & & & & & & & & 7 & & & \\
\hline A200 & & & & & & & & & Subtotal & \begin{tabular}{|l|l|}
$s 11,085,347$ \\
\end{tabular} & & $\begin{array}{l}\$ 8,473,522 \\
\end{array}$ & 2.47 & $\$ 20,929,599$ & \begin{tabular}{l|l|}
$24,770,572$ \\
\end{tabular} & $\$ 11,028,572$ & \begin{tabular}{|l|l}
$\$ 27,796,794$ \\
\end{tabular} & $\$ 11,253,763$ \\
\hline & & & & & & & & & & & & & & & & & & \\
\hline s-306 & 1 & & Tar Refómer Cyclone & STRM.А30.A300TR.325A & 244,995 & 481,871 & 1.99 & so & 2002 & so & 0.65 & so & 2.47 & so & so & so & so & so \\
\hline H-AP-5 & 1 & & Cold FCAirPreett Hot Watersilwdn Exchanger & $\begin{array}{lll}\text { PINCH } \\
\end{array}$ & 285,327 & 285,327 & 1.00 & $\$ 24,323$ & 2006 & $\$ 24,323$ & 0.65 & $\$ 24,323$ & 2.47 & 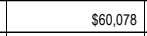 & \begin{tabular}{|c|}
556,302 \\
\end{tabular} & $\$ 22,794$ & $\$ 63,180$ & $\$ 25,579$ \\
\hline H-AP-6 & 1 & & Hot RefiEkhauench /Cold SiteamGen Exchanger & PINCH & $112,484,802$ & $112,484,802$ & 1.00 & $\$ 87,215$ & 2006 & $\$ 87,215$ & 0.65 & $\$ 87,215$ & 2.47 & $\$ 215,421$ & $\$ 201,882$ & $\$ 81,734$ & $\$ 226,546$ & $\$ 91,719$ \\
\hline H.AP-8 & 1 & & Hot RerExhhQuench/Cold AlCSynPreett Exchanger & PINCH & $35,051,271$ & $35,051,271$ & 1.00 & $\$ 689,447$ & 2006 & $\$ 689,447$ & 0.65 & $\begin{array}{l}689,447 \\
\end{array}$ & 2.47 & $\$ 1,702,934$ & $\$ 1,595,904$ & $\$ 646,115$ & $\$ 1,790,876$ & $\$ 725,051$ \\
\hline H-AP-10 & 1 & & Hot RefExhQuench /Cold RefBleedPreAt Exchanger & PINCH & $11,080,311$ & $11,080,311$ & 1.00 & $\$ 131,015$ & 2006 & $\$ 131,015$ & 0.65 & $\$ 131,015$ & 2.47 & $\$ 323,607$ & $\$ 303,268$ & $\$ 122,781$ & $\$ 340,319$ & $\$ 137,781$ \\
\hline H-BP-4 & 1 & & Cold FCAirretett/Hot Reformate Exchanger & PINCH & $9,790,141$ & $9,790,141$ & 1.00 & $\$ 87,215$ & 2006 & $\$ 87,215$ & 0.65 & $\$ 87,215$ & 2.47 & $\$ 215,421$ & $\$ 201,882$ & $\$ 81,734$ & $\$ 226,546$ & $\$ 91,719$ \\
\hline H-BP-7 & 1 & & Cold RefibledPreett Hot Reformate Exchanger & PINCH & 755,215 & 755,215 & 1.00 & $\$ 24,050$ & 2006 & $\$ 24,050$ & 0.65 & $\$ 24,050$ & 2.47 & $\$ 59,404$ & $\$ 55,670$ & $\$ 22,538$ & $\$ 662,471$ & $\$ 25,292$ \\
\hline
\end{tabular}




\begin{tabular}{|c|c|c|c|c|c|c|c|c|c|c|c|c|c|c|c|c|c|c|}
\hline $\begin{array}{l}\text { Equipment } \\
\text { Number }\end{array}$ & $\begin{array}{l}\text { Number } \\
\text { Required }\end{array}$ & $\begin{array}{l}\text { Number } \\
\text { Spares }\end{array}$ & Equipment Name & Scaling Stream & $\begin{array}{c}\text { Scaling Stream Flow } \\
\text { (blhhror btuhlr) }\end{array}$ & New Stream Flow & Size Ratio & $\begin{array}{l}\text { Original Equip } \\
\text { cost (per unit) }\end{array}$ & Base Year & \begin{tabular}{|c|}
$\begin{array}{c}\text { Total Original Equip Cost } \\
\text { Reg'd } 8 \text { Spare) in Base } \\
\text { Year }\end{array}$ \\
\end{tabular} & Scaling Exp. & $\begin{array}{r}\text { Scaled Cost in Base } \\
\text { Year }\end{array}$ & $\begin{array}{l}\text { Instal } \\
\text { Factor }\end{array}$ & $\begin{array}{l}\text { Installed Cost in Base } \\
\text { Year }\end{array}$ & \begin{tabular}{c|c} 
Installed Cost in \\
2005s
\end{tabular} & $\begin{array}{c}\text { Scaled Uninstalled Cost } \\
\text { in } 20055\end{array}$ & $\begin{array}{l}\text { Installed Cost in } \\
20075\end{array}$ & $\begin{array}{c}\text { Scaled Uninstalled } \\
\text { Costin } 20075\end{array}$ \\
\hline H-BP-12 & 1 & & Cold Water /Hot Reformate Exchanger & PINCH & $5,451,970$ & $5,451,970$ & 1.00 & $\$ 26,115$ & 2006 & $\$ 26,115$ & 0.65 & $\$ 26,115$ & 2.47 & $\$ 64,504$ & $\$ 60,450$ & $\$ 24,474$ & $\$ 67,835$ & $\$ 27,464$ \\
\hline H-BP-13 & 1 & & Cold RefibledPreatt Hot Reformate Exchanger & PINCH & $1,030,540$ & $1,030,540$ & 1.00 & $\$ 24,315$ & 2006 & $\$ 24,315$ & 0.65 & $\$ 24,315$ & 2.47 & $\$ 60,058$ & $\$ 56,283$ & $\$ 22,787$ & $\$ 63,160$ & $\$ 25,571$ \\
\hline H-BP-15 & 1 & & Cold FCAirprett /Hot Reformate Exchanger & PINCH & $14,257,111$ & $14,257,111$ & 1.00 & $\$ 92,515$ & 2006 & $\$ 92,515$ & 0.65 & 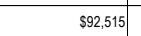 & 2.47 & $\$ 228,512$ & $\$ 214,150$ & $\$ 86,700$ & $\$ 240,313$ & 997,293 \\
\hline K-305 & 1 & & Regeneratator Combustion Air Blower & $\begin{array}{l}\text { STRM.A300.A300TR.A300FC.329 } \\
\end{array}$ & 304,578 & 582,915 & 1.91 & $\$ 35,020$ & 2002 & $\$ 35,020$ & 0.59 & \begin{tabular}{c|c|c|}
51,362 \\
\end{tabular} & 2.47 & $\$ 126,864$ & $\$ 150,146$ & $\$ 60,788$ & $\$ 168,489$ & $\$ 68,214$ \\
\hline K-313 & 1 & & Blower for Dyer Exhaust to Fuel Combustor & STRM.A300.A300TR.A300FC.113 & 8,907 & 8,907 & 1.00 & $\$ 7,521$ & 2006 & 57,521 & 0.59 & $\$ 7,521$ & 2.47 & $\$ 18,577$ & $\$ 17,409$ & $\$ 7,048$ & $\$ 19,536$ & $\$ 7,009$ \\
\hline R-303 & 1 & & Tar Reformer & STRM.A300.A300TR.325A & 208,770 & 481,871 & 2.31 & $\$ 5,542,673$ & 2002 & $\$ 5,542,673$ & 0.65 & $\$ 9,546,404$ & 2.47 & $\$ 23,579,618$ & $\$ 27,906,918$ & $\$ 11,298,348$ & $\$ 31,316,307$ & $\$ 12,678,667$ \\
\hline$R-301 \mathrm{~A}$ & 1 & & Tar Reformer Catalyst Regenerator & STRM.A300.A30TR.325A & 234,433 & 481,871 & 2.06 & $\$ 2,429,379$ & 2002 & $\$ 2,429,379$ & 0.65 & $\$ 3,880,502$ & 2.47 & $99,584,839$ & $\$ 11,343,336$ & $\$ 4,592,646$ & $\$ 12,729,713$ & $\$ 5,153,730$ \\
\hline H-301 & 1 & & Quench Water Recirculation Cooler & STRM.A300.A300Q.301 & 241,995 & 481,871 & 1.99 & so & 2002 & \$0 & 0.44 & so & 2.47 & so & so & so & so & so \\
\hline $\mathrm{H}-303$ & 1 & & Water-cooled Affercooler & HЕАТ.А700.वСCH303СТ & $2,938,799$ & $3,803,978$ & 1.29 & $\$ 20,889$ & 2002 & $\$ 20,889$ & 0.44 & $\$ 23,401$ & 2.47 & $\$ 57,800$ & 968,407 & $\$ 27,695$ & \begin{tabular}{c|c|c|c|}
576,764 & &
\end{tabular} & $\$ 31,079$ \\
\hline H-301c-1 & 1 & & \begin{tabular}{|l|} 
Pre-syngas water Knockout, water-cooled exchanger \\
\end{tabular} & HEAT.A300.A3000.QCH301C & $14,024,659$ & $14,024,660$ & 1.00 & $\$ 55,715$ & 2006 & $\$ 55,715$ & 0.6 & $\$ 55,715$ & 2.47 & $\$ 137,616$ & \begin{tabular}{|l|l|l|l|l|} 
\\
128,967
\end{tabular} & $\$ 52,213$ & $\$ 144,723$ & $\$ 58,592$ \\
\hline H-306 & 1 & & Waste Water Cooler / Cooling Water & HEAT.A300.A3000..QCH306 & 478.964 & 478,964 & 1.00 & $\$ 3,423$ & 2006 & $\$ 3,423$ & 0.44 & $\$ 3,423$ & 2.47 & $\$ 8,455$ & $\$ 7,923$ & $\$ 3,208$ & $\$ 8,891$ & $\$ 3,600$ \\
\hline M-300 & 1 & & Fuel Mixer for Combustor & STRM.A300.A300TR.A300FC.328 & 241,496 & 133,736 & 0.55 & so & 2002 & so & 0.65 & so & 2.47 & so & so & so & so & so \\
\hline M-30OH & 1 & & Mixer Prior to Tar Reformer & STRM.A300.A300TR.386 & 241,496 & 325,315 & 1.35 & so & 2002 & so & 0.65 & so & 2.47 & so & so & so & so & so \\
\hline M-330 & 1 & & Mixer Prior to Reformate Quench & STRM.A300.A300TR.330 & 241,496 & 481,871 & 2.00 & so & 2002 & so & 0.65 & so & 2.47 & so & so & so & so & so \\
\hline M-301 & 1 & & Syngas Quench Chamber & STRM.A300.A3000.301 & 241,496 & 481,871 & 2.00 & so & 2002 & so & 0.65 & so & 2.47 & so & so & so & so & so \\
\hline M-302 & 1 & & Syngas Venturi Scrubber & STRM.A300.A300Q.301 & 241,496 & 481,871 & 2.00 & so & 2002 & so & 0.65 & so & 2.47 & so & so & so & so & so \\
\hline P-301 & 1 & 1 & Sudge Pump & STRM.A300.A300Q.336 & 997 & 1 & 0.00 & $\$ 3,911$ & 2002 & $\$ 7,822$ & 0.33 & $\$ 862$ & 2.47 & $\$ 2,128$ & $\$ 2,519$ & $\$ 1,020$ & $\$ 2,827$ & $\$ 1,144$ \\
\hline M-312A & 1 & & Mixer In Syngas Quench Exchangers Train & STRM.A300.A30AGR.331 & 241,496 & 388,067 & 1.61 & so & 2002 & s0 & 0.65 & so & 2.47 & so & so & so & so & so \\
\hline SP-312B & 1 & & Flow Split I Syngas Quench Exchangers Train & STRM.A300.A300AGR.331 & 241,496 & 388,067 & 1.61 & so & 2002 & so & 0.65 & so & 2.47 & so & so & so & so & so \\
\hline SP-330 & 1 & & Flow Split Before Reformer Exhaust Quench Exchangers & STRM.A300.A300AGR.331 & 241,496 & 388,067 & 1.61 & so & 2002 & so & 0.65 & so & 2.47 & so & so & so & sol & so \\
\hline P-302 & 1 & 1 & Quench Water Recirculation Pump & STRM.A300.A3000.307 & $1,272,120$ & 27,104 & 0.02 & so & 2002 & so & 0.65 & so & 2.47 & so & so & so & so & so \\
\hline P-303 & 1 & 1 & LO-CAT Absorbent Solution Circulating Pump & STRM.A300.A3000.301 & 241,496 & 481,871 & 2.00 & so & 2002 & so & 0.65 & so & 2.47 & so & so & so & so & so \\
\hline s-301 & 1 & & Syngas Recyde Water Knockout Vessel & STRM.A300.A300Q.315 & 220,009 & 388,895 & 1.77 & $\$ 157,277$ & 2002 & $\$ 157,277$ & 0.6 & $\$ 221,361$ & 2.47 & $\$ 546,760$ & $\$ 647,101$ & $\$ 261,984$ & s726,158 & $\$ 223,991$ \\
\hline s-303 & 1 & & Pre-Amine System Knock-out & STRM.A300.A300Q.318 & 179,394 & 388,895 & 2.17 & $\$ 40,244$ & 2002 & $\$ 40,244$ & 0.6 & 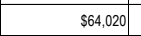 & 2.47 & $\$ 158,129$ & $\$ 187,149$ & $\$ 75,769$ & $\$ 210,013$ & $\$ 85,026$ \\
\hline T-301 & 1 & & Sludge Setting Tank & $\begin{array}{ll}\text { STRM.A300.A3000.302 } \\
\end{array}$ & 21,718 & 2,136 & 0.10 & $\$ 11,677$ & 2002 & $\$ 11,677$ & 0.6 & $\$ 2,904$ & 2.47 & \begin{tabular}{c|c|}
5,174 \\
\end{tabular} & $\$ 8,490$ & $\$ 3,437$ & $\$ 9,528$ & \$3,857 \\
\hline$T-302$ & 1 & & Quench Water Recirculation Tank & $\begin{array}{l}\text { STRM.A300.A300Q.301 } \\
\end{array}$ & 241,496 & 481,871 & 2.00 & so & 2002 & so & 0.65 & so & 2.47 & so & so & so & so & so \\
\hline H-304-1 & 1 & & LO-CAT Preheater/Stitam & A300.A300S.OH304 & 267,157 & 267,157 & 1.00 & $\$ 2,423$ & 2006 & $\$ 2,423$ & 0.6 & $\$ 2,423$ & 2.47 & $\$ 5,985$ & 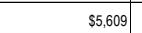 & $\$ 2,271$ & $\$ 6,294$ & \$2,548 \\
\hline H-305 & 1 & & LO-CAT Absorbent Solution Cooler & STRM.A300.A300S.320 & 179,394 & 19,165 & 0.66 & so & 2002 & so & 0.44 & so & 2.47 & so & so & so & so & so \\
\hline K-302 & 1 & & LO.CAT Feed Air Blower & $\begin{array}{ll}\text { STRM.A300.A300S.322 } \\
\end{array}$ & 359 & 211 & 0.59 & so & 2002 & so & 0.65 & so & 2.47 & so & so & so & so & so \\
\hline K-373 & 1 & & LLight:Ends for Alcohol Sep to Reformer Compressor & WORK.A300.A300TR.WK373 & 678 & 211 & 0.31 & $\$ 403,122$ & 2002 & $\$ 403,122$ & 0.8 & $\$ 158,437$ & 2.47 & $\$ 391,339$ & $\$ 463,157$ & $\$ 187,513$ & $\$ 519,740$ & $\$ 210,421$ \\
\hline K-3834 & 1 & & C02 Recycle into Tar Reformer & STRM.A300.A3005.384REC & 45,330 & 45,330 & 1.00 & $\$ 337,092$ & 2006 & $\$ 337,092$ & 0.59 & $\$ 337,090$ & 2.47 & $\$ 832,613$ & $\$ 780,283$ & $\$ 315,904$ & $\$ 875,611$ & $\$ 354,498$ \\
\hline M-303 & 1 & & LO-CAT Ventur Precontactor & STRM.A300.A3005.323 & 517 & 304 & 0.59 & so & 2002 & so & 0.65 & so & 2.47 & so & so & so & so & 80 \\
\hline M.304 & 1 & & $\begin{array}{l}\text { Lo-CAT Liquid-filled Absorber } \\
\end{array}$ & STRM.A300.A300S.320 & 179,394 & 119,165 & 0.66 & so & 2002 & so & 0.65 & so & 2.47 & so & so & so & so & 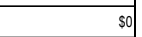 \\
\hline$R \cdot 304$ & 1 & & \begin{tabular}{|l} 
LO-CAT Oxidizer Vessel \\
\end{tabular} & STRM.A300.A300S.323 & 517 & 304 & 0.59 & $\$ 1,000,000$ & 2002 & $\$ 1,000,000$ & 0.65 & \begin{tabular}{l|l}
708,245 \\
\end{tabular} & 2.47 & $\$ 1,749,366$ & $\$ 2,070,408$ & $\$ 838,222$ & $\$ 2,323,349$ & $\$ 940,627$ \\
\hline \multirow[t]{2}{*}{ s:310 } & 1 & & L.P. Anine System & STRM.A300.A300AGR.331 & 263,170 & 388.067 & 1.47 & $\$ 3,485,685$ & 2002 & $\$ 3,485,685$ & 0.75 & $\$ 4,664,349$ & 2.47 & $\$ 11,520,941$ & $\$ 13,635,250$ & $\$ 5,520,344$ & $\$ 15,301,068$ & $\$ 6,194,764$ \\
\hline & & & & & & & & & & & & & & & & & & \\
\hline \multirow[t]{2}{*}{ A300 } & & & & & & & & & Subtotal & $\begin{array}{l}\$ 14,726,172 \\
\end{array}$ & & $\begin{array}{l}\$ 20,914,228 \\
\end{array}$ & 2.47 & $\begin{array}{l}\$ 51,658,143 \\
\end{array}$ & $\begin{array}{l}\$ 50,169,364 \\
\end{array}$ & $\begin{array}{l}\$ 24,360,066 \\
\end{array}$ & $\begin{array}{l}967,520,256 \\
\end{array}$ & $\begin{array}{l}527,336,136 \\
\end{array}$ \\
\hline & & & & & & & & & & & & & & & & & & \\
\hline K-410 & 1 & & Mixed Alcohol Gas Compressor & WORK.A400.A400CMPR.WK410 & 10,617 & 9,167 & 0.86 & $\$ 851,523$ & 2002 & $\$ 851,523$ & 0.8 & $\$ 757,160$ & 2.47 & $\$ 1,870,186$ & $\$ 2,213,401$ & $\$ 896,114$ & $\$ 2,483,812$ & $\$ 1,005,592$ \\
\hline K-412 & 1 & & Purge Gas Expander & WORK.A400.WK412 & 2,500 & 9,540 & 3.82 & $\$ 642,014$ & 2002 & $\begin{array}{l}642,014 \\
\end{array}$ & 0.8 & $\$ 1,874,278$ & 2.47 & $\$ 4,629,466$ & $\$ 5,479,059$ & $\$ 2,218,243$ & $\$ 6,148,436$ & $\$ 2,489,245$ \\
\hline H-AP-9 & 1 & & Hot RefExhhuench Cold AlcSyunnRXToRef Exchanger & PINCH & $118,523,406$ & $118,523,406$ & 1.00 & $\$ 3,265,799$ & 2006 & $\$ 3,265,799$ & 0.65 & $\$ 3,265,799$ & 2.47 & $\$ 8,066,524$ & $\$ 7,559,540$ & $\$ 3,060,543$ & $\$ 8,483,089$ & $\$ 3,434,449$ \\
\hline H-AP-11 & 1 & & Hot Alc.R.E.EXx. ICold Waterpreett Exchanger & PINCH & $29,355,899$ & $29,355,899$ & 1.00 & $\$ 114,315$ & 2006 & $\$ 114,315$ & 0.65 & $\$ 114,315$ & 2.47 & $\$ 282,358$ & $\$ 264,612$ & $\$ 107,130$ & $\$ 2296,939$ & $\$ 120,218$ \\
\hline H-AP-12 & 1 & & Hot Wateril wan/ Cold WaterPreett Exchanger & PINCH & $1,767,803$ & $1,767,803$ & 1.00 & $\$ 20,958$ & 2006 & $\$ 22,958$ & 0.65 & $\$ 20,958$ & 2.47 & $\$ 51,766$ & $\$ 48,513$ & $\$ 19,641$ & $\$ 54,440$ & $\$ 22,040$ \\
\hline H-BP-1 & 1 & & Hot Reformate /Cold AlcSypreett Exchanger & PINCH & $7,628,739$ & $7,628,739$ & 1.00 & $\$ 93,215$ & 2006 & 993,215 & 0.65 & 993,215 & 2.47 & $\$ 230,241$ & $\$ 215,770$ & $\$ 87,356$ & $\$ 242,131$ & $\$ 98,029$ \\
\hline H-BP.5 & 1 & & Hot Reformate/ /Cold AlcSynUnRx Exchanger & PINCH & $6,030,150$ & $6,030,150$ & 1.00 & $\$ 71,315$ & 2006 & $\$ 71,315$ & 0.65 & $\$ 71,315$ & 2.47 & $\$ 176,148$ & $\$ 165,077$ & $\$ 66,833$ & $\$ 185,245$ & $\$ 74,998$ \\
\hline
\end{tabular}




\begin{tabular}{|c|c|c|c|c|c|c|c|c|c|c|c|c|c|c|c|c|c|c|}
\hline $\begin{array}{l}\text { Equipment } \\
\text { Number }\end{array}$ & $\begin{array}{l}\text { Number } \\
\text { Required }\end{array}$ & $\begin{array}{l}\text { Number } \\
\text { Spares }\end{array}$ & Equipment Name & Scaling Stream & $\begin{array}{c}\text { Scaling Stream Flow } \\
\text { (blhhr or buthlhr) }\end{array}$ & New Stream Flow & Size Ratio & $\begin{array}{l}\text { Original Equip } \\
\text { Cost (per unit) }\end{array}$ & Base Year & \begin{tabular}{|c} 
Total Original Equip Cost \\
(Req'd \& Spare) in Base \\
Year
\end{tabular} & Scaling Exp. & $\left|\begin{array}{r}\text { Scaled Cost in Base } \\
\text { Year }\end{array}\right|$ & \begin{tabular}{|l|} 
Instal \\
Factor \\
\end{tabular} & \begin{tabular}{|l} 
Installed Cost tin Base \\
Year
\end{tabular} & $\begin{array}{l}\text { Installed Cost tin } \\
\text { 2005s }\end{array}$ & $\left|\begin{array}{c}\text { Scaled Uninstalled cost } \\
\text { in } 20055\end{array}\right|$ & $\begin{array}{l}\text { Installed Cost in } \\
\text { 20075 }\end{array}$ & $\begin{array}{c}\text { Scaled Uninstalled } \\
\text { Costi in } 20075\end{array}$ \\
\hline H-BP-10 & 1 & & Hot Reformate ICold Alcsypresth Exchanger & PINCH & $6,680,484$ & $6,680,484$ & 1.00 & $\$ 56,515$ & 2006 & $\$ 56,515$ & 0.65 & $\$ 56,515$ & 2.47 & $\$ 139,592$ & $\$ 130,819$ & $\$ 52,963$ & $\$ 146,801$ & $\$ 59,434$ \\
\hline H-BP-14 & 1 & & Hot Reformatele Cold AlcSynUnRx Exchanger & PINCH & $10,638,427$ & $10,638,427$ & 1.00 & $\$ 76,415$ & 2006 & $\$ 76,415$ & 0.65 & $\$ 76,415$ & 2.47 & $\$ 188,745$ & $\$ 176,882$ & $\$ 71,612$ & $\$ 198,492$ & $\$ 80,361$ \\
\hline H-BP-17 & 1 & & Hot Alc.Rx.Exh. ICold Water Exchanger & PINCH & $7,786,153$ & $7,786,153$ & 1.00 & $\$ 6,415$ & 2006 & $\$ 68,415$ & 0.65 & 968,415 & 2.47 & $\$ 168,985$ & $\$ 158,364$ & $\$ 64,115$ & $\$ 177,712$ & $\$ 71,948$ \\
\hline K-414A & 1 & & Mixed Alcohol Recycle Gas Compressor & $\begin{array}{l}\text { STRM.A400.478 } \\
\end{array}$ & 217 & 217 & 1.00 & $\$ 124,749$ & 2006 & $\$ 124,749$ & 0.8 & $\$ 124,893$ & 2.47 & $\$ 308,485$ & 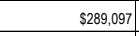 & $\$ 117,043$ & $\$ 324,416$ & $\$ 131,342$ \\
\hline H-414-1 & 1 & & Mixed Acohol Condenser & A400.0CH414 & $4,427,038$ & 4,427,039 & 1.00 & $\$ 34,015$ & 2006 & $\$ 34,015$ & 0.44 & $\begin{array}{l}34,015 \\
\end{array}$ & 2.47 & $\$ 84,017$ & \begin{tabular}{|c|c|}
578,737 \\
\end{tabular} & $\$ 31,877$ & $\$ 88,356$ & $\$ 35,772$ \\
\hline H.413 & 1 & & Mixed Alcohol first Condenser (air cooled) & WORK.A900.WK413FAN & 88 & 110 & 1.24 & $\$ 51,431$ & 1990 & $\$ 51,431$ & 1 & $\$ 51,431$ & 2.47 & $\$ 127,034$ & $\$ 166,324$ & $\$ 67,337$ & $\$ 186,643$ & $\$ 75,564$ \\
\hline s.501 & 1 & & Mixed Alcohols Condensation Knock-out & $\begin{array}{l}\text { STRM.A400.472 } \\
\end{array}$ & 142,038 & 273,514 & 1.93 & $\$ 5,447$ & 2002 & $\$ 55,447$ & 0.6 & $\$ 82,153$ & 2.47 & $\$ 202,918$ & 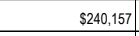 & $\$ 97,230$ & $\$ 269,497$ & $\$ 109,108$ \\
\hline R.410 & 1 & & Mixed Alcohol Reactor & STRM.A400.470 & 847,552 & 273,514 & 0.32 & $\$ 2,026,515$ & 2002 & $\$ 2,026,515$ & 0.56 & $\$ 1,075,686$ & 2.47 & $\$ 2,656,944$ & $\$ 3,144,543$ & $\$ 1,273,094$ & $\$ 3,528,712$ & $\$ 1,428,628$ \\
\hline SP-470 & 1 & & Flow Split Before Alc.Syn. Below Pinch Exchangers & STRM.A400.470 & 241,496 & 273,514 & 1.13 & so & 2002 & \$o & 0.65 & so & 2.47 & $\$ 0$ & so & so & so & so \\
\hline \multirow[t]{2}{*}{ M-470A } & 1 & & Mixer Affer Alc.Syn. Below Pinch Exchangers & STRM.A400.470 & 241,496 & 273,514 & 1.13 & so & 2002 & so & 0.65 & so & 2.47 & $\$ 0$ & so & so & so & so \\
\hline & & & & & & & & & & & & & & & & & & \\
\hline \multirow[t]{2}{*}{$A 400$} & & & & & & & & & Subtotal & $\$ 7,552,641$ & & \begin{tabular}{ll|l}
$57,76,563$ \\
\end{tabular} & 2.47 & $\$ 19,183,410$ & $\$ 20,330,895$ & \begin{tabular}{ll|}
$88,231,132$ \\
\end{tabular} & \begin{tabular}{|l|l|l}
$\$ 22,814,721$ \\
\end{tabular} & $\$ 9,236,729$ \\
\hline & & & & & & & & & & & & & & & & & & \\
\hline H.513 & 1 & & Mol Sieve Fush Condenser (air coolede) & $\begin{array}{ll}\text { WORK.A900.WK513FAN } \\
\end{array}$ & 60 & 11 & 0.18 & $\$ 20,678$ & 1990 & $\$ 20,678$ & 1 & $\$ 20,678$ & 2.47 & $\$ 51,075$ & $\$ 66,871$ & $\$ 27,073$ & $\$ 57,041$ & $\$ 30,381$ \\
\hline H.504C & 1 & & D. 504 condenser (air cooled) & $\begin{array}{l}\text { WORK.A900.WK504FAN } \\
\end{array}$ & 82 & 45 & 0.55 & $\$ 36,248$ & 1990 & $\$ 36,248$ & 1 & $\$ 36,248$ & 2.47 & $\$ 89,533$ & $\$ 117,224$ & $\$ 47,459$ & $\$ 131,545$ & $\$ 53,257$ \\
\hline H.505C & 1 & & D.505 condenser (air cooled) & $\begin{array}{l}\text { WORK.A900.WK505FAN } \\
\end{array}$ & 285 & 137 & 0.48 & $\$ 56,196$ & 1990 & $\$ 56,196$ & 1 & $\$ 56,196$ & 2.47 & $\$ 138,803$ & $\$ 181,733$ & $\$ 77,576$ & $\$ 203,935$ & $\$ 82,565$ \\
\hline M-500B & 1 & & Mol-Sieve Off Gas Mixer & STRM.A500.505 & 241,496 & 52,573 & 0.22 & so & 2002 & so & 0.65 & 50 & 2.47 & $\$ 0$ & so & 50 & so & so \\
\hline $\begin{array}{l}\mathrm{s}-503 \\
\end{array}$ & 1 & & Molecular Sieve (9 pieces) & STRM.A500.505 & 45,175 & 52,573 & 1.16 & $\$ 904,6955$ & 1998 & $\$ 904,6955$ & 0.7 & $\$ 1,006,028$ & 2.47 & $\$ 2,484,888$ & \begin{tabular}{ll|l}
$2,986,970$ \\
\end{tabular} & $\$ 1,209,300$ & 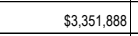 & $\$ 1,357,040$ \\
\hline s.502 & 1 & & LP Syngas Separator & STRM.A500.503 & 142,038 & 56,202 & 0.40 & $\$ 55,447$ & 2002 & $\$ 55,447$ & 0.6 & $\$ 31,790$ & 2.47 & $\$ 78,520$ & \begin{tabular}{c|c|}
92,930 \\
\end{tabular} & \begin{tabular}{|l|l|}
37,624 \\
\end{tabular} & $\$ 104,283$ & $\$ 42,220$ \\
\hline 0.504 & 1 & & Ehthoolipropanol Splitter & DD504 & 13.5 & 6.0 & 0.45 & $\$ 478,100$ & 1998 & $\$ 478,100$ & 1.32 & $\$ 165,100$ & 2.1 & $\$ 346,709$ & $\$ 416,763$ & $\$ 198,459$ & $\$ 467,679$ & $\$ 222,704$ \\
\hline 0.505 & 1 & & MethanollEhanol Splitter & DD505 & 13.5 & 6.5 & 0.48 & $\$ 478,100$ & 1998 & $\$ 478,100$ & 1.32 & $\$ 183,212$ & 2.1 & $\$ 384,745$ & $\$ 462,4855$ & $\$ 220,231$ & $\$ 518,986$ & $\$ 247,136$ \\
\hline H-504R & 1 & & EthanollPropanol Splitter Reboiler & $\begin{array}{l}\text { HEAT.A500.A504.QRHH504 } \\
\end{array}$ & $-112,341,710.7$ & $\begin{array}{lll}-16,430,402 \\
\end{array}$ & 0.15 & $\$ 158,374$ & 1996 & $\$ 158,374$ & 0.68 & \begin{tabular}{|l|l|}
$\$ 42,851$ \\
\end{tabular} & 2.1 & \begin{tabular}{c|c|c|}
589,986 \\
\end{tabular} & $\$ 110,379$ & $\$ 52,561$ & $\$ 123,864$ & $\$ 58,983$ \\
\hline H-505R & 1 & & MethanolEEhthan ISpititer Reboiler & HEAT.A500.A504.QRH505 & $-112,341,710.7$ & $-23,566,276$ & 0.21 & $\$ 158,374$ & 1996 & $\$ 158,374$ & 0.68 & $\$ 54,761$ & 2.1 & $\$ 114,999$ & $\$ 141,060$ & $\$ 67,171$ & $\$ 158,293$ & $\$ 75,378$ \\
\hline P. $504 \mathrm{~B}$ & 1 & 1 & Ethanolipropanol Spliter Bottoms Pump & FLD504 & 40,528 & 1,444 & 0.04 & $\$ 42,300$ & 1997 & $\$ 84,600$ & 0.79 & 56,071 & 2.8 & $\$ 16,998$ & $\$ 20,591$ & $\$ 7,354$ & $\$ 23,107$ & $\$ 8,252$ \\
\hline P. $505 \mathrm{~B}$ & 1 & 1 & Methanol/Ethanol Spititer Bottoms Pump & FLD505 & 40,528 & 2,593 & 0.06 & $\$ 42,300$ & 1997 & $\$ 84,600$ & 0.79 & $\$ 99,643$ & 2.8 & $\$ 27,000$ & \begin{tabular}{c|c}
32,708 \\
\end{tabular} & $\$ 11,681$ & $\begin{array}{l}336,703 \\
\end{array}$ & $\$ 13,108$ \\
\hline P. $504 \mathrm{R}$ & 1 & 1 & EthanoliPropanol Splitter Reflux Pump & A500.A504.0AH504 & $3,968,983.2$ & $18,833,690$ & 0.37 & $\$ 1,357$ & 1998 & $\$ 2,714$ & 0.79 & $\$ 1,240$ & 2.8 & $\$ 3,471$ & $\$ 4,172$ & $\$ 1,490$ & $\begin{array}{l}4,682 \\
\end{array}$ & $\$ 1,672$ \\
\hline P.505R & 1 & 1 & MethanolEEthanol Spiliter Refiux Pump & A500.A504.0AH505 & $3,968,983.2$ & $36,817,833$ & 0.37 & $\$ 1,357$ & 1998 & $\$ 2,714$ & 0.79 & $\$ 1,240$ & 2.8 & $\$ 3,471$ & $\$ 4,172$ & $\$ 1,490$ & $\$ 4,682$ & $\$ 1,672$ \\
\hline T.504 & 1 & & EthanoliPropanol Spliter Reflux Drum & A500.A504.0AH504 & $3,968,983.2$ & $18,833,690$ & 0.37 & $\$ 1,900$ & 1997 & $\$ 11,900$ & 0.93 & $\$ 4,731$ & 2.1 & \$9,934 & $\$ 12,034$ & $\$ 5,731$ & $\$ 13,505$ & $\$ 6,431$ \\
\hline T-505 & 1 & & Methanol|Ethanol Spiltiter Reflux Drum & A500.A504..QAH505 & $3,968,983.2$ & $36,817,833$ & 0.37 & $\$ 11,900$ & 1997 & $\$ 11,900$ & 0.93 & $\$ 4,731$ & 2.1 & \$9,934 & $\begin{array}{l}12,034 \\
\end{array}$ & $\$ 5,731$ & $\$ 13,505$ & s6,431 \\
\hline$P-590$ & 1 & & Mixed Alcohol Product Pump & STRM. 590 & 40,894 & 7,204 & 0.18 & $\$ 7,500$ & 1997 & 57,500 & 0.79 & $\$ 1,903$ & 2.47 & $\$ 4,699$ & 55,693 & $\$ 2,305$ & \begin{tabular}{c|c}
6,388 \\
\end{tabular} & $\$ 2,586$ \\
\hline$P-592$ & 1 & & Ethanol Product Pump & STRM.592 & 40,894 & 39,731 & 0.97 & $\$ 7,500$ & 1997 & 87,500 & 0.79 & $\$ 7,331$ & 2.47 & $\$ 18,108$ & $\$ 21,935$ & $\$ 8,881$ & $\$ 24,615$ & 99,966 \\
\hline P.591 & 2 & & Mixed Alcohol Product Pump & STRM. 590 & 40,895 & 7,204 & 0.18 & $\$ 7,501$ & 1998 & $\$ 15,02$ & 1.79 & S670 & 3.47 & $\$ 2,326$ & $\$ 2,796$ & 5806 & $\$ 3,138$ & 5904 \\
\hline $\begin{array}{l}P-593 \\
\end{array}$ & 3 & & Ethanol Product Pump & $\begin{array}{l}\text { STRM.592 } \\
\end{array}$ & 40,896 & 39,731 & 0.97 & $\$ 7,502$ & 1999 & \begin{tabular}{l|l}
22,506 \\
\end{tabular} & 2.79 & $\$ 20,763$ & 4.47 & 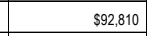 & $\$ 111,248$ & 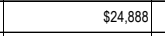 & $\$ 124,840$ & $\$ 27,928$ \\
\hline H-592-1 & 1 & & Eihnon Product Cooler (air cooled) & WORK.A900.WK592FAN & 8 & 7 & 0.86 & $\$ 17,065$ & 1990 & $\$ 17,065$ & 1 & $\$ 17,065$ & 2.47 & $\$ 42,150$ & $\begin{array}{c}555,187 \\
\end{array}$ & $\$ 22,343$ & \$561,929 & $\$ 25,072$ \\
\hline H-590-1 & 1 & & Mixed Alcohol Product Cooler (air coolede) & $\begin{array}{l}\text { WORK.A900.WK500FAN } \\
\end{array}$ & 2 & 1 & 0.84 & $\$ 9,024$ & 1990 & $\$ 9,024$ & 1 & $\$ 9,024$ & 2.47 & $\$ 22,290$ & $\$ 29,184$ & $\$ 11,815$ & $\$ 332,749$ & $\$ 13,259$ \\
\hline H-591-1 & 1 & & Higher Alcohol Product Finishing cooler & HEAT.A500.QCH591 & 235,135 & 235,135 & 1.00 & $\$ 2,923$ & 2006 & $\$ 2,223$ & 0.6 & $\$ 2,923$ & 2.47 & $\begin{aligned} 7,220 \\
\end{aligned}$ & $\begin{array}{l}6,766 \\
\end{array}$ & $\begin{array}{l}2,739 \\
\end{array}$ & $\$ 7,593$ & $\$ 3,074$ \\
\hline H-593-1 & 1 & & ETHANOL Product Finishing cooler & HEAT.A500.QCH593 & $1,433,684$ & $1,435,684$ & 1.00 & $\$ 19,158$ & 2006 & $\$ 19,158$ & 0.6 & $\$ 19,158$ & 2.47 & $\$ 47,320$ & $\$ 44,346$ & $\$ 17,954$ & $\$ 49,764$ & $\$ 20,147$ \\
\hline H-BP-2 & 1 & & Cold MolSievPreHt Hot Reformate Exchanger & PINCH & $3,151,827$ & $3,151,827$ & 1.00 & $\$ 28,415$ & 2006 & $\$ 28,415$ & 0.65 & $\$ 28,415$ & 2.47 & $\$ 70,185$ & $\$ 66,774$ & $\$ 26,629$ & $\$ 773,809$ & $\$ 29,882$ \\
\hline H-BP-3 & 1 & & Cold MolSievPreett Hot Reformate Exchanger & PINCH & 441,157 & 441,157 & 1.00 & $\$ 19,758$ & 2006 & $\$ 19,758$ & 0.65 & $\begin{array}{l}\$ 9,758 \\
\end{array}$ & 2.47 & $\$ 48,802$ & $\$ 44,735$ & $\$ 18,516$ & $\begin{array}{l}551,322 \\
\end{array}$ & $\$ 20,778$ \\
\hline H-BP-16 & 1 & & Cold Molsievpreett Hot Reformate Exchanger & PINCH & $21,278,310$ & $21,278,310$ & 1.00 & $\$ 81,615$ & 2006 & $\$ 881,615$ & 0.65 & 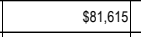 & 2.47 & $\$ 2201,589$ & $\$ 188,919$ & $\$ 76,485$ & $\$ 211,999$ & $\$ 85,830$ \\
\hline T-592 & 2 & & Ethanol Product Storage Tank & STRM.592 & 40,894 & 39,731 & 0.97 & $\$ 165,800$ & 1997 & $\$ 331,600$ & 0.51 & $\$ 326,757$ & 2.47 & $\$ 807,090$ & \begin{tabular}{c|c|}
5977,697 \\
\end{tabular} & $\$ 395,829$ & $\$ 1,097,142$ & $\$ 444,187$ \\
\hline \multirow[t]{2}{*}{ T.590 } & 2 & & Mixed Alconol Product Storage Tank & STRM. 590 & 40,894 & 7,204 & 0.18 & $\$ 165,800$ & 1997 & $\$ 331,600$ & 0.51 & $\$ 136,784$ & 2.47 & $\begin{array}{lll}5337,857 \\
\end{array}$ & $\$ 409,275$ & $\$ 165,698$ & $\$ 459,276$ & $\$ 185,942$ \\
\hline & & & & & & & & & & & & & & & & & & \\
\hline \multirow[t]{2}{*}{1500} & & & & & & & & & Subtotal & $\begin{array}{l}3,43,306 \\
\end{array}$ & & \begin{tabular}{l|l}
$2,296,684$ & 2 \\
\end{tabular} & 2.41762336 & \$\$ & $\begin{array}{l}\$ 6,626,682 \\
\end{array}$ & $\$ 2,741,819$ & \begin{tabular}{l|l}
$\$ 7,436,264$ \\
\end{tabular} & $\$ 3,076,787$ \\
\hline & & & & & & & & & & & & & & & & & & \\
\hline
\end{tabular}




\begin{tabular}{|c|c|c|c|c|c|c|c|c|c|c|c|c|c|c|c|c|c|c|}
\hline $\begin{array}{l}\text { Equipment } \\
\text { Number }\end{array}$ & $\begin{array}{l}\text { Number } \\
\text { Required }\end{array}$ & $\begin{array}{l}\text { Number } \\
\text { Spares }\end{array}$ & Equipment Name & Scaling Stream & $\begin{array}{c}\text { Scaling Stream Flow } \\
\text { (blhhro or bulhr) }\end{array}$ & New Stream Flow & Size Ratio & $\begin{array}{l}\text { Original Equip } \\
\text { Cost (per unit) }\end{array}$ & Base Year ${ }^{\top}$ & \begin{tabular}{|c} 
Total Original Equip Cost \\
(Reg'd \& Spare) in Base \\
Year
\end{tabular} & Scaling Exp. & $\begin{array}{r}\text { scaled Cost in Base } \\
\text { Year }\end{array} \mid$ & $\begin{array}{l}\text { Instal } \\
\text { Factor }\end{array}$ & $\begin{array}{l}\text { Installed Cost in Base } \\
\text { Year }\end{array}$ & $\begin{array}{l}\text { Installed Cost in } \\
2005 \$\end{array}$ & $\left|\begin{array}{c}\text { Scaled Uninstalled cost } \\
\text { in 2005s }\end{array}\right|$ & $\begin{array}{l}\text { Installed Cost in } \\
20075\end{array}$ & $\begin{array}{l}\text { Scaled Uninstalled } \\
\text { Costin } 20075\end{array}$ \\
\hline H-601 & 1 & & Steam Turbine Condenser & STRM.A600.A6000ST.614 & 93,974 & 147 & 0.00 & so & 2002 & $\$ 0$ & 0.71 & so & 2.47 & $\$ 0$ & $\$ 0$ & so & \$0 & so \\
\hline H-603 & 1 & & Blowdown Water-cooled Cooler & НЕАТ.А700.АСН603СT & 626,343 & $1,804,297$ & 2.88 & $\$ 16,143$ & 2002 & $\$ 16,143$ & 0.44 & $\$ 25,714$ & 2.47 & $\$ 63,513$ & $\$ 75,168$ & $\$ 30,432$ & $\$ 84,352$ & $\$ 34,150$ \\
\hline H-BP-6 & 1 & & Hot Reformate / Cold Water Exchanger & PINCH & 19,468,447 & 19,468,447 & 1.00 & $\$ 163,847$ & 2006 & $\$ 163,847$ & 0.65 & $\$ 163,847$ & 2.47 & $\$ 404,702$ & $\$ 379,266$ & $\$ 153,549$ & $\$ 425,601$ & $\$ 172,308$ \\
\hline H-BP-8 & 1 & & Cold Water I Hot Reformate Exchanger & 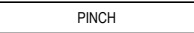 & 227,758 & 227,758 & 1.00 & $\$ 19,148$ & 2006 & \begin{tabular}{c|c|c|}
$\$ 98$ \\
\end{tabular} & 0.65 & $\begin{array}{l}\$ 19,148 \\
\end{array}$ & 2.47 & $\$ \$ 47,296$ & $\$ 44,323$ & $\$ 17,945$ & $\$ 49,738$ & $\$ 20,137$ \\
\hline H-BP.9 & 1 & & Cold Water IHot Reformate Exchanger & PINCH & 995,500 & 995,500 & 1.00 & $\$ 20,850$ & 2006 & $\$ 20,850$ & 0.65 & $\$ 20,850$ & 2.47 & $\$ 51,500$ & $\$ 48,263$ & $\$ 19,540$ & $\$ 54,159$ & $\$ 21,927$ \\
\hline H-BP-11 & 1 & & Hot Reformate / Cold WaterRecy Exchanger & PINCH & $7,281,081$ & $7,281,081$ & 1.00 & $\$ 4,915$ & 2006 & $\$ 4,915$ & 0.65 & $\$ 48,915$ & 2.47 & $\$ 120,820$ & $\$ 113,226$ & $\$ 45,841$ & $\$ 127,059$ & $\$ 51,441$ \\
\hline M-601 & 1 & & Hot Process Water Softener System & STRM.A600.A600BF. 631 & 349,266 & 437,614 & 1.25 & $\$ 1,031,023$ & 1999 & $\$ 1,031,023$ & 0.82 & $\$ 1,240,437$ & 2.47 & $\$ 3,063,880$ & $\$ 3,672.577$ & $\$ 1,486,873$ & $\$ 4,121,256$ & $\$ 1,668,25$ \\
\hline M-602 & 1 & & Extraction Siteam Turbine/Generator & STRM.A600.607 & 342,283 & 428,864 & 1.25 & $\$ 4,045,870$ & 2002 & $\$ 4,045,870$ & 0.71 & $\$ 4,748,381$ & 2.47 & $\$ 11,728,502$ & $\$ 13,880,902$ & $55,619,798$ & $\$ 15,576,732$ & $\$ 6,306,369$ \\
\hline $\begin{array}{l}P-601 \\
\end{array}$ & 1 & 1 & 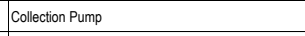 & $\begin{array}{l}\text { STRM.618 } \\
\end{array}$ & 255,292 & 32,032 & 0.13 & $\$ 7,015$ & 2002 & $\$ 14,030$ & 0.33 & $\$ 7,073$ & 2.47 & $\$ 17,469$ & $\$ 20,675$ & $\$ 8,370$ & $\$ 23,201$ & 99,393 \\
\hline$P-602$ & 1 & 1 & Condensate Pump & STRM.A600.616 & 93,974 & 147 & 0.00 & $\$ 5,437$ & 2002 & $\$ 10,874$ & 0.33 & $\$ 1,290$ & 2.47 & $\$ 3,186$ & $\$ 3,771$ & $\$ 1,527$ & $\$ 4,232$ & $\$ 1,713$ \\
\hline \begin{tabular}{|c|c|c|}
-603 \\
\end{tabular} & 1 & 1 & Deaerator Feed Pump & $\begin{array}{l}\text { STRM.A600.A6000F. } 628 \\
\end{array}$ & 349,266 & 437,614 & 1.25 & $\$ 8,679$ & 2002 & $\$ 17,358$ & 0.33 & 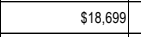 & 2.47 & \begin{tabular}{|l|l|}
546,187 \\
\end{tabular} & $\$ 54,663$ & $\$ 22,131$ & $\$ 66,341$ & $\$ 24,834$ \\
\hline $\begin{array}{l}P-604 \\
-1\end{array}$ & 1 & 1 & Boiler Feed Water Pump & STRM.A600.A600BL.639 & 349,268 & 437,617 & 1.25 & $\$ 95,660$ & 2002 & $\$ 191,320$ & 0.33 & $\$ 206,100$ & 2.47 & $\$ 509,068$ & $\$ 602,492$ & $\$ 243,924$ & $\$ 676,098$ & $\$ 273,724$ \\
\hline$T-601$ & 1 & & Condensate Collection Tank & STRM.A600.A600BF. 627 & 349,266 & 437,614 & 1.25 & $\$ 24,493$ & 2002 & $\$ 24,493$ & 0.6 & $\$ 28,042$ & 2.47 & $\$ 69,263$ & $\$ 81,974$ & $\$ 33,188$ & $\$ 91,988$ & $\$ 37,242$ \\
\hline$T-602$ & 1 & & Condensate Surge Drum & $\begin{array}{l}\text { STRM.A600.A600BL.638 } \\
\end{array}$ & 349,268 & 437,617 & 1.25 & $\$ 28,572$ & 2002 & $\$ 28,572$ & 0.6 & $\$ 32,712$ & 2.47 & 980,798 & 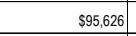 & $\$ 38,715$ & $\$ 107,308$ & $\$ 43,445$ \\
\hline$T-603$ & 1 & & Deaerator & STRM.A600.633 & 349,266 & 437,614 & 1.25 & $\$ 130,721$ & 2002 & $\$ 130,721$ & 0.72 & $\$ 153,765$ & 2.47 & $\$ 379,800$ & $\$ 449,501$ & $\$ 181,984$ & $\$ 504,416$ & $\$ 204,217$ \\
\hline$T-604$ & 1 & & Steam Drum & STRM.A600.644 & 349,268 & 437,617 & 1.25 & $\$ 9,200$ & 1997 & $\$ 9,200$ & 0.72 & \begin{tabular}{|l|l|l|l|l|}
1022 \\
\end{tabular} & 2.47 & $\$ 26,730$ & $\$ 32,380$ & $\$ 13,109$ & $\$ 36,336$ & $\$ 14,711$ \\
\hline \multirow[t]{2}{*}{ s.601 } & 1 & & Blowdown Flash Drum & STRM.A600.604 & 6,985 & 8,752 & 1.25 & $\$ 14,977$ & 2002 & $\$ 14,977$ & 0.6 & $\$ 17,147$ & 2.47 & $\$ 42,354$ & $\$ 50,127$ & $\$ 20,294$ & $\$ 56,251$ & $\$ 22,774$ \\
\hline & & & & & & & & & & & & & & & & & & \\
\hline \multirow[t]{2}{*}{ A600 } & & & & & & & & & $\begin{array}{l}\text { Subtotal } \\
\end{array}$ & $\$ 55,787,341$ & & \begin{tabular}{|l|l|}
$56,742,942$ \\
\end{tabular} & 2.47 & \begin{tabular}{|l|l|}
$16,655,067$ \\
\end{tabular} & $\$ \$ 19,604,933$ & $\begin{array}{l}\$ 7,937,220 \\
\end{array}$ & $\$ 22,000,068$ & $\$ 8,00,90910$ \\
\hline & & & & & & & & & & & & & & & & & & \\
\hline K-701 & 2 & 1 & \begin{tabular}{|l|} 
Plant Air Compressor \\
\end{tabular} & STRM.A100.101 & 367,437 & 367,437 & 1.00 & $\$ 32,376$ & 2002 & $\$ 97,129$ & 0.34 & 597,129 & 2.47 & $\$ 239,908$ & $\$ 283,936$ & $\$ 114,954$ & $\$ 318,624$ & $\$ 128,998$ \\
\hline M-701 & 1 & & Cooling Tower System & HEAT.A700.0CTOTAL & $139,850,763$ & $34,800,014$ & 0.25 & $\$ 267,316$ & 2002 & $\begin{array}{l}267,316 \\
\end{array}$ & 0.78 & 990,331 & 2.47 & $\$ 223,118$ & $\$ 264,065$ & 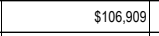 & $\$ 229,326$ & $\$ 119,970$ \\
\hline M-702 & 1 & & Hydraulic Truck Dump with Scale & STRM.A100.101 & 367,437 & 367,437 & 1.00 & $\$ 80,000$ & 1998 & $\$ 80,000$ & 0.6 & $\$ 88,000$ & 2.47 & $\$ 197,600$ & $\$ 237,526$ & $\$ 96,164$ & $\$ 266,544$ & $\$ 107,913$ \\
\hline M-703 & 1 & & Five Gas Stack & STRM.335 & $1,174,206$ & 716,651 & 0.61 & $\$ 51,581$ & 2002 & $\$ 51,581$ & 1 & $\$ 31,481$ & 2.47 & $\$ 77,759$ & $\begin{array}{c}592,229 \\
\end{array}$ & $\$ 37,259$ & $\$ 103,272$ & $\$ 41,811$ \\
\hline P.701 & 1 & 1 & Cooling Water Pump & STRM.A700.715 & $6,088,320$ & $1,617,066$ & 0.27 & $\$ 158,540$ & 2002 & $\$ 317,080$ & 0.33 & $\$ 204,722$ & 2.47 & $\$ 505,664$ & $\begin{array}{l}598,462 \\
\end{array}$ & $\$ 242,293$ & $\$ 671,577$ & $\$ 271,993$ \\
\hline $\begin{array}{l}P-702 \\
\end{array}$ & 1 & 1 & Firewater Pump & STRM.A100.101 & 367,437 & 367,437 & 1.00 & $\$ 18,400$ & 1997 & $\$ 36,800$ & 0.79 & $\$ 36,800$ & 2.47 & $\begin{array}{ll}590,896 \\
\end{array}$ & $\$ 110,110$ & $\$ 44,579$ & $\$ 123,562$ & $\$ 50,025$ \\
\hline P.703 & 1 & 1 & Diesel Pump & STRM.A100.101 & 367,437 & 367,437 & 1.00 & $\$ 6,100$ & 1997 & $\$ 12,200$ & 0.79 & $\$ 12,200$ & 2.47 & $\$ 30,134$ & 936,504 & $\$ 14,779$ & $\$ 40,963$ & $\$ 16,584$ \\
\hline P.704 & 1 & 1 & Ammonia Pump & STRM.A100.101 & 367,437 & 367,437 & 1.00 & $\$ 5,000$ & 1997 & $\$ 10,000$ & 0.79 & $\$ 10,000$ & 2.47 & $\$ 24,700$ & $\$ 29,921$ & $\$ 12,114$ & $\$ 33,577$ & $\$ 13,594$ \\
\hline P.705 & 1 & & Hydrazine Pump & STRM.A100.101 & 367,437 & 367,437 & 1.00 & $\$ 5,500$ & 1997 & $\$ 5,500$ & 0.79 & $\$ 5,500$ & 2.47 & $\$ 13,585$ & $\$ 16,457$ & $\begin{array}{l}5,663 \\
\end{array}$ & $\$ 18,467$ & \$7, 747 \\
\hline s-701 & 1 & 1 & Instrument Air Dryer & STRM.A100.101 & 367,437 & 367,437 & 1.00 & $\$ 8,349$ & 2002 & $\$ 16,698$ & 0.6 & $\$ 16,698$ & 2.47 & $\$ 44,244$ & $\$ 48,813$ & $\$ 19,762$ & $\$ 54,777$ & $\$ 22,177$ \\
\hline$T-701$ & 1 & & \begin{tabular}{|l|} 
Plant Air Receiver \\
\end{tabular} & STRM.A100.101 & 367,437 & 367,437 & 1.00 & $\$ 7,003$ & 2002 & $\$ 7,003$ & 0.72 & $\$ 7,003$ & 2.47 & $\$ 17,297$ & \$20,472 & $\$ 8,288$ & $\$ 22,973$ & 99,301 \\
\hline$T-702$ & 1 & & Firiewater Storage Tank & STRM.A100.101 & 367,437 & 367,437 & 1.00 & $\$ 166,100$ & 1997 & $\$ 166,100$ & 0.51 & $\$ 166,100$ & 2.47 & $\$ 410,267$ & $\$ 496,991$ & $\$ 201,211$ & $\begin{array}{l}557,708 \\
\end{array}$ & $\$ 225,793$ \\
\hline T-703 & 1 & & Diesel Storage Tank & STRM.A100.101 & 367,437 & 367,437 & 1.00 & $\$ 14,400$ & 1997 & $\$ 14,400$ & 0.51 & $\$ 14,400$ & 2.47 & $\$ 335,568$ & $\$ 43,086$ & $\$ 17,444$ & $\$ 48,350$ & $\$ 19,575$ \\
\hline$T-704$ & 1 & & 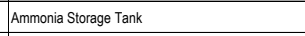 & STRM.A100.101 & 367,437 & 367,437 & 1.00 & $\$ 287,300$ & 1997 & $\$ 287,300$ & 0.72 & $\begin{array}{l}287,300 \\
\end{array}$ & 2.47 & $\$ 709,631$ & $\begin{array}{lll}9859,635 \\
\end{array}$ & $\$ 348,030$ & $\begin{array}{lll}5964,657 & \\
\end{array}$ & $\$ 390,549$ \\
\hline$T-705$ & 1 & & 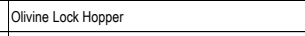 & STRM.A100.101 & 367,437 & 367,437 & 1.00 & so & 1998 & so & 0.71 & so & 2.47 & so & so & so & so & so \\
\hline$T-706$ & 1 & & Mgo Lock Hopper & STRM.A100.101 & 367,437 & 367,437 & 1.00 & so & 1998 & so & 0.71 & so & 2.47 & so & s0 & so & so & so \\
\hline \multirow[t]{2}{*}{$\mathrm{T}-707$} & 1 & & Hydrazine Storage Tank & STRM.A100.101 & 367,437 & 367,437 & 1.00 & $\$ 12,400$ & 1997 & $\$ 12,400$ & 0.93 & $\$ 12,400$ & 2.47 & $\begin{array}{l}30,628 \\
\end{array}$ & $\$ 37,102$ & $\$ 15,021$ & $\$ 41,635$ & $\$ 16,856$ \\
\hline & & & & & & & & & & & & & & & & & & \\
\hline \multirow[t]{2}{*}{ A700 } & & & & & & & & & Subtotal & $\$ 1,381,507$ & & \begin{tabular}{|l|l|}
$\$ 1,072,064$ \\
\end{tabular} & 2.47 & \begin{tabular}{|l|l|}
$\$ 2,647,999$ \\
\end{tabular} & \begin{tabular}{|l|l|l|l}
$\$ 3,175,109$ \\
\end{tabular} & \begin{tabular}{|l|l|l|l}
$11,28,469$ \\
\end{tabular} & $\$ 3,563,012$ & $\$ 1,42,515$ \\
\hline & & & & & & & & & & & & & & & & & & \\
\hline H.802N & 1 & & \begin{tabular}{|l|} 
N2-compressoro water cooled affercooler \\
\end{tabular} & HEAT.A100.A100HOP.AK802N & 272,195 & 4.642,551 & 17.06 & $\$ 16,828$ & 2002 & $\$ 16,828$ & 0.44 & 558,622 & 2.47 & $\$ 144,796$ & $\$ 171,368$ & $\$ 69,380$ & $\$ 192,304$ & $\$ 77,856$ \\
\hline K-802N & 1 & & post ASU N2 compressor & WORK.A600.WK802N & 1,907 & 1,907 & 1.00 & $\$ 1,187,100$ & 2004 & $\$ 1,187,100$ & 0.8 & $\$ 1,187,000$ & 2.47 & $\$ 2,931,891$ & $\$ 3,090,300$ & $\$ 1,251,134$ & $\$ 3,467,842$ & $\$ 1,403,985$ \\
\hline M-802 & 1 & & Air Separation Unit (ASU) including air compressor & STRM.A800.820 & 52,911 & 42,281 & 0.80 & 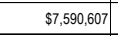 & 1999 & $\$ 7,590,607$ & 0.75 & $\$ 6,415,385$ & 2.47 & $\$ 15,846,002$ & $\$ 18,994,107$ & \$7,689,922 & $\$ 21,314,617$ & $\$ 8,629,400$ \\
\hline $5-801 \mathrm{~N}$ & 1 & & Pre N2-compressor KO & STRM.A800.810 & 34,856 & 34,856 & 1.00 & $\$ 8,763$ & 2002 & $\$ 8,763$ & 0.6 & 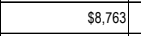 & 2.47 & $\$ 21,645$ & $\$ 25,617$ & $\$ 10,371$ & 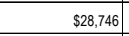 & $\$ 11,638$ \\
\hline s-802N & 1 & & \begin{tabular}{|l|l|} 
Post N2-compressor KO \\
\end{tabular} & STRM.A100.A100HOP. 812 & 34,856 & 34,593 & 0.99 & $\$ 9,277$ & 2002 & s9,277 & 0.6 & 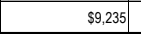 & 2.47 & $\$ 22,810$ & $\$ 22,997$ & $\$ 10,930$ & $\$ 30,225$ & $\$ 12,265$ \\
\hline
\end{tabular}




\begin{tabular}{|c|c|c|c|c|c|c|c|c|c|c|c|c|c|c|c|c|c|c|}
\hline $\begin{array}{c}\text { EEuipment } \\
\text { Number } \\
\text { Nets }\end{array}$ & 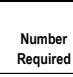 & $\begin{array}{l}\text { Nomber } \\
\text { Spares }\end{array}$ & Equipment Name & Scaling Stream & $\begin{array}{l}\text { (llhhror or buthhr) } \\
\text { (n) }\end{array}$ & New Stream Flo & Size Ratio & 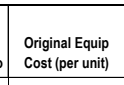 & \begin{tabular}{|l|l|} 
Base Year \\
\end{tabular} & 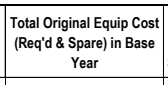 & Scaling Exp. & 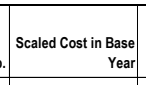 & 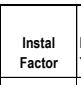 & \begin{tabular}{|l|} 
Ynstarled Cost in Base \\
Year
\end{tabular} & 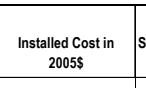 & $\begin{array}{l}\text { in } 20055 \\
\text { ins }\end{array}$ & $\begin{array}{l}\text { statede Coss tin } \\
\text { 20075 } \\
\end{array}$ & 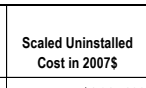 \\
\hline |-802 & 1 & & post ASU 02 compressor & WORK A800.WKOO2 & 1.508 & 1,508 & 1.00 & $\$ 1,113,800$ & 2004 & \$1,113,8000 & $\begin{array}{l}0.8 \\
0\end{array}$ & $\$ 1,113,541$ & 2.47 & $\$ 2,750,45$ & $\$ 2,899,051$ & $\$ 1,173,705$ & \$33,253,228 & $\$ 1,317,096$ \\
\hline 5.803 & 1 & & Pre 02-compresssor KO & STRMABO0.815 & 34,556 & 42,281 & $\begin{array}{l}1.21 \\
\end{array}$ & 58,763 & 2002 & 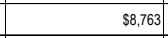 & 0.6 & 59,8399 & 2.47 & 524,303 & $\begin{array}{c}52,764 \\
\end{array}$ & \$11,645 & $\begin{array}{lll}532278 \\
\end{array}$ & $\$ 13,068$ \\
\hline A880 & $\bar{~}$ & 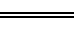 & 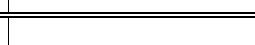 & 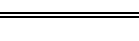 & 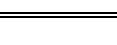 & $\bar{~}$ & 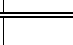 & 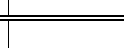 & subtotal & s9,935,138 & & $\$ 8,802,385[$ & 247 & \$21.741,891 & 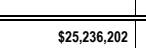 & \$10.277.086 & 528.3919.310 & $\begin{array}{l}511,465,3008 \\
\end{array}$ \\
\hline & & & & & & & & & & & & & & & & & & \\
\hline
\end{tabular}


Appendix D

Discounted Cash Flow Rate of Return and Operating Costs Summary 


\begin{tabular}{|c|c|c|c|c|c|c|c|c|c|c|c|c|c|}
\hline \\
\hline \begin{tabular}{|l|} 
DCFROR Worksheet \\
Year
\end{tabular} & & & & & & & & & & 6 & & 8 & \\
\hline $\begin{array}{l}\text { Year } \\
\text { Fixed Capital Investment }\end{array}$ & & $\$ 24,770,233$ & \begin{tabular}{|l|}
$\$ 152,459,806$ \\
\end{tabular} & $\$ 81,311,896$ & & & & & & & & & \\
\hline Working Capital & & & & $\$ 12,704,984$ & & & & & & & & & \\
\hline Loan Payment & & & & & & $\$ 0$ & 50 & & So & $\$ 0$ & & 50 & \\
\hline \begin{tabular}{|l} 
Loan Interest Payment \\
\end{tabular} & & $\$ 0$ & so & so & $\$ 0$ & $\$ 0$ & $\$ 0$ & $\$ 0$ & $\$ 0$ & $\$ 0$ & $\$ 0$ & 50 & \\
\hline \begin{tabular}{|l} 
Loan Principal \\
\end{tabular} & & $\$ 0$ & so & so & $\$ 0$ & $\$ 0$ & 50 & $\$ 0$ & $\$ 0$ & $\$ 0$ & 50 & $\$ 0$ & \\
\hline & & & & & $\begin{array}{r}\$ 59,183,847 \\
884628\end{array}$ & \begin{tabular}{|l}
$\$ 78,911,796$ \\
$\$ 10521171$
\end{tabular} & 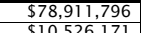 & $\begin{array}{l}\$ 78,911,796 \\
\$ 10526171\end{array}$ & $\begin{array}{l}\$ 78,911,796 \\
\$ \$ 10526171\end{array}$ & $\begin{array}{l}\$ 78,911,796 \\
\$ 1056,171 \\
\end{array}$ & $\begin{array}{l}\$ 78,911,796 \\
\$ 10526171\end{array}$ & $\begin{array}{l}\$ 78,911,796 \\
\$ \$ 10526,1711\end{array}$ & $\begin{array}{l}\$ 78,911,796 \\
\$ 10.526,171\end{array}$ \\
\hline \begin{tabular}{|l|} 
Byy-Product Credit \\
Total Annual Sales \\
\end{tabular} & & & & & $\begin{array}{r}\$ 7,894,628 \\
\$ 67,078,476\end{array}$ & $\begin{array}{l}\$ 10,526,171 \\
\$ 8947967\end{array}$ & $\begin{array}{l}\$ 10,526,171 \\
\$ 89,437,967\end{array}$ & $\begin{array}{l}\$ 10,526,171 \\
\$ 8947967\end{array}$ & $\begin{array}{l}\$ 10,526,171 \\
\$ 89,437,967\end{array}$ & $\begin{array}{l}\$ 10,526,171 \\
\$ 89,437,967\end{array}$ & $\begin{array}{l}\$ 10,526,171 \\
\$ 89,437,967\end{array}$ & $\begin{array}{l}\$ 10,526,171 \\
\$ 89.47,967\end{array}$ & $\begin{array}{l}\$ 10,526,171 \\
\$ 89,437,967\end{array}$ \\
\hline Annual Manufacturing Cost & & & & & & & & $309,451,906$ & $\$ 89,437,967$ & & & & \\
\hline \begin{tabular}{|l} 
Raw Materials \\
\end{tabular} & & & & & $\$ 23,647,650$ & $\$ 27,025,885$ & $\$ 27,025,885$ & $\$ 27,025,885$ & $\$ 27,025,885$ & $\$ 27,025,885$ & $\$ 27,025,885$ & $\$ 27,025,885$ & $\$ 27,025,885$ \\
\hline Tar reforming catalysts & & & & & $\$ 986,684$ & & & & & & & & \\
\hline $\begin{array}{l}\text { Steam reforming catalysts } \\
\text { Zno }\end{array}$ & & & & & $\begin{array}{l}50 \\
50\end{array}$ & & & & & 80 & & & \\
\hline $\begin{array}{l}\text { Zno } \\
\text { Mixed Alcohol catalysts }\end{array}$ & & & & & $\begin{array}{r}\$ 0 \\
\$ 356,865\end{array}$ & so & so & so & so & $\begin{array}{r}\$ 0 \\
\$ 356,865\end{array}$ & $\$ 0$ & so & so \\
\hline Baghouse $\mathrm{BaC}$ & & & & & $\$ 415,430$ & & & & & $\$ 415,430$ & & & \\
\hline \begin{tabular}{|l} 
Other \\
\end{tabular} & & & & & $\$ 2,4$ & $\$ 2,800,464$ & $\$ 2,800,464$ & $\$ 2,800,464$ & $\$ 2,800,464$ & & $\$ 2,800,464$ & $\$ 2,800,464$ & $\$ 2,800,464$ \\
\hline ing Costs & & & & & $\$ 14,590,072$ & $\$ 14,590,072$ & 0,072 & $\$ 14,590,072$ & $\$ 14,590,072$ & $\$ 14,590,072$ & $\$ 14,590,072$ & $\$ 14,590,072$ & $\$ 14,590,072$ \\
\hline Total Product Cost & & & & & $\$ 42,462,782$ & $\$ 44,416,421$ & $\$ 44,416,421$ & $\$ 44,416,421$ & $\$ 44,416,421$ & $\$ 45,188,716$ & $\$ 44,416,421$ & $\$ 44,416,421$ & $\$ 44,416,421$ \\
\hline $\begin{array}{l}\text { Annual Depreciation } \\
\text { General llant }\end{array}$ & & & & & & & & & & & & & \\
\hline \begin{tabular}{|l} 
General Plant \\
DDB
\end{tabular} & & & & & $\$ 64,816,821$ & $\$ 46,297,729$ & S9,807 & $\$ 23,621,290$ & $\$ 16,872,350$ & $\$ 12,051,679$ & $\$ 8,608,342$ & & \\
\hline SL & & & & & & & & & $\$ 19,684,409$ & $\$ 19,684,409$ & $\$ 19,684,409$ & & \\
\hline Remain & & & & & $\$ 162,042,052$ & $\$ 115,744,323$ & 1,516 & 53,226 & 0.876 & 29,197 & 521 & & \\
\hline Actual & & & & & $\$ 64,816,821$ & $\$ 46,297,729$ & $\$ 33,069,807$ & $\$ 23,621,290$ & $\$ 19,684,409$ & $\$ 19,684,409$ & $\$ 19,684,409$ & & \\
\hline Steam Plant & & & & & & & & & & & & & \\
\hline DDB & & & & & $\$ 2,043,060$ & $\$ 1,889,831$ & $\$ 1,74$ & $\$ 1,616,986$ & $\$ 1,495,712$ & $\$ 1,383,534$ & $\$ 1,279,769$ & $\$ 1,183,786$ & $\$ 1,095,002$ \\
\hline & & & & & $\$ 1$ & & $\$ 1$ & & $\$ 1$. & & $\$ 1,2$ & $\$ 1,214,140$ & $\$ 1,214,140$ \\
\hline \begin{tabular}{|l|} 
Remaining Value \\
\end{tabular} & & & & & & & & & & 3,586 & $\$ 15$ & $\$ 14$ & $\$ 13,505,029$ \\
\hline$A c$ & & & & & $\$ 2,043,060$ & & & & & & $\$ 1,279,769$ & $\$ 1,214,140$ & $\$ 1,214,140$ \\
\hline 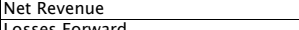 & & & & & $(\$ 42,244,188)$ & $\begin{array}{r}(\$ 3,166,013) \\
\end{array}$ & $\$ 10,203,647$ & $\$ 19,7$ & , 425 & $\$ 23,181,309$ & $\$ 24,057,369$ & $\$ 43,807,407$ & $\$ 43,807,407$ \\
\hline $\begin{array}{l}\text { Losses F } \\
\text { Taxable } \\
\end{array}$ & & & & & $(\$ 42,244,188)$ & $\frac{(\$ 4,244,488)}{(\$ 45,410,201)}$ & $\frac{(\$ 45,410,20)}{(\$ 35,206,554)}$ & $\frac{(\$ 35,206,554)}{(\$ 15,423,285)}$ & $\frac{(\$ 15,423,285)}{\$ 8,418,141}$ & $\begin{array}{r}\$ 0 \\
\$ 23,181,309\end{array}$ & $\begin{array}{r}\$ 0 \\
\$ 24,057,369 \\
\end{array}$ & $\begin{array}{r}50 \\
7.407\end{array}$ & $\begin{array}{r}50 \\
7,407\end{array}$ \\
\hline Incon & & & & & & $\$ 0$ & $\begin{array}{r}(335,200,354) \\
\$ 0\end{array}$ & \$0 & & & & 44,889 & $\$ 17,084,889$ \\
\hline Annual & & & & & $\$ 24,615,694$ & $\$$ & $\$ 45,021,547$ & 5 & $\$ 41,7$ & $\$ 35$, & & $\$ 27,936,658$ & 658 \\
\hline & & 1.21 & 1.1 & & & 0.826446281 & 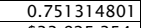 & 0.683013455 & 0.020561 & 0.56447393 & 0.513158118 & 0.46650738 & 0.424097618 \\
\hline \begin{tabular}{|l} 
Annual Present Value \\
\end{tabular} & $\$ 289,806,134$ & 2997198199 & 167.705 .786 .39 & 4016 & $\$ 22,377,903$ & $\$ 37,207,890$ & $\$ 33,825,354$ & $\$ 30,750,322$ & $\$ 25,916,307$ & $\$ 19,874,303$ & $\$ 18,288,531$ & $\$ 13,032,657$ & $\$ 11,847,870$ \\
\hline Net Present Worth & & $329,991,981,99$ & $3107,105,180.39$ & $\begin{array}{r}594,010,800.25 \\
\$ 0\end{array}$ & & & & & & & & & \\
\hline
\end{tabular}




\begin{tabular}{|c|c|c|c|c|c|c|c|c|c|c|c|}
\hline DCFROR Worksheet & & & & & & & & & & & \\
\hline \begin{tabular}{|l} 
Year \\
Fexpod Citalnostmet
\end{tabular} & 10 & 11 & 12 & 13 & 14 & 15 & 16 & 17 & 18 & 19 & 20 \\
\hline $\begin{array}{l}\text { Fixed Capital Investment } \\
\text { Working Capital }\end{array}$ & & & & & & & & & & & $(\$ 12,704,984)$ \\
\hline Loan Payment & 50 & 50 & $\$ 0$ & So & 50 & 50 & $\$ 0$ & $\$ 0$ & 50 & 50 & \\
\hline \begin{tabular}{|l} 
Loan Interest Payment \\
\end{tabular} & $\frac{50}{80}$ & $\$ 0$ & $\$ 0$ & 80 & 50 & $\frac{\$ 0}{80}$ & $\$ 0$ & $\$ 0$ & $\frac{50}{50}$ & $\frac{\$ 0}{50}$ & \\
\hline \begin{tabular}{|l|} 
Loan Principal \\
Ethanol Sales \\
\end{tabular} & & & & & & $\$ 0$ & & & $\$ 0$ & $\$ 0$ & \\
\hline \begin{tabular}{|l} 
Ethanol Salas \\
By-Product Credit \\
\end{tabular} & $\begin{array}{l}\$ 78,911,796 \\
\$ 10,526,171\end{array}$ & $\frac{\$ \$ \$ 7,911,796}{\$ 10,526,171}$ & $\frac{\$ 78,911,796}{\$ 10,526,171}$ & $\begin{array}{l}\$ 78,911,796 \\
\$ 10,526,171\end{array}$ & $\begin{array}{l}\$ 78,91,196 \\
\$ 10,526,171\end{array}$ & $\frac{\$ 78,911,796}{\$ 10,526,171}$ & $\begin{array}{l}\$ \$ 8,911,796 \\
\$ 10,526,171\end{array}$ & $\begin{array}{l}\$ 78,911,796 \\
\$ 10,526,171\end{array}$ & $\begin{array}{l}\$ 78,911,796 \\
\$ 10,526,171\end{array}$ & $\begin{array}{l}\$ 78,911,796 \\
\$ 10,526,171\end{array}$ & \begin{tabular}{|l|}
$\$ 78,911,796$ \\
$\$ 10,526,171$ \\
\end{tabular} \\
\hline Total Annual Sales & $\$ 89,437,967$ & $\$ 89,437,967$ & $\$ 89,437,967$ & $\$ 89,437,967$ & $\$ 89,437,967$ & $\$ 89,437,967$ & $\$ 89,437,967$ & $\$ 89,437,967$ & $\$ 89,437,967$ & $\$ 89,437,967$ & $\$ 89,437,967$ \\
\hline Annual Manufacturing Cost & & & & & & & & & & & \\
\hline Raw Mat & $\$ 27,025,885$ & $\$ 27,025,885$ & $\$ 27,025,885$ & $\$ 27,025,885$ & $\$ 27,025,885$ & $\$ 27,025,885$ & $\$ 27,025,885$ & $\$ 27,025,885$ & $\$ 27,025,885$ & $\$ 27,025,885$ & $\$ 27,025,885$ \\
\hline $\begin{array}{l}\text { Catalysts } \\
\text { ing catalysts }\end{array}$ & & $\$ 0$ & & & & & so & & & & \\
\hline \begin{tabular}{|l}
$\mathrm{ZnO}$ \\
\end{tabular} & & set & & & & & 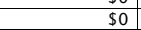 & & & & \\
\hline \begin{tabular}{|l} 
Mixed Alcohol catalysts \\
\end{tabular} & $\$ 0$ & $\$ 356,865$ & so & so & $\$ 0$ & $\$ 0$ & $\$ 356,865$ & so & $\$ 0$ & $\$ 0$ & \\
\hline \begin{tabular}{|l|} 
Baghouse B \\
\end{tabular} & & $\$ 415,430$ & & & & & $\$ 415,430$ & & & & \\
\hline Costs & $\$ 2,800,464$ & $\$ 2,800,464$ & $\$ 2,800,464$ & $\$ 2,800,464$ & $\$ 2,800,464$ & $\$ 2,800,464$ & $\$ 2,800,464$ & $\$ 2,800,464$ & $\$ 2,800,464$ & $\$ 2,800,464$ & $\begin{array}{l}\$ 2,800,464 \\
\$ \$ 50,072\end{array}$ \\
\hline \begin{tabular}{|l|l|} 
Fixed C \\
Total Pro \\
\end{tabular} & $\begin{array}{l}\$ 14,590,072 \\
\$ 44,416421\end{array}$ & \begin{tabular}{|l|l|}
$\$ 14,590,072$ \\
$\$ 45188716$
\end{tabular} & $\begin{array}{l}\$ 14,590,072 \\
\$ 446,421\end{array}$ & \begin{tabular}{|l|l|l}
$14,590,072$ \\
44,416421
\end{tabular} & 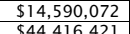 & $\frac{\$ 14,590,072}{\$ 44,16421}$ & \begin{tabular}{|l|l|}
$\$ 14,590,072$ \\
$\$ 45188716$
\end{tabular} & $\$ 14,590,072$ & $\begin{array}{l}\$ 14,590,072 \\
\$ 4441642\end{array}$ & $\frac{\$ 14,590,072}{\$ 44,16421}$ & $\begin{array}{l}\$ 14,590,072 \\
\$ \$ 44,416,421 \\
\end{array}$ \\
\hline Annual Depreciation & $\$ 44,416,421$ & $\$ 45,188,716$ & $\$ 44,416,421$ & $\$ 44,416,421$ & $\$ 44,416,421$ & $\$ 44,416,421$ & $\$ 45,188,716$ & $\$ 44,416,421$ & $\$ 44,416,421$ & $\$ 44,416,421$ & $\$ 44,416,421$ \\
\hline General Plant & & & & & & & & & & & \\
\hline & & & & & & & & & & & \\
\hline$S L$ & & & & & & & & & & & \\
\hline $\begin{array}{l}\text { Remaining Value } \\
\text { Actual }\end{array}$ & & & & & & & & & & & \\
\hline \begin{tabular}{|l} 
Steam Plant \\
\end{tabular} & & & & & & & & & & & \\
\hline DDB & $\$ 1,012,877$ & $\$ 936,911$ & $\$ 866,643$ & , 645 & $\$ 741,521$ & $\$ 685,907$ & $\$ 634,464$ & $\$ 586,879$ & $\$ 542,863$ & $\$ 502,149$ & $\$ 464,488$ \\
\hline SL & & $\$ 1,214,140$ & & & $\$ 1,214,140$ & $\$ 1,2$ & & & $\$ 1,2$ & $\$ 1,214,140$ & $\$ 1,214,140$ \\
\hline Remaining Value & $\$ 12,4$ & $\$ 11,555,240$ & $\$ 10,6$ & & & $\$ 8,459,524$ & \begin{tabular}{|l|l|}
$\$ 7,825,059$ \\
$\$ 21,0$
\end{tabular} & $\$ 7,238,180$ & $\begin{array}{l}56,695,316 \\
62,10\end{array}$ & $\$ 6,193,168$ & $\begin{array}{l}\$ 5,728,680 \\
121410 \\
1210\end{array}$ \\
\hline ACt & $\$ 1,214,140$ & $\$ 1,214,140$ & $\$ 1,214,140$ & $\$ 1,214$ & $\$ 1,214,140$ & $\$ 1,214,140$ & $\$ 1,214,140$ & $\$ 1,214$ & $\$ 1,214,140$ & $\$ 1,214,140$ & $\$ 1,214,140$ \\
\hline $\begin{array}{l}\frac{\text { Net Revenue }}{\text { Losses Forwa }} \\
\text { Les }\end{array}$ & $\begin{array}{r}\$ 43,807,407 \\
\$ 0\end{array}$ & $\begin{array}{r}\$ 43,035,111 \\
\$ 0\end{array}$ & $\begin{array}{r}\$ 43,807,407 \\
\$ 0\end{array}$ & $\begin{array}{r}\$ 43,807,407 \\
\$ 0\end{array}$ & $\begin{array}{r}\$ 43,807,407 \\
\$ 0\end{array}$ & $\begin{array}{r}\$ 43,807,407 \\
\$ 0\end{array}$ & $\begin{array}{r}\$ 43,035,111 \\
\$ 0\end{array}$ & $\begin{array}{r}\$ 43,807,407 \\
\$ 0\end{array}$ & $\begin{array}{r}\$ 43,807,407 \\
\$ 0\end{array}$ & $\begin{array}{r}\$ 43,807,407 \\
\$ 0\end{array}$ & $\begin{array}{r}\$ 43,807,407 \\
\$ 0\end{array}$ \\
\hline Taxab &, 407 & $\$ 43,0$ & 543 & & & & & & & $\$ 43,807,407$ & ,, 407 \\
\hline Inco & & & & & & & & & & & 4,889 \\
\hline come & $\$ 27,936,658$ & $\$ 27,465,558$ & $\$ 27,936,658$ & $\$ 27,936,658$ & $\$ 27,936,658$ & $\$ 27$ & $\$ 27,465,558$ & $\$ 2$ & $\$ 27$ & $\$ 27,936,658$ & \\
\hline Discol & 0.385543289 & 0.350493899 & 0.318630818 & 0.28966438 & 0.263331254 & & 0.217629136 & 0.197844669 & 0.17985879 & 0.163507991 & \\
\hline Annual Present & $\$ 10,770,791$ & $\$ 9,626,510$ & $\$ 8,901,480$ & $\$ 8,092,255$ & $\$ 7,356,595$ & $\$ 6,687,814$ & $\$ 5,977,306$ & $\$ 5,527,119$ & $\$ 5,024,653$ & $\$ 4,567,867$ & $\$ 4,152,606$ \\
\hline \begin{tabular}{|l} 
Total \\
Not pro
\end{tabular} & & & & & & & & & & & $(\$ 1,888,514.89)$ \\
\hline Net Present Worth & & & & & & & & & & & \\
\hline
\end{tabular}




\section{Ethanol from Mixed Alcohols Production Process Engineering Analysis}

2012 Market Target Case: 2010 Tar Reforming Goal \& Mixed Alcohol Production

2,000 Dry Metric Tonnes Biomass per Day

GTI Gasifier, Tar Reformer, Sulfur Removal, MoS2 Catalyst, Fuel Purification, Steam- Power Cycle All Values in $2005 \$$

\section{Minimum Ethanol Selling Price (\$/gal) \$1.57}

EtOH Production at Operating Capacity (MM Gal / year) 50.4 EtOH Product Yield (gal / Dry US Ton Feedstock) 65.3 Mixed Alcohols Production at Operating Capacity (MM Gal / year) 59.3 Mixed Alcohols Product Yield (gal / Dry US Ton Feedstock) 76.8 Delivered Feedstock Cost \$/Dry US Ton $\$ 35$ Internal Rate of Return (After-Tax) 10\% Equity Percent of Total Investment 100\%

\begin{tabular}{l} 
Capital Costs \\
\hline Feed Handling \& Drying \\
Gasification \\
Tar Reforming \& Quench \\
Acid Gas \& Sulfur Removal \\
Alcohol Synthesis - Compression \\
Alcohol Synthesis - Other \\
Alcohol Separation \\
Steam System \& Power Generation \\
Cooling Water \& Other Utilities \\
Air Separation Unit \\
Total Installed Equipment Cost \\
Indirect Costs \\
(\%of TPI) \\
Project Contingency
\end{tabular}

Total Project Investment (TPI)

Installed Equipment Cost per Annual Gallon Total Project Investment per Annual Gallon

Loan Rate

Term (years)

Capital Charge Factor

Maximum Yields based on carbon content Theoretical Ethanol Production (MM gal/yr) Theoretical Ethanol Yield (gal/dry ton) Current Ethanol Yield (Actual/Theoretical)

Gasifier Efficiency - HHV \%

Gasifier Efficiency - LHV \%

Overall Plant Efficiency - HHV \%

Overall Plant Efficiency - LHV \%

Plant Hours per year $\%$

$$
\begin{array}{r}
\$ 22,800,000 \\
\$ 24,800,000 \\
\$ 43,200,000 \\
\$ 17,000,000 \\
\$ 7,700,000 \\
\$ 12,600,000 \\
\$ 6,600,000 \\
\$ 19,600,000 \\
\$ 3,200,000 \\
\$ 25,200,000 \\
\hline \$ 182,700,000 \\
71,400,000 \\
28.1 \% \\
5,500,000
\end{array}
$$

$\$ 254,100,000$

$\$ 3.62$

$\$ 5.04$

$\mathrm{N} / \mathrm{A}$

N/A

0.176

158.9

205.8

$32 \%$

79.7

78.2

39.5

38.4

8406

$96.0 \%$
Operating Costs (cents/gal product)

\begin{tabular}{lr}
\hline Feedstock & 53.6 \\
Natural Gas & 0.0 \\
Catalysts & 0.4 \\
Olivine & 2.8 \\
Other Raw Materials & 3.2 \\
Waste Disposal & 3.0 \\
Electricity & -3.6 \\
Fixed Costs & 28.9 \\
Co- product credits & 20.8 \\
Capital Depreciation & 25.2 \\
Average Income Tax & 17.7 \\
Average Return on Investment & 46.1
\end{tabular}

Operating Costs (\$/yr)

Feedstock

$\$ 27,000,000$

Natural Gas

Catalysts

Olivine

Other Raw Matl. Costs

Waste Disposal

Electricity

Fixed Costs

Co-product credits @ \$1.15 per gal

Capital Depreciation

Average Income Tax

Average Return on Investment

$\$ 200,000$

$\$ 1,400,000$

$\$ 200,000$

$\$ 1,500,000$

$-\$ 1,800,000$

$\$ 14,600,000$

$-\$ 10,500,000$

$\$ 12,700,000$

$\$ 8,900,000$

$\$ 23,200,000$

Total Plant Electricity Usage (KW)

Electricity Produced Onsite (KW)

Electricity Purchased from Grid (KW)

7,136

10,994

Electricity Sold to Grid (KW)

3,858

Steam Plant + Turboexpander Power Generated (hk $\quad 38,784$

Used for Main Compressors (hp) 24,041

Used for Electricity Generation (hp) 14,743

Plant Electricity Use (KWh/gal product) $\quad 1.6$

Gasification \& Reforming Steam Use (lb/gal) 19.1 


\begin{tabular}{|c|c|c|c|c|c|c|c|c|c|c|c|}
\hline \multicolumn{12}{|c|}{ Variable Operating Costs } \\
\hline $\begin{array}{l}\text { Costing } \\
\text { Code }\end{array}$ & Raw Material & Stream No. & $\begin{array}{c}\mathrm{kg} / \mathrm{hr} \text { (or } \\
\mathrm{kW} \text { ) }\end{array}$ & $\begin{array}{c}\mathrm{lb} / \mathrm{hr} \text { (or } \\
\mathrm{HP})\end{array}$ & $\begin{array}{c}\text { Quoted Price } \\
\text { (cents/ton, or } \\
\text { cents / kWh) }\end{array}$ & $\begin{array}{c}\text { Year of } \\
\text { Price } \\
\text { Quote }\end{array}$ & $\begin{array}{c}2000 \text { Cost } \\
\text { (cents / } \\
\text { ton) }\end{array}$ & $\begin{array}{c}2000 \text { Cost } \\
(\$ / \mathrm{lb})\end{array}$ & $\$ /$ hour & $\begin{array}{l}\text { MM\$/yr } \\
(2005)\end{array}$ & $\begin{array}{l}\text { Cents/gal } \\
(2005)\end{array}$ \\
\hline $\mathrm{F}-3$ & Feedstock - wood chips & STRM. 100 & 166,667 & 367,437 & 1750 & 2005 & 1464.10 & 0.0073 & $2,689.81$ & 27.03 & 53.61 \\
\hline $\mathrm{R}-12$ & Magnesium Oxide $(\mathrm{MgO})$ & STRM.220 & 3 & 7 & 36500 & 2004 & 33099.25 & 0.1655 & 1.09 & 0.01 & 0.02 \\
\hline $\mathrm{R}-13$ & Fresh Olivine Makeup & STRM.204 & 826 & 1,821 & 17290 & 2004 & 15679.07 & 0.0784 & 142.77 & 1.43 & 2.85 \\
\hline$S-26$ & Natural Gas for Gasifier & STRM.206 & 0 & 0 & 22176 & 2003 & 21111.66 & 0.1056 & 0.00 & 0.00 & 0.00 \\
\hline$R-14$ & Tar Reformer Catalyst & $\begin{array}{l}\text { STRM.A300.A300TR.3 } \\
26\end{array}$ & 1 & 1 & 934000 & 2002 & 930437.38 & 4.6522 & 6.05 & 0.06 & 0.12 \\
\hline$s-28$ & LO-CAT chemicals & STRM.324 & 40 & 87 & 13605 & 2004 & 12337.40 & 0.0617 & 5.39 & 0.05 & 0.11 \\
\hline$S-23$ & Natural Gas for Reformer & $\begin{array}{l}\text { STRM.A300.A300TR.A } \\
\text { 300FC.340 }\end{array}$ & 0 & 0 & 22176 & 2003 & 21111.66 & 0.1056 & 0.00 & 0.00 & 0.00 \\
\hline & Amine Make-Up & $\begin{array}{l}\text { STRM.A300.A300AGR. } \\
\text { AM-COLD }\end{array}$ & 65 & 143 & 218000 & 2005 & 182384.41 & 0.9119 & 130.62 & 1.31 & 2.60 \\
\hline $\mathrm{S}-25$ & $\begin{array}{l}\text { Boiler Feed Water } \\
\text { Makeup }\end{array}$ & STRM.618 & 14,529 & 32,032 & 2. & 1990 & 30.43 & 0.0002 & 4.87 & 0.05 & 0.10 \\
\hline $\mathrm{S}-21$ & Boiler Chemicals & STRM.635 & 1 & 3 & 280000 & 1991 & 349331.21 & 1.7467 & 5.35 & 0.05 & 0.11 \\
\hline$S-22$ & Cooling Tower Chems & STRM.711 & 0 & 0 & 200000 & 1999 & 209352.04 & 1.0468 & 0.34 & 0.00 & 0.01 \\
\hline$S-24$ & Cooling Tower Makeup & STRM.710 & 12,929 & 28,503 & 24 & 1990 & 30.43 & 0.0002 & 4.34 & 0.04 & 0.09 \\
\hline$S-27$ & No. 2 Diesel Fuel & & 31 & 69 & 29133 & 2003 & 27734.76 & 0.1387 & 9.60 & 0.10 & 0.19 \\
\hline $\mathrm{P}-2$ & Electricity & WORK.WNET & $-3,858$ & $-5,173$ & 4.74 & 2003 & & & -182.86 & -1.84 & -3.64 \\
\hline & Subtotal & & & & & & & & $2,817.36$ & 28.31 & 56.15 \\
\hline & & & & & & & & & & & \\
\hline & Waste Streams & & & & & & & & & & \\
\hline $\mathrm{W}-4$ & Sand and Ash Purge & STRM.219 & 6,128 & 13,509 & 1820 & 1993 & 2224.60 & 0.0111 & 150.26 & 1.51 & 2.99 \\
\hline & $\begin{array}{l}\text { tar reformer catalyst } \\
\text { disposal }\end{array}$ & & & 1 & 1820 & 1993 & 2224.60 & 0.0111 & 0.01 & 0.00 & 0.00 \\
\hline & wwt COST & STRM.305 & 1,344 & 2,963 & 67 & 2004 & 60.30 & 0.0003 & 0.89 & 0.01 & 0.02 \\
\hline & Subtotal & & & & & & & & 151.17 & 1.52 & 3.01 \\
\hline & & & & & & & & & & & \\
\hline & By-Product Credits & & & & & & & & & & \\
\hline & Mixed Alcohol & STRM. 590 & 3,268 & 7,204 & 34716 & 2005 & 29043.95 & 0.1452 & $1,046.18$ & 10.51 & 20.85 \\
\hline & Carbon Dioxide & STRM.A300.384VENT & 33,449 & 73,743 & 0 & 2005 & 0.00 & 0.0000 & 0.00 & 0.00 & 0.00 \\
\hline & Sulfur & STRM.324 & 40 & 87 & 4000 & 2005 & 3346.50 & 0.0167 & 1.46 & 0.01 & 0.03 \\
\hline & Subtotal & & & & & & & & $1,047.64$ & 10.53 & 20.88 \\
\hline & & & & & & & & & & & \\
\hline & $\begin{array}{l}\text { Total Variable Operating } \\
\text { Costs }\end{array}$ & & & & & & & & $1,920.89$ & 19.30 & 38.29 \\
\hline & & & & & & & & & & & \\
\hline & & & & & & & & & & & \\
\hline & Fixed Operating Costs & & & & & & & & & & \\
\hline & Plant Manager & 110000 & 1 & 110,000 & & 53 & & & & & \\
\hline & Plant Engineer & 65000 & 1 & 65,000 & & 31 & & & & & \\
\hline & Maintenance Supr & 60000 & 1 & 60,000 & & 29 & & & & & \\
\hline & Lab Manager & 50000 & 1 & 50,000 & & 24 & & & & & \\
\hline & Shift Supervisor & 45000 & 5 & 225,000 & & 22 & & & & & \\
\hline & Lab Technician & 35000 & 2 & 70,000 & & 17 & & & & & \\
\hline & Maintenance Tech & 40000 & 8 & 320,000 & & 19 & & & & & \\
\hline & Shift Operators & 40000 & 20 & 800,001 & & 19 & & & & & \\
\hline & Yard Employees & 25000 & 12 & 300,000 & & 12 & & & & & \\
\hline & General Manager & 100000 & 0 & 0 & & 48 & & & & & \\
\hline & Clerks \& Secretaries & 25000 & 3 & 75,000 & & 12 & & & & & \\
\hline & Total Salaries & & 54 & $2,075,002$ & & & & & & 2.27 & 4.51 \\
\hline & & & & & & & & & & & \\
\hline & Overhead/Maint & $95 \%$ & $\begin{array}{l}\text { of Labor } \& \\
\text { Supervison }\end{array}$ & $2,154,783$ & & 37.66 & \begin{tabular}{|l|} 
PEP 2003 \\
(uses 37.66)
\end{tabular} & & & 2.15 & 4.27 \\
\hline & Maintenance & $2 \%$ & of TPI & $5,081,994$ & & & avg salary (u & $v /$ benefits) & & 5.08 & 10.08 \\
\hline & Insurance $\&$ Taxes & $2.0 \%$ & of TPI & $5,081,994$ & & & 78329.35 & & & 5.08 & 10.08 \\
\hline & & & & & & & & & & & \\
\hline & Costs & & & & & & & & & 14.59 & 28.94 \\
\hline & & & & & & & & & & & \\
\hline & & & & & & & & & & & \\
\hline & Total Cash Cost & & & & & & & & & 33.89 & 67.23 \\
\hline & & & & & & & & & & & \\
\hline & Annual Capital Charge & & & & & & & & & 44.72 & 88.72 \\
\hline
\end{tabular}




\section{Appendix E}

\section{Process Parameters \& Operation Summary}




\section{Energy Efficiencies}

Gasifier Efficiency - HHV \%

Gasifier Efficiency - LHV \%

Overall Plant Efficiency - HHV \%

Overall Plant Efficiency - LHV \%

\section{Dryer}

Temperature $\left({ }^{\circ} \mathrm{F}\right)$

Moisture Content ( $w \mathrm{t} \%)$

Outlet:

Temperature $\left({ }^{\circ} \mathrm{F}\right)$

Moisture Content ( $\mathrm{wt} \%)$

Inlet Flue Gas ( ${ }^{\circ} \mathrm{F}$ )

Outlet Flue Gas ( $\left.{ }^{\circ} \mathrm{F}\right)$

Dew Point Flue Gas $\left({ }^{\circ} \mathrm{F}\right)$

Difference

\section{Gasifier}

Temperature $\left({ }^{\circ} \mathrm{F}\right)$

Pressure (psia)

H2:CO Molar Ratio After Gasifier

Methane (vol\%)

Benzene (vol\%)

$\operatorname{Tar}(w t \%)$

$\operatorname{Tar}\left(\mathrm{g} / \mathrm{Nm}^{3}\right)$

Char (wt\%)

H2S (ppm)

Residual Heat (MBtu/hr)

\section{Syngas Usage}

To Reformer (lb/hr)

To Fuel System (b/hr)

\section{Fuel System}

Additional fuel (lb/hr)

Raw Syngas (lb/hr)

Unconverted Syngas (lb/hr)

Into Reformer $\left({ }^{\circ} \mathrm{F}\right)$

Out of Reformer ( $\left.{ }^{\circ} \mathrm{F}\right)$

\section{Air Separation Unit}

Air in $(\mathrm{lb} / \mathrm{hr})$

Liquefaction Compressor Pressure (psia)

N2 to Vent (lb/hr)

N2 to Feed Dryer (lb/hr)

N2 pressure (psia)

02 to Gasifier

02 to Gasifier Pressure (psia)

\section{Tar Reformer}

Inlet Molar Flow (MMscf/hr)

Space Velocity $\left(\mathrm{hr}^{-1}\right)$

39.5 Reactor Volume ( $\left.\mathrm{ft}^{3}\right)$

38.4 Inlet:

Temperature $\left({ }^{\circ} \mathrm{F}\right)$

Carbon as $\mathrm{CO}(\mathrm{mol} \%)$

Carbon as tar (ppmv)

60.0 H2:CO Ratio (mole)

$50.0 \%$

Reformer Conversions:

$\mathrm{CO} 2->\mathrm{CO}$

Methane $-\rightarrow \mathrm{CO}$

Methane $->>\mathrm{CO}$ (\% of equilibrium)

Ethane $-\rightarrow \mathrm{CO}$

Benzene --> CO

Tar $->$ CO

Ammonia $-\rightarrow \mathrm{CO}$

Ammonia --> $\mathrm{CO}$ (\% of equilibrium)

1,600 Outlet:

438.0 Temperature $\left({ }^{\circ} \mathrm{F}\right)$

1.23 Carbon as $\mathrm{CO}(\mathrm{mol} \%)$

$13.9 \%$ Carbon as tar (ppmv)

$0.99 \%$ H2:CO Ratio (mole)

$4.54 \% \quad$ Methane (vol\%)

52.7 Benzene (ppmv)

3.8\% Tars (ppmv)

448 Tars $\left(\mathrm{g} / \mathrm{Nm}^{3}\right)$

$15,757 \quad$ H2S (ppm)

$\mathrm{NH} 3(\mathrm{ppm})$

156,554 Quench

107,461 Benzene (ppmv)

Tars (ppmv)

Tars $\left(\mathrm{g} / \mathrm{Nm}^{3}\right)$

$0 \quad \mathrm{H} 2 \mathrm{~S}(\mathrm{ppm})$

107,461 NH3 (ppm)

17,367 Acid Gas Removal

3,120 Inlet:

2,161 CO2 (mol/hr)

$\mathrm{CO} 2(\mathrm{~mol} \%)$

$\mathrm{H} 2 \mathrm{~S}$ ( $\mathrm{mol} / \mathrm{hr})$

176,280 H2S (ppmv)

132 Outlet:

$98,071 \quad \mathrm{CO} 2(\mathrm{~mol} / \mathrm{hr})$

$34,856 \quad \mathrm{CO} 2(\mathrm{~mol} \%)$

72 Fraction $\mathrm{CO} 2$ removed

$42,281 \quad \mathrm{H} 2 \mathrm{~S}(\mathrm{~mol} / \mathrm{hr})$

$440 \quad \mathrm{H} 2 \mathrm{~S}(\mathrm{ppmv})$

Fraction $\mathrm{H} 2 \mathrm{~S}$ removed
Alcohol Synthesis

8.17 Syngas from Conditioning 268,724

2,476 Recycled from initial flash tank

3,301 Recycled from MolSieve Flush

Total

68,724
217

4,573

273,514

$22.0 \%$

55,624 Conditioned Syngas H2:CO Ratio

1.47 Recycled Gas H2:CO Ratio $\quad 1.56$

At Reactor Inlet

Temperature $\left({ }^{\circ} \mathrm{F}\right)$

Pressure (psia)

$\mathrm{CO} 2(\mathrm{~mol} \%)$

Methane (mol\%)

$\mathrm{H} 2 \mathrm{O}(\mathrm{wt} \%)$

Inlet Molar Flow (MMscf/hr)

Space Velocity $\left(\mathrm{hr}^{-1}\right)$

Reactor Volume ( $\left.\mathrm{ft}^{3}\right)$

CO Conversion - Overall

CO Conversion - Singlepass

Conversion To:

$\mathrm{CO} 2$

Methane

Ethane

Methanol

Ethanol

Propanol

Butanol

Pentanol

1.56

Tota

570

991

1.20

$6.8 \%$

$0.86 \%$

6.4

6,000

$59.3 \%$

$21.9 \%$

$3.4 \%$

$0.2 \%$

$28.0 \%$

$4.6 \%$

$0.6 \%$

$59.2 \%$

Selectivity (CO2 Free)

49 Alcohols

Hydrocarbons

$90.1 \%$

At Reactor Outlet

3,535 Temperature $\left({ }^{\circ} \mathrm{F}\right)$

$8.4 \% \quad$ Pressure $(\mathrm{psia})$

$\mathrm{CO} 2(\mathrm{~mol} \%)$

$\mathrm{H} 2 \mathrm{O}(\mathrm{wt} \%)$

986

$18.6 \%$

$11.4 \%$

829

Total Alcohol Productivity (kg/kg/hr)

Total Ethanol Productivity (kg/kg/hr)

0.751

4

44

$99.6 \%$ 
Alcohol Synthesis

Distribution After Reactor

Methanol

Propanol

Butanol

Flash Separato

Temperature $\left({ }^{\circ} \mathrm{F}\right)$

Pressure (psia)

Relative Alcohol Distribution After Flash Tank

Methanol

Ethanol

Propanol

Butanol

Pentanol +

Vapor Losses From Flash Tank

Methanol

Ethanol

Propanol

Butanol

Pentanol +

Cleaned Gas Recycled to Reactor

\section{Residual Syngas}

Recycled to synthesis reactors (lb/hr)

To Tar Reformers (lb/hr)

To Fuel System (lb/hr)

To Reformer for Process (lb/hr)
Alcohol Separation

Upstream of LP Separator Valve

$\begin{array}{ll}8.5 \% & \text { Temperature }\left({ }^{\circ} \mathrm{F}\right) \\ 81.7 \% & 110.0\end{array}$

$81.7 \%$ Pressure (psia) 972.0

$0.9 \% \quad$ LP Separator

$0.1 \% \quad$ Temperature $\left({ }^{\circ} \mathrm{F}\right) \quad 98.8$

$\begin{array}{ll}\text { Pressure (psia) } & 60.0\end{array}$

110 LP Separator Recoveries (Liquid)
972 Methanol

$\begin{array}{lr}\text { Methanol } & 99.4 \% \\ \text { Ethanol } & 99.7 \%\end{array}$

Propanol 99.9\%

$8.3 \%$ Butanol $\quad 100.0 \%$

$81.8 \%$ Pentanol +

$9.0 \%$ Water $\quad 99.9 \%$

$0.9 \%$

0.1\% Mole Sieve Effluent (mol\%)
$\mathrm{H} 2 \mathrm{O}$

$\begin{array}{ll}\text { H2O } & 47.5 \% \\ \text { Methanol } & 47.4 \%\end{array}$

Butanol $\quad 0.0 \%$

Relative C3+ Alcohol Distribution $\quad 0.0 \%$

Ethanol - $7.6 \%$

Propanol

217 Butanol $8.4 \%$

217,095 Pentanol +

17,367
199,726 Ethanol Recoveries:

Initial flash tank $\quad 97.5 \%$

$\begin{array}{ll}\text { LP Separator } & 99.7 \% \\ \mathrm{C} 2 \mathrm{OH} / \mathrm{C} 3 \mathrm{OH} \text { Splitter } & 99.0 \%\end{array}$

Final $\mathrm{MeOH}$ Stripper $\quad 99.0 \%$

Overall 
Appendix $F$

Process Flow Diagrams (PFDs) 


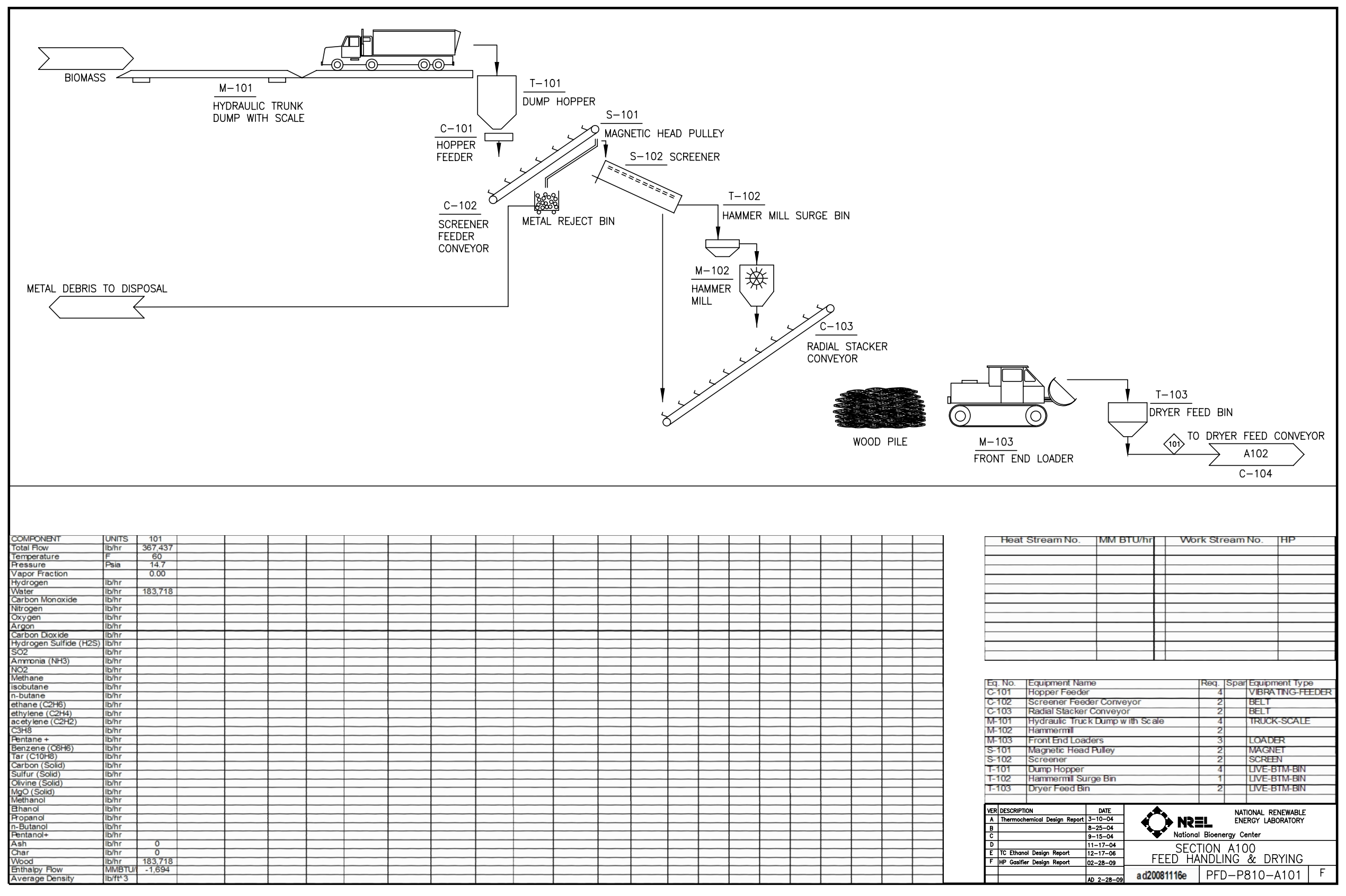




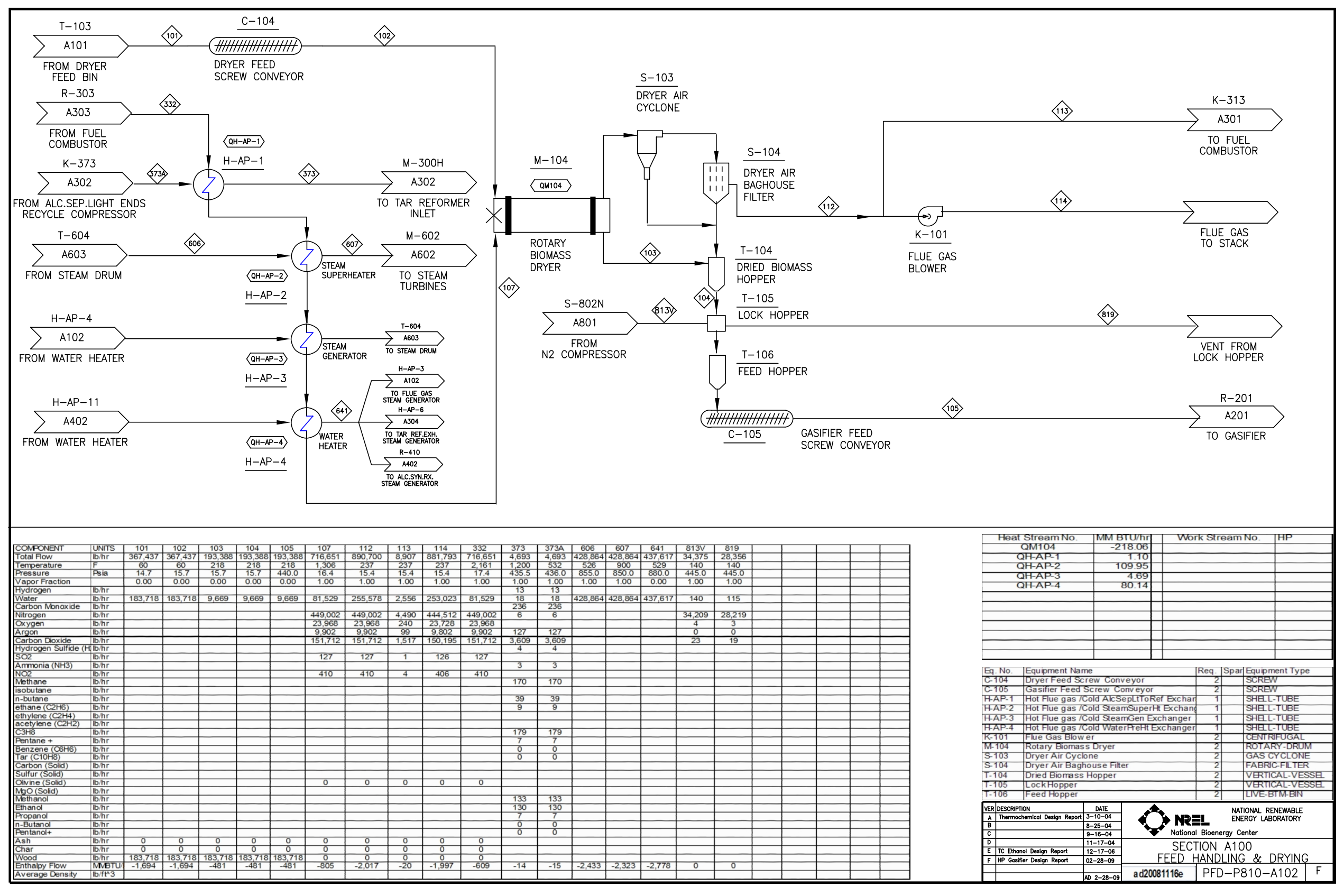




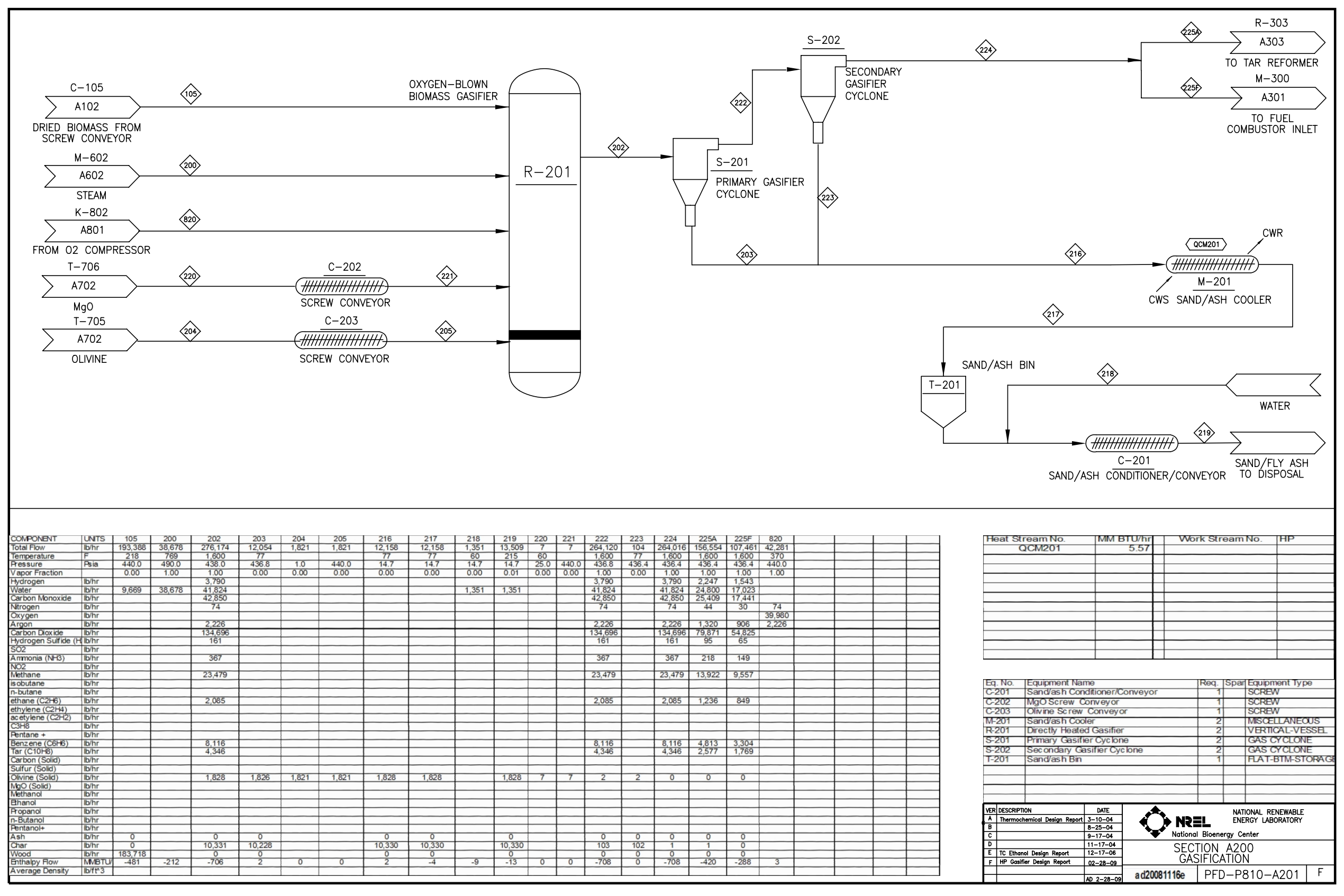




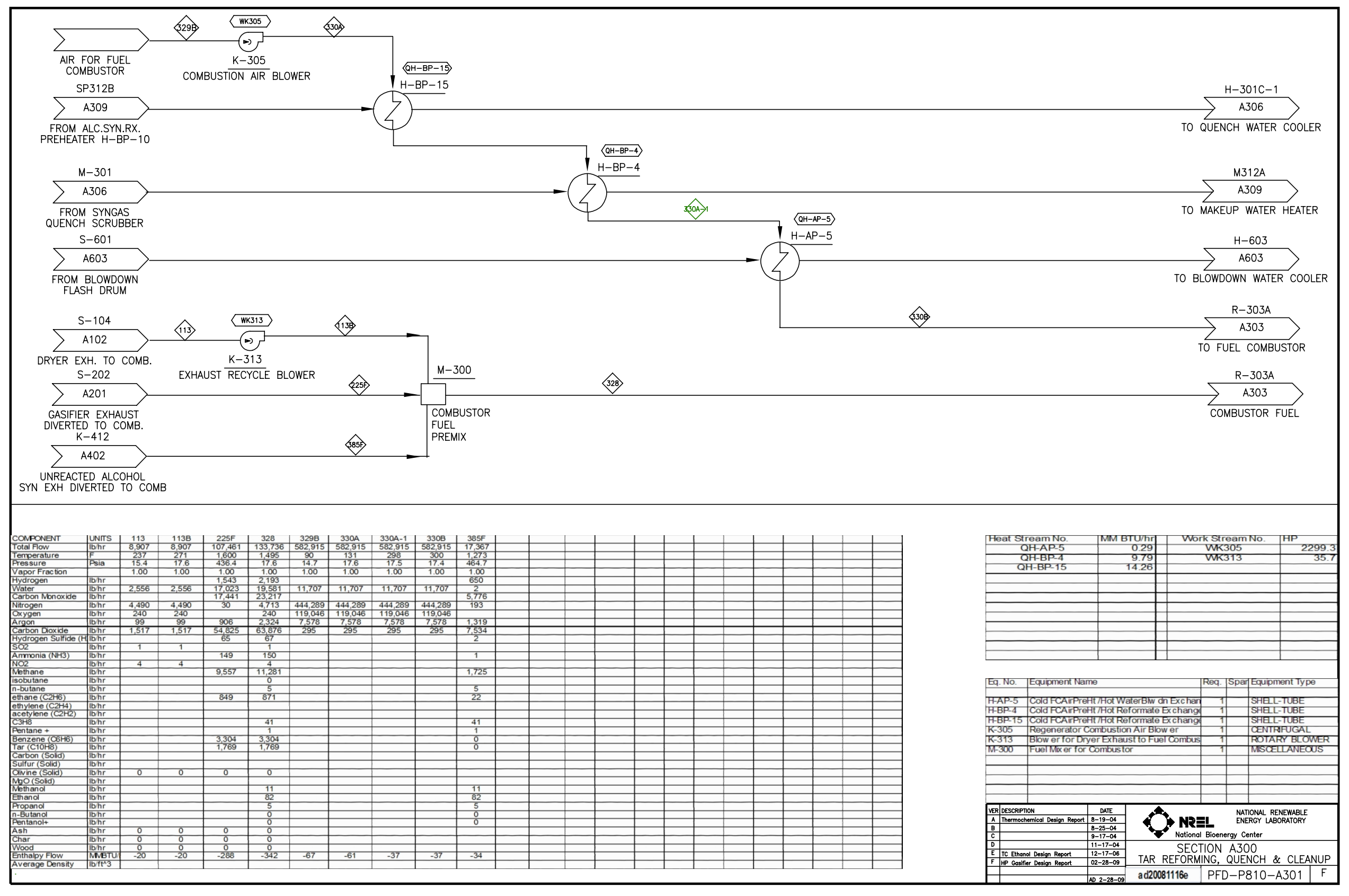




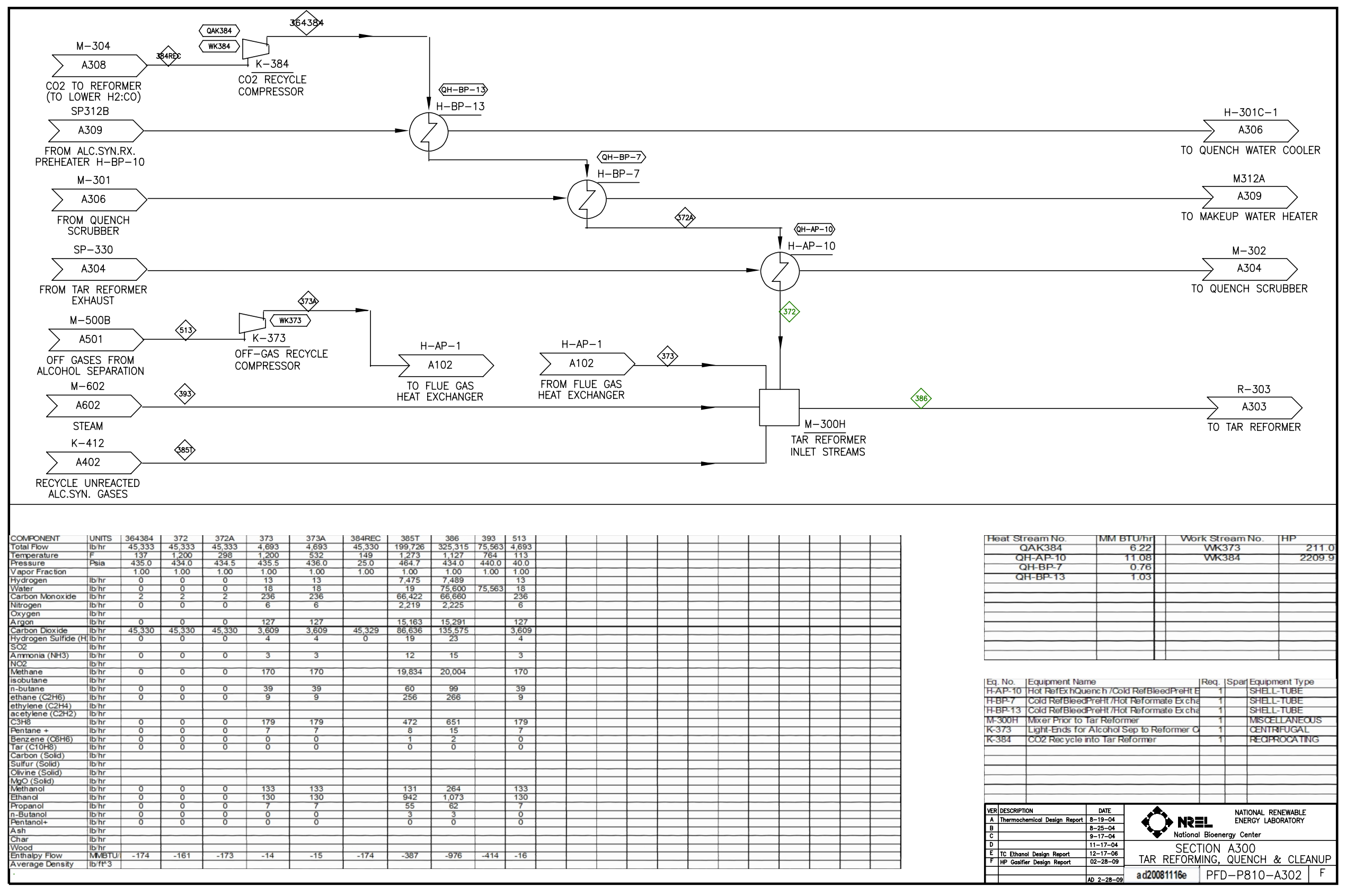




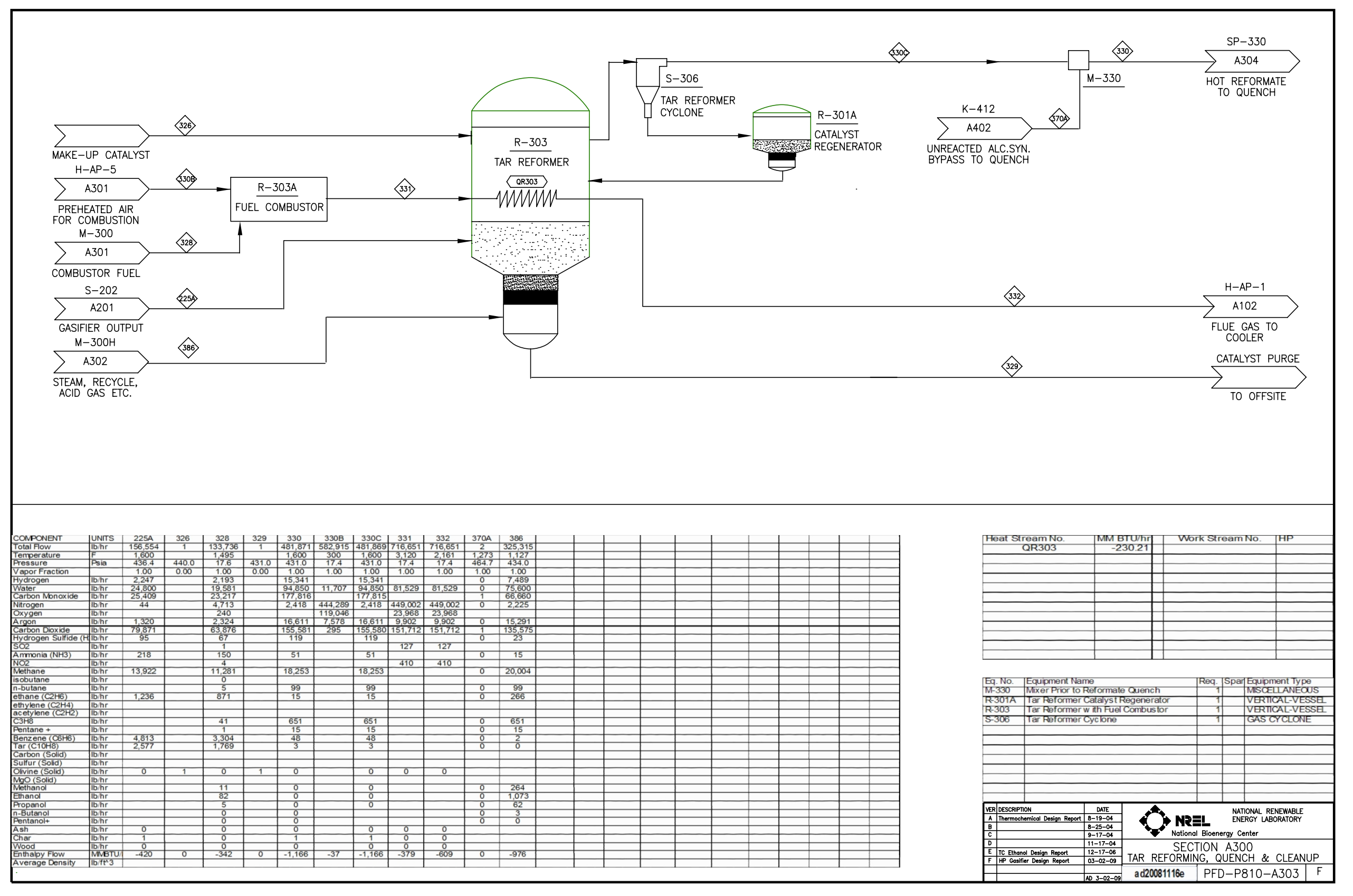




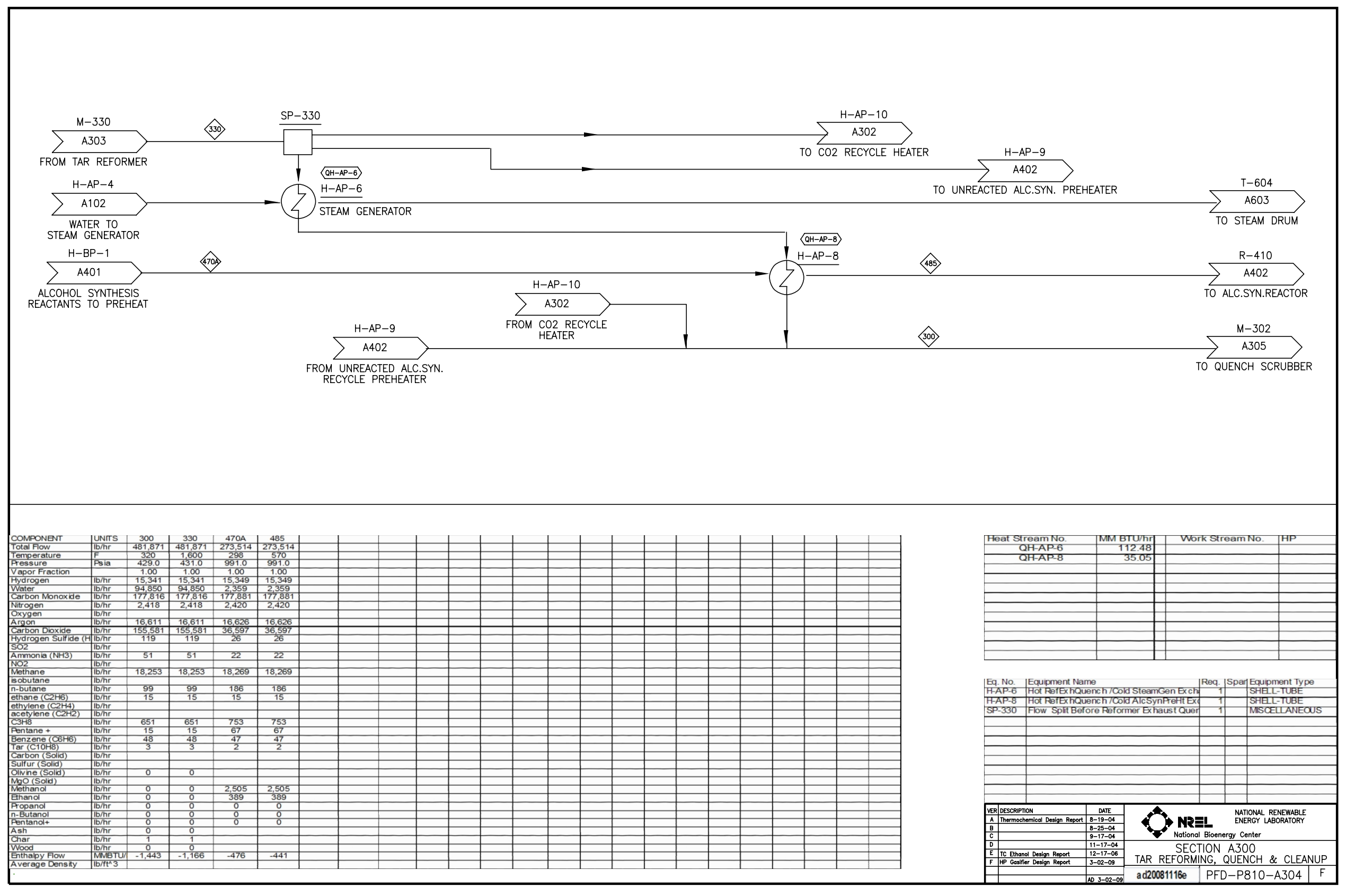




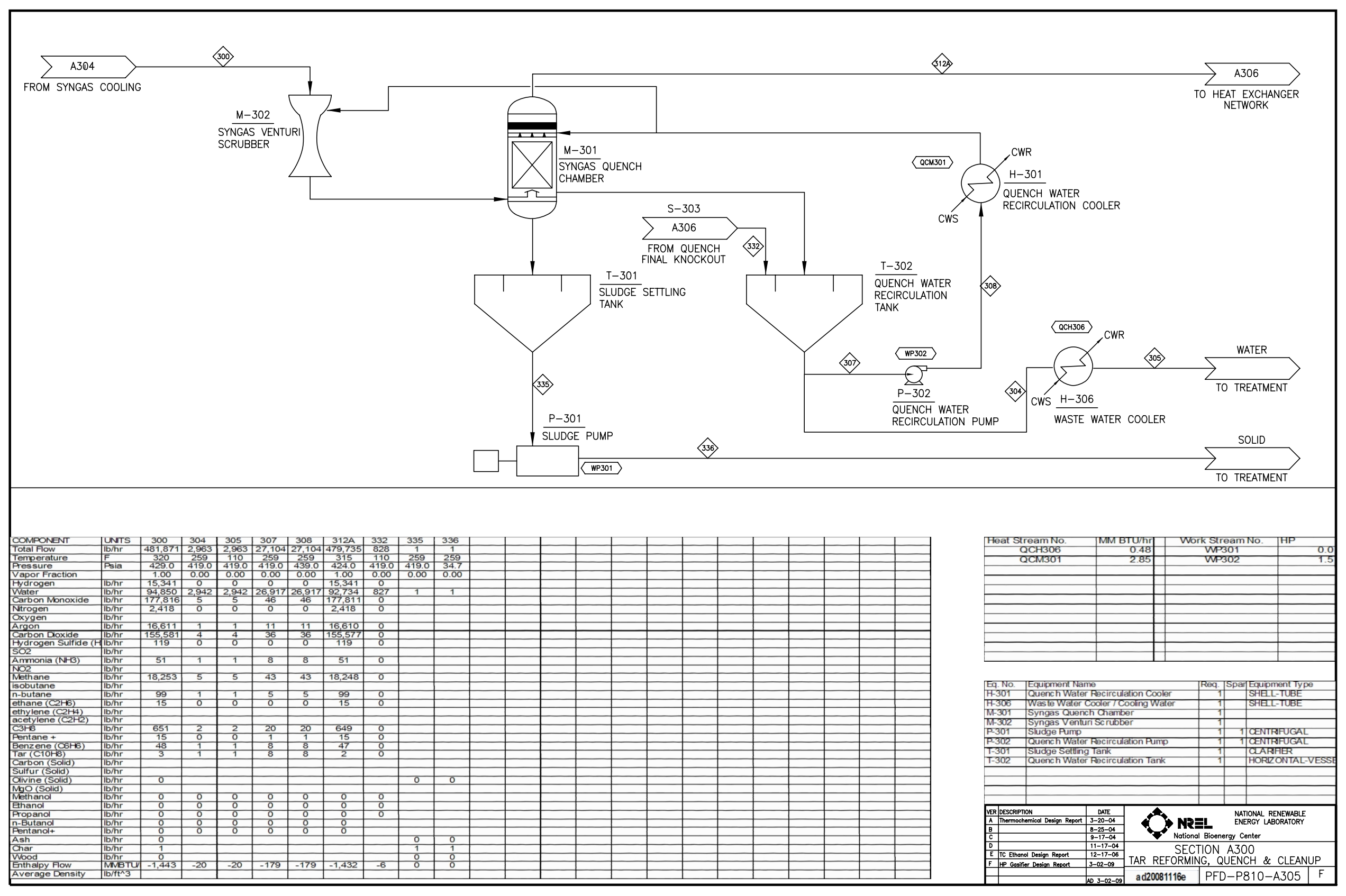



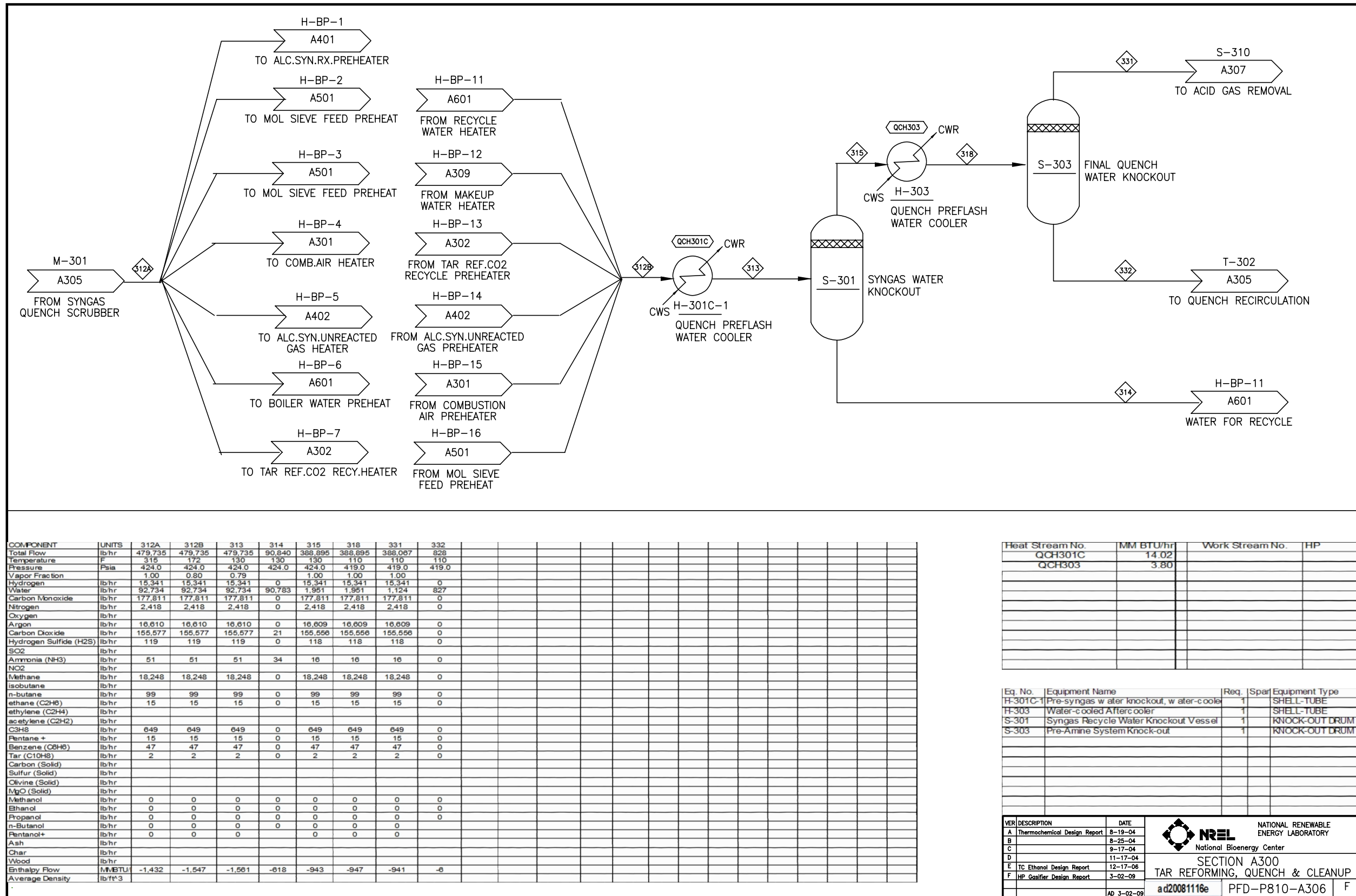

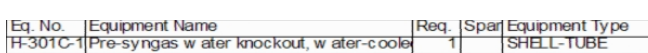

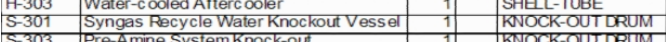
5-303 Pre-Amine System Knock-oul

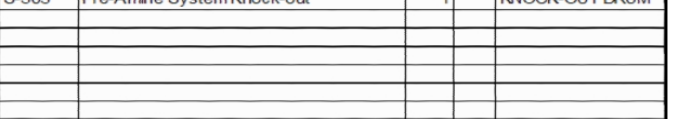

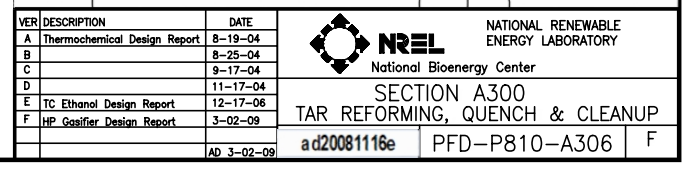



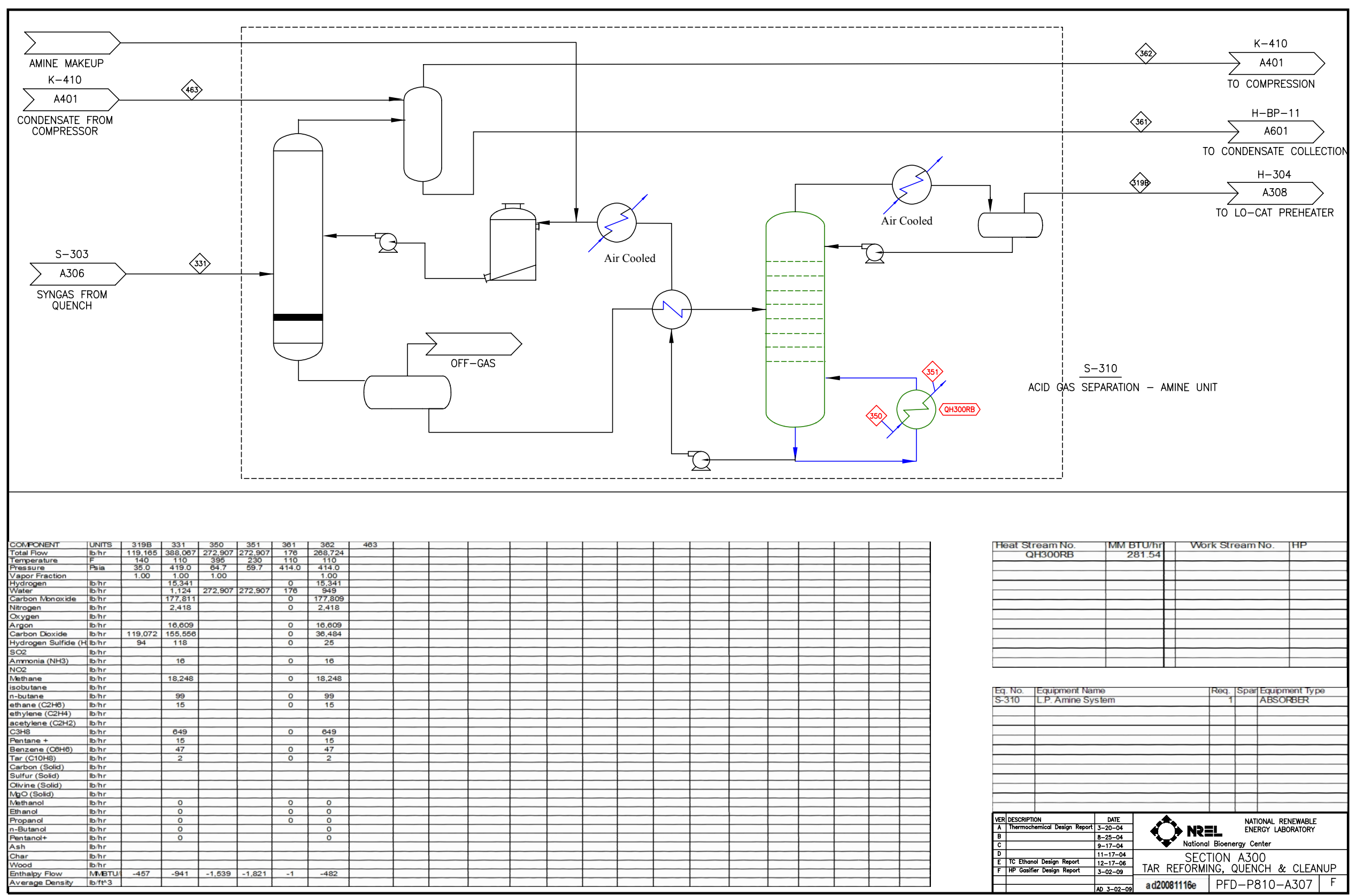

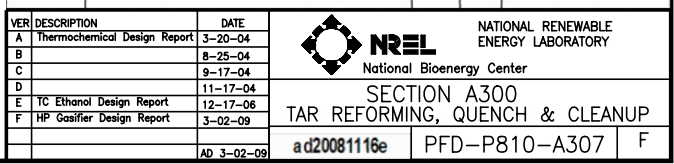




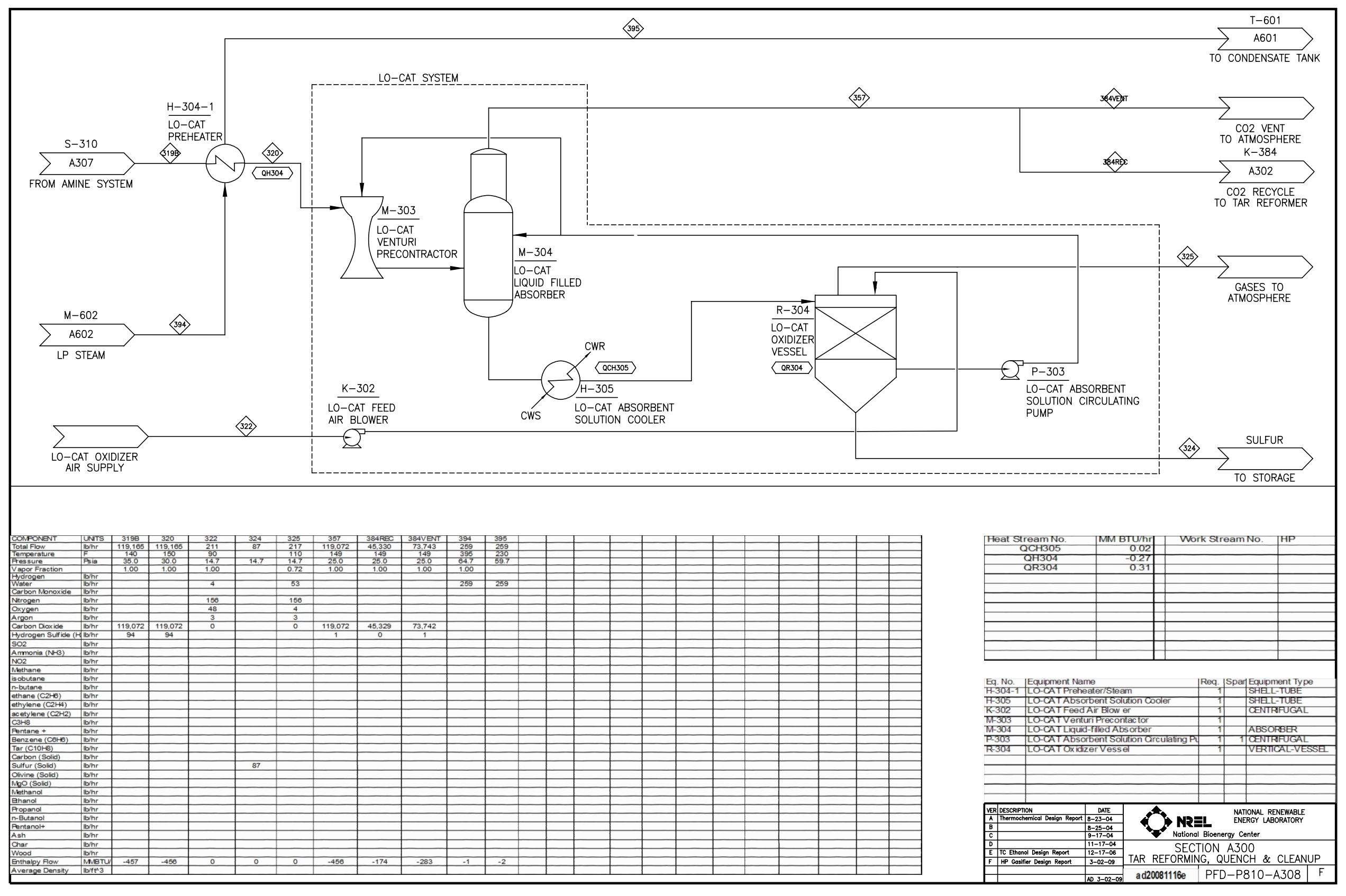




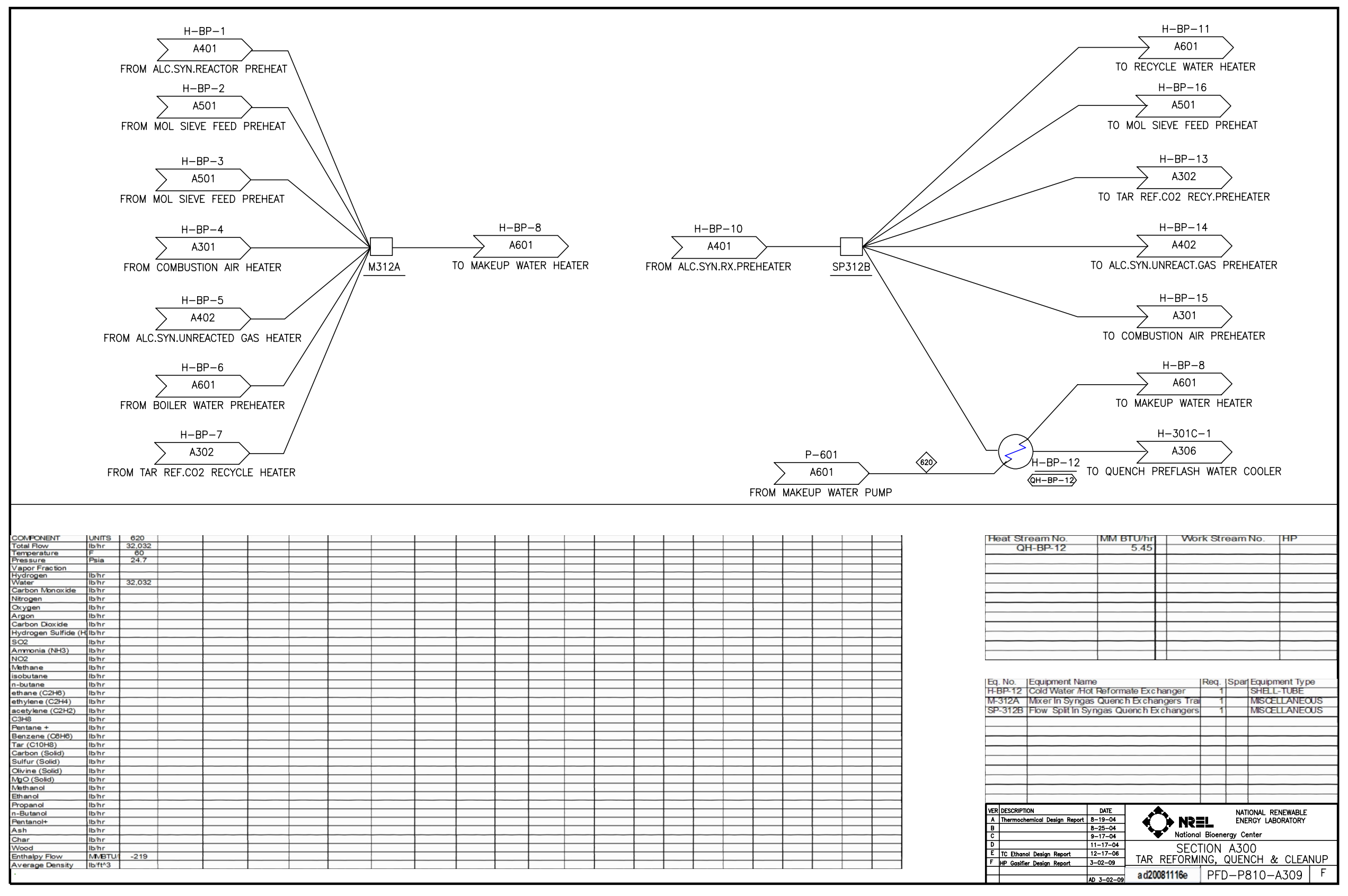




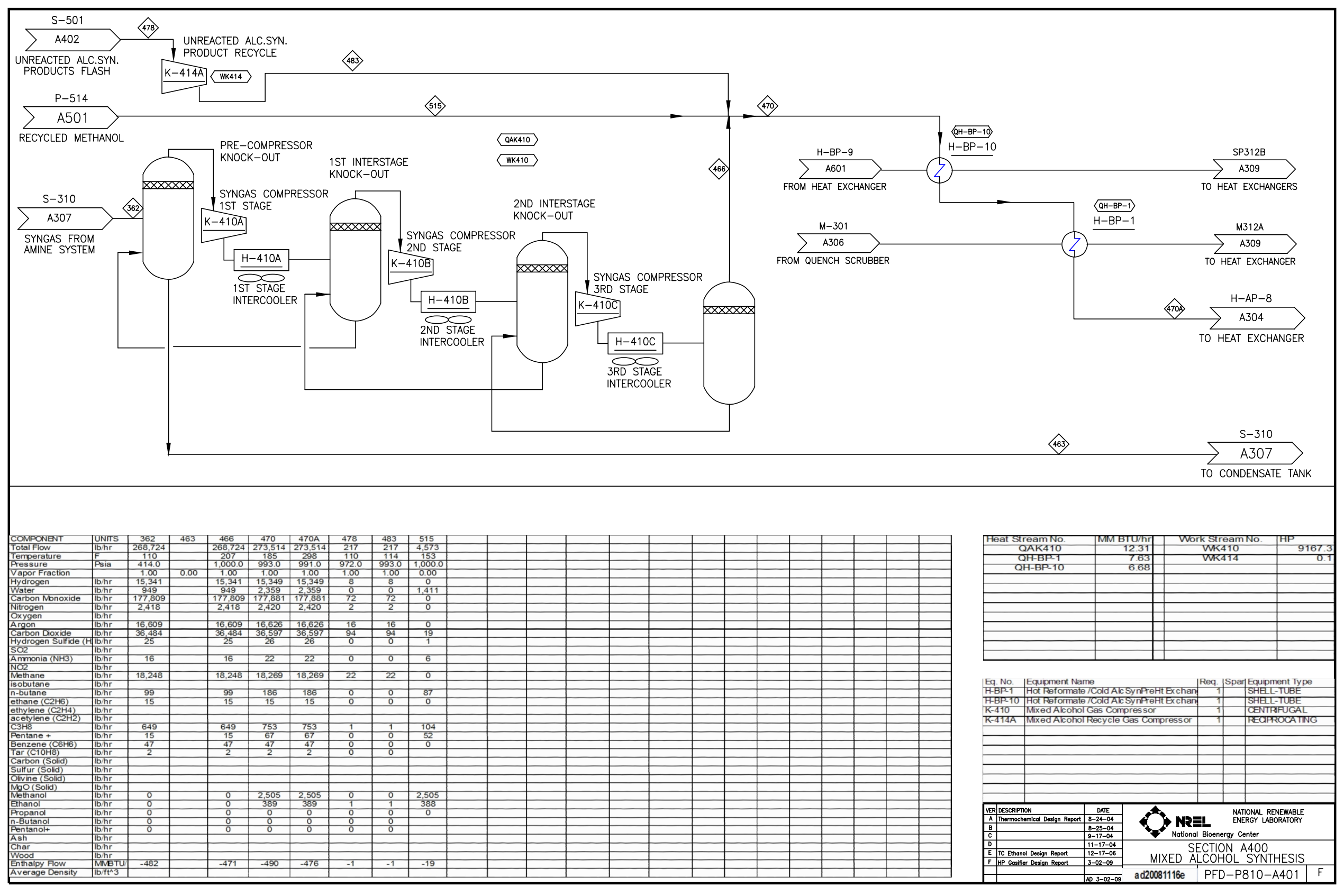




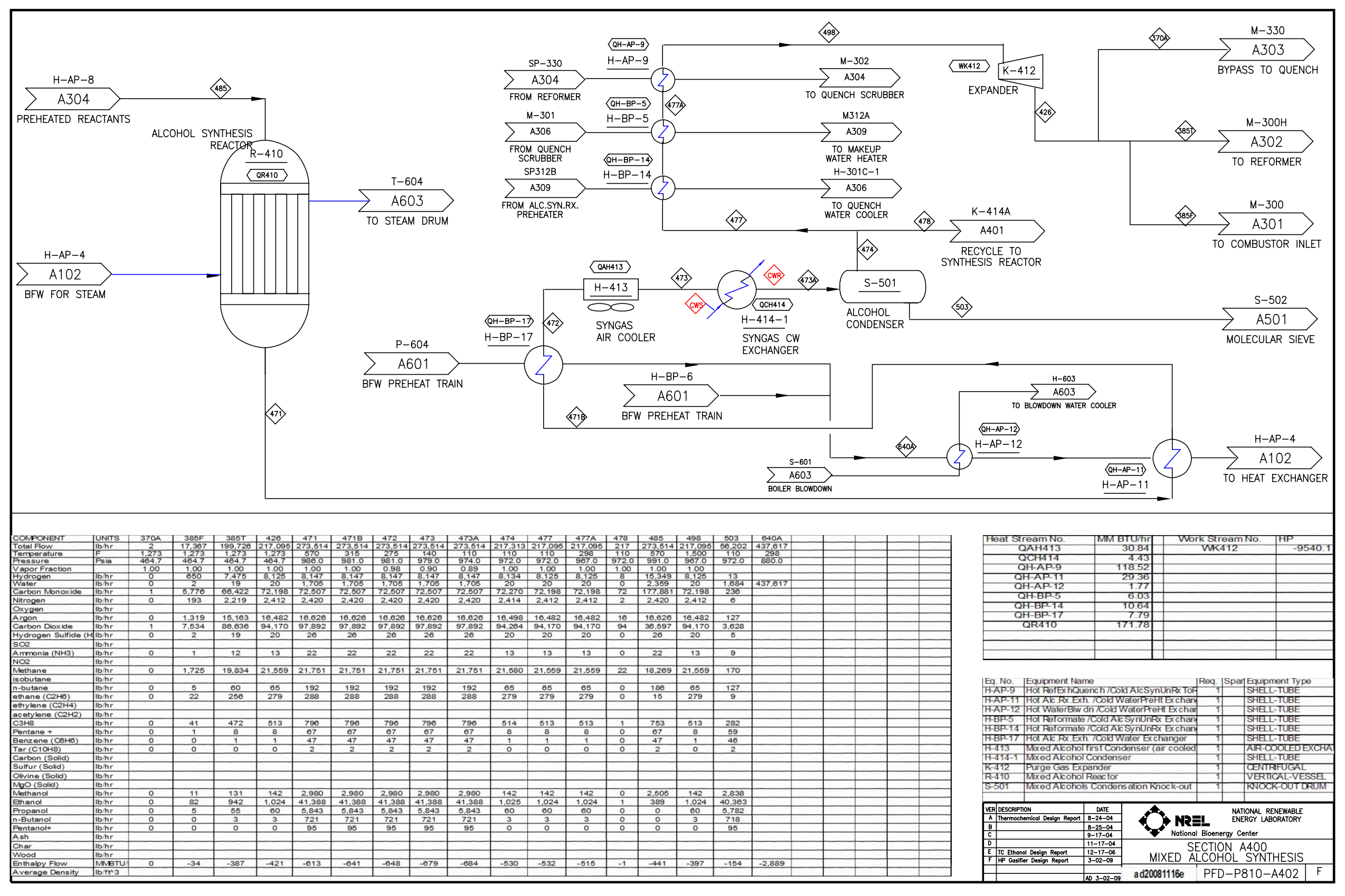




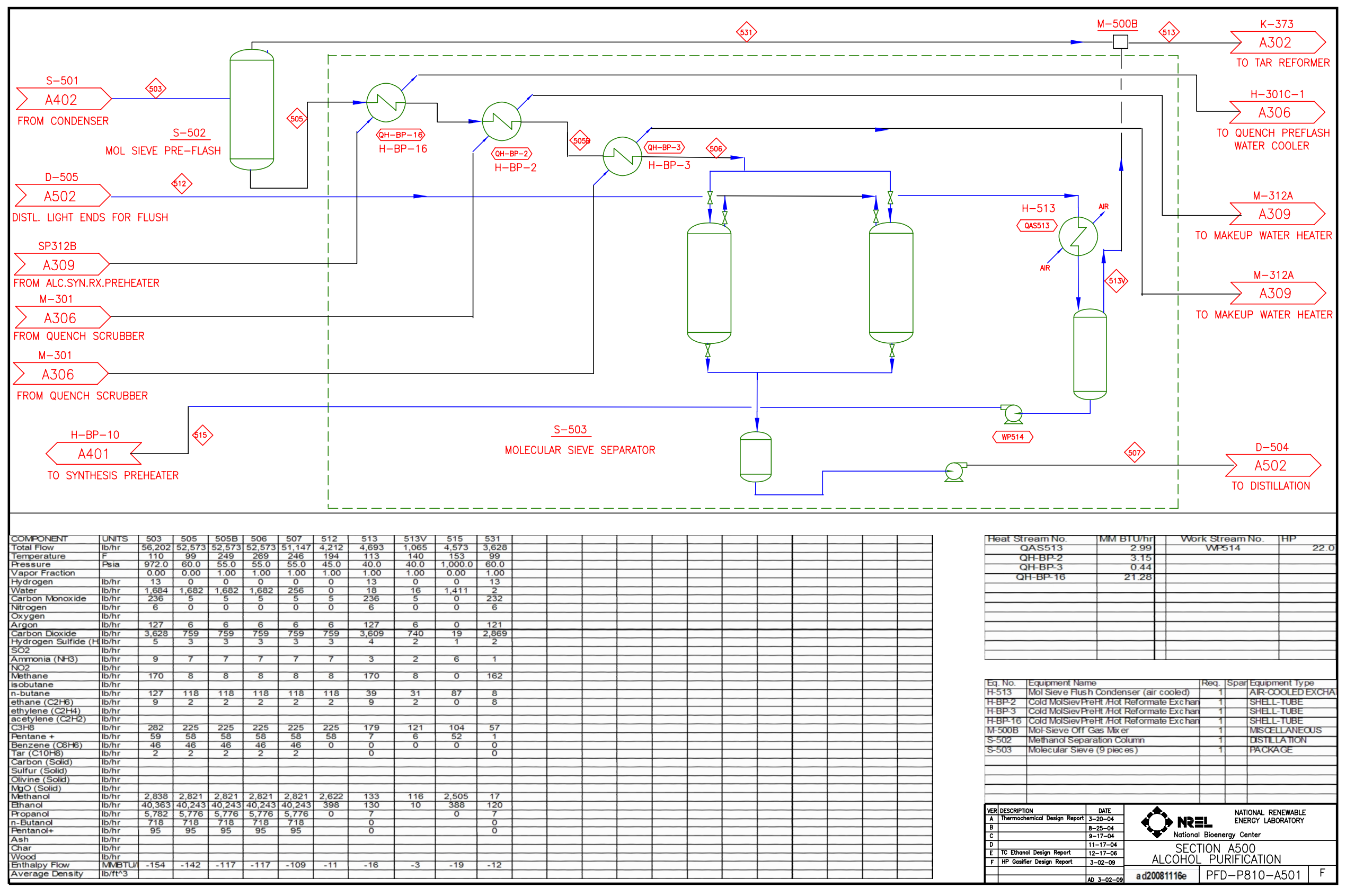




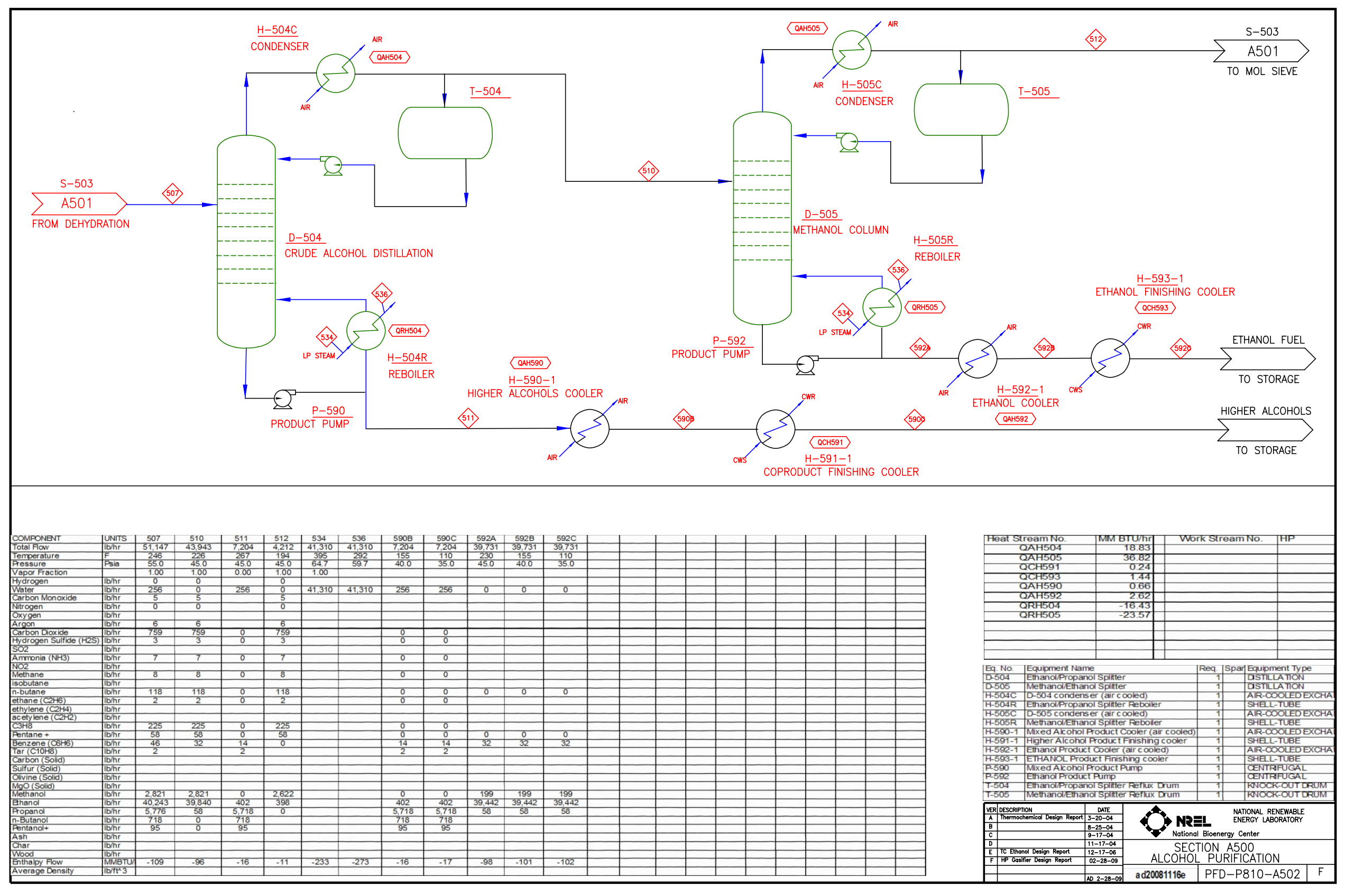




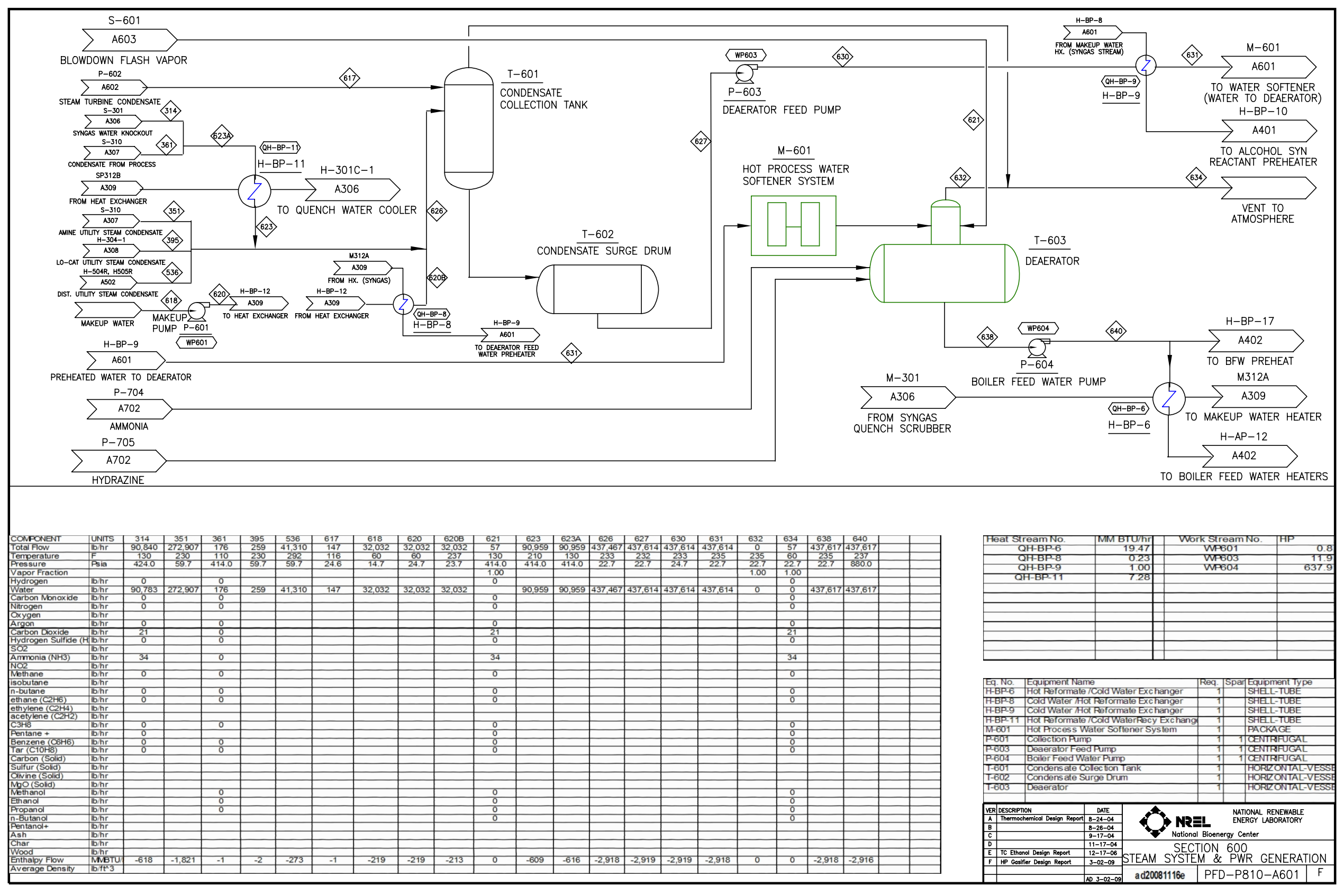




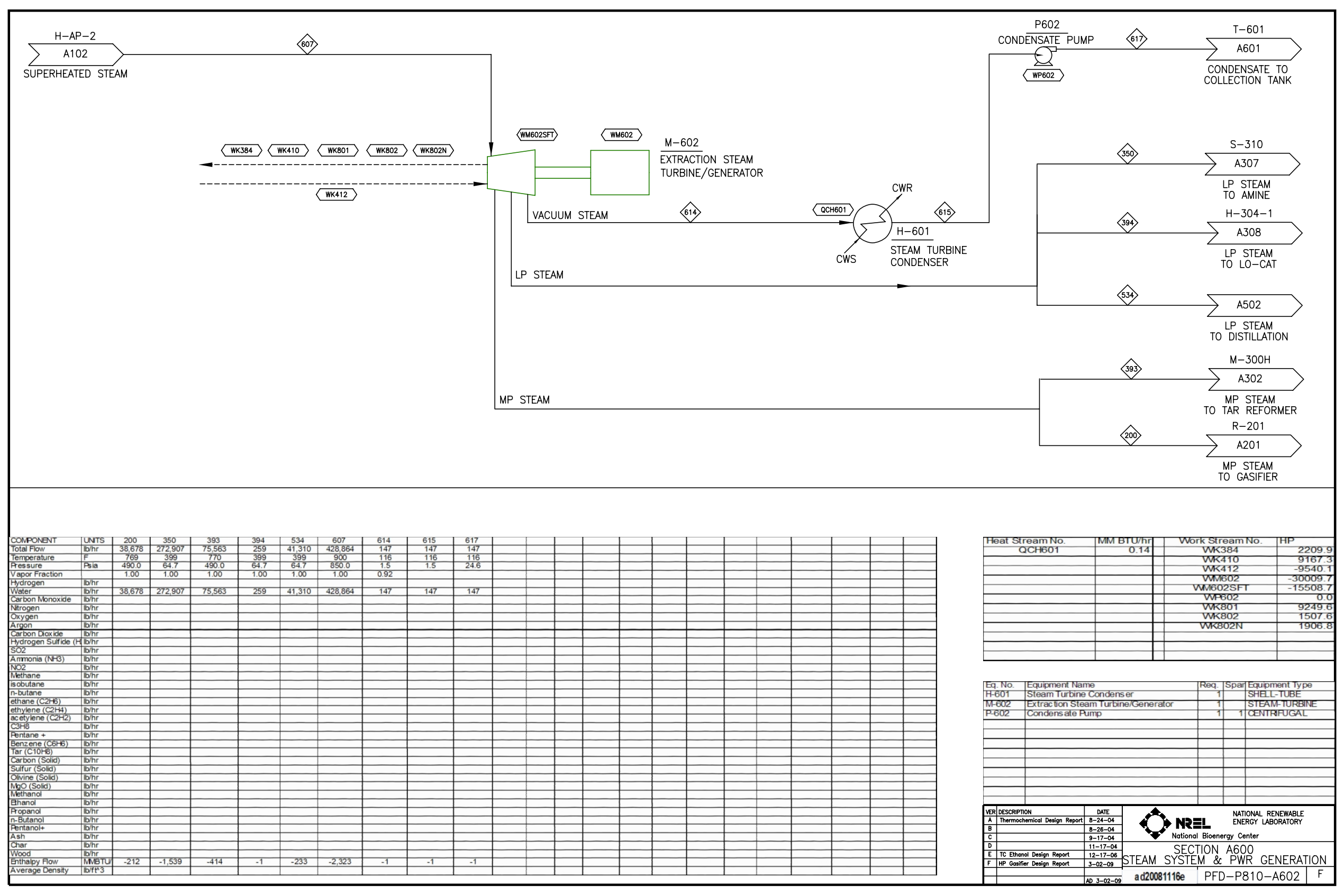




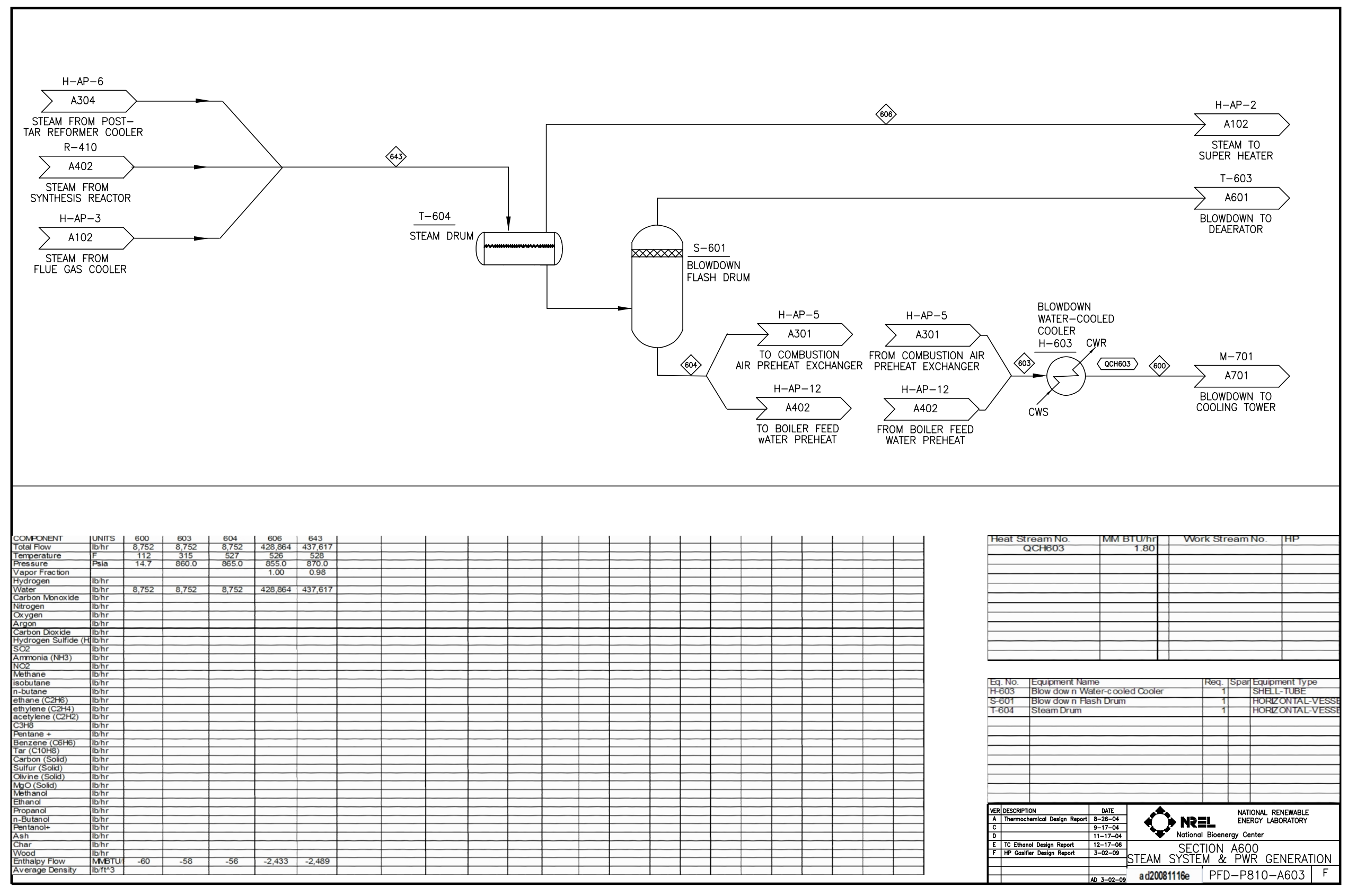



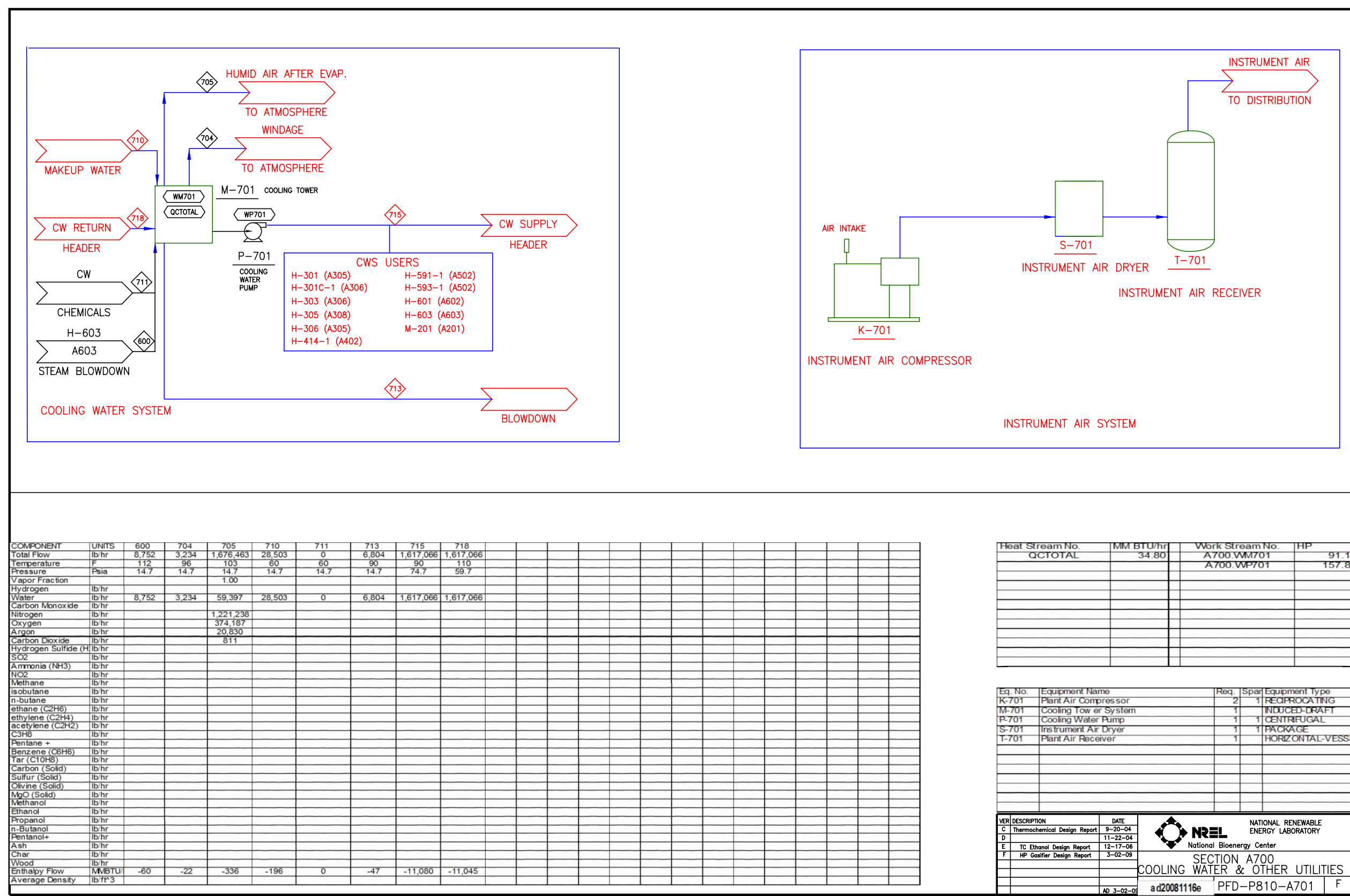

\begin{tabular}{|c|c|c|c|}
\hline $\begin{array}{r}\text { Heat Stream No } \\
\text { QCTOTAL }\end{array}$ & $\begin{array}{r}\text { MIM BTU/1TI } \\
34.80 \\
\end{array}$ & $\begin{array}{c}\text { Work Stream No. } \\
\text { A700.WMT101 } \\
\text { A700W }\end{array}$ & $\begin{array}{r}\text { PHP } 91 . \\
1578\end{array}$ \\
\hline & & & \\
\hline & & & \\
\hline & & & \\
\hline & & & \\
\hline & & & \\
\hline
\end{tabular}

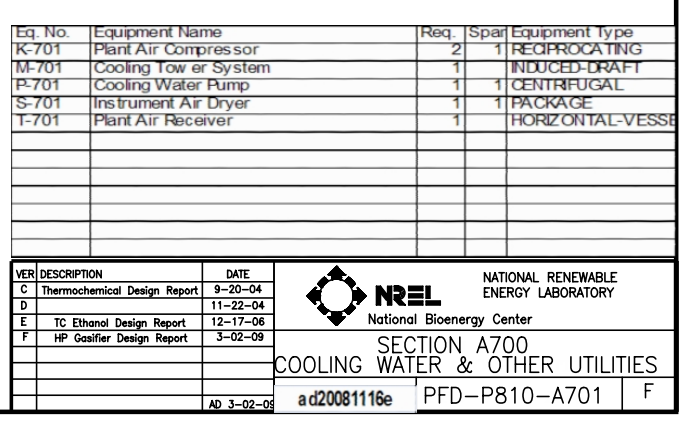




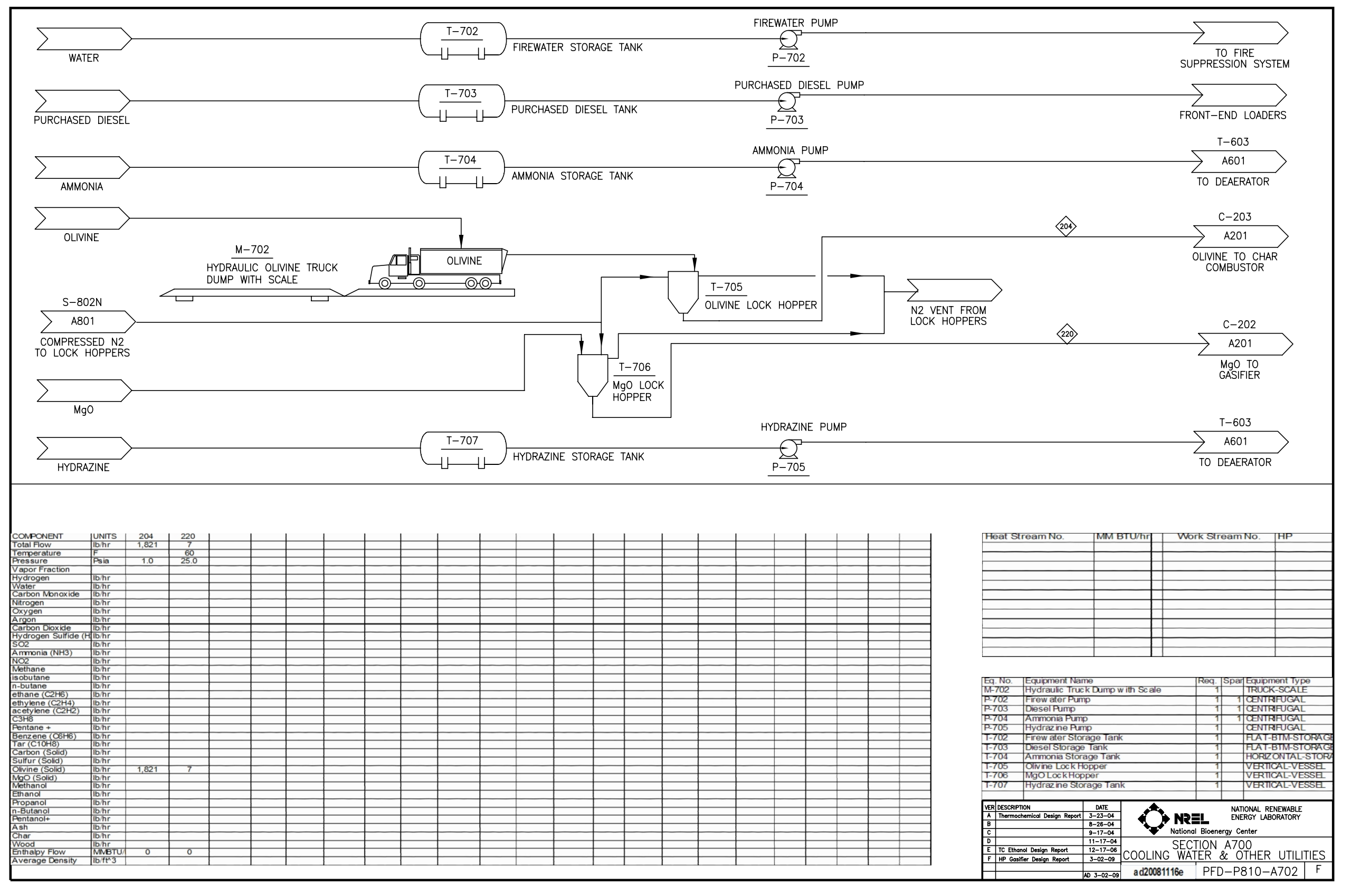



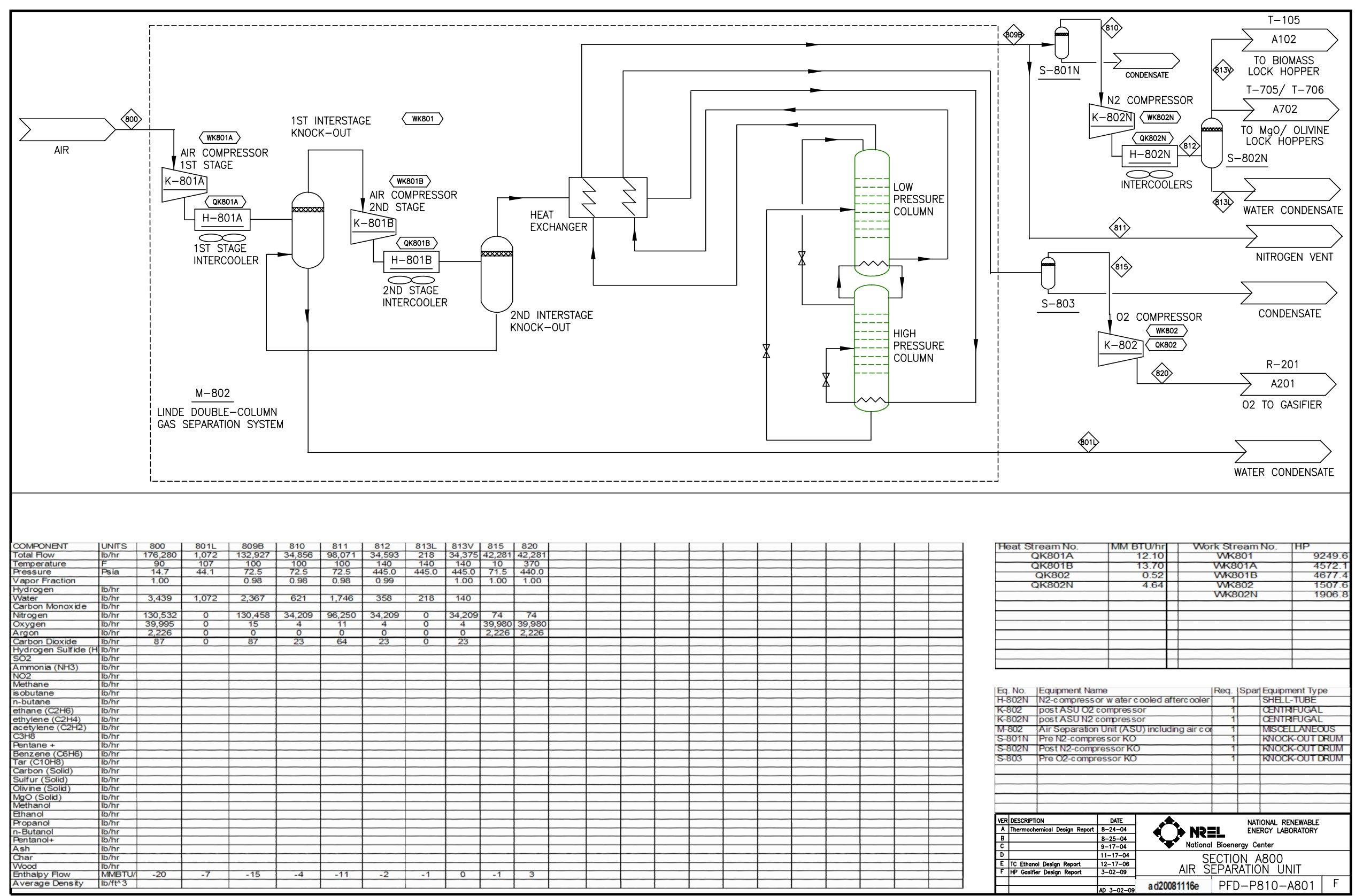


\section{Appendix G}

Syngas and Char Correlations 
The gasifier was modeled using correlations based on data from the Gas Technology Institute (GTI - formerly Institute of Gas Technology) 12 ton/day test facility. The data and original correlations for the gasifier can be found in Evans et al (1988). ${ }^{1}$ The temperature range for the data is $1,390^{\circ} \mathrm{F}$ to $1,800^{\circ} \mathrm{F}$, the pressure range is 83.7 to $344.7 \mathrm{psia}$, the oxygen to feed carbon molar ratio is 0.148 to 0.343 , and the water to feed carbon molar ratio is 0.24 to 1.97 ; the majority of the data are in the range of $1,500^{\circ} \mathrm{F}$ to $1,672^{\circ} \mathrm{F}$. The experimental data was collected from 22 runs using maple wood chips, whole tree chips from Pennsylvania $(90 \%$ red oak; balance chestnut, aspen, and black birch) or whole tree chips from Wisconsin (34\% maple, $33.5 \%$ oak, $19.6 \%$ birch, $12.9 \%$ pine and brush) as feedstocks. The correlations used in this report are from Eggeman (2005). ${ }^{2}$

The GTI test facility's gas production data was correlated to gasifier temperature, pressure, $\mathrm{O}_{2}$ :Feed C molar ratio, and $\mathrm{H}_{2} \mathrm{O}$ :Feed $\mathrm{C}$ molar ratio. $1 \%$ of the higher heating value of wood is assumed to be lost from the gasifier. The steam supplied to the gasifier is $20 \%$ by weight of the dried wood going into the gasifier, where the dried wood contains $5 \%$ water by weight. The oxygen supplied to the gasifier is adjusted to maintain the specified gasifier temperature of $1600^{\circ} \mathrm{F}$. Details of the correlation equations and parameters are shown in the following table. 
Table G-1. GTI Gasifier Correlation ${ }^{a}$

\begin{tabular}{|c|c|c|c|c|c|c|c|}
\hline Eq. & Form & $\mathrm{A}$ & B & C & D & $E$ & $\mathrm{R}^{2}$ \\
\hline 1 & $\mathrm{H}_{2} /$ Feed $\mathrm{H}=\mathrm{A}+\mathrm{B}^{*} \mathrm{P}+\mathrm{C} * \mathrm{~T}+\mathrm{D}^{*}\left(\frac{\mathrm{O}_{2}}{\mathrm{Feed} \mathrm{C}}\right)+E^{*}\left(\frac{\mathrm{H}_{2} \mathrm{O}}{\text { Feed } \mathrm{C}}\right)$ & $-3.830761 \mathrm{E}-01$ & 1.894350E-04 & 2.666675E-04 & $1.060088 \mathrm{E}-01$ & $7.880955 \mathrm{E}-02$ & 0.7828 \\
\hline 2 & $C O /$ Feed $C=A+B * P+C * T+D *\left(\frac{\mathrm{O}_{2}}{\text { Feed } C}\right)+E *\left(\frac{\mathrm{H}_{2} \mathrm{O}}{\text { Feed } C}\right)$ & $-8.130017 \mathrm{E}-02$ & $-3.340050 \mathrm{E}-04$ & $2.614482 \mathrm{E}-04$ & 1.495730E-01 & $-5.268367 \mathrm{E}-02$ & 0.7984 \\
\hline 3 & $\mathrm{CO}_{2} /$ Feed $C=A+B * P+C * T+D *\left(\frac{\mathrm{O}_{2}}{\text { Feed C }}\right)+E *\left(\frac{\mathrm{H}_{2} \mathrm{O}}{\text { Feed } \mathrm{C}}\right)$ & $7.157172 \mathrm{E}-02$ & $3.843454 \mathrm{E}-04$ & $1.286060 \mathrm{E}-05$ & $6.124545 \mathrm{E}-01$ & $9.980868 \mathrm{E}-02$ & 0.9080 \\
\hline 4 & $\mathrm{CH}_{4} /$ Feed $\mathrm{C}=\mathrm{A}+\mathrm{B} * \mathrm{P}+\mathrm{C} * \mathrm{~T}+\mathrm{D} *\left(\frac{\mathrm{O}_{2}}{\text { Feed } \mathrm{C}}\right)+E *\left(\frac{\mathrm{H}_{2} \mathrm{O}}{\text { Feed C }}\right)$ & $1.093589 \mathrm{E}-02$ & $1.388446 \mathrm{E}-04$ & $8.812765 \mathrm{E}-05$ & $-2.274854 \mathrm{E}-01$ & $3.427825 \mathrm{E}-02$ & 0.6243 \\
\hline 5 & $\mathrm{C}_{2} \mathrm{H}_{4} /$ Feed $\mathrm{C}=\mathrm{A}+\mathrm{B} * \mathrm{P}+\mathrm{C} * \mathrm{~T}+\mathrm{D} *\left(\frac{\mathrm{O}_{2}}{\text { Feed } \mathrm{C}}\right)+E *\left(\frac{\mathrm{H}_{2} \mathrm{O}}{\text { Feed } \mathrm{C}}\right)$ & $5.301812 \mathrm{E}-02$ & $-6.740399 \mathrm{E}-05$ & $-1.372749 \mathrm{E}-05$ & $-9.076286 \mathrm{E}-03$ & $-4.854082 \mathrm{E}-03$ & 0.8910 \\
\hline 6 & $\mathrm{C}_{2} \mathrm{H}_{6} /$ Feed $\mathrm{C}=\mathrm{A}+\mathrm{B}^{*} \mathrm{P}+\mathrm{C}^{*} \mathrm{~T}+\mathrm{D}^{*}\left(\frac{\mathrm{O}_{2}}{\mathrm{Feed} C}\right)+E^{*}\left(\frac{\mathrm{H}_{2} \mathrm{O}}{\mathrm{Feed} C}\right)$ & $1.029750 \mathrm{E}-01$ & $-5.440777 \mathrm{E}-06$ & $-5.350103 \mathrm{E}-05$ & $-3.377091 \mathrm{E}-02$ & $-1.915339 \mathrm{E}-03$ & 0.7451 \\
\hline 7 & $\mathrm{C}_{6} \mathrm{H}_{6} /$ Feed $\mathrm{C}=A+B * P+C * T+D *\left(\frac{\mathrm{O}_{2}}{\text { Feed } C}\right)+E *\left(\frac{\mathrm{H}_{2} \mathrm{O}}{\text { Feed } C}\right)$ & 4.676833E-02 & $-1.937444 \mathrm{E}-05$ & $-1.270868 \mathrm{E}-05$ & $-1.046762 \mathrm{E}-02$ & $-8.459647 \mathrm{E}-03$ & 0.3242 \\
\hline 8 & $\mathrm{C}_{10} \mathrm{H}_{8} /$ Feed $C=A+B * P+C * T+D *\left(\frac{\mathrm{O}_{2}}{\text { Feed } C}\right)+E *\left(\frac{\mathrm{H}_{2} \mathrm{O}}{\text { Feed } C}\right)$ & 1.827359E-02 & $-2.328921 \mathrm{E}-06$ & $-5.951746 \mathrm{E}-06$ & $-1.936385 \mathrm{E}-02$ & $-7.678310 \mathrm{E}-04$ & 0.4726 \\
\hline 9 & $\%$ Feed $N$ in Char $=A$ & $3.360000 \mathrm{E}+00$ & & & & & \\
\hline 10 & $\%$ Feed S in Char $=A$ & $8.450000 \mathrm{E}+00$ & & & & & \\
\hline 11 & $\%$ Feed O in Char $=A+B * P+C * T+D *\left(\frac{\mathrm{O}_{2}}{\text { Feed } C}\right)+E *\left(\frac{\mathrm{H}_{2} \mathrm{O}}{\text { Feed } C}\right)$ & $1.512040 \mathrm{E}+00$ & $1.582010 \mathrm{E}-04$ & $-6.972612 \mathrm{E}-04$ & $1.573581 \mathrm{E}-01$ & $-1.420915 \mathrm{E}-01$ & 0.3332 \\
\hline
\end{tabular}

${ }^{\mathrm{a}} \mathrm{All}$ ratios are on a molar basis, pressure in psia, temperature in ${ }^{\circ} \mathrm{F}$ 
The following general procedure is used for the gasifier production:

- Gasifier temperature $T$, pressure $P$, supplied $\mathrm{O}_{2}$, and the total $\mathrm{H}_{2} \mathrm{O}$ in the wood and supplied steam is gathered.

- The mass and molar amounts of carbon, hydrogen, oxygen, sulfur, nitrogen, and ash (as a pseudo-element) are determined from the biomass's ultimate analysis.

- The amount of syngas and its composition is determined from the gasifier correlations.

- The amount of carbon in the syngas and tar is determined. Residual carbon is parsed in the char.

- The amount of oxygen in the syngas is determined. A minimum fraction of the biomass oxygen is required to be parsed to the char based on equation 11 above. If there is a deficit of oxygen, then the associated water is decomposed to make sure that this amount of oxygen is parsed to the char; if there is excess oxygen, then that is parsed to the char without decomposing hydrogen.

- A set amount of sulfur is parsed to the char (8.4\%). All remaining sulfur is set as $\mathrm{H}_{2} \mathrm{~S}$ in the syngas.

- A set amount of nitrogen is parsed to the char (3.4\%). All remaining nitrogen is set as $\mathrm{NH}_{3}$ in the syngas.

- The amount of hydrogen in the syngas (including tar, $\mathrm{H}_{2} \mathrm{~S}, \mathrm{NH}_{3}$, and decomposed water) is determined. All remaining hydrogen is parsed to the char.

- All ash is parsed to the char.

- The heat of formation of the char is estimated from the resulting ultimate analysis from this elemental material balance and is used for the energy balance calculations.

The composition of syngas at $1600^{\circ} \mathrm{F}$ for the base case used in this report is shown below.

Table G-2. Gasifier Outlet Composition for Base Case

\begin{tabular}{|c|c|c|c|}
\hline Component & Weight \% & Component & Weight \% \\
\hline $\mathrm{H}_{2}$ & $1.38 \%$ & $\mathrm{NH}_{3}$ & $0.13 \%$ \\
\hline $\mathrm{CO}$ & $15.62 \%$ & $\mathrm{CH}_{4}$ & $8.56 \%$ \\
\hline $\mathrm{AR}$ & $0.81 \%$ & $\mathrm{C}_{2} \mathrm{H}_{6}$ & $0.76 \%$ \\
\hline $\mathrm{CO}_{2}$ & $49.10 \%$ & $\mathrm{C}_{6} \mathrm{H}_{6}$ & $2.96 \%$ \\
\hline $\mathrm{H}_{2} \mathrm{O}$ & $15.24 \%$ & $\mathrm{Tar}$ & $1.58 \%$ \\
\hline $\mathrm{H}_{2} \mathrm{~S}$ & $0.06 \%$ & $\mathrm{Char}$ & $3.77 \%$ \\
\hline
\end{tabular}




\section{References}

${ }^{1}$ Evans, R.J.; Knight, R.A.; Onischak, N.; Babu, S.P. Development of Biomass Gasification to Produce Substitute Fuels. PNL-6518. Work performed by the Institute of Gas Technology for Pacific Northwest Laboratory under contract DE-AC06-76RLO 1830 with the U.S. Department of Energy. Richland, WA: Pacific Northwest Laboratory, March 1988.

${ }^{2}$ Eggeman, T. Updated Correlations for GTI Gasifier - WDYLD8. Work performed by Neoterics International, Lakewood, CO for National Renewable Energy Laboratory, June 27, 2005. 
Appendix $\mathrm{H}$

Pinch Analysis 
Some of the details of the pinch analysis are shown in this section. They include the hot and cold composite curves and the specific heat exchanger network design chosen for the base case. Some of the assumptions used to get the heat exchanger costs using Aspen Icarus Process Evaluator are also shown.

The upper and lower pinch temperatures were $314.8^{\circ} \mathrm{F}$ and $298^{\circ} \mathrm{F}$ as shown below.

Figure 1 - Process Composite Curves

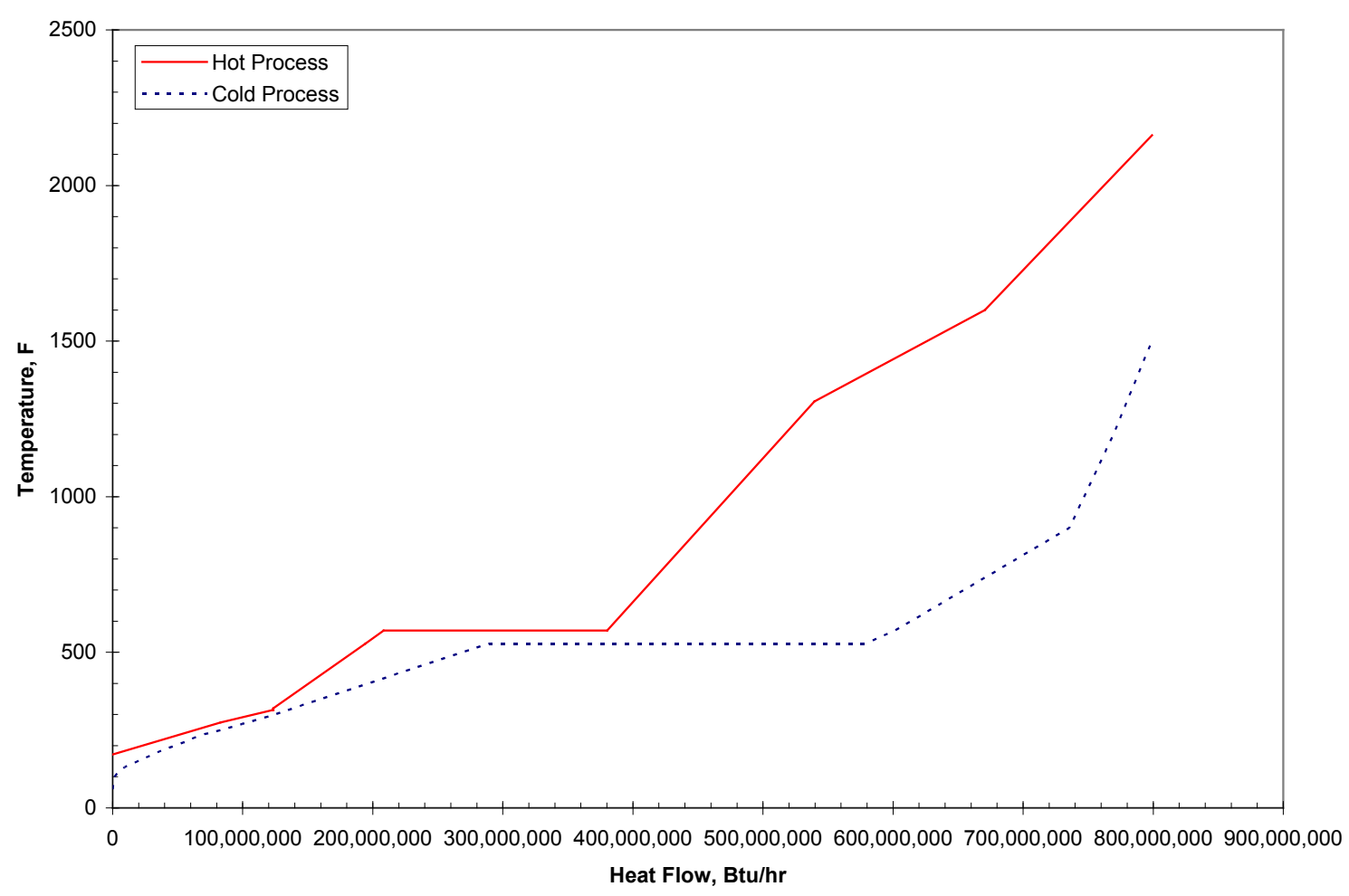

Figure H-1. Process hot and cold composite curves 


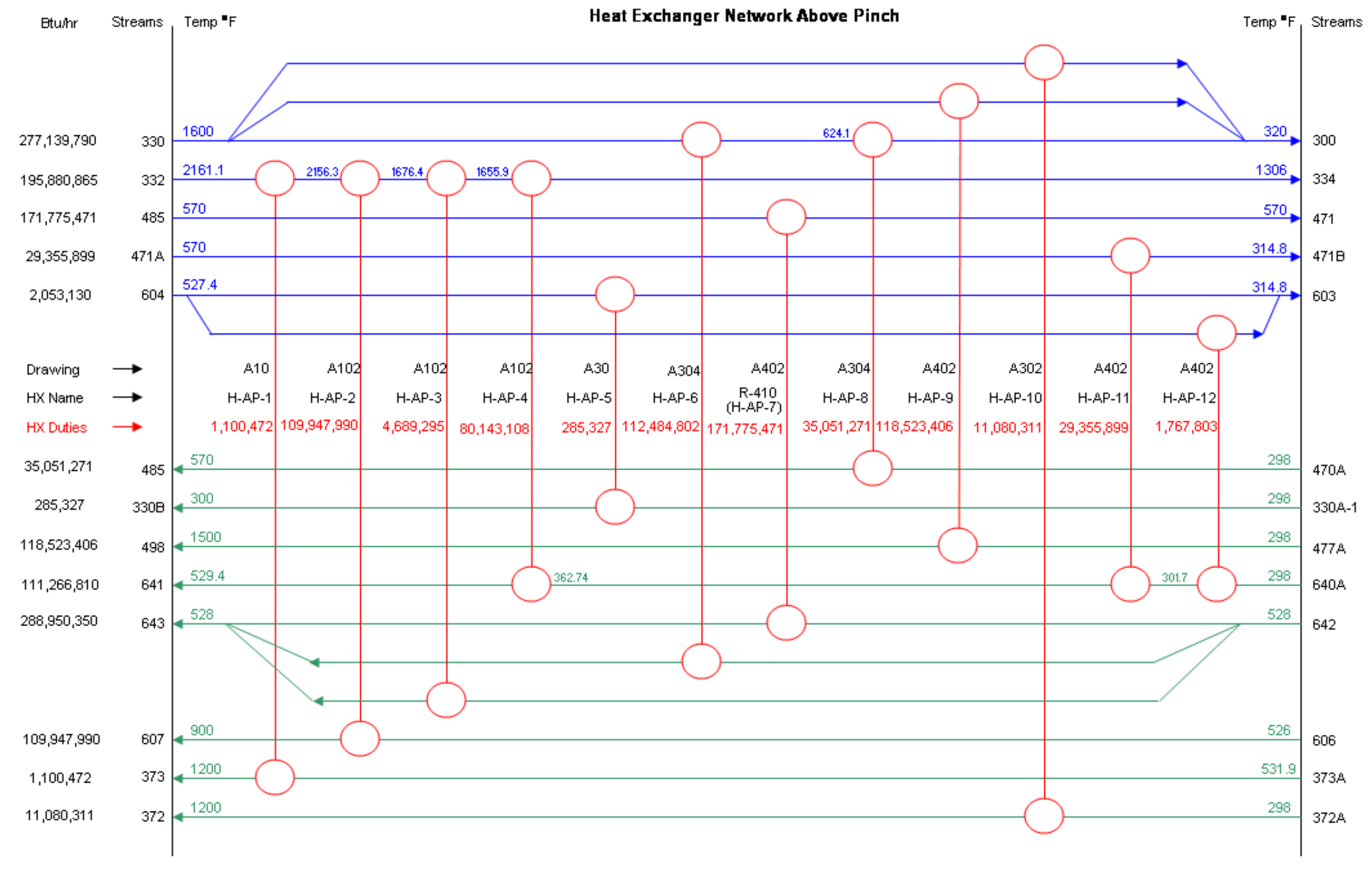

Figure $\mathrm{H}-2$. Heat exchanger network above the pinch 


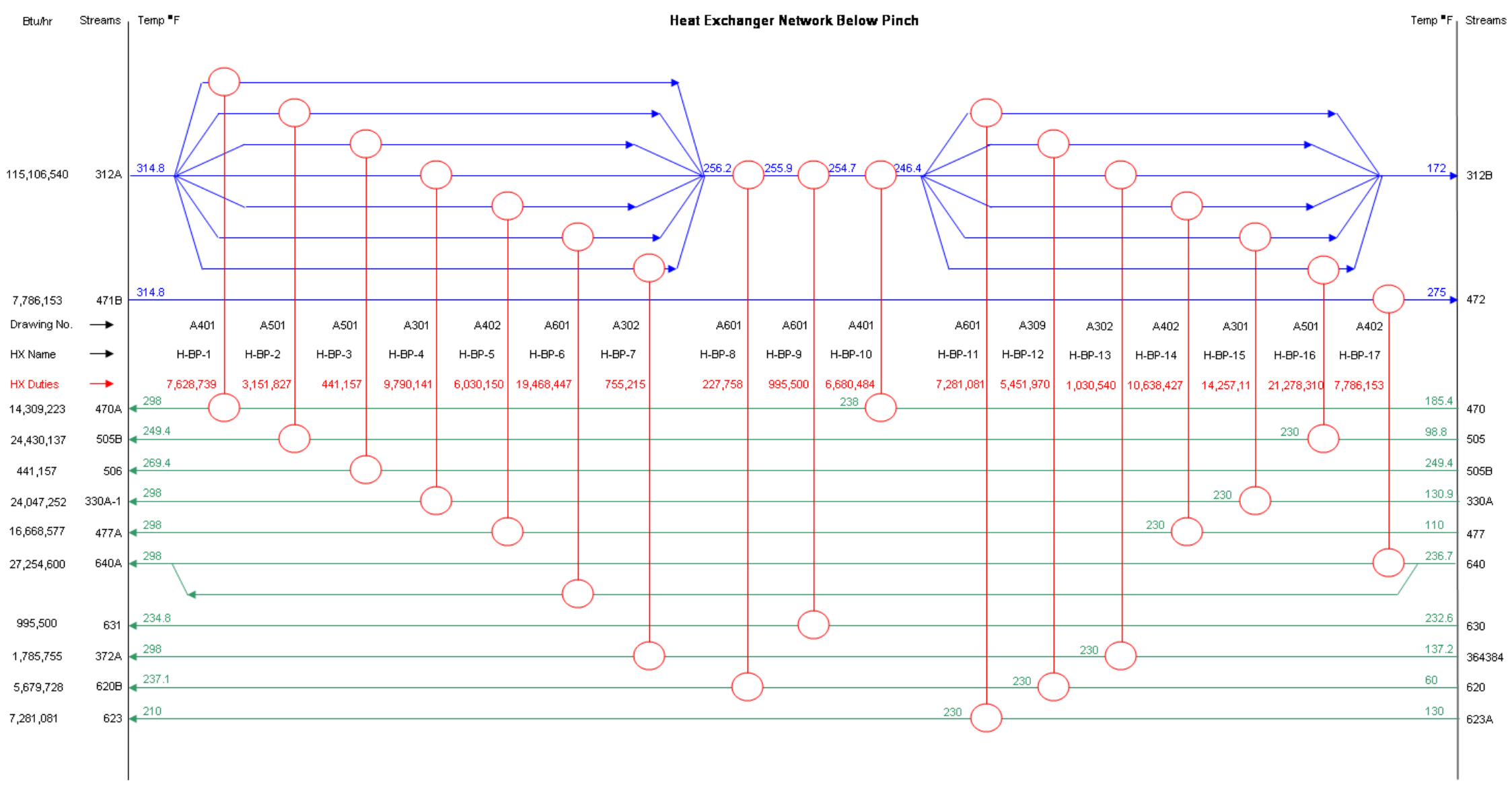

Figure H-3. Heat exchanger network below the pinch 


\begin{tabular}{|c|c|c|c|c|c|c|}
\hline Ilame & Description & $\begin{array}{c}\text { Duty } \\
\text { (Btu/hr) }\end{array}$ & $\begin{array}{c}\text { LMTD } \\
\text { (F) }\end{array}$ & $\begin{array}{c}\text { Assumed } \\
\text { Overall U } \\
\text { (BTU/hr F) }\end{array}$ & $\begin{array}{c}\text { Area } \\
\text { (ft2) }\end{array}$ & $\begin{array}{c}\text { Aspen IPE } \\
\text { Cost } \\
(2006 \$)\end{array}$ \\
\hline $\mathrm{H}-\mathrm{BP}-1$ & Hot Reformate Kold AlcSynPreHt Exchanger & $7,628,739$ & 17.49 & 100 & 4361.6 & $\$ 93,215$ \\
\hline $\mathrm{H}-\mathrm{BP}-2$ & Cold MolSievPreHt Hot Reformate Exchanger & $3,151,827$ & 30.91 & 120 & 849.7 & $\$ 28,415$ \\
\hline $\mathrm{H}-\mathrm{BP}-3$ & Cold MolSievPreHt Hot Reformate Exchanger & 441,157 & 20.33 & 100 & 217.0 & $\$ 19,758$ \\
\hline $\mathrm{H}-\mathrm{BP}-4$ & Cold FCAirPreHt IHot Reformate Exchanger & $9,790,141$ & 21.15 & 90 & 5142.5 & $\$ 87,215$ \\
\hline H-BP-5 & Hot Reformate /Cold AlcSynUnRx Exchanger & $6,030,150$ & 21.15 & 100 & 2850.7 & $\$ 71,315$ \\
\hline $\mathrm{H}-\mathrm{BP}-6$ & Hot Reformate Mold Water Exchanger & $19,468,447$ & 18.12 & 150 & 7164.2 & $\$ 163,847$ \\
\hline H-BP-7 & Cold RefEleedPreHt Hot Reformate Exchanger & 755,215 & 21.15 & 90 & 396.7 & $\$ 24,050$ \\
\hline H-BP-8 & Cold Water Hot Reformate Exchanger & 227,758 & 22.33 & 150 & 68.0 & $\$ 19,148$ \\
\hline $\mathrm{H}-\mathrm{BP}-\mathrm{g}$ & Cold Water Hot Reformate Exchanger & 995,500 & 21.60 & 150 & 307.3 & $\$ 20,850$ \\
\hline H-BP-10 & Hot Reformate ICold AlcSynPreHt Exchanger & $6,680,484$ & 34.20 & 100 & 1953.6 & $\$ 56,515$ \\
\hline $\mathrm{H}-\mathrm{BP}-11$ & Hot Reformate ICold WaterRecy Exchanger & $7,281,081$ & 27.22 & 150 & 1783.1 & $\$ 48,915$ \\
\hline $\mathrm{H}-\mathrm{BP}-12$ & Cold Water Hot Reformate Exchanger & $5,451,970$ & 49.76 & 150 & 730.4 & $\$ 26,115$ \\
\hline H-BP-13 & Cold RefEleedPreHt Hot Reformate Exchanger & $1,030,540$ & 24.46 & 90 & 468.2 & $\$ 24,315$ \\
\hline H-BP-14 & Hot Reformate ICold AlcSynUnRx Exchanger & $10,638,427$ & 34.29 & 100 & 3102.5 & $\$ 76,415$ \\
\hline H-BP-15 & Cold FCAirPreHt IHot Reformate Exchanger & $14,257,111$ & 26.89 & 90 & 5892.2 & $\$ 92,515$ \\
\hline H-BP-16 & Cold MolSievPreHt Hot Reformate Exchanger & $21,278,310$ & 37.97 & 120 & 4670.0 & $\$ 81,615$ \\
\hline H-BP-17 & Hot Alc.Rx.Exh. Mold Water Exchanger & $7,786,153$ & 26.09 & 150 & 1989.6 & $\$ 68,415$ \\
\hline H-A.P-1 & Hot Flue gas iCold AlcSepLtToRef Exchanger & $1,100,472$ & 1263.87 & 90 & 9.7 & $\$ 23,723$ \\
\hline H-AP-2 & Hot Flue gas ICold SteamSuperHt Exchanger & $109,947,990$ & 1202.57 & 90 & 1015.9 & $\$ 103,115$ \\
\hline H-A.P-3 & Hot Flue gas iCold SteamGen Exchanger & $4,689,295$ & 1138.12 & 120 & 34.3 & $\$ 24,123$ \\
\hline H-A.P-4 & Hot Flue gas ICold WaterPreHt Exchanger & $80,143,108$ & 1032.19 & 120 & 647.0 & $\$ 72,115$ \\
\hline H-AP-5 & Cold FCAirPreHt Mot WaterBlwdn Exchanger & 285,327 & 80.83 & 100 & 35.3 & $\$ 24,323$ \\
\hline H-AP-6 & Hot RefExhQuench /Cold SteamGen Exchanger & $112,484,802$ & 404.62 & 120 & 2316.7 & $\$ 87,215$ \\
\hline HAP 7 & 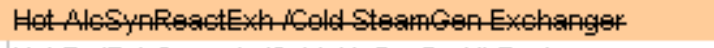 & $171,775,474$ & 42,00 & 120 & 34082.4 & $\$ 978,648$ \\
\hline H-AP-8 & Hot RefExhQuench ICold AlcSynPreHt Exchanger & $35,051,271$ & 35.67 & 90 & 10916.9 & $\$ 689,447$ \\
\hline H-AP-9 & Hot RefExhQuench ICold AlcSynUnRxToRef Exchanger & $118,523,406$ & 51.51 & 90 & 25564.0 & $\$ 3,265,799$ \\
\hline H-AP-10 & Hot RefExhQuench /Cold RefEleedPreHt Exchanger & $11,080,311$ & 130.33 & 90 & 944.7 & $\$ 131,015$ \\
\hline H-AP-11 & Hot Alc.Rx.Exh. ICold WaterPreHt Exchanger & $29,355,899$ & 70.32 & 120 & 3478.7 & $\$ 114,315$ \\
\hline $\mathrm{H}-\mathrm{AP}-12$ & Hot WaterBlwdn ICold WaterPreHt Exchanger & $1,767,803$ & 80.41 & 150 & 146.6 & $\$ 20,958$ \\
\hline
\end{tabular}

*H-AP-7 cost is crossed out because it is included in the alcohol synthesis reactor cost

Figure H-4. Heat exchanger costs using Aspen Icarus Process Evaluator (IPE) 
Appendix I

Results in 2007 Dollars with Updated Feedstock Costs 
The results in the main report use a feedstock cost of $\$ 35 /$ dry ton and 2005 dollar values. This is consistent with the indirect gasifier study ${ }^{1}$ by Phillips et al. (2007) and allows for easy comparison with it. However, it is imperative that the results be updated to reflect recent changes in projected feedstock costs, which are now targeted to cost $\$ 50.70 /$ dry ton in $2012^{2}$ (Biomass Multi-Year Program Plan, to be published in 2009). Of the $\$ 50.70, \$ 35.00$ is the cost of getting the feedstock and $\$ 15.70$ is for grower payment. The numbers presented here are in 2007 dollars.

The observations about the results shown are not repeated because the trends are similar to those in the main report. It is to be noted that the process related data remained unchanged and that the only differences are in the economics. The change in the labor cost index between 2005 and 2007 was negligible and the labor related data is not repeated. 


\section{Ethanol from Mixed Alcohols Production Process Engineering Analysis}

2012 Market Target Case: 2010 Tar Reforming Goal \& Mixed Alcohol Production

2,000 Dry Metric Tonnes Biomass per Day

GTI Gasifier, Tar Reformer, Sulfur Removal, MoS2 Catalyst, Fuel Purification, Steam-Power Cycle

All Values in $2007 \$$

\section{Minimum Ethanol Selling Price (\$/gal) \$1.95}

\begin{tabular}{|c|c|c|c|}
\hline \multicolumn{4}{|c|}{$\begin{array}{r}\text { EtOH Production at Operating Capacity (MM Gal / year) } 50.4 \\
\text { EtOH Product Yield (gal / Dry US Ton Feedstock) } 65.3 \\
\text { Mixed Alcohols Production at Operating Capacity (MM Gal / year) } 59.3 \\
\text { Mixed Alcohols Product Yield (gal / Dry US Ton Feedstock) } 76.8 \\
\text { Delivered Feedstock Cost \$/Dry US Ton } \$ 51 \\
\text { Internal Rate of Return (After-Tax) } 10 \% \\
\text { Equity Percent of Total Investment } 100 \%\end{array}$} \\
\hline \multicolumn{2}{|l|}{ Capital Costs } & \multicolumn{2}{|l|}{ Operating Costs (cents/gal product) } \\
\hline Feed Handling \& Drying & $\$ 25,600,000$ & Feedstock & 77.7 \\
\hline Gasification & $\$ 27,800,000$ & Natural Gas & 0.0 \\
\hline Tar Reforming \& Quench & $\$ 48,500,000$ & Catalysts & 0.4 \\
\hline Acid Gas \& Sulfur Removal & $\$ 19,000,000$ & Olivine & 3.1 \\
\hline Alcohol Synthesis - Compression & $\$ 8,600,000$ & Other Raw Materials & 3.5 \\
\hline Alcohol Synthesis - Other & $\$ 14,200,000$ & Waste Disposal & 3.3 \\
\hline Alcohol Separation & $\$ 7,400,000$ & Electricity & -4.0 \\
\hline Steam System \& Power Generation & $\$ 22,000,000$ & Fixed Costs & 31.4 \\
\hline Cooling Water \& Other Utilities & $\$ 3,600,000$ & Co-product credits & -20.8 \\
\hline Air Separation Unit & $\$ 28,300,000$ & Capital Depreciation & 28.4 \\
\hline Total Installed Equipment Cost & $\$ 205,000,000$ & Average Income Tax & 19.9 \\
\hline & & Average Return on Investment & 51.8 \\
\hline Indirect Costs & $80,100,000$ & \multirow{2}{*}{\multicolumn{2}{|c|}{ Operating Costs $(\$ / y r)$}} \\
\hline (\% of TPI) & $28.1 \%$ & & \\
\hline Project Contingency & $6,100,000$ & $\begin{array}{l}\text { Feedstock } \\
\text { Natural Gas }\end{array}$ & $\begin{array}{r}\$ 39,100,000 \\
\$ 0\end{array}$ \\
\hline \multirow[t]{2}{*}{ Total Project Investment (TPI) } & $\$ 285,100,000$ & Catalysts & $\$ 200,000$ \\
\hline & & Olivine & $\$ 1,600,000$ \\
\hline Installed Equipment Cost per Annual Gallon & $\$ 4.07$ & Other Raw Matl. Costs & $\$ 200,000$ \\
\hline \multirow[t]{2}{*}{ Total Project Investment per Annual Gallon } & $\$ 5.66$ & Waste Disposal & $\$ 1,600,000$ \\
\hline & & Electricity & $-\$ 2,000,000$ \\
\hline Loan Rate & N/A & Fixed Costs & $\$ 15,800,000$ \\
\hline Term (years) & N/A & Co-product credits@ $@ 1.15$ per gal & $-\$ 10,500,000$ \\
\hline \multirow[t]{2}{*}{ Capital Charge Factor } & 0.177 & Capital Depreciation & $\$ 14,300,000$ \\
\hline & & Average Income Tax & $\$ 10,000,000$ \\
\hline Maximum Yields based on carbon content & & Average Return on Investment & $\$ 26,100,000$ \\
\hline Theoretical Ethanol Production (MM gal/yr) & 158.9 & & \\
\hline Theoretical Ethanol Yield (gal/dry ton) & 205.8 & Total Plant Electricity Usage $(\mathrm{KM})$ & 7,136 \\
\hline Current Ethanol Yield (Actual/Theoretical) & $32 \%$ & $\begin{array}{l}\text { Electricity Produced Onsite (KM) } \\
\text { Electricity Purchased from Grid (KM) }\end{array}$ & $\begin{array}{r}10,994 \\
0\end{array}$ \\
\hline Gasifier Efficiency - HHV \% & 79.7 & Electricity Sold to Grid (KM) & 3,858 \\
\hline Gasifier Efficiency - LHV \% & 78.2 & & \\
\hline Overall Plant Efficiency - HHV \% & 39.5 & Steam Plant + Turboexpander Power Generated (hp) & 38,784 \\
\hline Overall Plant Efficiency - LHV\% & 38.4 & Used for Main Compressors (hp) & 24,041 \\
\hline & & Used for Electricity Generation (hp) & 14,743 \\
\hline Plant Hours per year & 8406 & & \\
\hline$\%$ & $96.0 \%$ & $\begin{array}{l}\text { Plant Electricity Use (KWh/gal product) } \\
\text { Gasification \& Reforming Steam Use (lb/gal) }\end{array}$ & $\begin{array}{r}1.6 \\
19.1^{\top}\end{array}$ \\
\hline
\end{tabular}

Figure I-1. Techno-economic summary (in 2007\$) 


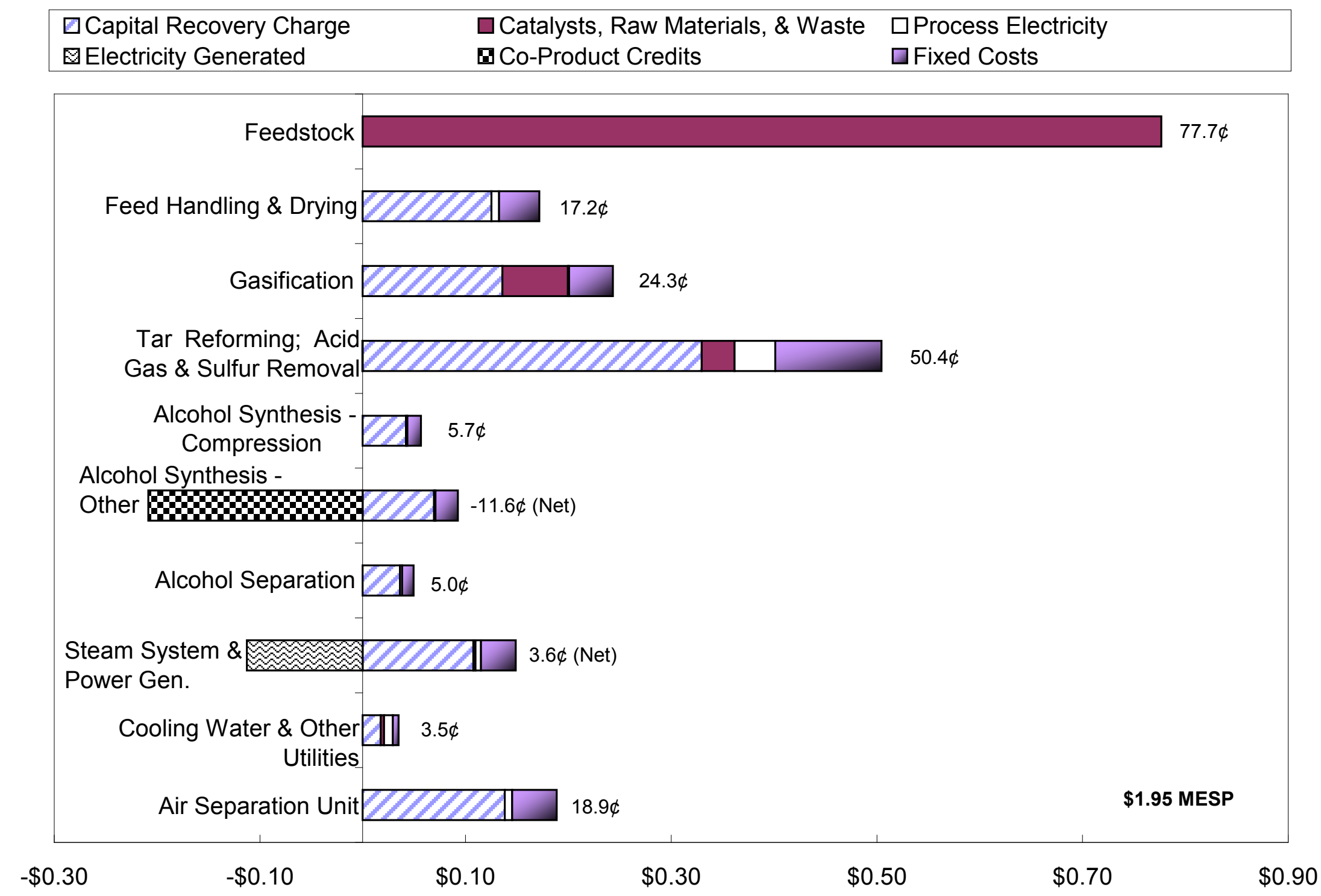

Figure I-2. Cost distribution details (in 2007\$) 
Cost Year

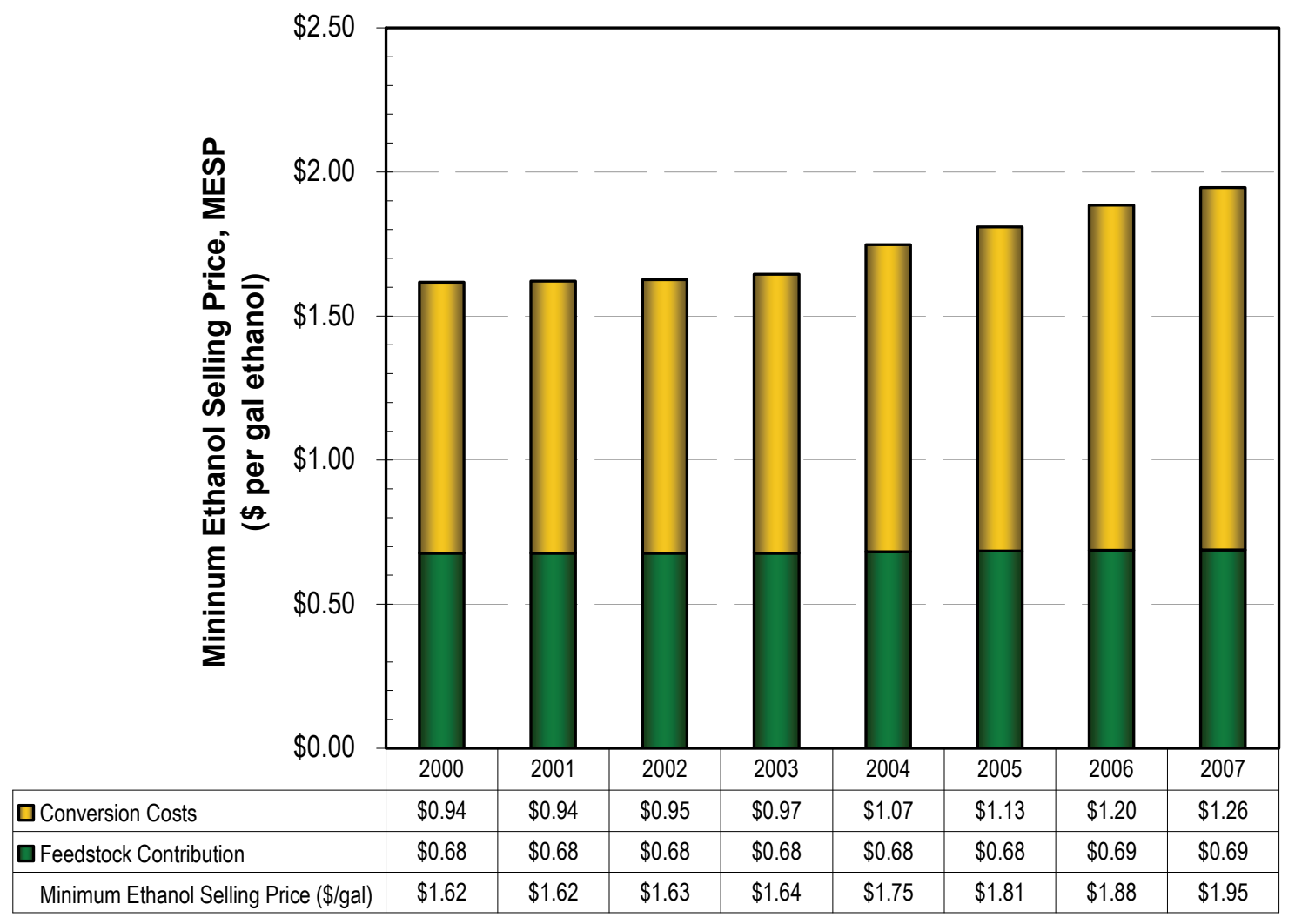

Figure l-3. Effect of cost year on MESP (2009 MYPP feedstock costs, 2007\$) 
Recycling Unconverted Syngas to Synthesis Reactor (0\%:0\%:25\%) Catalyst cost $(\$ 2.50: \$ 5.25: \$ 2,250$ per lb) Catalyst Poison Allowability (100:50:10 ppm) Catalyst Lifetime (10 yrs:5yrs: 1 yr) Total Alcohol Catalyst Productivity (1,000:600:200 g/kg-catihr) Operating Pressure (800:1000:2,000 psia) co Selectivity to Alcohols (95\%:90\%:70\%) Single Pass Co conversion $(80 \%: 60 \%: 30 \%)$

Level of CO2 removal (10:5:0.1 mol\%) Acid Gas Removal Costs (-10\%:baseline: $+100 \%$ ) Tar Reformer Equipment Costs $(-10 \%$ :baseline $+100 \%)$

Combined Tar Reformer Conversions Tar Reformer Tar Conversion (99.9\%:99.9\%:95\%) Tar Reformer Benzene Conversion (99.9\%:99\%:90\%) Tar Reformer Methane Conversion (95\%:80\%:50\%)

Olivine cost (1/10:baseline: $10 \mathrm{X}$ More $\mathrm{C}$ in char to $\mathrm{CO}(75 \%$ of baseline:baseline:baseline)

Feed Moisture Content (15\%:50\%:70\%) Sulfur Content (Baseline to $4 \mathrm{X})$ Feedstock Quality - Ash (1\%:1\%:12\%) Feedstocks (Ligninwood:Corn Stover) Feedstock Cost (\$10:\$50.70:\$63.50 per dry ton)

Loan vs. Equity Financing (100\% debt $(97.5 \%: 100 \%$ Equity: $100 \%$ Equity) Return on Investment $(0 \%: 10 \%: 30 \%)$ Contingency (0\%:3\%:15\% of TIC) Average Installation Factors (-10\%:baseline: $+30 \%$ Total Project Investment (-10\%:baseline $+30 \%)$

Plant Size (10,000:2000:600 dry tonnesiday). Co-Product Values (69\% Chemical Market:baseline:Fuel Oil Value)

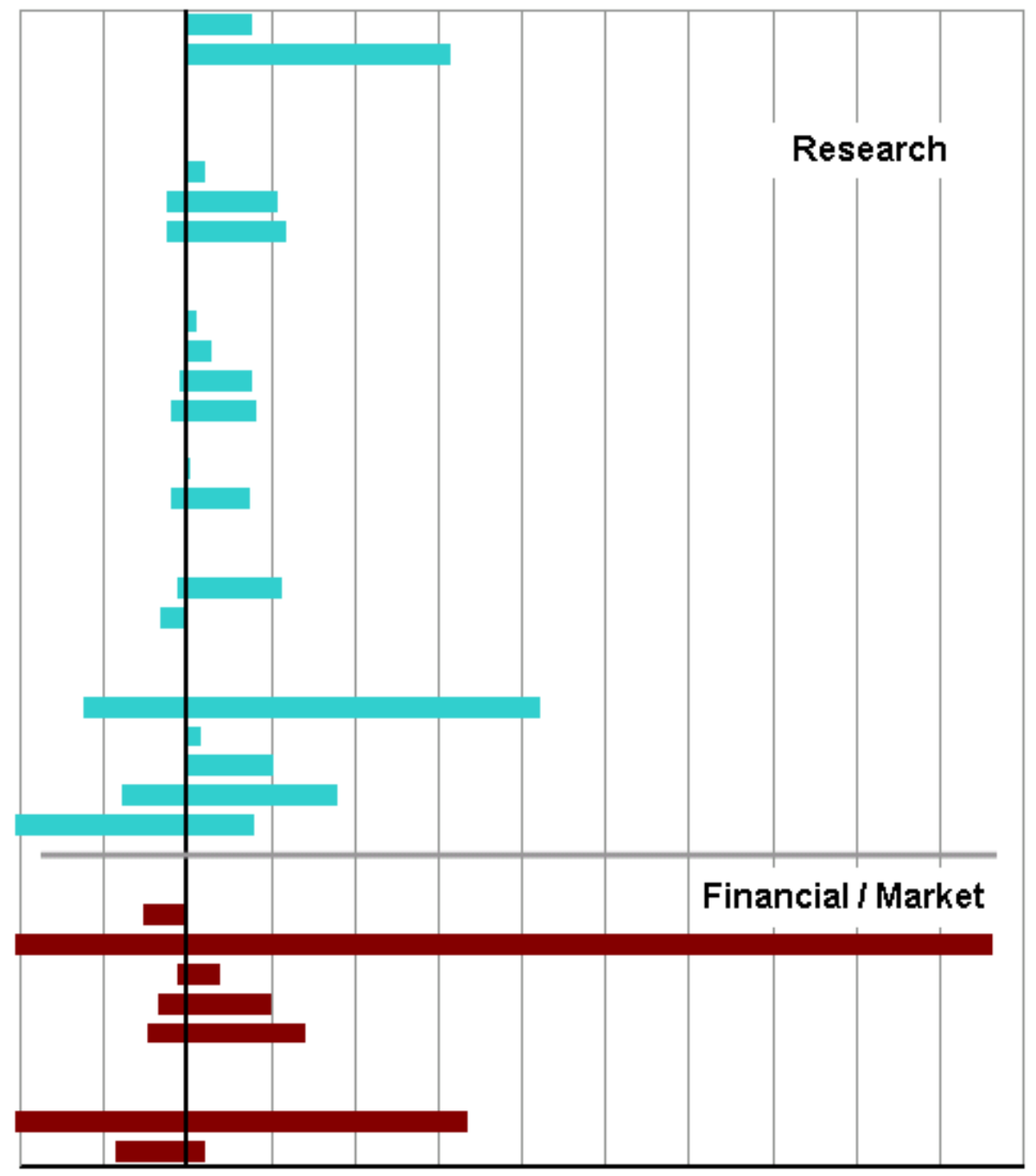

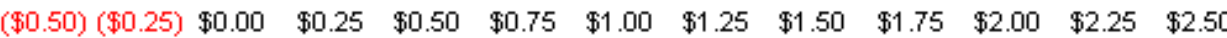
Change to MESP ( $\$$ per gallon Ethanol)

Figure I-4. Results of sensitivity analysis (2007\$) 


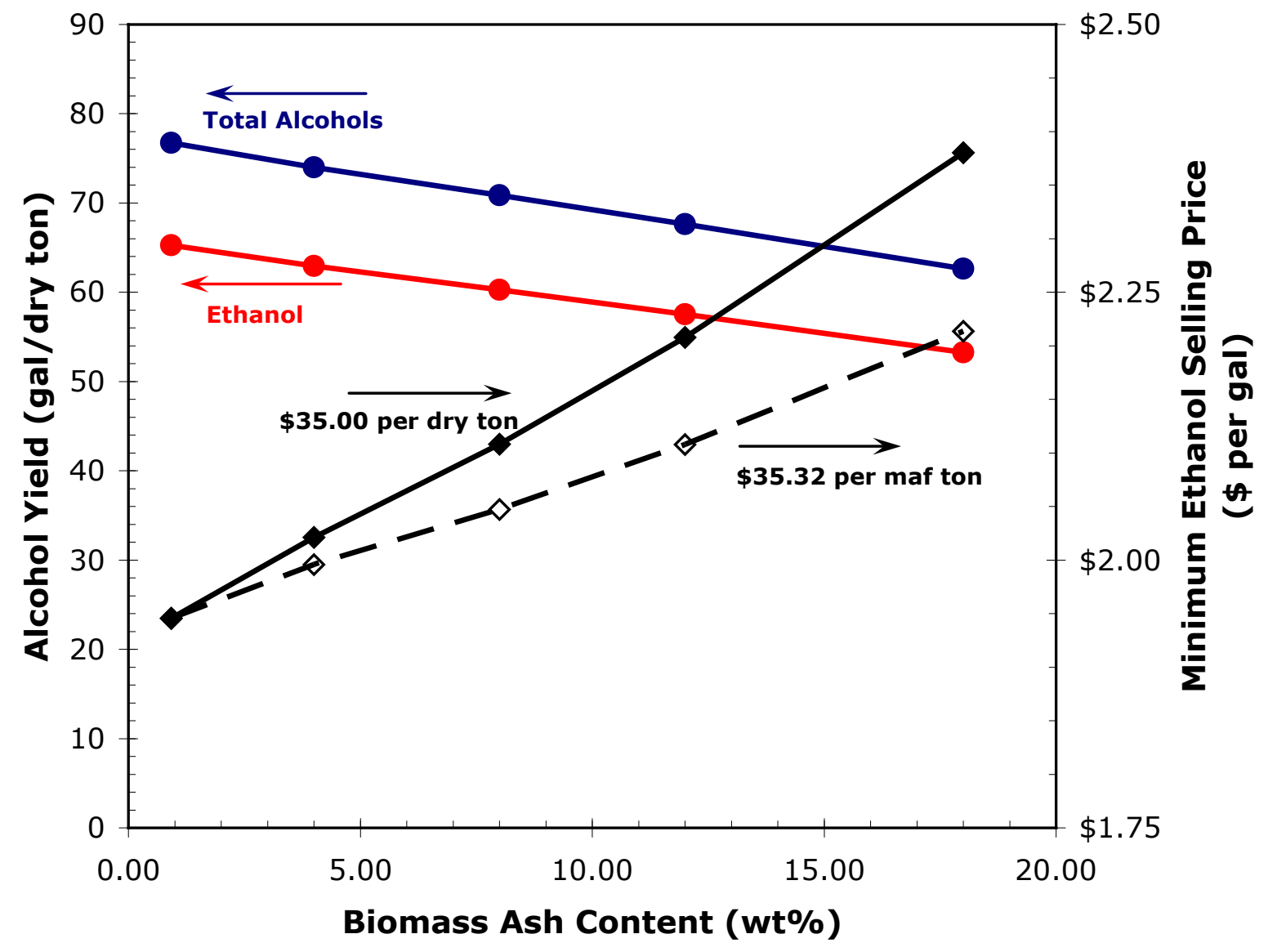

Figure I-5. Sensitivity analysis of biomass ash content (2007\$) 


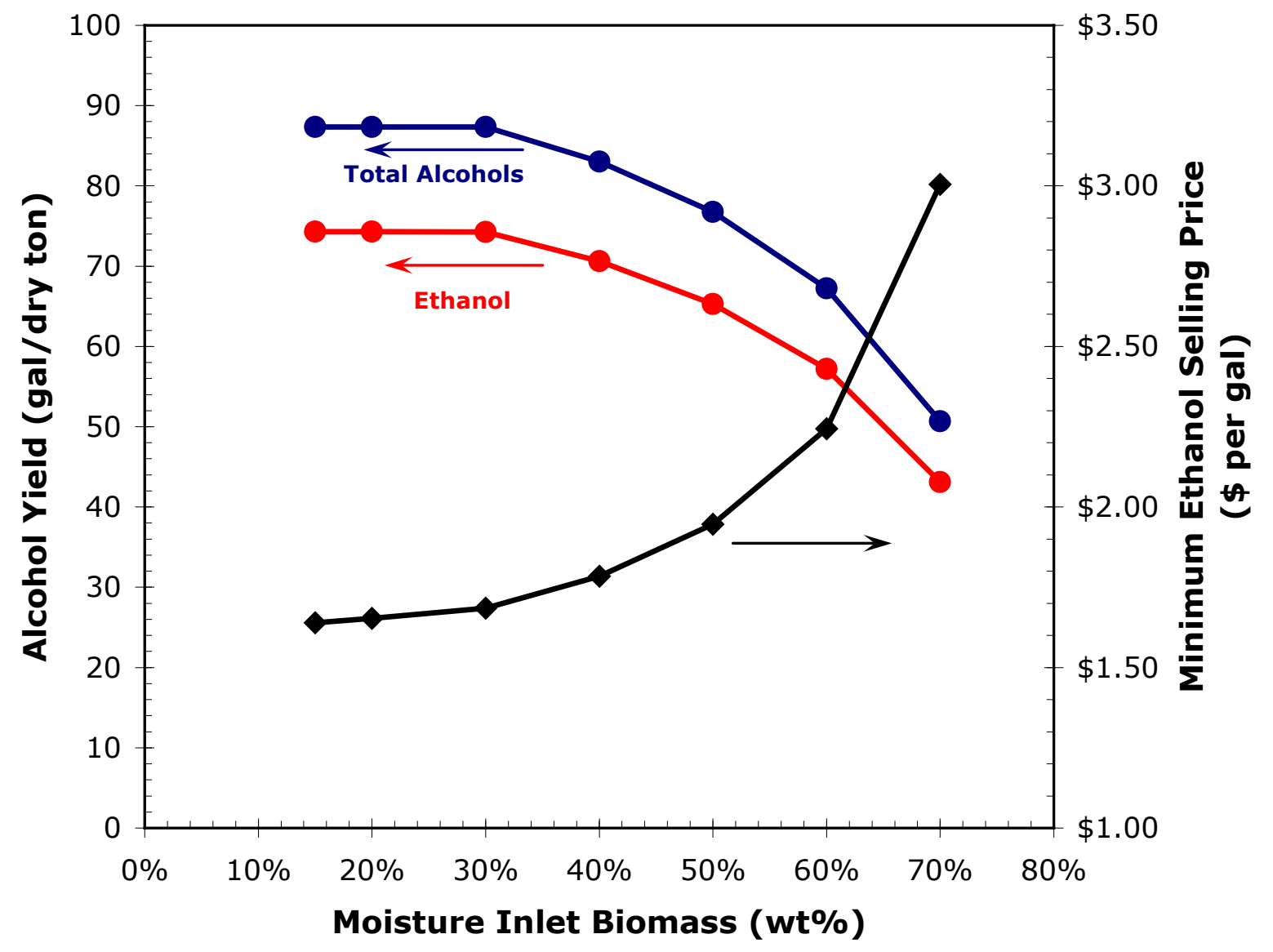

Figure I-6. Sensitivity analysis of biomass moisture content (2007\$) 


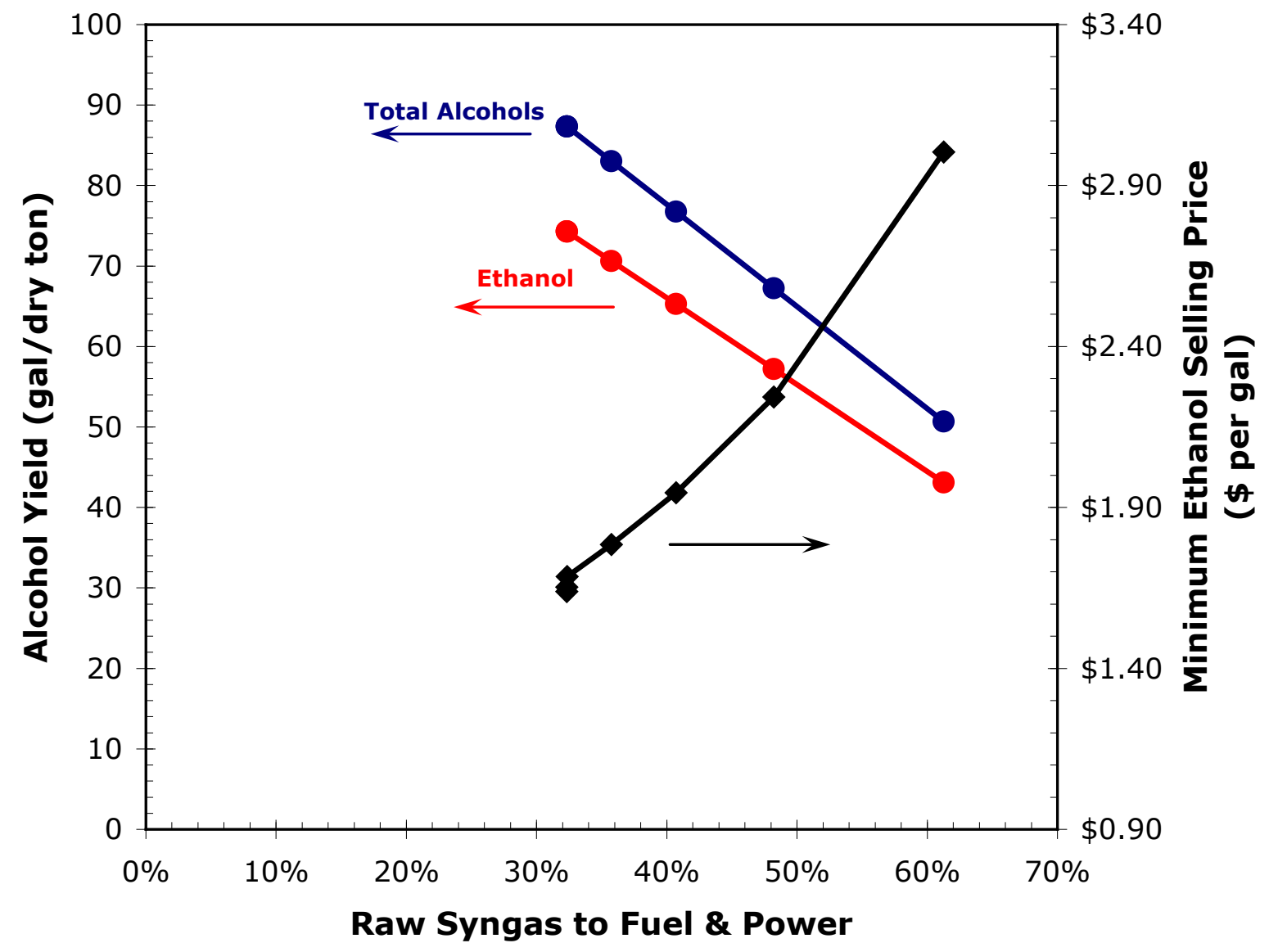

Figure 1-7. Sensitivity analysis of raw syngas diverted to heat and power due to biomass moisture content $(2007 \$)$

\section{References}

${ }^{1}$ Phillips, S.; Aden, A.; Jechura, J.; Dayton, D.; Eggeman, T. Thermochemical Ethanol via Indirect Gasification and Mixed Alcohol Synthesis of Lignocellulosic Biomass. NREL/TP-51041168. Golden, CO: National Renewable Energy Laboratory, April 2007. http://www.nrel.gov/docs/fy07osti/41168.pdf.

${ }^{2}$ Office of the Biomass Program. Biomass Multi-Year Program Plan March 2008. Washington, DC: Office of the Biomass Program, Energy Efficiency and Renewable Energy, U.S. Department of Energy, March 2008. New revision forthcoming in 2009. http://www1.eere.energy.gov/biomass/pdfs/biomass_program_mypp.pdf. 


\section{Appendix $\mathbf{J}$ \\ Comparison of Direct and Indirect Gasification Processes using 2005 and 2007 Assumptions}




\title{
Ethanol from Mixed Alcohols Production Process Engineering Analysis
}

2012 Market Target Case: 2010 Tar Reforming Goal \& Mixed Alcohol Production

2,000 Dry Metric Tonnes Biomass per Day

BCL Gasifier, Tar Reformer, Sulfur Removal, MoS2 Catalyst, Fuel Purification, Steam-Power Cycle

All Values in $2005 \$$

\section{Minimum Ethanol Selling Price (\$/gal) \$1.01}

\author{
EtOH Production at Operating Capacity (MM Gal / year) 61.9 \\ EtOH Product Yield (gal/ Dry US Ton Feedstock) 80.1 \\ Mixed Alcohols Production at Operating Capacity (MM Gal / year) 72.7 \\ Mixed Alcohols Product Yield (gal/Dry US Ton Feedstock) 94.1 \\ Delivered Feedstock Cost $\$$ /Dry US Ton $\$ 35$ \\ Internal Rate of Return (After-Tax) 10\% \\ Equity Percent of Total Investment $100 \%$
}

\begin{tabular}{|c|c|c|c|}
\hline \multicolumn{2}{|l|}{ Capital Costs } & \multicolumn{2}{|c|}{ Operating Costs (cents/gal product) } \\
\hline Feed Handling \& Drying & $\$ 23,200,000$ & Feedstock & 43.7 \\
\hline Gasification & $\$ 12,900,000$ & Natural Gas & 0.0 \\
\hline Tar Reforming \& Quench & $\$ 38,400,000$ & Catalysts & 0.3 \\
\hline Acid Gas \& Sulfur Removal & $\$ 14,500,000$ & Olivine & 0.7 \\
\hline Alcohol Synthesis - Compression & $\$ 16,000,000$ & Other Raw Materials & 1.6 \\
\hline Alcohol Synthesis - Other & $\$ 4,600,000$ & Waste Disposal & 0.4 \\
\hline Alcohol Separation & $\$ 7,200,000$ & Electricity & 0.0 \\
\hline Steam System \& Power Generation & $\$ 16,800,000$ & Fixed Costs & 19.5 \\
\hline Cooling Water \& Other Utilities & $\$ 3,600,000$ & Co-product credits & -20.8 \\
\hline \multirow[t]{2}{*}{ Total Installed Equipment Cost } & $\$ 137,200,000$ & Capital Depreciation & 15.4 \\
\hline & & Average Income Tax & 11.8 \\
\hline Indirect Costs & $53,600,000$ & Average Return on Investment & 28.6 \\
\hline$(\%$ of TPI) & $28.1 \%$ & & \\
\hline \multirow[t]{2}{*}{ Project Contingency } & $4,100,000$ & \multicolumn{2}{|l|}{ Operating Costs (\$/yr) } \\
\hline & & Feedstock & $\$ 27,000,000$ \\
\hline \multirow[t]{2}{*}{ Total Project Investment (TPI) } & $\$ 190,900,000$ & Natural Gas & $\$ 0$ \\
\hline & & Catalysts & $\$ 200,000$ \\
\hline Installed Equipment Cost per Annual Gallon & $\$ 2.22$ & Olivine & $\$ 400,000$ \\
\hline \multirow[t]{2}{*}{ Total Project Investment per Annual Gallon } & $\$ 3.09$ & Other Raw Matl. Costs & $\$ 300,000$ \\
\hline & & Waste Disposal & $\$ 300,000$ \\
\hline Loan Rate & $\mathrm{N} / \mathrm{A}$ & Electricity & $\$ 0$ \\
\hline Term (years) & $N / A$ & Fixed Costs & $\$ 12,100,000$ \\
\hline \multirow[t]{2}{*}{ Capital Charge Factor } & 0.181 & Co-product credits@\$1.15 per gal & $-\$ 12,900,000$ \\
\hline & & Capital Depreciation & $\$ 9,500,000$ \\
\hline Maximum Yields based on carbon content & & Average Income Tax & $\$ 7,300,000$ \\
\hline Theoretical Ethanol Production (MM gal/yr) & 158.9 & Average Return on Investment & $\$ 17,700,000$ \\
\hline Theoretical Ethanol Yield (gal/dry ton) & 205.8 & & \\
\hline \multirow[t]{2}{*}{ Current Ethanol Yield (Actual/Theoretical) } & $39 \%$ & Total Plant Electricity Usage (KW) & 7,934 \\
\hline & & Electricity Produced Onsite (KW) & 7,934 \\
\hline Gasifier Efficiency - HHV \% & 76.6 & Electricity Purchased from Grid (KW) & 1 \\
\hline Gasifier Efficiency - LHV\% & 76.1 & Electricity Sold to Grid (KW) & 0 \\
\hline Overall Plant Efficiency - HHV \% & 47.4 & & \\
\hline \multirow[t]{2}{*}{ Overall Plant Efficiency - LHV \% } & 45.9 & Steam Plant + Turboexpander Power Generated (hp) & 66,399 \\
\hline & & Used for Main Compressors (hp) & 55,207 \\
\hline \multirow{4}{*}{$\begin{array}{l}\text { Plant Hours per year } \\
\%\end{array}$} & 8406 & Used for Electricity Generation (hp) & 11,192 \\
\hline & $96.0 \%$ & & \\
\hline & & Plant Electricity Use (KWh/gal product) & 1.4 \\
\hline & & Gasification \& Reforming Steam Use (lb/gal) & 9.9 \\
\hline
\end{tabular}

Figure J-1. Indirect gasification process cost summary using 2005 dollars and $\$ 35 /$ dry ton feedstock cost 


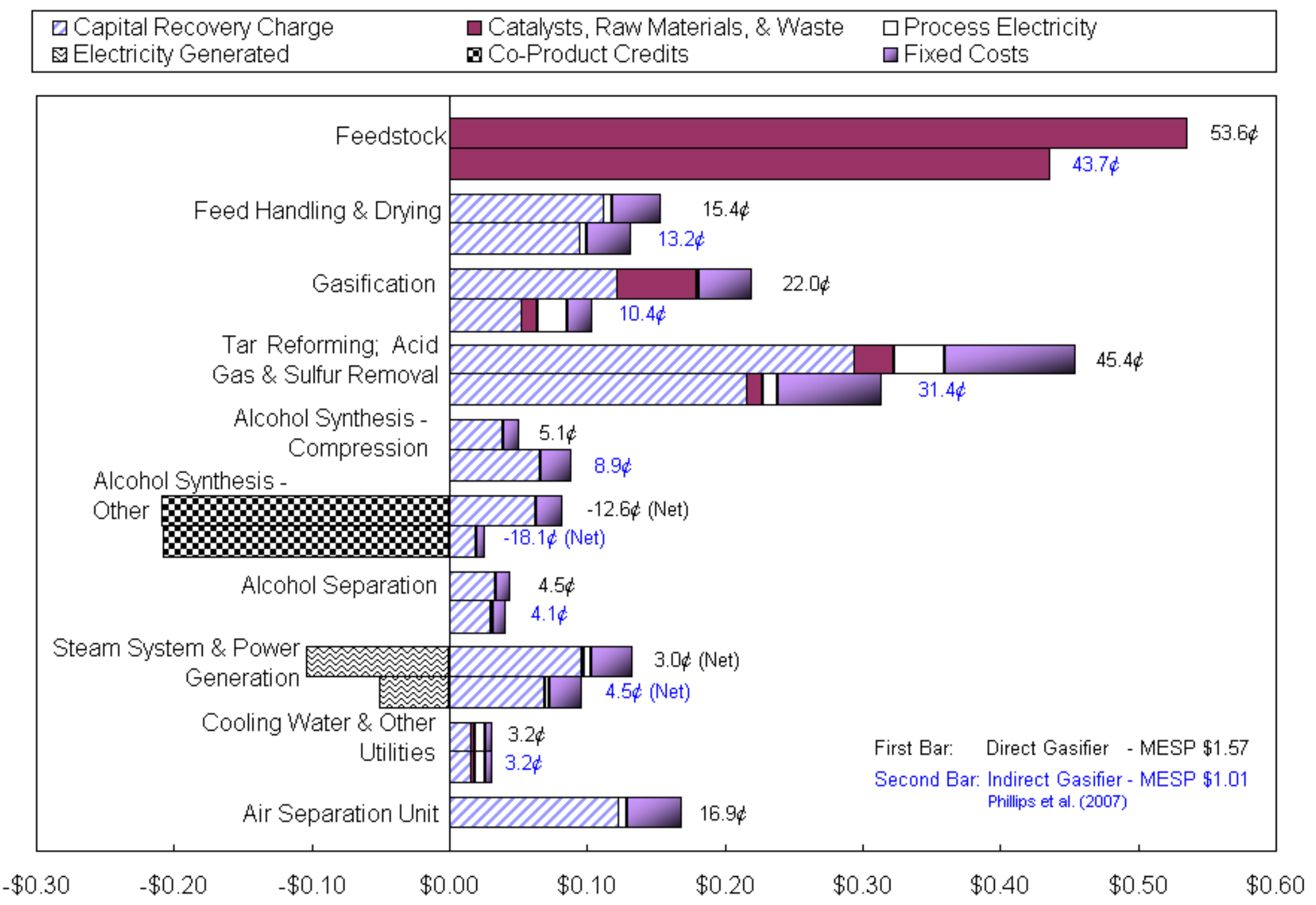

Figure J-2. Comparison of contributions to MESP for the base case in this report with the indirect gasifier report (Phillips et al. 2007) using 2005 dollars and $\$ 35 /$ dry ton feedstock costs 


\section{Ethanol from Mixed Alcohols Production Process Engineering Analysis}

2012 Market Target Case: 2010 Tar Reforming Goal \& Mixed Alcohol Production

2,000 Dry Metric Tonnes Biomass per Day

BCL Gasifier, Tar Reformer, Sulfur Removal, MoS2 Catalyst, Fuel Purification, Steam-Power Cycle

All Values in $2007 \$$

\section{Minimum Ethanol Selling Price (\$/gal) \$1.29}

\begin{tabular}{|c|c|c|c|}
\hline \multicolumn{4}{|c|}{$\begin{array}{r}\text { EtOH Production at Operating Capacity (MM Gal / year) } 61.9 \\
\text { EtOH Product Yield (gal / Dry US Ton Feedstock) } 80.1 \\
\text { Mixed Alcohols Production at Operating Capacity (MM Gal / year) } \\
72.7 \\
\text { Mixed Alcohols Product Yield (gal / Dry US Ton Feedstock) } 94.1 \\
\text { Delivered Feedstock Cost } \$ / D r y \text { US Ton } \$ 51 \\
\text { Internal Rate of Return (After-Tax) } \\
\text { Equity Percent of Total Investment } 100 \%\end{array}$} \\
\hline \multicolumn{2}{|l|}{ Capital Costs } & \multicolumn{2}{|c|}{ Operating Costs (cents/gal product) } \\
\hline Feed Handling \& Drying & $\$ 26,000,000$ & Feedstock & 63.3 \\
\hline Gasification & $\$ 14,500,000$ & Natural Gas & 0.0 \\
\hline Tar Reforming \& Quench & $\$ 43,100,000$ & Catalysts & 0.3 \\
\hline Acid Gas \& Sulfur Removal & $\$ 16,300,000$ & Olivine & 0.7 \\
\hline Alcohol Synthesis - Compression & $\$ 17,900,000$ & Other Raw Materials & 1.7 \\
\hline Alcohol Synthesis - Other & $\$ 5,200,000$ & Waste Disposal & 0.5 \\
\hline Alcohol Separation & $\$ 8,100,000$ & Electricity & 0.0 \\
\hline Steam System \& Power Generation & $\$ 18,800,000$ & Fixed Costs & 21.0 \\
\hline Cooling Water \& Other Utilities & $\$ 4,000,000$ & Co-product credits & -20.8 \\
\hline \multirow[t]{2}{*}{ Total Installed Equipment Cost } & $\$ 153,900,000$ & Capital Depreciation & 17.3 \\
\hline & & Average Income Tax & 13.2 \\
\hline \multirow{2}{*}{$\begin{array}{r}\text { Indirect Costs } \\
(\% \text { of TPI) }\end{array}$} & $60,200,000$ & Average Return on Investment & 32.2 \\
\hline & $28.1 \%$ & \multirow{2}{*}{\multicolumn{2}{|c|}{ Operating Costs (\$/yr) }} \\
\hline \multirow[t]{2}{*}{ Project Contingency } & $4,600,000$ & & \\
\hline & & Feedstock & $\$ 39,100,000$ \\
\hline \multirow[t]{2}{*}{ Total Project Investment (TPI) } & $\$ 214,200,000$ & Natural Gas & $\$ 0$ \\
\hline & & Catalysts & $\$ 200,000$ \\
\hline Installed Equipment Cost per Annual Gallon & $\$ 2.49$ & Olivine & $\$ 500,000$ \\
\hline Total Project Investment per Annual Gallon & $\$ 3.46$ & Other Raw Matl. Costs & $\$ 300,000$ \\
\hline Installed Equipment Cost per Annual Gallon Mixed Alcor & $\$ 2.12$ & Waste Disposal & $\$ 300,000$ \\
\hline Loan Rate & N/A & Electricity & $\$ 0$ \\
\hline Term (years) & N/A & Fixed Costs & $\$ 13,000,000$ \\
\hline \multirow[t]{2}{*}{ Capital Charge Factor } & 0.181 & Co-product credits @ $\$ 1.15$ per gal & $-\$ 12,900,000$ \\
\hline & & Capital Depreciation & $\$ 10,700,000$ \\
\hline \multicolumn{2}{|l|}{ Maximum Yields based on carbon content } & Average Income Tax & $\$ 8,200,000$ \\
\hline Theoretical Ethanol Production (MM gal/yr) & 158.9 & Average Return on Investment & $\$ 19,900,000$ \\
\hline Theoretical Ethanol Yield (gal/dry ton) & 205.8 & & \\
\hline \multirow[t]{2}{*}{ Current Ethanol Yield (Actual/Theoretical) } & $39 \%$ & Total Plant Electricity Usage (KM) & 7,934 \\
\hline & & Electricity Produced Onsite (KM) & 7,934 \\
\hline Gasifier Efficiency - HHV\% & 76.6 & Electricity Purchased from Grid (KM) & 1 \\
\hline Gasifier Efficiency - LHV\% & 76.1 & Electricity Sold to Grid (KM) & 0 \\
\hline Overall Plant Efficiency - HHV\% & 47.4 & & \\
\hline \multirow[t]{2}{*}{ Overall Plant Efficiency - LHV \% } & 45.9 & Steam Plant + Turboexpander Power Generated ( $h p$ ) & 66,399 \\
\hline & & Used for Main Compressors (hp) & 55,207 \\
\hline \multirow{3}{*}{$\begin{array}{l}\text { Plant Hours per year } \\
\%\end{array}$} & 8406 & Used for Electricity Generation (hp) & 11,192 \\
\hline & $96.0 \%$ & icity Use (KWh/gal product) & \\
\hline & & Gasification \& Reforming Steam Use (lb/gal) & $\begin{array}{l}1.4 \\
9.9^{\prime}\end{array}$ \\
\hline
\end{tabular}

Figure J-3. Indirect gasification process cost summary using 2007 dollars and $\$ 50.70 /$ dry ton feedstock cost 


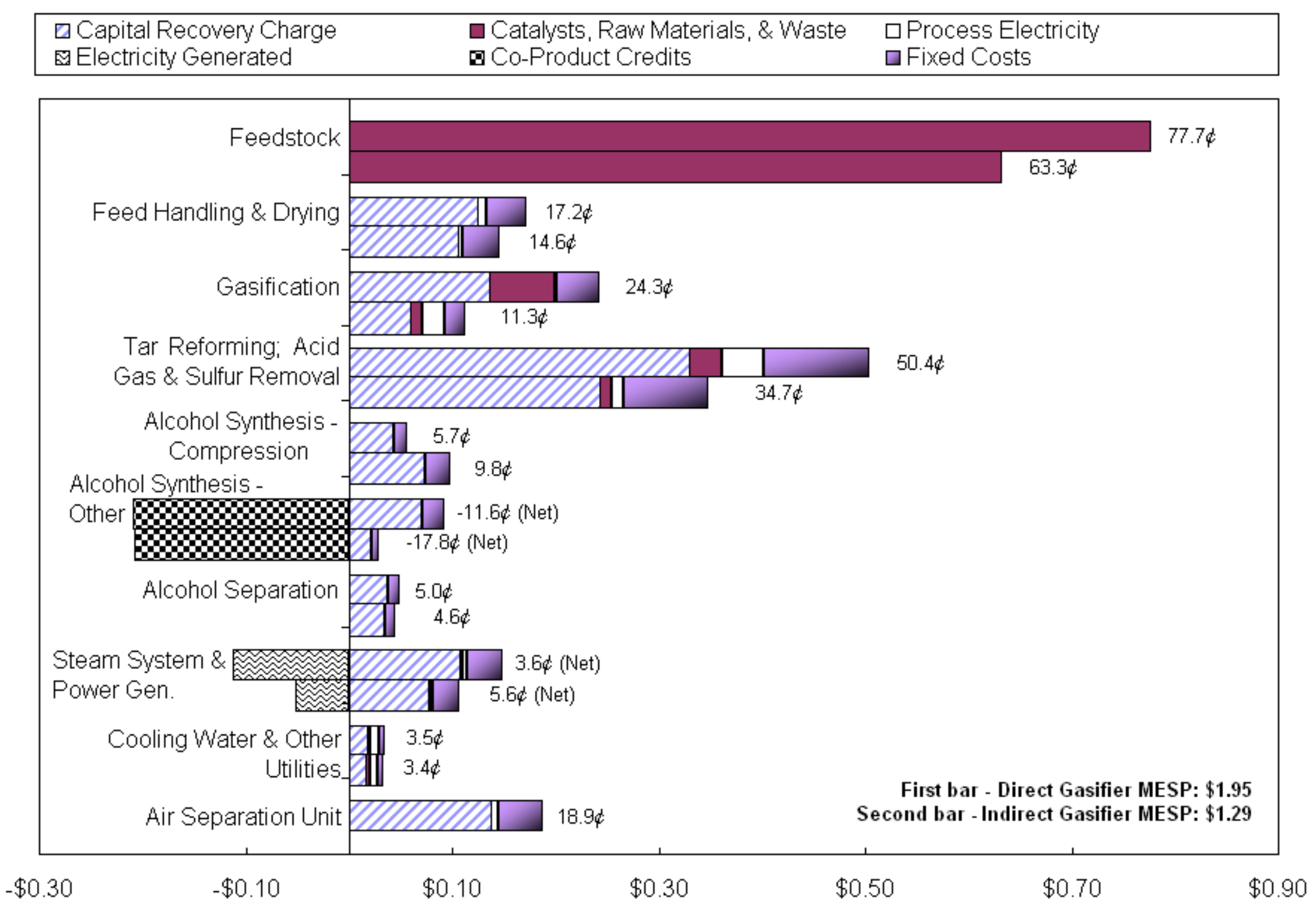

Figure J-4. Comparison of contributions to MESP for the base case in this report with the indirect gasifier report (Phillips et al. 2007) using 2007 dollars and $\$ 50.70 /$ dry ton feedstock costs 
Appendix K

Operating the Direct Gasifier at a Lower Pressure 
This Appendix analyzes a case in which the GTI gasifier is simulated at $100 \mathrm{psi}$ instead of at the more common operational pressure of around $400 \mathrm{psi}$. It is assumed that the capital cost of the gasifier and the tar reformer remained the same based on the mass flow into the gasifier. A detailed impact of the primary tradeoffs mentioned below was not factored in:

1. Lower pressure will result in higher cost because of a higher gasifier volume, which will require a bigger volume for the same mass throughput.

2. Lower pressure will result in lower cost because of the potential changes in the thickness of the materials used for construction.

This lower pressure scenario was not used as the base case for this report because it was less economical than the base case. This reinforces the reason why it is more common to operate the direct gasifier at the higher pressures (above $300 \mathrm{psi}$ ). Most of the data for the gasifier correlations in Evans et al. ${ }^{1}$ are at that range.

There were four data points for the GTI gasifier at lower pressures available from the Evans et al. report, which clearly show a drop in the feed rate and illustrate point 1 , above.

The existing logic in the FORTRAN routine (WDYD10) used to empirically predict the outlet composition had to be modified because it predicted oxygen breakthrough at the lower pressures. The predictions for $\mathrm{CO}$ were higher and for $\mathrm{CO}_{2}$ were lower than the experimental data (four data points from the Evans et al. report: GT-10, T12-2, T12-4a, T12-4b). The code was modified to transfer $\mathrm{CO}$ to $\mathrm{CO}_{2}$ to correct this and most importantly to fix the oxygen breakthrough prediction. These changes were made in a new version of the correlation for gasifier outputs (WDYD11).

The primary reason for studying this scenario was to see how far operating at a lower pressure could offset some of the negative economic impacts of the lower conversions in the tar reformer (at the higher pressures in the base case). The main tradeoff is between higher conversions (primarily of methane) in the tar reformer at lower pressures vs. higher compression costs. It costs less to bring solid biomass up to higher pressures than gasified biomass.

As with the other variations from the base case, a detailed pinch analysis was not done and the capital costs of heat exchangers were assumed to remain the same. The impact of variations in the heat exchanger costs on the MESP was on the order of $2 \varnothing$ even when there was a big difference in the total costs, as mentioned in Section 2.11 of the main report.

Some equipment costs, such as those for the oxygen and nitrogen compressors, were reevaluated. However the reevaluation did not make any significant difference when compared with the scaled costs obtained from previously evaluated equipment.

A comparison of conversions assumed in the tar reformer in the base case (440 psi) and the lower pressure case (100 psi) is shown in the following table. These are based on maintaining the same percent approach to equilibrium as in the indirect gasification case (Phillips et al. 2007). ${ }^{2}$ 
Table K-1. Tar Reformer Conversions Used at Different Pressures

\begin{tabular}{|c|c|c|c|}
\hline Compound & $\begin{array}{c}\text { Target Conversion } \\
\text { to CO \& } \mathbf{H}_{\mathbf{2}} \\
\text { (Phillips et al. - } \\
\text { gasifier at 25 psi) }\end{array}$ & $\begin{array}{c}\text { Target Conversion } \\
\text { to CO \& } \mathbf{H}_{\mathbf{2}} \\
\text { (Lower pressure - } \\
\text { gasifier at 100 psi) }\end{array}$ & $\begin{array}{c}\text { Target Conversion } \\
\text { to CO \& } \mathbf{H}_{\mathbf{2}} \\
\text { (Base case - } \\
\text { gasifier at 440 psi) }\end{array}$ \\
\hline Methane $\left(\mathrm{CH}_{4}\right)$ & $80 \%$ & $72.6 \%$ & $46.2 \%$ \\
\hline Ethane $\left(\mathrm{C}_{2} \mathrm{H}_{6}\right)$ & $99 \%$ & $90 \%$ & $99 \%$ \\
\hline Ethylene $\left(\mathrm{C}_{2} \mathrm{H}_{4}\right)$ & $90 \%$ & $90 \%$ & $90 \%$ \\
\hline Tars $\left(\mathrm{C}_{10+}\right)$ & $99.9 \%$ & $99.9 \%$ & $99.9 \%$ \\
\hline Benzene $\left(\mathrm{C}_{6} \mathrm{H}_{6}\right)$ & $99 \%$ & $99 \%$ & $99 \%$ \\
\hline Ammonia $\left(\mathrm{NH}_{3}\right)$ & $90 \%$ & $86.6 \%$ & $78 \%$ \\
\hline
\end{tabular}

As mentioned in the main report, methane conversion has the greatest economic impact. Some of the other conversions also changed. They are not reflected in the preceding table because their flow rates were too low to affect the overall economics significantly.

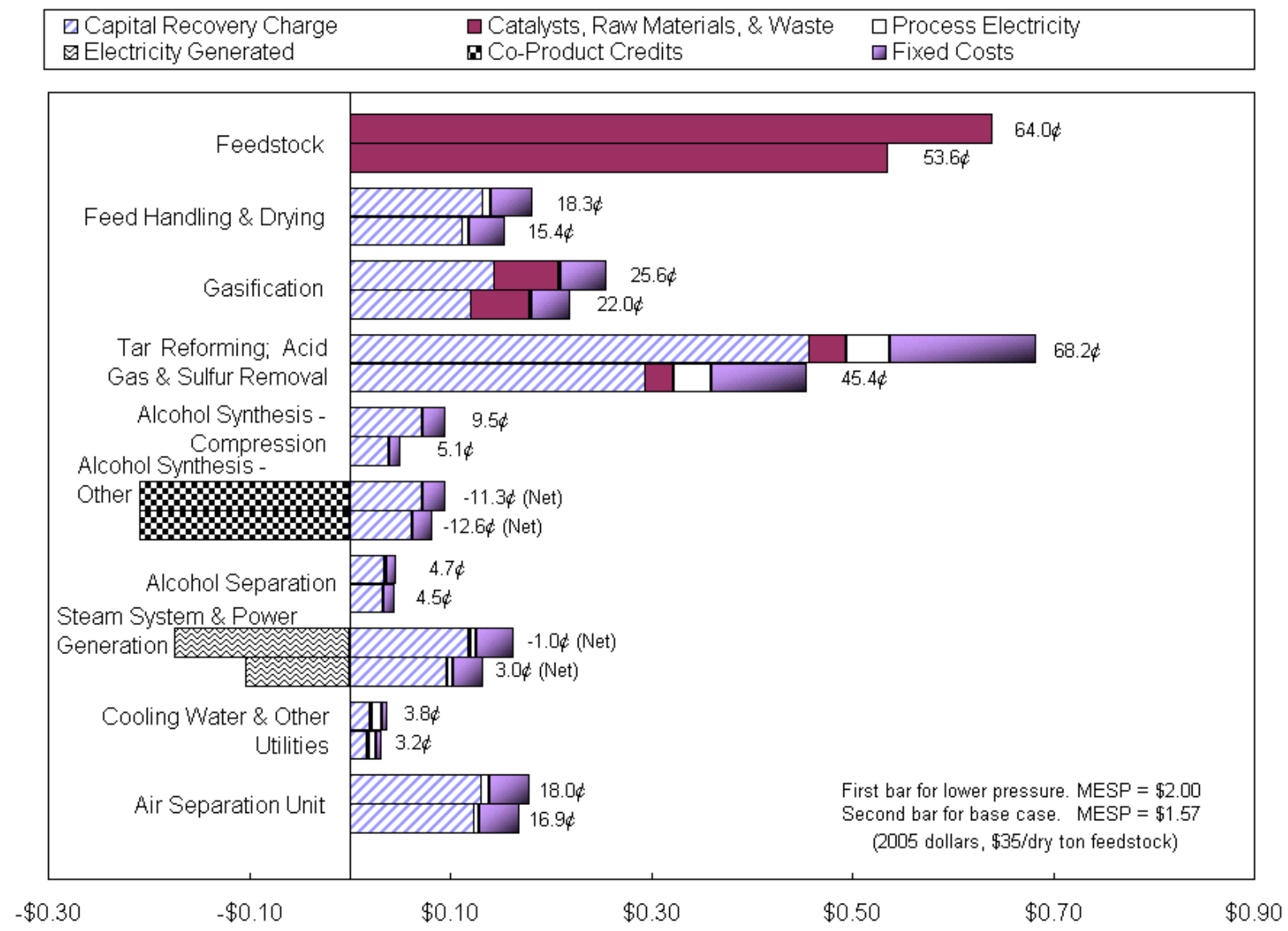

Figure K-1. Comparison of cost distribution for process with gasifier at 100 psi vs. the base case operated at $440 \mathrm{psi}$ 
Note that the capital recovery charges are per gallon. The capital costs for the "Feed Handling and Drying" and some others are identical for the two cases, but the cost per gallon is higher because the gallons of ethanol per dry ton yield is lower at 54.7 vs. 65.3 in the base case. The biggest cost increase is in the "Tar Reforming; Acid Gas \& Sulfur Removal" section because of the added syngas compressor. The savings from using a smaller oxygen compressor is insignificant compared with the compressor required for the syngas. Overall energy requirements are also higher because of added energy requirements for compression. The biggest impact of higher energy requirements is the diversion of syngas to drive compressors rather than to make liquid fuels. The cost comparison indicates that the gains from higher methane conversion possible at lower pressures (100 psi) are more than offset by added compression costs.

\section{References}

${ }^{1}$ Evans, R.J.; Knight, R.A.; Onischak, N.; Babu, S.P. Development of Biomass Gasification to Produce Substitute Fuels. PNL-6518. Work performed by the Institute of Gas Technology for Pacific Northwest Laboratory under contract DE-AC06-76RLO 1830 with the U.S. Department of Energy. Richland, WA: Pacific Northwest Laboratory, March 1988.

${ }^{2}$ Phillips, S.; Aden, A.; Jechura, J.; Dayton, D.; Eggeman, T. Thermochemical Ethanol via Indirect Gasification and Mixed Alcohol Synthesis of Lignocellulosic Biomass. NREL/TP-51041168. Golden, CO: National Renewable Energy Laboratory, April 2007. http://www.nrel.gov/docs/fy07osti/41168.pdf. 


\section{Appendix L \\ Hypothetical Case if Tar Reformer Conversions are not affected by Higher Pressures}


This section considers a hypothetical case if tar reformer conversions were not adversely affected by higher pressures and the tar reformer conversions in the Phillips et al. (2007) report were achievable in the high pressure case. This case will help delineate the economic impacts of the tar reformer conversions from the other factors that impact the MESP. A list of the factors that affect the MESP is shown in the "Conclusions" section of the main report. This section shows that the target MESP of $\$ 1.07 /$ gallon is not achievable even with higher conversions in the tar reformer. The MESP for this case is \$1.30/gallon (the MESP for the base case of the main report is $\$ 1.57 /$ gallon). This means the negative impact of lower conversion in the tar reformer (at the higher pressures) on the MESP is about $27 \varnothing /$ gallon.

\section{Ethanol from Mixed Alcohols Production Process Engineering Analysis}

2012 Market Target Case: 2010 Tar Reforming Goal \& Mixed Alcohol Production

2,000 Dry Metric Tonnes Biomass per Day

GTI Gasifier, Tar Reformer, Sulfur Removal, MoS2 Catalyst, Fuel Purification, Steam-Power Cycle All Values in $2005 \$$

Minimum Ethanol Selling Price (\$/gal) $\$ 1.30$

\begin{tabular}{|c|c|c|c|}
\hline \multicolumn{4}{|c|}{$\begin{array}{r}\text { EtOH Production at Operating Capacity (MM Gal / year) } 59.2 \\
\text { EtOH Product Yield (gal / Dry US Ton Feedstock) } 76.7 \\
\text { Mixed Alcohols Production at Operating Capacity (MM Gal / year) } \\
\text { Mixed Alcohols Product Yield (gal / Dry US Ton Feedstock) } \\
\text { Delivered Feedstock Cost \$/Dry US Ton } \$ 35 \\
\text { Internal Rate of Return (After-Tax) } 10 \% \\
\text { Equity Percent of Total Investment } 100 \%\end{array}$} \\
\hline \multicolumn{2}{|l|}{ Capital Costs } & \multicolumn{2}{|l|}{ Operating Costs (cents/gal product) } \\
\hline Feed Handling \& Drying & $\$ 22,700,000$ & Feedstock & 45.6 \\
\hline Gasification & $\$ 24,800,000$ & Natural Gas & 0.0 \\
\hline Tar Reforming \& Quench & $\$ 41,600,000$ & Catalysts & 0.3 \\
\hline Acid Gas \& Sulfur Removal & $\$ 16,700,000$ & Olivine & 2.4 \\
\hline Alcohol Synthesis - Compression & $\$ 8,100,000$ & Other Raw Materials & 2.0 \\
\hline Alcohol Synthesis - Other & $\$ 12,800,000$ & Waste Disposal & 2.6 \\
\hline Alcohol Separation & $\$ 7,400,000$ & Electricity & -0.8 \\
\hline Steam System \& Power Generation & $\$ 16,000,000$ & Fixed Costs & 24.2 \\
\hline Cooling Water \& Other Utilities & $\$ 3,100,000$ & Co-product credits & -20.8 \\
\hline Air Separation Unit & $\$ 25,200,000$ & Capital Depreciation & 20.9 \\
\hline \multirow[t]{2}{*}{ Total Installed Equipment Cost } & $\$ 178,400,000$ & Average Income Tax & 14.6 \\
\hline & & Average Return on Investment & 38.4 \\
\hline Indirect Costs & $69,700,000$ & \multirow{2}{*}{\multicolumn{2}{|c|}{ Operating Costs ( $\$ / y r)$}} \\
\hline$(\%$ of TPI) & $28.1 \%$ & & \\
\hline Project Contingency & $5,400,000$ & $\begin{array}{l}\text { Feedstock } \\
\text { Natural Gas }\end{array}$ & $\begin{array}{r}\$ 27,000,000 \\
\$ 0\end{array}$ \\
\hline \multirow[t]{2}{*}{ Total Project Investment (TPI) } & $\$ 248,200,000$ & Catalysts & $\$ 200,000$ \\
\hline & & Olivine & $\$ 1,400,000$ \\
\hline Installed Equipment Cost per Annual Gallon & $\$ 3.01$ & Other Raw Matl. Costs & $\$ 200,000$ \\
\hline \multirow[t]{2}{*}{ Total Project Investment per Annual Gallon } & $\$ 4.19$ & Waste Disposal & $\$ 1,500,000$ \\
\hline & & Electricity & $-\$ 500,000$ \\
\hline Loan Rate & N/A & Fixed Costs & $\$ 14,400,000$ \\
\hline Term (years) & $\mathrm{N} / \mathrm{A}$ & Co-product credits@ $\$ 1.15$ per gal & $-\$ 12,300,000$ \\
\hline \multirow[t]{2}{*}{ Capital Charge Factor } & 0.176 & Capital Depreciation & $\$ 12,400,000$ \\
\hline & & Average Income Tax & $\$ 8,700,000$ \\
\hline Maximum Yields based on carbon content & & Average Return on Investment & $\$ 22,700,000$ \\
\hline Theoretical Ethanol Production (MM gal/yr) & 158.9 & & \\
\hline Theoretical Ethanol Yield (gal/dry ton) & 205.8 & Total Plant Electricity Usage ( $(\mathrm{KM})$ & 6,497 \\
\hline Current Ethanol Yield (Actual/Theoretical) & $37 \%$ & $\begin{array}{l}\text { Electricity Produced Onsite (KW) } \\
\text { Electricity Purchased from Grid (KW) }\end{array}$ & $\begin{array}{r}7,472 \\
0\end{array}$ \\
\hline Gasifier Efficiency - HHV \% & 79.7 & Electricity Sold to Grid (KM) & 975 \\
\hline Gasifier Efficiency - LHV\% & 78.2 & & \\
\hline Overall Plant Efficiency - HHV \% & 46.0 & Steam Plant + Turboexpander Power Generated (hp) & 32,851 \\
\hline \multirow[t]{2}{*}{ Overall Plant Efficiency - LHV\% } & 44.6 & Used for Main Compressors (hp) & 22,767 \\
\hline & 8406 & Used for Electricity Generation (hp) & J,084 \\
\hline$\%$ & $96.0 \%$ & $\begin{array}{l}\text { Plant Electricity Use (KWh/gal product) } \\
\text { Gasification \& Reforming Steam Use (lb/gal) }\end{array}$ & $\begin{array}{r}1.2 \\
13.0^{\circ}\end{array}$ \\
\hline
\end{tabular}




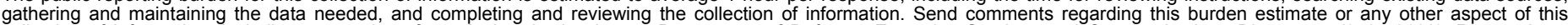

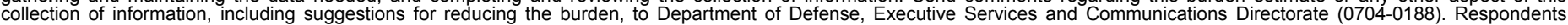

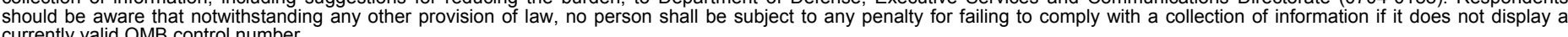

PLEASE DO NOT RETURN YOUR FORM TO THE ABOVE ORGANIZATION.
1. REPORT DATE (DD-MM-YYYY) July 2009
4. TITLE AND SUBTITLE
Thermochemical Ethanol via Direct Gasification and Mixed Alcohol Synthesis of Lignocellulosic Biomass

6. AUTHOR(S)

A. Dutta and S.D. Phillips
3. DATES COVERED (From - To)

5a. CONTRACT NUMBER

DE-AC36-08-GO28308

5b. GRANT NUMBER

5c. PROGRAM ELEMENT NUMBER

5d. PROJECT NUMBER

NREL/TP-510-45913

5e. TASK NUMBER

BB07.3710

5f. WORK UNIT NUMBER
7. PERFORMING ORGANIZATION NAME(S) AND ADDRESS(ES)

National Renewable Energy Laboratory

1617 Cole Blvd.

Golden, CO 80401-3393

9. SPONSORING/MONITORING AGENCY NAME(S) AND ADDRESS(ES)
8. PERFORMING ORGANIZATION REPORT NUMBER

NREL/TP-510-45913

10. SPONSOR/MONITOR'S ACRONYM(S) NREL

11. SPONSORING/MONITORING AGENCY REPORT NUMBER

\section{DISTRIBUTION AVAILABILITY STATEMENT}

National Technical Information Service

U.S. Department of Commerce

5285 Port Royal Road

Springfield, VA 22161

\section{SUPPLEMENTARY NOTES}

\section{ABSTRACT (Maximum 200 Words)}

This work continues the study of thermochemical conversion processes for biomass to ethanol. An earlier study by Phillips et al. (NREL/TP-510-41168) looked into a process that used an indirect gasifier and showed that the process is capable of producing cost-competitive cellulosic ethanol below the $\$ 1.07$ per gallon minimum plant gate price targeted in 2012 using 2005 cost assumptions. A high-pressure oxygen-blown direct gasifier is used in this study. The conversion costs for this process are higher than the 2012 cost target. This is primarily because of two reasons, 1) Extra capital cost of an air-separation unit, and 2) Lower conversion of methane to syngas after reformation at the higher pressures in this process. The minimum ethanol selling price (MESP) for the base case process was $\$ 1.57 /$ gallon using 2005 cost assumptions, compared with $\$ 1.01 /$ gallon in the indirect gasification process. The MESP was \$1.95/gallon using 2007 cost assumptions and 2012 performance targets (compared with \$1.29/gallon for the indirect process).

\section{SUBJECT TERMS}

Thermochemical; gasification; direct gasifier; biomass; MESP; ethanol; technoeconomic; syngas

\begin{tabular}{|c|c|c|c|c|}
\hline 16. SECURIT & CLASSIFICATI & N OF: & 17. LIMITATION & 18. NUMBER \\
\hline $\begin{array}{l}\text { a. REPORT } \\
\text { Unclassified }\end{array}$ & $\begin{array}{l}\text { b. ABSTRACT } \\
\text { Unclassified }\end{array}$ & $\begin{array}{l}\text { c. THIS PAGE } \\
\text { Unclassified }\end{array}$ & UL & \\
\hline
\end{tabular}

\begin{tabular}{l} 
19a. NAME OF RESPONSIBLE PERSON \\
\hline 19b. TELEPHONE NUMBER (Include area code) \\
\hline
\end{tabular}

